


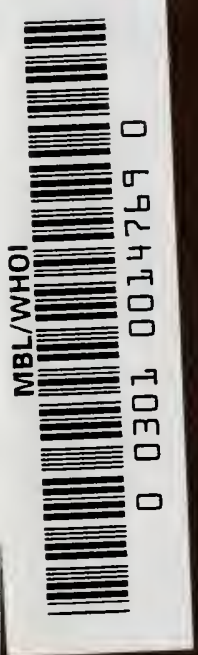







\title{
GENERAL PRINCIPLES
}

\section{ZOOLOGY}

\author{
BY \\ RICHARD HERTWIG \\ Professor of Zoology and Comparatize Anatomy in the \\ University of IIunich
}

TRANSLATED BY

GEORGE W. FIELD

Associate Professor of Cellular Biology

in Brown University

SECOND EDITION

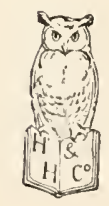

NEW YORK

HENRY HOLT AND COMPANY

I 897 
Copyright, 1896,

BY

HENRY HOLT \& CO.

ROBERT DRUMMOND, ELECTROTYPER AND PRINTER, NEW YORK. 


\section{'TRANSLATOR'S PREFACE.}

THIs volume comprises the First or General Part of Professor Richard Hertwig's "Lehrbuch der Zoologie," which embodies the results of his long and eminently successful experience in teaching. The translation has been made with his consent and active cooperation and thus really constitutes a fourth edition. When the "Lehrbuch" was prepared, the author did not contemplate the contingency of a separate publication of the General Part, but it is believed that his masterly treatment of the larger generalizations of the subject will be of service by itself to teacher, student, and general reader.

The term "Anlage" has been rendered "rudiment," in the sense that rudimentary organs are such as are in process of development. Conversely, organs in process of disappearance are termed "vestigial organs." The adjective "vegetal," as corresponding with " animal," has been used in preference to "vegetative"; e.g., the vegetal and the animal pole of the egg.

It is too much to hope that errors have not crept in, and as the most satisfactory text-books result from the cooperation of many workers, the editor invites such corrections and suggestions as may tend to widen the usefulness of the work. In reading proof much assistance has been given by Miss Ada G. Wing, a graduate student of Biology in Brown University, and to her the translator is indebted for many valuable suggestions.

G. IV. F.

Brown University, July 15 , I 896 . 



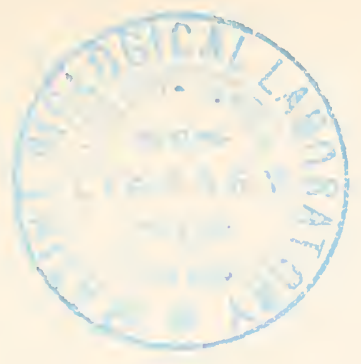

\section{TABLE OF CONTENTS.}

\section{INTRODUCTION.}

Man's Relation to Other Animals . . . . . . . . I

Purpose of Zoological Study . . . . . . . . . . I

Morphology . . . . . . . . . . . . . 2

Comparative Anatomy . . . . . . . . . . 3

Ontogeny . . . . . . . . . . . . . . 4

Physiology • . . . . . . . . . . . . . 4

Biology . . . . . . . . . . . . . . 5

Paleontology . • . . . . . . . . . . . 5

HISTORY OF ZOOLOGY • • . . . . . . . . . . . . . 7

Methods of Zoological Study . . . . . . . . . 7

Aristotle . . . . . . . . . . . . . . . 7

Development of Systematic Zoology • • • • • • . . . 9

Pliny . . . . . . . . . . . . . . . . 9

Zoology of the Middle Ages . . . . . . . . . . . 9

Wotton . . . . . . . . . . . . . . 10

Linnæus . . . . . . . . . . . . . . . 10

Improvements Introduced into Zoological Nomenclature by

Linnæus . . . . . . . . . . . . . . . II

Influence of the Linnean System . . . . . . . 12

Development of Morphology . . . . . . . . . . . 13

Anatomists of Classic Antiquity . . . . . . . . 13

of the Middle Ages . . . . . . . I4

Vesal . . . . . . . . . . . . . . It

Beginning of Zootomy . . . . . . . . . . . . It

The Dawn of Independent Observation . . . . . . I5

Period of Comparative Anatomy . . . . . . . I6

Correlation of Parts . . . . . . . . . . . . I6

Homology and Analogy . . . . . . . . . . . I6

Cuvier . . . . . . . . . . . . . I7

Type Theory . . . . . . . . . . . . . . . I7

Comparative Embryology (Evolution vs. Epigenesis) . . I9

Von Baer . . . . . . . . . . . . . . 20

Cell Theory . . . . . . . . . . . . 20

Reform of the System . . . . . . . . . . . 2I 
Foundation of Modern Zoology . . . . . . . . 2I

The Division of the Radiata . . . . . . . . 2 I

C. Th. v. Siebold . . . . . . . . . . . 2 I

Leuckart . . . . . . . . . . . . . . 22

The Present System . . . . . . . . . . . 22

History of the Theory of Descent . . . . . . . . 23

Importance of the Subject . . . . . . . . . 23

The Nature of Species . . . . . . . . . 23

Ray's Conception of Species . . . . . . . . . 23

The "Cataclysm Theory" . . . . . . . . . 24

Objections to the Cataclysm Theory . . . . . . 25

Darwin's Predecessors . . . . . . . . . . 26

Lamarck . . . . . . . . . . . . . . 26

Evolution vs. Creation . . . . . . . . . . 27

Lyell . . . . . . . . . . . . . . 27

Darwin . . . . . . . . . . . . . . 28

Post-Darwinian Writers . . . . . . . . . 29

Darwin's Theory of the Origin of Species . . . . . . . 30

The Problem Stated . . . . . . . . . . 30

Morphological Characiers . . . . . . . . 30

Physiological Characters . . . . . . . . . 32

A. Crossing of Species and Varieties . . . . . . 32

B. The Intercrossing of Species . . . . . . . . 33

C. The Fertility of Hybrids and Mongrels . . . . . 34

D. Inbreeding . . . . . . . . . . . 35

Conditions Governing Fertility in Sexual Reproduction . . 35

Difficulties in Systemization . . . . . . . . . 35

Change of Varieties into Species . . . . . . . . 36

Species may be Related to Each Other in Unequal Degrees 36

Phylogeny . . . . . . . . . . . . 36

Spontaneous Generation . . . . . . . . . . 37

Variability Not Proven to be a Universal Principle . . . 38

Proofs of Phylogeny . . . . . . . . . . . 35

(I) Proofs from Systemization . . . . . . . . 35

(2) Paleontological Demonstration . . . . . . 39

Examples of Paleontological Proof . . . . . 39

(3) Morphological Proofs . . . . . . . . to

Fundamental Law of Biogenesis . . . . . . . . 4 I

Examples of the Application of this Law . . . . . . . 4

Study of the Distribution of Animals . . . . . . 49

Instances of Proofs . . . . . . . . . . . . 50

Causal Foundation of the Theory of Descent . . . . 5 I

Artificial Selection . . . . . . . . . . . 52

Factors of Evolution in Breeding . . . . . . . 53

Factors of Evolution in Nature . . . . . . . . 53

Natural Selection Struggle for Existence . . . . . 53 
PAGE

The "Struggle for Existence" . . . . . . . . 54

Instances of the Struggle for Existence . • . . . 55

Sympathetic Coloration . . . . . . . . . 56

Mimicry . . . . . . . . . . . . . 56

Examples of Mimicry . . . . . . . . . . 57

Sexual Selection . . . . . . . . . . . . 59

On the Efficiency of Natural Selection . . . . . . 6 I

Migration Theory . . . . . . . . . . 63

Lamarckism . . . . . . . . . . . . 64

Influence of Environment . . . . . . . . 64

Use and Disuse . . . . . . . . . . . . 65

Nageli's Principle of Progression . . . . . . . 65

General Morphology and Physiology . • . . • . . 68

General Zoology: Animal Morphology . • • . . 68

Ecology or Biology . . . . . . . . . . . . 68

General Anatomy . . . . . . . . . . 68

I. General Anatomy.

The Morphological Units . . . . . . . . . $C_{9}$

I. The Morphological Units of the Animal Body . . . . . 69

The Cell . . . . . . . . . . . . 69

History of the Cell Theory. . . . . . . . . 70

The Schleiden-Schwann Cell Theory . . . . . . 70

Reform Movements . . . . . . . . . . . 7I

Discovery of Protoplasm . . . . . . . . . 72

Schultze's Protoplasm Theory . • • • • • • . 73

Nature of the Cell . . . . . . . . . . 73

Protoplasm . . . . . . . . . . . . . it

General Properties of Protoplasm . . . . . . . it

Movement of Protoplasm . . . . • • • • . 75

Irritability of Protoplasm . . • . . . • • • • . 77

Heat-rigor . . . . . . . . . . . . . 77

Cold-rigor . . . . . . . . . . • . . 77

Nutrition and Reproduction . • • • • • • • • 77

Cell-nucleus . . . . . . . . . . . 75

The Nuclear Substance . . . . . . . . . 79

Structure of the Nucleus . . . . . . . . 79

Nuclein and Paranuclein . . . . . . . . . . So

Significance of the Cell-nucleus . . . . . . . . . So

Cell-budding. . . . . . . . . . . . . . $S_{I}$

Indirect Nuclear Division, Karyokinesis or Mitosis . . . $S_{2}$

Nuclear Spindle and Centrosomes . . . . . . . . $8_{3}$

Multinuclearity, Multicellularity . . . . . . . . $8_{3}$

Direct Nuclear Division . . . . . . . . . . . . $s_{4}$

Probable Significance of Direct and of Indirect Nuclear

Division . . . . . . . . . . . . . $s_{t}$

II. The Tissues of the Animal Body . . . . . . . 85 
PAGE

Definiticrn of Tissue . . . . . . . . . . $S_{5}$

Nature of Histological Differentiation . . . . . . 85

Classification of Tissues . . . . . . . . . . 87

I. Epithelial Tissues . . . . . . . . . . . . . . $8_{7}$

Morphology of Epithelial Tissues . . . . . . . sT $_{7}$

Function of Epithelium . . . . . . . . . . 87

Glandular Sensory Epithelia . . . . . . . . 88

Covering Epithelium . . . . . . . . . . . . 89

One-layered Epithelium . . . . . . . . . . 89

Flagellated and Ciliated Epithelia . . . . . . . S9

Cuticle . . . . . . . . . . . . . . . ৎ̧

Many-layered Epithelia . . . . . . . . . . 90

Glandular Epithelium . . . . • . . . . . 92

Unicellular Glands . • . . . . . . . . . . . 92

Multicellular Glands . . . . . . . . . . . . 92

Sexual Epithelium . . . . . . . . . . . 94

Egg-cell . . . . . . . . . . . . . . 96

The Spermatozoa . . . . . . . . . . . 95

Sensory Epithelium . • . • . . . • . • . $9^{\mathrm{s}}$

Supporting Cells . . . . . . . . . . . . 199

2. Connective Substances . . . . . . . . . . . 99

Contrast of Epithelium with Connective Tissue . . . . 99

Function of Connective Tissue . . . . . . . . . 100

Cellular Connective Tissue. . . . . . . . . . . IOO

Homogeneous Connective Tissue . . . . . . . . IOO

Fibrous Connective Tissue . . . . . . . . . . . . IOI

Elastic Tissue . . . . . . . . . . . . IO2

Cartilage. . . . . . . . . . . . . . 102

Bone . . . . . . . . . . . . . . . IO3

Formation of Bone . . . . . . . . . . . . . 105

Blood and Lymph . . . . . . . . . . . . . . 105

Red Blood-corpuscles . . . . . . . . . . . I06

Hamoglobin. . . . . . . . . . . . . . . 107

Lymph . . . . . . . . . . . . . . . IO7

Relations of Plasma to Corpuscles . . . . . . . . Ios

3. Muscular Tissue.

Marked Characteristics of Muscular Tissue . . . . . . IoS

The Formation of Muscle-substance . . . . . . . . Io9

Smooth and Cross-striated Muscle-fibres . . . . . . . I Io

Epithelial and Connective-substance Muscle-cells . . . . I o

4. Nervous Tissue . . . . . . . . . . . . . . II3

Function of Nervous Tissue . . . . . . . . . . II3

Elements of the Nervous Substance . . . . . . . II3

Summary of Chapters on Cells and Tissues . . . . . II6

III. The Combination of Tissues into Organs. . . . . . IIs

An Organ Defined. . . . . . . . . . . IIs 
Principal and Accessory Tissues . . . . . . . . II8

Effect of Use and Disuse . . . . . . . . . . Irg

Change of Functicn of Organs . . . . . . . . II

Homology and Analogy . . . . . . . . . . I20

Systems of Organs . . . . . . . . . . . I20

Vegetal and Animal Organs . . . . . . . . . I2I

Vegetal Organs . . . . . . . . . . . . . 122

A. Organs of Assimilation . . . . . . . . . . . I22

Assimilation Defined . . . . . . . . . . . . I22

Assimilation in Animals . . . . . . . . . . 22

Different Organs of Assimilation . . . . . . . . : 22

I. The Digestive Tract.

Archenteron, or Primitive Digestive Tract . . . . I24

Stomodœum and Proctodœum . . . . . . . . I25

Various Divisions and Appendages of the Digestive

Tract . . . . . . . . . . . . I 26

II. Respiratory Organs . . . . . . . . . I2S

Sources of the Oxygen Used in Breathing . . . . I 28

Distincticns between the Respiratory Systems of

Vertebrates and Invertebrates . . . . . . I30

111. Circulatory Apparatus . . . . . . . . I3I

Colom . . . . . . . . . . . . . . . $\mathrm{I} 32$

Heart, Arteries, Veins, Capillaries . . . . . I32

The Higher Development of the Heart . . . . . I32

Blood-vessels . . . . . . . . . . . . . I 33

Correlation of Respiratory Organs and Blood-system I 33

Arterial and Venous Blocd . . . . . . . . I 35

Closed and Lacunar Blood-vascular Systems . . . I35

Example of Lacunar Blood-vascular System . . . 136

Lymph-ressels . . . . . . . . . . . I36

Cold- and Warm-blooded Animals . . . . . . I37

IV. Excretory Organs . . . . . . . . . . I3s

Nature of the Organs of Excretion. . . . . . I3s

Nephridia . . . . . . . . . . . . Ifo

B. Sexual Organs. . . . . . . . . . . . I to

Sexual Glands and Outlets . . . . . . . Ifo

Germinal Epithelium and Germinal Glands. . . . I

Gonochorism and Hermaphroditism . . . . . . IfI

Occurrence of Herma phroditism . . . . . . I I 2

True Hermaphroditism . . . . . . . . . I 43

Outlets . . . . . . . . . . . . . I I

Accessory Sexual Apparatus . . . . . . . I I4

Animal Organs . . . . . . . . . . . . . Itt

I. Organs of Locomotion . . . . . . . . I IH

Voluntary Locomotion . . . . . . . . . IHH

Locomotion among the Lower Animals . . . . I+5 
PAGE.

II. Nervous System . . . . . . . . . . I45

Its Regular Development . . . . . . . I I45

Diffuse Nervous System . . . . . . . . I46

Linear Nervous System . . . . . . . . I 46

Ganglionic Central Nervous System . . . . I46

Subosophageal (or Brain) Ganglia . . . . . . I47

Ladder Nervous System . . . . . . . . I47

Tubular System . . . . . . . . . . Its

Relations between the Nervous System and the Skin. I 48

III. Sensory Organs. . . . . . . . . . I I

Sensations of the Lower Animals . . . . . Its

Anatomy Gives Insufficient Knowledge of Sensory

Organs . . . . . . . . . . . . . I 49

Tactile Organs . . . . . . . . . . . . I50

Organs of Smell and of Taste . . . . . . I50

Organs of Hearing and of Sight . . . . . I5I

History of the Auditory Organs . . . . . . I5I

Auditory Pit . . . . . . . . . . . . I52

Other Forms of Auditory Organs . . . . . . I53

Function of the Semicircular Canals . . . . . I53

The Eye . . . . . . . . . . . . 153

The Rods and Cones . . . . . . . . . . I53

The Optic Ganglion . . . . . . . . . . I5t

Refractive Bodies in the Eye . . . . . . . I54

The Eye of the Vertebrates . . . . . . . I55

The Various Types of Eyes . . . . . . . 156

Summary of the Most Important Points of Organology i 56

IV. Promorphology, or Study of the Fundamental

Forms of Animals . . . . . . . . . I5s

Organic and Inorganic Bodies . . . . . . I58

Symmetry . . . . . . . . . . . . I59

Bilateral Symmetry . . . . . . . . . . I62

Antimeres and Metameres . . . . . . . I63

Internal and External Metamerism . . . . . I6t

Homonomous and Heteronomous Metamerism . . I64

Heteronomy and Homonomy . . . . . . . 165

II. General Embryology . . . . . . . . . . . . I65

Origin of Organisms . . . . . . . . . . $16_{5}$

I. Generatio Spontanea: Archegony . . . . . . . . I66

Theory of Spontaneous Generation. . . . . . . . I66

First Origin of Life . . . . . . . . . . . . I67

II. Generation by Parents, or Tocogony . • • . . . I68

Two Principal Methods . . . . . . . . . . I68

a. Asexual Reproduction: Monogony. . . . . . . . I68

Monogony Defined . . . . . . . . . . . I68 
Division

Budrling

b. Sexual Reproduction: Amphigony

Amphigony Defined

Parthenogenesis and Pædogenesis

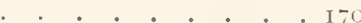

Parthenogenesis and Typical Amphigony . . . . . . izo

Sexual and Somatic Cells . . . . . . . . . . I I

c. Combined Modes of Reproduction . . . . . . . . 172

Occurrence in the Same Species . . . . . . . . 172

Progressive Alternation of Generations: Metagenesis . . I72

Heterogony . . . . . . . . . . . . . . . . I It

Asexual and Sexual Reproduction . . . . . . . . I7t

General Phenomena of Sexual Reproduction . . . . I75

I. Maturation . . . . . . . . . . . . . . . I75

Formation of the Polar Bodies . . . . . . . . . 176

Relation between Maturation and Fertilization . . . 177

2. Fertilization, Copulation, and Artificial Fecundation . 177

Fertilization . . . . . . . . . . . . . . $17^{3}$

Monospermy and Polyspermy . . . . . . . . . . I

Essential Feature in Fertilization. . . . . . . . . 179

Part Played by the Two Nuclei in Fertilization. . . . Iso

Heredity . . . . . . . . . . . . J $8_{\mathrm{I}}$

The Material Basis of Heredity . . . . . . . ISI

3. Cleavage Process . . . . . . . . . . Isz

Arrangement of the Cleavage-planes . . . . . . Is 2

Influence of the Yolk upon the Cleavage Process . . . Is?

Distribution of the Yolk . . . . . . . . . . $\mathrm{I}_{3}$

Various Modes of Cleavage . . . . . . . . . . Ist

a. Holoblastic Eggs with Total Cleavage. . . . Is5

b. Meroblastic Eggs with Partial Cleavage . . . Is 5

Distribution of the Modes of Clearage. . . . . . I\$6

Blastula . . . . . . . . . . . . . . . I 87

4. Formation of the Germ-layers . . . . . . . . 187

Gastrula . . . . . . . . . . . . . . IS7

Invagination . . . . . . . . . . . . . . . Iss

Modified Mlodes of Gastrulation . . . . . . . . Iss

Epiblast and Hypoblast . . . . . . . . . . Iss

Delamination . . . . . . . . . . . . . . Iss

Formation of the Mesoblast. The Mesenchyme . . . isg

Meseptthelium . . . . . . . . . . . . . Igo

Colomic Pouches . . . . . . . . . . . . . I9I

Occurrence of Mesenchyme and Mesepithelium . . . I9I

Histological and Organological Differentiation . . . . I9I

Relations of the Germ-layers in Budding . . . . . . I92

5. The Different Forms of Sexual Development . . . I92

Embryonic and Post-embryonic Development . . . . I92 
Direct and Indirect Development-Metamorphosis PAGE

Oviparous and Viviparous Animals . . . . . . . . 194

Oro-viviparous Animals . . . . . . . . . . . I94

No Sharp Line to be Drawn between Oriparous and

Viviparous . . . . . . . . . . . . . . J95

Summary of the Facts of Ontogeny . . . . . . . 195

III. Relations of Animals to One Another . . . . . . . Igs

General Relations . . . . . . . . . . . . Ig3

I. Relations between Individuals of the Same Species. . . I9s

Colony Formation . . . . . . . . . . . . . . 198

Colony Formation by Fusion . . . . . . . . . . . I99

Colony Formation by Incomplete Division and Budding. I 99

Community of Functions . . . . . . . . . . 200

Polymorphism . . . . . . . . . . . . 200

State Formation . . . . . . . . . . . . . . 201

II. Relations between Individuals of Different Species . . . 202

Causes of Close Relation . . . . . . . . . . . 202

Parasitism . . . . . . . . . . . . . . 202

True Parasitism. . . . . . . . . . . . . 202

Degeneration Caused by Parasitism . . . . . . . 203

Modification of the Sexual Apparatus by Parasitism . . 203

Ectoparasites and Entoparasites . . . . . . . 204

Symbiosis . . . . . . . . . . . . . 205

Occurrence of Symbiosis . . . . . . . . . . . . . . 206

IV. Animal and Plant . . . . . . . . . . . . . 207

Distinction between Animal and Plant . . . . . 207

Doubtful Cases . . . . . . . . . . . 207

Distinction on a Physiological Basis . . . . . . 203

Difference in Metabolism Not a Safe Criterion . . . 208

Cellulose not a Sure Test . . . . . . . . . . 209

Distinction on a Morphological Basis . . . . . 209

Plant-cells have a Cellulose Membrane . . . . . 209

Transitions . . . . . . . . . . . . . . . 209

V. Geographical Distribution of Animals . . . . . . . . 210

The Different Faunal Regions . . . . . . . . . 210

Climate Not the Only Consideration . . . . . 2 2 IO

Factors in Distribution . . . . . . . . . . 2II

Difficulties of the Subject . . . . . . . . 212

The Six Primary Regions . . . . . . . . 213

Arctic and Antarctic Provinces . . . . . . . 215

The Distribution of Aquatic Animals . . . . . . 216

Changes in the Fauna Conditioned by Depth . . . . 2I6

The Plankton . . . . . . . . . . . . 216

Distribution of Fresh-water Animals . . . . . 2I7 


\title{
GENERAL PRINCIPLES
}

\author{
OF \\ ZOOLOGY
}

\section{INTRODUCTION.}

Man's Relation to Other Animals. - The man who has learned to observe nature in an unbiassed manner sees himself in the midst of a manifold varicty of organisms, which in their structure, and even more in their vital phenomena, disclose to him a similarity to his own being. This similarity meets him among many of the mammals, especially the anthropoid apes, with the sharpness of a caricature. In the invertebrated animals it is not so distinct; yet even in the lowest organisms, for our knowledge of which we are indebted to the microscope, it is still to be found; for we can come to understand those vital processes which in our own bodies have reached an astonishing completeness and complexity, only through a thorough investigation of their simplest characteristics. Man is part of a great whole, the Animal Kingdom, one form among the many thousand forms in which animal organization has found expression.

Purpose of Zoological Study.-If we would, therefore, completely understand the structure of man, we must, as it were, look at it upon the background which is formed by the conditions of organization of the other animals, and for this purpose we must investigate these conditions. To such efforts principally does the scientific knowledge of animal life, or Zoology, owe its origin and continued advancement; even to-day that object is not fully accomplished and they should not be neglected by the zoologist. 
But meanwhile the subject of Zoology has widened; for, apart from its relations to man, Zoology has to explain the organization of animals and their relations to one another. This is a rich field for scientific activity; its enormous range is a consequence, on the one hand, of the well-nigh exhaustless variety of animal organization, and, on the other hand, of the different points of view from which the zoologist enters upon the solution of his problem.

In the first half of this century the conception, which is still held by the public at large, was prevalent, if not quite universal, in scientific circles, that the aim of Zoology is to furnish every animal with a name, to characterize it according to some easily recognizable features, and to classify it in a way to facilitate quich identification. By Natural History was understood the systemization of animals, that is to say, only one part of Zoology, indeed a part of minor scientific importance. This conception has during the past four decades become more and more subordinated. The ambition to describe the largest possible number of new forms and to shine by means of an extensive knowledge of species belongs to the past. In fact there is a tendency to undue neglect of systemization. Morphology and Physiology to-day dominate the sphere of the zoologist's work.

Morphology, or the study of form, begins with the appearances of animals, and particularly has to describe all which can be seen externally, as size, color, proportion of parts. But since the external appearance of an animal cannot be understood without knowledge of the internal organs which condition the external form, the morphologist must make these accessible by the aid of dissection, of Anatomy, and likewise describe them according to their form and method of combination. In his investigation he stops only when he has arrived at the morphological elements of the animal body, the cells. Everywhere the morphologist has to do with conditions of form: the only difference lies in the instruments by means of which he 
obtains his insight, according to whether he gathers his knowledge through immediate observation, or after a previous dissection with scalpel and scissors, or by use of the microscope. Therefore it is not justifiable to place Morphology and Anatomy over against one another, and to ascribe to the former the description of only the external, and to the latter of only the internal parts. The distinction is not logically correct, since the kind of knowledge and the mental processes of the research are the same in both cases. The distinction, too, is unnatural, since in many instances organs which in some cases lie in the interior of the body, and require for their knowledge an anatomical preparation, belong in other cases to the surface of the body, and are accessible for direct description. Further, the internal parts of many animals on account of their transparency can be studied without dissection.

Comparative Anatomy.-For Morphology, as for every science, the proposition is true that the mere accumulation of observed facts is not sufficient to give the subject the character of a science; an additional mental elaboration of this material is necessary. Such a result is reached through comparisons of anatomical discoveries. The morphologist compares animals with each other according to their structure, in order to ascertain what parts of the organization recur everywhere, what only within narrow limits, possibly restricted to the representatives of a single species. He thereby gains a double advantage: (I) an insight into the relationships of animals, and hence the foundation for a Natural System; (2) the evidence of a law which governs organisms. The single organism is not a structure which has arisen independently and which is hence by itself intelligible: it stands rather in a legitimate dependent relation to the other branches of the animal kingdom. We can only understand its structure when we compare it with the closely and the more distantly related animals, e.g., when we compare man with the other vertebrates and with many lower invertebrated forms. Here we have to consider one of the most mys- 
terious phenomena or the organic world, the path to the full explanation of which was first broken by the Theory of Descent, as will be shown in another chapter.

Ontogeny.-To Morphology belongs, as an important integral part, Ontogeny or Embryology. Only a few animais at the beginning of their individual existence are completely formed in all their parts; nost of them arise from the egs, a relatively simple body, and then step by step attain their permanent form in the course of complicated changes. The morphologist must, in the completest possible series, determine by observation the different stages, compare them with the mature animals, and with the structure and developmental stages of other animals. Here is revealed to him the same conformity to law which dominates the mature animals, and a knowledge of this conformity is of fundamental importance as well for systemization as for the causal explanation of the animal form. The developmental stages of man show definite regular agreements, not only with the structure of the adult human being which in and of itself would be intelligible, but also with the structure of lower vertebrates, like the fishes, and even with many of the still lower animals of the invertebrated groups.

Physiology.- In the same way as the morphologist studies the structure, the physiologist studies the vital phenomena of animals and the functions of their organs. Formerly life was regarded as the expression of a special vital energy peculiar to organisms, and thereby any attempt at a logical explanation of the vital processes was renounced. Modern physiology has abandoned this theory of vital energy; it has begun the attempt to explain life as the summation of extremely complicated chemicophysical processes, and thus to apply to the organic world those explanatory principles which prevail in the inorganic realm. The results attained by this course show that this is the correct method.

Since each organic form is the product of its development, since, further, the development represents to us the 
summation of most complicated vital processes, the explanation of the organic bodily form is, therefore, in ultimate analysis a physiological problem; though of course a problem whose solution lies still in the indefinitely distant future. What has been actually accomplished in this direction is only the smallest beginning, even in comparison with that which many falsely regard as already attained.

Biology.-According as the relations of each organism to the external world are brought about through its vital phenomena, there belongs to Physiology, or at least is connected with it, the study of the conditions of animal existence, Aicology or Biology. This branch of the science has of late attained a very considerable importance. How animals are distributed over the globe, how climate and the configuration of the earth's surface influence their distribution, how by known factors the structure and the mode of life become changed, are questions which are to-day discussed nore than ever before.

Paleontology.-Finally in the realm of Zoology belongs also Palcozoology or Palcontology, the study of the extinct animals. For between the extinct and the living animals. there exists a genetic relationship: the former are the precursors of the latter, and their fossil remains are the most trustworthy records of the history of the race, or Phylogeny. As in human affairs the present conditions can only be completely understood by the aid of History, so in many cases the zoologist must draw upon the results of Paleontology for an explanation of the living animal world.

The science of Zoology would be subdivided in the above-mentioned manner if we wished to proceed entirely on a scientific basis. Yet practical considerations have made necessary many modifications. On account of their paramount importance to the medical profession Human Anatomy and Embryology have been raised to independent branches of science. In Animal Physiology only the most general foundations have been laid; a more 
special Physiology exists only for man and the higher vertebrates; this, too, for the above-named reasons has been made a special branch of science. Paleontology also has, in addition to its specific zoological tasks, attained importance as a scientific aid to Geology, since it furnishes the materials for characterizing and fixing the various geological ages and the earth's history during those ages. When, therefore, at the present day we speak of Zoology, we have principally in mind Morphology and Systemization of living animals with consideration of their general vital? phenomena.

The views here given of the character of Zoology have not been the same in all time. Like every science Zoology has developed gradually; it has varied with each epoch and tendency, according as the systematic or the morpho. logical or the physiological point of view was the prevailing one. It will now be interesting to take a hasty glance at the most important phases in the development of Zoology. The reader will bring an increased intelligence to the questions which now dominate zoological inquiry. if he knows how these have arisen historically. 


\section{HISTORY OF ZOOLOGY.}

Methods of Zoological Study.-In the history of Zoology we can distinguish two great currents, which have come in contact or united in a few men, but which on the whole have developed independently, nay, more often in pronounced opposition to each other; these are on the one side the systematic, on the other the morphologico-physiological mode of studying animals. In this brief historical summary they will be kept distinct from one another, although in the commencement of zoological investigation there was no opposition between the two points of view, and even later this has in many instances disappeared.

Aristotle, the great Greek philosopher, has been distinguished by the title of "Father of Natural History," which means that his predecessors' fragmentary knowledge of Zoology could not be compared with the well-arranged order in which Aristotle had brought together his own and the previously existing knowledge of the nature of animals. In Aristotle favorable external conditions were united with more favorable mental ability. Equipped with the literary aid of an extensive library, and the pecuniary means then more than now indispensable for natural-history investigation, he pursued the inductive method, the only one which is capable of furnishing secure foundations in the realm of natural science. It is a matter for great regret that there have been preserved only parts of his three most important zoological works, "Historia animalium," "De partibus," and "De generatione," works in which Zoology is founded as a universal science, since Anatomy and Embryology, Physiology and System. 
ization find equal consideration. How far Aristotle, notwithstanding many errors, attained to a correct knowledge of the structure and embryology of animals, gains strongest proof from the fact that many of his discoveries have obtained confirmation only in the present century. Thus it was known to Aristotle, though only lately rediscovered by Johannes Muller, that many sharks are not only viviparous, but that also in their case the embryo becomes fixed to the maternal uterus and there is formed a contrivance for nutrition resembling the mammaliam and even the human placenta; he knew the difference between male and female cephalopods, and that the young cuttlefish has a preoral yolk-sac.

The position which Aristotle took in reference to the systemization of animals is of great interest; he mentions in his writings the very considerable number of about five hundred species. Since he does not mention the very well known forms, like the badger, dragon-fly, etc., we can with certainty assume that he knew many more, but that he did not regard it necessary to give a catalogue of all the forms known to him, and that he mentioned them only if it was of consequence to refer to certain physiological or morphological conditions found in them.

This abeyance of systematic interest also finds expression in the fact that the great philosopher is satisfied with two systematic categories, with $\epsilon i \delta o s$, species or kind, and $\gamma$ '́vos or group. His eight $\gamma \in \dot{v} \eta \mu \dot{e}^{\prime} \imath \sigma \tau \alpha$ would about correspond with the Classes of modern Zoology; they have been the starting-point for all later attempts at classification, and may therefore be here enumerated.

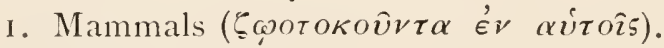

2. Birds (óp $\rho \theta \epsilon s)$.

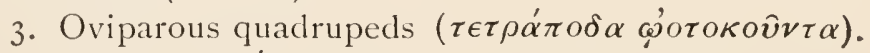

4. Fishes $\left(i \chi \chi^{\prime} i^{\prime} \in 5\right)$.

5. Mollusks $(\mu \alpha \lambda \alpha \kappa \imath \alpha)$.

6, Crustaceans ( $\mu \alpha \lambda \alpha \kappa o ́ \sigma \tau \rho \alpha \kappa \alpha)$.

7. Insects $(\ddot{\epsilon} v \tau o \mu \alpha)$.

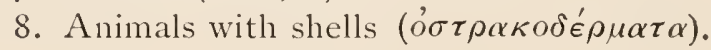


Aristotle has also noticed the relationship of the first four groups, since he, without indeed actually carrying out the division, has placed the animals with blood, "̈vor $\mu \alpha$ (animals proper, with red blood), over against the bloodless,

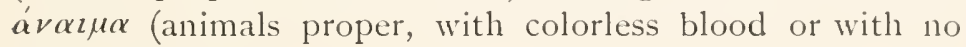
blood at all).

\section{DEVELOPMENT OF SYSTEMATIC ZOOLOGY}

Pliny.-It is an extremely remarkable fact that suc. ceeding the writings of Aristotle, in which systemization is much subordinated and only serves to express the anatomical conditions of relationship in animals, an exclusively systematic direction should have been taken. This is explainable only when we consider that the above-mentioned connection is merely a superficial one; that in point of fact the mental continuity of investigation was completely broken on the one hand by the decline and ultimate complete collapse of ancient classic civilization, and on the other hand by the triumphant advance of Christianity. The decay of zoological investigation, that had only just begun to bloom, is announced by the writings of Pliny. Although this Roman general and teacher was long lauded as the foremost zoologist of antiquity, he is now given the place of a not even fortunate compiler, who collected from the writings of others the accurate and the fabulous indiscriminately, and replaced the natural classification of animals according to their structure by the unnatural, purely arbitrary division according to their place of abode (flying animals, land animals, water animals).

Zoology of the Middle Ages. - The rise of Christianity resulted in the complete annihilation of natural science and investigation. The world-shunning character, which originally was peculiar to the Christian conception, led naturally to a disposition hostile to any mental occupation with natural things. Then came a time when answers to questions capable of solution by the simplest observations were sought by painstaking learned rummaging of the works of standard authors. How many teeth the horse 
has, was debated in many contentious writings, which would have led to bloodshed if one of the authors had not taken occasion to look into a horse's mouth. Significant of this mental bias which prevailed throughout the entire Middle Ages is the Physiologus or Bestiarius, a book from which the authors of zoological writings in the Middle Ages drew much material. The book in its various editions and reprints names about seventy animals, among them many creatures of fable: the dragon, the unicorn, the phœnix, etc. Some of the accounts given of various animals are fables, intended to illustrate religious or ethical teachings. In a similar way the religious element played an important rôle in the many-volumed Natural History of the Dominican Albertus Magnus, and Vincentius Bellovacensis, and of the Augustine Thomas Cantipratensis, although these used as a foundation for their expositions the Latin translation of Aristotle, the works of Pliny and other authors of antiquity.

Wotton.-Under such conditions we must regard it as an important advance that at the close of the Middle Ages, when the interest in scientific investigation awoke anew, Aristotle's conceptions were taken up and elaborated from a scientific standpoint. In this sense we can call the Englishman Wotton the successor of Aristotle. In 1552 he wrote his work "De differentiis animalium," in which he essentially copied the system of Aristotle, except that he admitted the new group of flower-animals or zoophytes. However, the title, "On the Distinguishing Characters of Animals," shows that of the rich treasury of Aristotelian knowledge the systematic results had obtained the chief recognition, and thus Wotton's work inaugurated the period of systematic zoology, which in the Englishman Ray, but even more in Linneus, has found its most brilliant exponents.

Linnæus, the descendant of a Swedish clergyman, whose family name "Iñgemarsson" had been changed after a linden-tree near the parsonage in Lindelius, was born in Rashult in 1707. Pronounced by his teachers to 
be good for nothing at study, he was saved through the influence of a physician, who recognized the fine abilities of the boy, from the fate of learning the cobbler's trade, and won for medical studies. He studied at Lund and Upsala; at the age of twenty-eight he made extended tours on the Continent, and at that time gained recognition from the foremost men in his profession. In I74I he became Professor of Medicine in Upsala, some years later Professor of Natural History. He died in 1778 .

\section{Improvements Introduced into Zoological Nomen-} clature by Linnæus-Linnæus's most important work is his “Systema Natura," which, first appearing in 1735, up to :766-68 passed through twelve editions; indeed after his death there came out a thirteenth which was edited by Gmelin. This has become the foundation for systematic zoology, since it introduces for the first time (I) a sharper division into the system, (2) a definite scientific terminology, the binomial nomenclature, and (3) brief, comprehensive, clear diagnoses. In the division of the system Linnæus employed four categories; he divided the entire Animal Kingdom into Classes, the Classes into Orders, these into Genera, the Genera finally into Species. The term Family was not employed in the "Systema Naturæ." Still more important was the binomial nomenclature. Hitherto the common names were in use in the scientific world, and led to much confusion; the same animals had different names, and different animals had the same names; in the naming of newly-discovered animals there prevailed no generally accepted principle. This inconvenience was entirely obviated by Linnæus in the tenth edition of his Systema by the introduction of a special scientific nomenclature. The first word, a noun, designates the genus to which the animal belongs, the following word, usually an adjective, the species within the genus. The names Canis familiaris, Canis lupus, Canis vulpes, indicate that the dog, wolf, and fox are related to one another, since they belong to the same genus, the genus of doglike animals, of which they are different species. Linnæus's method of naming was particu- 
larly valuable in the description of new species, inasmuch as it from the very beginning informed the reader to what position of relationship the new species was to be assigned.

In his characterization of the various systematic groups Linnæus broke completely with the hitherto-prevailing custom. His predecessors, as Gessner, Aldrovandus, in their Natural Histories had given of each animal a verbose and detailed description, from which the beginner was scarcely able to deduce what was specially characteristic for that animal, a matter which should have been chiefly emphasized in the definition. Linnaus, on the other hand, introduced brief diagnoses, which in a few words, never in sentence form, gave only what was necessary for recognition. Thus a way was found by whicl it would be possible to insure comprehensibility in the enormously increasing number of known animals.

Influence of the Linnean System.-But in the great superiority of the Linnean System lay at the same time the germ of the one-sided development which Zoology came to take under the influence of Linnæus. The logical perfecting of the System, which undoubtedly had become necessary, gave that a brilliant aspect, and hid the fact that systemization is not the ultimate purpose of investigation, but only an important and indispensable aid to it. In the zeal for naming and classifying animals, the higher goal of investigation, knowledge of the nature of animals, was lost sight of, and the interest in Anatomy, Physiology, and Embryology lagged.

From these reproaches we can scarcely spare Linnæus himself, the father of this tendency. For while he in his "Systema Natura" treated of an extraordinarily larger number of animals than any earlier zoologist, he brought about no deepening of our knowledge. The manner in which he divided the animal kingdom, in comparison with the Aristotelian system, is to be called rather a retrogression than an advance. Linnaus divided the animal kingdom into six classes: Mammalia, Aves, Amphibia, Pisces, Insecta, Vermes. The first four classes correspond 
to Aristotle's four groups of animals with blood. In the division of the invertebrated animals into Insecta and Vermes Linnæus stands undoubtedly behind Aristotle, who attempted, and in part indeed successfully, to set up a larger number of groups.

But in his successors even more than in Linnaus himself we see the damage wrought by the systematic method of consideration. The diagnoses of Linnaus were for the most part models, which, mutatis mutandis, could be employed for new species with little trouble. There was needed only some exchanging of adjectives to express the differences. With the hundreds of thousands of different species of animals there was no lack of material, and so the arena was opened for that spiritless zoology of species which in the first half of this century brought Zoology into such discredit. Zoology would have been in danger of growing into a Tower of Babel of species-description if a counterpoise had not been created in the strengthening of the physiologico-anatomical method of consideration.

\section{DEVELOPMENT OF MORPHOLOGY.}

Anatomists of Classic Antiquity.-Comparative Anatomy-for this chiefly concerns us here-for a long time owed its development to the students of human anatomy; this is due to the fact that even up to a recent date Comparative Anatomy was assigned to the medical faculty, while Zoology belonged to the philosophical faculty, as if it were an entirely separate study. The disciples of Hippocrates had previously studied animal anatomy for the purpose of obtaining from the structure of other mammals an idea of human organization, thereby to gain a secure foundation for the diagnosis of human diseases. The work of classical antiquity most prominent in this respect, the celebrated Human Anatomy by Claudius Galenus ( 3 I-20 I A.D.), is based chiefly upon collected observations upon dogs, monkeys, etc. For in ancient times and even later, in the Middle Ages, men showed considerable repugnance 
to making the human cadaver a subject of scientific investigation.

Middle Ages.-The first thousand years in which Christianity formed the ruling power in the mental life of the people was even for anatomy quite fruitless; in the main they held to the writings of Galen and the works of his commentators, and only seldom took occasion to prove their correctness by their own observations. With the ending of the Middle Ages the interest in independent scientific research first broke its bounds.

Vesal (I5I4-I564), the creator of Modern Anatomy, had the courage to carefully investigate the human cadaver and to point out in Galen's writings numerous errors which had arisen through the unwarranted application to human anatomy of the discoveries made upon animals. By his corrections of Galen, Vesal was drawn into a violent controversy with his master Sylvius, an energetic defender of Galen's authority, and with his renowned contemporary Eustachius, which did much for the development of Comparative Anatomy. At first animal anatomy was built up only for the purpose of disclosing the cause of Galen's mistakes, but later through a zeal and love for facts. It is comprehensible that first of all vertebrates found consideration, since they stand next to man in structure and most of all challenge comparison. Thus there appeared in the same century with Vesal's Human Anatomy drawings of skeletions of vertebrates by the Nuremberg physician Coiter; the anatomical writings of Fabricius ab Aquapendente, and others.

Beginning of Zootomy.-But later attention was turned also to insects and mollusks, indeed even to the marine echinoderms, colenterates, and protozoa. Here, above all, three men who lived at the end of the seventeenth century deserve mention, the Italian Marcello Malpighi and the Dutchmen Swammerdam and Leeuwenhoek. The former's "Disscrtatio de bomyce" was the pioneer for insect anatomy, since by the discovery of the vasa Malpighi, the heart, the nervous system, the tracheæ, etc., an extraordinary exten- 
sion of our knowledge was brought about. Of Swammerdam's writings attention should be called particularly to "The Bible of Nature," a work to which no other of that time is comparable, since it contains discoveries of great accuracy on the structure of bees, May-flies, snails, etc. Leewwenhoek, finally, was a most fortunate discoverer in the field of microscopic research, by him introduced into science. Besides other things he studied especially the tiny inhabitants of the fresh waters, the "infusion-animalcules," a more careful investigation of which has led to a complete reversal of our conception of the essentials of animal organization.

The Dawn of Independent Observation.-The great service of the above-named men consists chiefly in this, that they broke away from the thraldom of book-learning and, relying alone upon their own eyes and their own judgment, won for man what had been quite lost, the blessing of independent and unbiassed observation. They spread the interest for observation of nature over a wide circle so that in the eighteenth century the number of independent naturalhistory writings had increased enormously. There were busy with the study of insect structure and development, de Geer in Sweden, Réaumur in France, Lyonet in Belgium, Rösel von Rosenhof in Germany; the latter besides wrote a monograph on the indigenous batrachia, which is, still worth reading. But particularly the investigation of the infusoria formed a favorite occupation for the learned and the laity, as Wrisberg, von Gleichen-Russwurm, Schäffer, Eichhorn, and $O$. F. Müller. In most of the writings the religious character of the contemplations of nature are extraordinarily emphasized, for since we find that among these writers numerous clergymen, Eichhorn in Danzig, Greze in Quedlinburg, Schäffer in Regensburg, had attained honorable positions, we have a sign that a reconciliation had taken place between Christianity and natural science. As a criterion of the progress made in comparison with the earlier centuries, a mere glance at the illustrations is sufficient. Any layman will at the first glance recognize the 
difference between the shabby drawings of an Aldrovandus and the quite masterly figures of a Lyonet or a Rösel von Rosenhof.

Period of Comparative Anatomy.-Thus through the zeal of numerous men filled with a love of nature a rich anatomical material was collected, which needed only a mental reworking; and this mental reworking was brought about, or at least entered upon, by the great comparative anatomists, who lived at the end of the previous, and the beginning of the present century. Among these are especially to be named the French zoologists Lamarck, Savigny, Geoffroy St. Hilaire, Cuvier, and the Germans Meckel and Goethe.

Correlation of Parts.-When the separate animals were compared with one another with reference to their structure there was obtained a series of important fundamental laws, particularly the law of the Correlation of Parts and the law of the Homology of Organs. The former established the fact that there exists a dependent relation between the organs of the same animal, that local changes in one single organ also lead to corresponding changes at some distant part of the body, and that therefore from the constitution of certain parts an inference can be drawn as to the constitution of another part of the body. Cuvier particularly made use of this principle in reconstructing the aspect of extinct animals.

Homology and Analogy.-Still more important was the theory of the Homology of Organs. In the organs of animals they learned to discriminate between an anatomical and a physiological character; the anatomical character is the sum of all the anatomical characteristics, as found in form, structure, position, and mode of connection of organs; the physiological character is their function. Anatomically similar organs in closely related anımals will usually have the same functions, as, for example, the liver of all vertebrates has the function of preparing gall; here anatomical and physiological characteristics go hand in hand. But this need not necessarily be the case; very 
often it may happen that one and the same function is possessed by organs anatomically different; as, for example, the respiration of vertebrates is carried on in fishes by gills, in mammals by lungs. Conversely, anatomically similar organs may have different functions, as the lungs of mammals and the swim-bladder of fishes; similar organs may also undergo a change of function from one group to another; the hydrostatic apparatus of fishes has in the mammals come to be the seat of respiration. Organs with like functions, physiologically equal organs, are called "analogous"; organs of like anatomical constitution, anatomically equal organs, are called "homologous." It should be regarded as the task of Comparative Anatomy to discover in the various parts of animals those which are homologous, i.e. those of equal anatomical value, and to follow out the changes in them conditioned by a change of function.

Cuvier. - The foremost representative of the comparative anatomical tendency was Georges Dagobert Cuvier. He was born in 1769 in the town of Mömpelgardt (Montbeillard), then belonging to Wurtemberg, and obtained his early training in the Karlschule at Stuttgart, where through the influence of his teacher Kielmeyer, for whom he ahways had great veneration, he was led to the study of Comparative Anatomy. The opportunity of going to the seashore which was offered to him as private instructor to Count d'Héricy he employed for his epoch-making investigations upon the structure of mollusks. In I794, upon the persuasion particularly of the man who afterwards became his great opponent, Geoffroy St. Hilaire, he moved to Paris, where he was made at first Professor of Natural History in the central school and in the College of France, later Professor of Comparative Anatomy in the Jardin des Plantes. As a sign of the great regard in which Cuvier was held, it should be noticed that he was repeatedly intrusted with high educational positions and was made a French peer. As such he died in 1832 .

Type Theory.-Cuvier's investigations, apart from the 
mollusks, extended to the colenterates, arthropods, and vertebrates, living and fossil. He collected his extensive observations into his two chief works "Le règne animal distribué d'après son organization" and "Leçons d'anatomie comparée." Of quite epoch-making importance was his little pamphlet "Sur un rapprochement à établir entre les différentes classes des animaux," in which he founded his celebrated type theory, and by which in I 8 I 2 was introduced a complete reform of systemization. The Cuvierian division, which has become the starting-point for all further classifications differed, broadly speaking, from all the earlier systems in this, that the classes of mammals, birds, reptiles, and fishes were brought together into a higher grade under the name, introduced by Lamarck, of "vertebrated animals" ; that further the so-called "invertebrated animals" were divided into three similar grades, each equal to that of the "vertebrated animals, viz., Mollusca, Articulata, and Radiata." Cuvier called these grades standing above the classes, provinces or chief branches (cmbranchements), for which later the name Types was introduced by Blainville. But still more important are the differences which appear in the internal grounding of the system. Instead of, like the earlier systematists, using in the division a few various external characteristics, Cuvier built upon the totality of internal organization, as expressed in the relative positions of the most important organs, especially the position of the nervous system, as determining the arrangement of the other organs. "The type is the relative position of parts" (von Baer). Thus for the first time was Comparative Anatomy employed in the formation of a natural system of animals.

Finally the type theory established an entirely new conception of the arrangement of animals. Cuvier found as the prevalent view the theory that all animals formed a single dependent series rising from the lowest infusorian up to man; within this series the position of each animal was definitely determined by the height of its organization. On the other hand Cuvier taught that the animal 
kingdom consisted of several co-ordinated unities, the types, which exist quite independently side by side, within which again there are higher and lower forms. The position of an animal is determined by two factors: in the first place, by its conformity to a type, through the structural plan which it represents; in the second place, by its degree of organization, through the stage to which it attains within its type.

Comparative Embryology.-Evolution vs. Epigenesis.-The same results which Cuvier reached by the way of Comparative Anatomy were attained two decades later by $C$. E. von Baer by the aid of Embryology. Embryology is the youngest branch of Zoology. What real material for this Aristotle knew, what was written by Fabricius ab Aquapendente and Malpighi upon the embryology of the chick, did not rise above the range of aphorisms, which were not of sufficient value to make a science. The difficulties which here encompassed observation, due to the delicacy and the minuteness of the developmental stages, were ameliorated by the invention of the microscope and microscopical technique. Further, the prevailing philosophical conceptions placed hindrances in the way; generally speaking, there was no belief in Embryology in the present sense of the word; each organism was thought to be laid down even from the beginning complete in all its parts, and only needed growth to unfold its organs (Evolutio*); either the spermatozoon must be the young creature which in the store of food in the egg found favorable conditions for growth, or the egg represents the individual and was stimulated to the "Evolutio" by the spermatozoon. In its further consequence this theory led to the doctrine of inclusion, which taught that in the ovary of Eve were included the germs of all human beings who have lived or ever will live.

Caspar Friedrich Wolff in I759 combated this idea with his "Theoria generationis"; he sought to prove by

* It should be carefully noted that this original meaning of "evolution" is quite different from that at present prevailing. 
aid of observation that the hen's egg at the beginning was without any organization, and that only gradually did the various organs appear in it. In the embryo there takes place a new formation of all parts, an Epigcnesis. This first assault upon the evolutionist school was entirely without result, chiefly for the reason that $A$. von Haller, the most celebrated physiologist of the last century, used all his influence to suppress the idea of Epigenesis. Wolff was not able to establish himself in a circle of scientific influence in Germany, and was obliged to emigrate to Russia. Only after his death did hiswritings find, through Oken and Meckel, proper recognition.

Von Baer.-Thus it remained for Carl Ernst von Baer in his classic work, "Die Entwicklung des Hühnchens, Beobachtung und Reflexion" (IS32), to establish Embryology as an independent study. Baer confirmed Wolff's doctrine of the appearance of layerlike rudiments, from which the organs arose, and on account of the accuracy with which he conducted the proof of this he is considered the founder of the germ-layer thcory. Further, he came to the conclusion that each type had not only its peculiar structural plan, but also its peculiar course of development ; that for icrtcbrates an evolutio bigemina was characteristic, for the articulates the evolutio gemina, for the mollusks the evolutio contorta, and for the radiates the evolutio radiata. Here we meet for the first time the idea that for the correct solution of the conditions of relationship of animals, and therewith results for a natural systemization, Comparative Embryology is indispensable; an idea which in recent years has proved exceedingly fruitful.

Cell Theory.-Of fundamental importance for the further building up of Comparative Anatomy and Embryology was the proof that all organisms, as well as their embryonic forms, were composed of the same elements, the cells. This knowledge is the quintessence of the cell theory, which during the first thirty years of this century was propounded by Schleiden and Schwann, and which two decades later was completely reformed by the protoplasm 
theory of Max Schultze. In the cell theory a simple organic principle was found for all living creatures, for highly and for lowly organized plants and animals, and the wide realm of Histology was laid open for scientific consideration.

\section{REFORM OF THE SYSTEM.}

Foundation of Modern Zoology.-With the establishment of Comparative Anatomy and Embryology and the application of these to systemization, and with the development of the cell theory and the scientific idea of tissues, which stands in connection with it, we may say that the foundation of Zoology was laid. Wonderful advances were made in the realm of vertebrate anatomy through the classic researches of Owen, Johannes Müller, Rathke, Gegenbaur, and others; our conceptions of organization have been completely reformed by the work of Dujardin, Max Schultze, Haeckel, and others, who have proven the unicellularity of the lowest animals. The germ-layer theory was further elaborated by Remak and Kölliker; and by Kowalewsky, Haeckel, and Huxley applied to the invertebrated animals. It is beyond the limits of this brief historical summary to go into what has been accomplished in regard to the other branches of the animal kingdom; it must here be sufficient to mention the most important reforms which the Cuvierian system has experienced under the influence of increasing knowledge.

The Division of the Radiata.-Of the four types of Cuvier undoubtedly the branch Radiata was the one of whose representatives he had the least knowledge; it was therefore naturally least condensed, since it comprised, be. sides the radially symmetrical coelenterates and echinoderms, other forms, which like the worms were bilaterally symmetrical, or like many infusorians were asymmetrically built. Thus it came about that most reforms have here found their point of attack.

C. Th. v. Siebold was the originator of the first important reform. He limited the type Radiata, or, as he 
termed them, the zoophytes, to those animals with radially symmetrical structure (Echinodcrms and the flower-animals); separating all the others, he formed of the unicellular organisms standing lower the branch of "primitive animals" or Protosoa; the higher organized animals he grouped together as worms or lermes; at the same time he transferred a part of the Articulata, the annclids, to the worm group, and proposed for the other articulates, crabs, millipedes, spiders, and insects, the term Arthropoda.

Leuckart - a decade later separated the branch Radiata into two branches of very different degrees of organization. The lower forms, in which as yet no special body-cavity is present, the interior of the body consisting only of a system of cavities serving for digestion, the alimentary canal, he called the Colcutcra (essentially the Zoophyta of the older zoologists); to the rest, in which the alimentary canal and the body-cavity occur as two separate cavities, close beside each other, he gave the name Echinodcrma.

The Present System.-Thus there resulted seven classes: Protozoa, Cœlentera, Echinoderma, Vermes, Arthropoda, Mollusca, and Vertebrata. Still this arrangement does not correspond to the views which we are justified in attaching to a natural system, and is hence more or less unsatisfactory. Upon the ground of important anatomical and embryological characters the Brachiopoda, the Bryozoa, and the Tunicata have been separated from the Mollusca; they form the subject of diverse opinions. The conditions of relationship of the first two groups have not yet been explained: of the Tunicata we know indeed that they are related to the Vertebrata, yet we cannot range them with these, since they show such quite essential differences in structure. Of late there has been a noticeable tendency to raise these small aberrant groups to independent branches of the animal kingdom, a procedure which can only lead to an injury to the comprehensibility and the practical value of the system. It seems therefore preferable to regard these forms as appendages of the branch of worms, and in this book the 
division into seven branches, just as they have historically developed, has been adopted.

\section{HISTORY OF THE THEORY OF DESCENT.}

Importance of the Subject.-Before we close the historical introduction we must consider the historical development of a question whose importance might on a superficial examination be underrated, but which from a small beginning has grown into a problem completely dominating zoological research, and has busied with its consequences not only zoologists, but all circles interested in science generally. I refer to the question of the logical value of the systematic terms species, genus, family, etc.

The Nature of Species.-In nature we find only separate animals: how comes it now that we classify them into larger and smaller groups? Are the single species, genera, and the other divisions which the systematist distinguishes, fixed quantities, as it were fundamental conceptions of nature, or a Creator's thoughts, which find expression in the single forms? Or are they abstractions which man has brought into nature for the purpose of making it comprehensible to his mental capabilities? Are the specific and generic names only expressions which have become necessary from the nature of our mental capacity, for the gradation of the circles of relationship in nature, which in and for themselves are not immutable, and hence can undergo a gradual change? Practically speaking, the problem reads: are the species constant or changeable? What is true for the species must necessarily be true for all the other categories of the system, all of which in the ultimate analysis rest upon the conception of species.

Ray's Conception of Species.-One of the first to consider the conception of species was Linnæus's predecessor, the Englishman John Ray. In the attempt to define what should be understood as a species he encountered difficulties. In practice, animals which differ little in structure and appearance from one another are ascribed to the same 
species; this practical procedure cannot be carried out theoretically; for there are males and females within the same species which, apart from their sexual organs, differ more from one another than do the representatives of different species. Thus John Ray attained to the genetic definition when he said: for plants there is no other more certain characteristic for determining species than their origin from the seeds of specifically or individually like plants; that is to say, generalized for all organisms: to one and the same species belong individuals which spring from similar ancestors.

The "Cataclysm Theory."-With Ray's definition an entirely uncontrollable element was brought into the conception of species, since no systematist knew anything, nor indeed could he know anything, as to whether the representatives of the species placed before him sprang from similar parents. It was therefore only natural that the conception of species put on a religious garb, since by resting upon religious ideas it found a firmer support. Linnæus said: "Tot sunt species quot ab initio creavit infinitum Ens"; with this he built up a conception of species upon the tradition of the Mosaic history of creation, a procedure quite unjustified upon grounds of natural science, since it drew one of its fundamental ideas from transcendental conceptions, not from the experience of natural science. Almost immediately Linnæus's definition showed itself untenable, and at the same time Paleontology began to make accessible a vast quantity of material, in the form of extinct animals deposited as fossils. With an odd fancy, the fossils, being inconvenient for study, were for a long time regarded as outside the pale of scientific research. They might be sports of nature, it was said, or remains of the Flood, or of the influence of the stars upon the earth, or products of an aura scminalis, a fertilizing breath, which, if it fell upon organic bodies, led to the formation of animals and plants, but if it strayed upon inorganic materials gave rise to fossils. The foundation of scientific Paleontology by Cuvier put an end to such empty speculations. 
Cuvier proved beyond a doubt that these fossils were the cmains of animals of a previous time. Just as the formation of the earth's crust by successive overlying layers made possible the discrimination of different natural periods of the earth's history, so Paleontology taught how to recognize also the different periods in the vegetable and animal world of life on our globe. Each geological age was characterized by a special world of animals quite peculiar to it; each period showed a successively higher development of the animal world, i.e., in the older periods of the earth's history only the lower animals existed, but with each new period higher animals appeared, culminating in the present period in man, the crowning glory of creation. All these generalizations led Cuvier to his cataclysm theory, that a great revolution brought to an end each period of the earth's history, destroying all life, and that upon the newiy-formed virgin earth a new organic world of constant species sprang up.

Objections to the "Cataclysm Theory."-By the supposition of numerous acts of creation the Linnean conception of species seemed to be rescued, though, to be sure, by summoning to its aid hypotheses which had neither foundation in natural history nor justification in theology. The logical following out of Cuvier's cataclysm theory led to conceptions of a Creator who built up an animal world only for the purpose of destroying it after a time as a troublesome toy; it has therefore at no time found warm supporters, at least among geologists, for whom it was intended. Of the prominent zoologists there is only to be mentioned Louis Agassiz, who till the end of his life remained faithful to this theory.

Under these conditions it is readily understood how thinking naturalists, who felt the necessity of explaining the character of organic nature simply and by a natural law capable of general application, began to doubt the fixity of species, and were led to the theory of change of form, the Theory of Descent. 
Darwin's Predecessors.-Already in Cuvier's time there prevailed a strong current in favor of this theory. It found expression in England in the writings of Erasmus Darwin (grandfather of the renowned Charles Darwin); in Germany in the works of Goethe, Oken, and the disciples of their school of natural philosophy; in France the genealogical theory was built up particularly by Buffon, Geoffroy St. Hilaire, and Lamarck. Its completest expression was found in Lamarck's "Philosophie zoologique "which appeared in I809; its arguments will be considered in the following paragraphs.

Lamarck (Jean Baptiste de Monet, Chevalier de Lamarck, born in Picardy, I744, died, Professor at the Jardin des Plantes, I 829 ) taught that on the earth at first organisms of the simplest structure arose in the natural way through spontaneous generation from non-living matter. From these simplest living creatures have developed in the course of an immeasurably vast space of time, by gradual changes, the at present living species of plants and animals, without any break in the continuity of life upon our globe; the terminal point of this series is man; the other animals are the descendants of those forms from which man has developed. Lamarck, in agreement with the then prevailing conceptions, regarded the animal kingdom as a series grading from the lowest primitive animal up to man. Among, the causes which may influence the change and perfecting of organisms, Lamarck emphasized particularly use and disusc; the giraffe has obtained a long neck because by a special condition of life he was compelled to stretch, in order to browse the leaves on high trees; conversely, the eyes of animals which live in the dark have from lack of use degenerated into small functionless bodies. The direct influence of the external world must be unimportant; the changes in the surroundings (Geoffroy St. Hilaire's - le mondc ambicnt) must for the most part act indirectly upon animals by altering the conditions for the use of organs. 
Evolution vs. Creation.-Lamarch's spirited writings remained almost unnoticed by his contemporaries. On the other hand there arose a violent controversy between the defenders and the opponents of the Evolution theory when in 1830 Geoffroy St. Hilaire in the Academy at Paris defended against Cuvier in a debate the thesis of a near relationship of the vertebrates and the insects, and set up the proposition that the latter were "vertebrates running on their backs." The conflict ended in the complete overthrow of the Descent Theory; the defeat was so complete that the problem vanished for a long time from scientific discussion, and the theory of the constancy of species again became dominant. This error was occasioned by many causes. Above all, the theory of Geoffroy St. Hilaire and Lamarck was rather a clever conception than founded on a rich empiric material; besides, it had in it as a fundamental error the doctrine of the serial arrangement of the animal world. Opposed to this stood Cuvier's great authority and his extensive knowledge, which latter made it easy for him to show that the animal kingdom was made up of separate co-ordinated groups, the types.

Lyell.-In the same year in which Cuvier obtained his victory, for a long time decisive, over Geoffroy St. Hilaire, his theory of the succession of numerous animal worlds upon the globe received its first destructive blow. Cuvier's cataclysm theory had its two sides, a geological and a botanico-zoological. Cuvier denied the continuity of the various terrestrial periods, as well as the continuity of the fauma and flora belonging to them. In I $830-32$ appeared the "Principles of Geology" by Lyell, an epoch-making work, which in the realm of geology completely set aside the cataclysm theory. Lyell proved that the supposition of violent revolutions on the earth was not necessary in order to explain the changes of the earth's surface and the superposition of its strata; that rather the constantly acting forces, the liftings and sinkings, the erosive action of water, be it as ebb and flow of the tide, as rain, snow, or ice, or as the flow of rivers 
and brooks rushing as torrents towards the sea, are sufficient to furnish a complete explanation. Very gradually in the course of a vast space of time the earth's surface has changed, and passed from one period into the next, and still at the present day the constant process of change is going on. The continuity in the geological history of the earth, here postulated for the first time, has since then become one of the fundamental axioms of Geology; on the other hand the discontinuity of living creatures, although the geological hypotheses touch lightly upon this, was for a long time regarded as correct.

Darwin.-It is the great merit of Charles Darwin that he took up the theory of descent anew after it had rested a decade, and brought it into general recognition. Thereby was introduced the most important period in the history of Zoology, a period in which the science not only made such an advance as never before, but also began to obtain a permanent influence upon the general views of men.

Charles Darwin was born at Shrewsbury, Eng., in I809. After a short course of study at the universities of Edinburgh and Cambridge, he joined as naturalist the English warship "Beagle" detailed from I 83 I-36 for nautical researches on a circumnavigation of the globe. Darwin recognized the peculiar character of island faunas, particularly of the Galapagos Islands, and the remarkabie distribution of Edentates in South America; these facts formed for him the germ of his epoch-making theory. Further results of this journey were his beautiful monograph on the Cirrepedia, and the classic investigation of coral-reefs. After his return to England Darwin lived, entirely devoted to scientific work, chiefly in the hamlet of Downs, county Kent, up to the time of his death in I882. Above all he was incessantly busy in building up his conception of the origin of species, and in collecting for this an ever richer empiric material. The first written notes, the fundamental ideas of which he communicated to friends, particularly the geologist Lyell and the botanist Hooker, were made in I 844 , but the author was 
not persuaded to give them publicity. Not until i 858 did Darwin decide to make his first contribution to science, in the Journal of the Linnean Society, being influenced by a special motive. In this year he received an essay sent by the traveller Wallace, which in its most important points coincided with Darwin's own views. Contemporaneously with Wallace's manuscript an abstract of Darwin's theory came into print. In the year after that (I 859) appeared the most important of his writings, "On the Origin of Species by means of Natural Selection," and in rapid succession a complete series of works, the fruit of many years of preparatory labors. For the history of the Descent theory the most important of this series are: (I) "Upon the Variation of Plants and Animals under Domestication," two volumes, which chiefly contain a collection of empiric material for proofs; (2) on "The Descent of Man," a work which gives the application to man of the theory of descent.

No scientific work of this century has attracted so much attention in the zoological, we may even say in the whole educated world, as Darwin's book upon "The Origin of Species." It was generally received as something entirely new, so completely had the scientific tradition been lost. In professional circles it was by one faction stoutly combated, with another it found well-wishing, but hesitating acceptance. Only a few men placed themselves in a decided manner from the beginning on the side of the great British investigator. There was kindled a lively scientific battle, which ended in a brilliant victory for the Descent Theory. At the present time all our scientific thoughts are so permeated with the idea of the Descent theory that we can scarcely speak of any considerable opposition to it.

Post-Darwinian Writers.-Among the men who have most influenced this rapid advance is to be mentioned, besides A. R. Wallace, the co-founder of Darwinism, above all E. Haeckel, who in his "General Morphology" and his "Natural History of Creation" has done much towards the methodical building up of the theory. Among 
other energetic defenders of the theory in Germany should be mentioned Fritz Müller, Carl Vogt, Weismann, Moritz Wagner, and Nägeli, even if they have assumed special standpoints in reference to the causes conditioning the changes of form. Among the English investigators of nature are to be named particularly Huxley, Hooker, and Lyell. Darwinism obtained latest an entrance into France.

\section{DARWIN'S THEORY OF THE ORIGIN OF SPECIES.}

The Problem Stated.-Darwin begins with a criticism of the term species. Is the conception of species on the one side and that of race and variety on the other something entirely different? Are there special criteria for determining beyond the possibility of a doubt whether in a definite case we have to do with a variety of a species or with a different species? or do the conceptions in nature pass into one another? Are species varieties which have become constant, and precisely in the same manner are varieties species in the process of formation?

Morphological Characters.-A. Distinction betwecn Spccics and l aricty.-For the settlement of this fundamental question morphological and physiological characters can be considered. In the practice of the systematists usually the morphological characters prevail exclusively; for that reason they will be here considered first. If, among a great number of forms similar to one another, two groups can be adduced which differ considerably from one another, if the difference between them is obliterated by no intermediate forms, and if in several successive generations they remain constant, then the systematist speaks of a good species; on the other hand he speaks of varieties of the same species when the differences are slight and inconstant, and still further when they lose their importance through the existence of intermediate forms. A definite application of this rule discloses great incongruities, wherewith is connected the fact that many animal and vegetable groups are by one set of systematists regarded as good species, by another set 
only as "sports," i.e. as varictics of the same species. The differences between the "sports" of our domestic animals are in many instances so considerable that formerly they

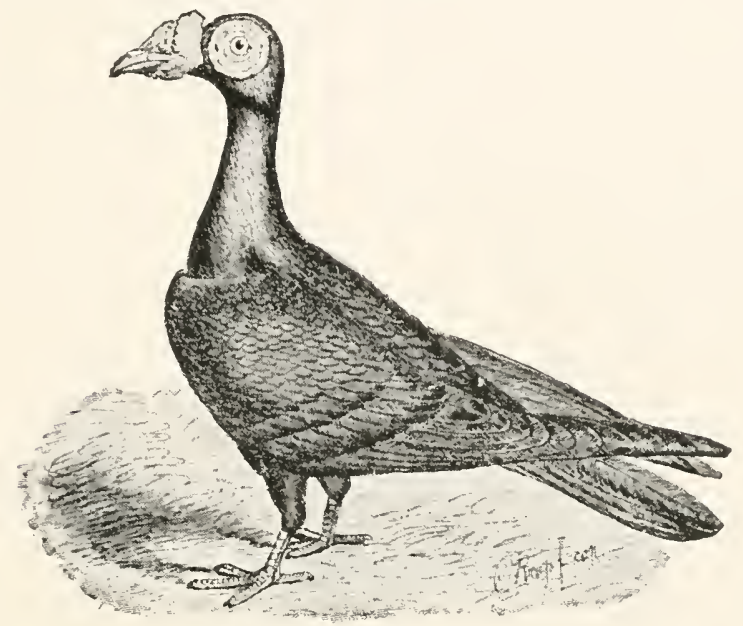

Fig. IA.-English Carrier-pigeon. (After Darwin.)

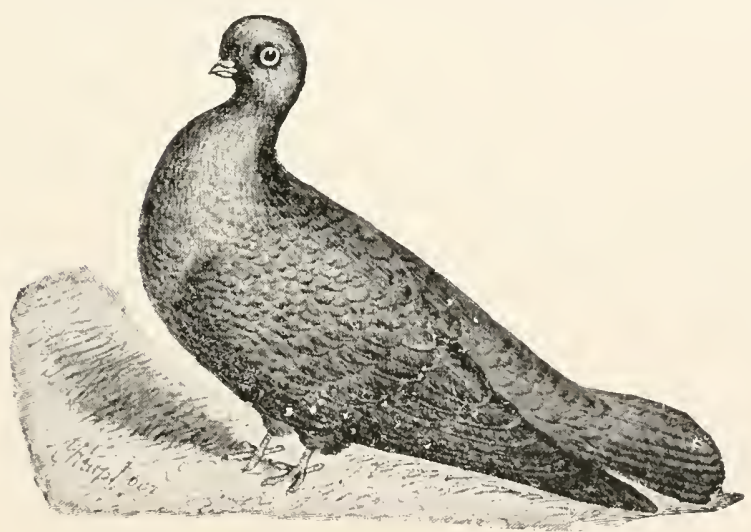

FIG. 1B.-English Tumbler-pigeon. (After Darwin.)

were regarded not only as sufficient for the distinction of good species, but even of genera and families. In the fantail pigeon the number of quill tail-feathers, formerly only I2-14, has increased to 30-42 (Fig. IC); among the 
other races of pigeons enormous variations are found in the size of the beak and feet in comparison with the rest of the body (Figs. IA, IB); even the skeleton itself participates in this variation, as is shown by the fact that the total number of vertebræ varies from 38 (in the carrierpigeon) to 43 (in the pouter), the number of sacral vertebra from $\mathrm{I}_{4}$ to II.

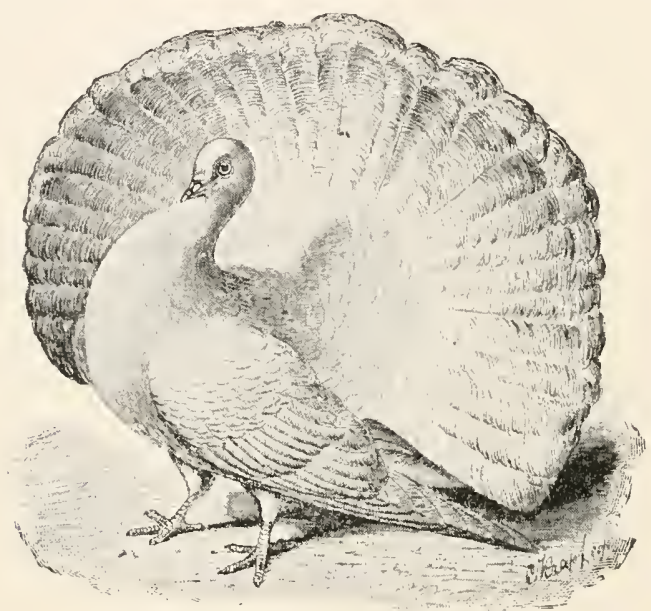

FlG. IC,-English Fantail Pigeon. (After Darwin.)

B. Variation within the Species.-Now in respect to the occurrence of transitional forms and the constancy of differences, there is within one and the same "good species" the greatest conceivable difference. In many strongly varying species the extremes are united by many transitions; in other cases sharply circumscribed groups of forms, i.e. races, can be distinguished within the same species. In the race, the peculiar characteristics are inherited from generation to generation with the same constancy as in good species. This is shown in the human races, and many pure, cultivated races of domesticated animals.

Physiological Characters.-A. Crossing of Species and Tarieties.-A critical examination leads to the conclusion that Morphology is indeed useful for grouping animals into species and varicties, but that it leaves us com- 
pletely in the lurch when it is called upon to show the distinctions between what should be called a species and what a variety. Therefore there remains open to the systematist only one resource for attaining his aim, i.e., by summoning Physiology to his aid. This has been done, and it has disclosed considerable distinctions in reproduction. IVe should expect a priori that the individuals of different species would not reproduce with each other; on the other hand under normal conditions the individuals of one and the same species, even though they are of different varieties or races, should be entirely fertile. One must beware of arguing in a circle in proof of these two propositions; it would be an argument in a circle if an experimenter should regard two animals as representatives of one species only because they proved to be fertile together, while under their former relations he assigned them to different species. Rather the question for him must read: does physiological experiment lead to the same systematic distinctions as does the common systematic experience, viz., the depreciation of constancy and the divergence of distinguishing characters?

B. The Intercrossing of Spccics. - The region which we here enter is as yet far from being sufficiently worked through experimentally; yet already some general propositions can be set up: (I) that not a few so-called "good species" can be crossed with one another; (2) that in general the difficulty of crossing increases, the more distant the systematic relationship of the species used; (3) but that these difficulties are by no means directly proportional to the systematic divergence of the species. The most favorable material for research is furnished by those animals in the case of which artificial fertilization can be carried out, i.e., of which one can take the eggs and spermatozoa and mix them independently of the will of the animals. Thus hybrids have been obtained from species which belong to quite different genera, while very often nearly-related species will not cross. Among fishes we know hybrids of Abramis brama and Blica Björkna, of 
Trutta salar (salmon) and Trutta fario (trout); among seaurchins the spermatoza of Strongylocentrotus lividus fertilize with great readiness the eggs of Echimns microtuberculatus, but only extremely seldom the eggs of Spharechinus granularis, which stands closer to it in the system. It also happens that crossing in one direction (male of $\mathrm{A}$ and female of $B$ ) is easily accomplished, but in the other direction (male of $B$ and female of $A$ ) it completely fails; as, for example, the sperm of Strongyloccntrotus lividus fertilizes well the eggs of Echinus microtubcrculatus, but, conversely, the sperm of E. microtubcrulatus does not fertilize the eggs of $S$. lividus.

In the case of animals where copulation is necessary the difficulties of experimentation increase, since here often between males and females of different species there exists an aversion which prevents any union of the sexes. Yet in this case we know crosses of different species; among the vertebrates crossing takes place, e.g., between the horse and the ass; our domestic cattle and the zebu; ibex (or wild buck) and she-goat; sheep and goats; dog and jackal; $\operatorname{dog}$ and wolf; hare and rabbit (Lcpus Darwini); etc.; among birds, between different species of finches and of grouse; mallard (Anas boschas) and the pintail duck (Dafila acuta); the European goose and the Chinese goose (Anscr forus and A. cygnoidcs).

C. Fertility of Hybrids and Mongrcls. - Since many hybrids, as the mule, have been known for thousands of years, the criterion is, as it were, pushed back one stage; if the infertility in cases of crosses in many species is not immediately noticeable, yet it may be apparent in the products of the cross. While the products of the crossing of varieties, the "mongrels," always have a normal, often an increased, fertility, the products of the crossing of species, the hybrids, should always be sterile. But even this is a rule, not a law. The mule (which only very rarely reproduces) and many other hybrids are indeed sterile, but there are not a few exceptions, although the number of experiments in reference to this point is very small. 
Hybrids of hares and rabbits have continued fruitful for generations; the same is true of hybrids obtained from the wild buck and the domesticated she-goat; from Anser cygnoides and Anserdomesticus; from Salmo saliclinus and S. fontinalis; Cyprimus carpio and Carassius vulgaris; Bombyx cynthia and B. arrindia.

D. Inbreding.-Even the second of the above statements, that individuals of a species, provided they are sound, always reproduce with one another, needs limitation. Breeders of animals have for a long time known the disastrous consequences of inbreeding - that the reproductive power is reduced even to sterility if, for breeding, descendants of a single pair are continually chosen. Darwin has collected not a few cases where undoubted members of the same species have been completely sterile with one another; thus certain forms of primrose and other di- and trimorphic species. Examples of the sterility of mongrels are known only in botany (certain varieties of maize and mullein).

Conditions Governing Fertility in Sexual Reproduction.-When we look over these known facts it would seem as if continued fertility in sexual reproduction were guaranteed by a not too considerable difference in the sexual products. Too great similarities, as these exist in inbreeding, and too great differences, as in the hybridization of different species, are injurious and are abhorred by Nature. Sexual reproduction possesses an optimum; if this is departed from in either direction diminution gradually follows. But for that reason it has already been said that here gradual and not primary differences exist, and thercfore this character cannot be employed as a primary distinction between species and varieties.

Difficulties in Systemization.-The final result of all this discussion may be summed up as follows: up to the present time, neither by physiological nor by morphological evidence has there been successfully fixed in a clear and generally applicable way a criterion which can guide the systematist in deciding whether certain series of forms 
are to be regarded as good species or as varieties of a species. Zoologists are guided rather in practice by a certain tact for systcmisation, which, however, in difficult cases leaves them in the lurch, and thus the opinions of various investigators vary.

Change of Varieties into Species. - The conditions. above discussed find their natural explanation in the as. sumption that sharp distinctions between species and variety do not exist; that spccies are ararictics which hawe become constant, and sarictics arc incipicnt specics. The meaning of the above can be made clear by explanation of a concrete case. Individuals of a species begin to vary, i.e., compared with one another they attain a great difference in character. So long as the extreme differences are bridged by transitional forms we speak of varieties of a species; if, on the other hand, the intermediate transitions have died out, and the differences have in the course of a long space of time become fixed, and so very much intensified that a sexual union of the extreme forms results either in complete sterility or at least in a tendency towards sterility, then we speak of different species.

\section{Species may be Related to each other in Unequal} Degrees.-In favor of this view, that varieties will in longer duration become species, speaks also the great agreement which in the large majority of cases exists between the two. In the case of genera which comprise a remarkable number of species, the species usually show also many varieties; the species are then usually grouped in subgenera, i.e., they are related to each other in unequal degrees, since they form small groups arranged around certain species. In regard to the varieties also the case is similar. In such genera the formation of species is in active progress; but each species formation presupposes a high degree of variability.

Phylogeny.-It is now clear that the same argument which has here been worked out in the case of the species must also apply to the other categories of the system. Just as by divergent development varieties become species, 
so must species by continued divergence become so far removed from one another that we distinguish them as genera. It will be only a question of time when these differences will become still greater, and cause the establishment of orders, classes, and branches, just as the tender shoots of the young plantlet become in the strong tree the chief branches from which spring out lateral branches and twigs. If we pursue this train of thought to its ultimate consequences, we reach the conception that all the animals and plants living at present have arisen by means of variation from a few primitive organisms. Inasmuch as at least many thousands of years are required for the formtion of several new species through the variability of one species, there must then have been necessary for rendering possible this historical development of the animal and vegetable kingdoms a space of time greater than our mental capacity can grasp, just as the astronomers deal with distances of which we can form no conception. Since now for the idea of the individual development of an animal the special term "Ontogeny" has been chosen, it has also proved convenient to apply to the historical development of animals-though this has not been observed, but only inferred-the special term "History of the Race" or "Phylogeny."

Spontaneous Generation.-If we attempt to derive all living animals from a common primitive form, we are compelled to assume that this was of extremely simple organization, that it was unicellular; for the simpler the organization, the less specialized and determined, so much the greater is its capacity for variation. Only from simply-formed organisms can the lower unicellular organisms, the Protozoa, be derived. Finally, for the simply-formed organisms alone can we conceive a first natural origin. Since there was undoubtedly a time when upon our earth temperatures prevailed which made any life impossible, life upon it must at some time have arisen anew, either through an act of creation or in the natural way through spontaneous generation. If, in agreement with the spirit of natural 
science, we invoke for the explanation of natural facts only the forces of nature, we are driven to the hypothesis of spontaneous generation, namely, that from materials without life, by a peculiar combination of them, the complicated mechanism which we call "life" has arisen. This hypothesis also supposes that the first organisms possessed the simplest conceivable structure.

Variability not proven to be a Universal Principle. - Starting from a basis of facts, by generalization of the results we reach a simple conception of the origin of the animal kingdom, but we have in equal measure departed from the results of direct observation. Observations only show us that species are capable of changes and can from themselves produce new species. That this capacity for variation is a universal principle, a principle which explains to us the origin of the animal world, needs further demonstration.

Proofs of Phylogeny.-The rise of the now living animal world is a process which has taken place in the thousands of years long past, but is no longer accessible for direct observation, and therefore it can never be proved in the sense that we explain the individual development of an organism. In regard to the conception of the simple evolution of animals we can attain merely to proving the probability; yet it is shown that all our observations of accessible facts not only agree with this conception, but find through this their only simple explanation. Such facts are furnished to us by the Systematic Arrangement of Animals, Paleontology, Animal Distribution, Comparative Anatomy, and Comparative Embryology.

(I) Proofs from Systemization.-For a long time it has been recognized, and in recent times finds ever-increasing confirmation, that if we wish to express graphically the conditions of relationship of animals, their classes, orders, genera, and species, simple co-ordination and subordination are not sufficient, but one must select a treelike arrangement, in which the principal divisions, more closely or distantly related to one another, the branches, phyla, or 
types, represent the main branches of the tree, while the finer branches correspond to the several classes, orders, etc. This is, in fact, the arrangement to which the de. scent theory, as seen above, necessarily leads.

(2) Paleontological Demonstration approaches nearest to what one might call direct proof; for Paleontology gives us the last traces of existence which the predecessors of the present animal world have left. Meanwhile we must take into consideration the fact that even here a hypothetical element has crept into the character of the demonstration. We can only observe that various grades of form of an animal group are found in successive strata; if we unite these grades of form among themselves into a developmental series, and think of the younger as derived from the older by variation, we depart, strictly speaking, from the basis of fact. But much more is the value of paleontological evidence weakened by its extreme incompleteness. In fossils only the hard parts of animals are generally preserved; the soft parts, on the other hand, which in many branches alone are present, or at least make up the most important part of their organization, are almost always lost. Even the hard parts preserve good articulations only under exceptionally favorable conditions. If further we take into consideration the fact that these treasures are buried in the bosom of the earth, and are usually obtained only by accident, in quarrying and roadbuilding, and besides only extremely seldom excavated with care and with scientific deliberation, it becomes sufficiently clear how little is to be expected from the past and indeed future material of Paleontology.

Examples of Paleontological Proof. - Yet Paleontology has already furnished many important proofs of the Theory of Descent. It has shown that the lower forms appeared first, and the higher organized only later. Among animals in general the latest to appear were the vertebrates, and of these the mammals; among the mammals the apes and man. For smaller groups it has indeed been fort unate in collecting genealogical material. Transitional forms lead 
from the single-toed horse of the present day to the fourtoed Eöhippos of the Eocene; for all the hoofed animals a common starting-point or ancestral form has been found in the Condlylarthra. Farther transitional forms have been found between the greater divisions, as, e.g., between reptiles and birds, the remarkable toothed birds, and the Archaopteryx (Fig. 2), a bird with a long, feathered, lizardlike tail.

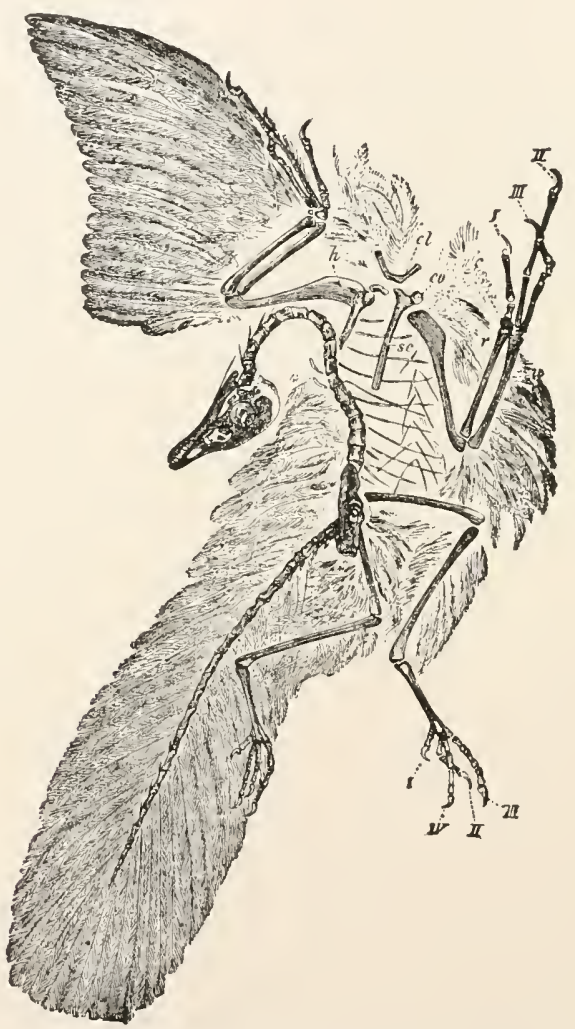

FIG. 2.- Archaepteryx lithographica. (After Zittel.) cl, clavicle; co, coracoid; $h$, humerus; $r$, radius ; $u$, ulna ; $c$, carpus; I-IV, digits ; sc, scapula.

(3) Morphological Proofs.-If we wish to employ Comparative Anatomy and Embryology in support of the Descent Theory, we find that the two studies have so many 
points in common that they can best be treated under a common head.

Cuvier and Carl E. v. Baer had taught that the separate types of the animal kingdom are units, under each one of which there lies a special structure and plan of development peculiar to it; farther, that there are no similarities in structure and in the development forming a bridge from type to type. The first of these two propositions is still as formerly regarded as correct, but the second, which alone is important for the Descent Theory, has become quite untenable. All animals have in the cell a common organic principle and are thereby brought close to one another; all multicellular animals agree during the first stages of their development, while the fertilization, cleavage of the egg, and the formation of the first two germlayers agree in the principal important points, and vary from one another only in such differences as occur within one and the same type. Also the peculiarities which distinguish each type in structure and in the mode of development do not occur in the animal world without intermediate phases. Especially from the branch of the worms there lead off transitional forms to the other branches: Balanoglossus to the Echinoderms, the Annelids and Peripatus to the Arthropods, the Tunicates and Amphioxus to the Tertebrates. In some representatives of each type the structure and the mode of development are simpler, thereby approaching to the conditions which obtain in the other types. The existence of such transitional forms is one of the most important proofs in favor of the Descent Theory, and speaks against the assumption of a rigid unvarying type in Cuvier's sense.

Fundamental Law of Biogenesis.-A fact that weighs heavily in the balance in favor of the Descent Theory is the fact that the structure and mode of development of animals is ruled by a conformity to a law which at this time can only be explained by the assumption of a common ancestry. Each animal during its development passes through essentially the stages which remain permanent in 
the case of lower or at least more primitively organized animals of the same branch, as the three following ex-

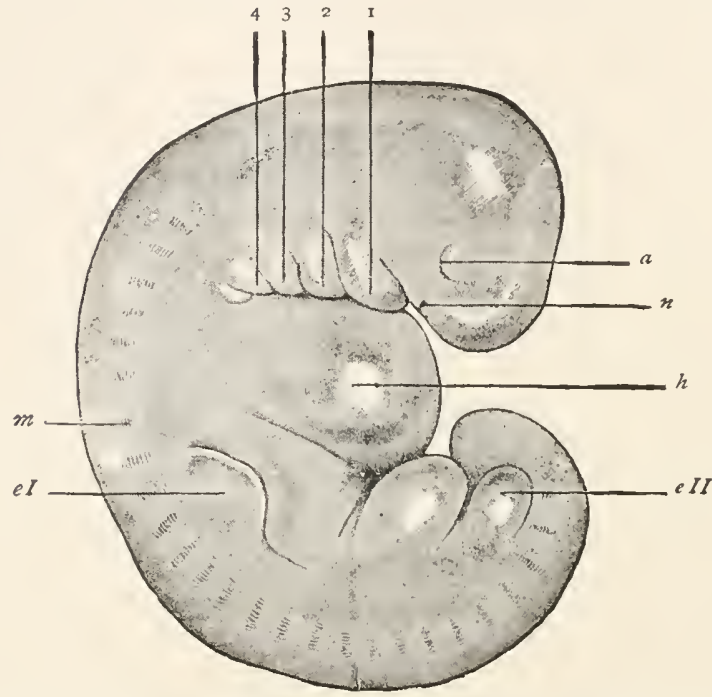

FIG. 3.-Human Embryo, about third or fourth week. I-4, visceral arches with gill-slits between them: 1 , lower-jaw arch; 2 , hyoid arch; 3 and 4 , first and second gill-arches. $a$, eye; $n$, nasal pit; $h$, cardiac region; $e I$ and $e I I$, fore and hind extremities; $m$, mesoblastic somites.

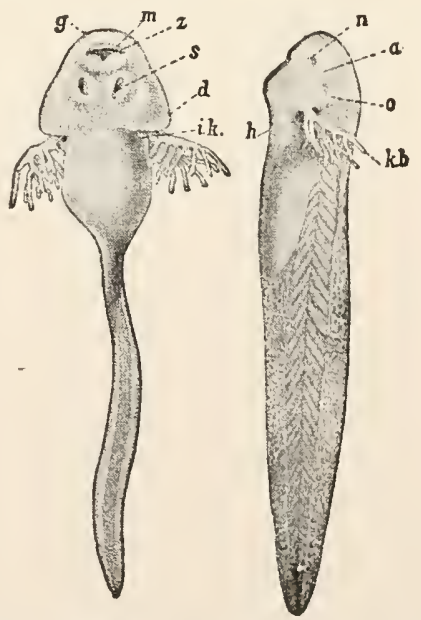

FIG. 4.-Tadpoles of Rana temporaria. m, mouth; $g$, upper jaw ; $z$, lower jaw ; s, sucking disk; $k b$, external gills; $i k$, region of the internal gills; $n$, nose; $a$, eye; $o$, auditory vesicle ; $h$, cardiac region; $d$, operculum.

amples will show: (I) In the early stages of development the human embryo (Fig. 3) possesses remalkable resem- 
blances to the lowest vertebrates, the fishes. Like these it has gill-slits, the same arrangement of the heart and of the arterial vessels, certain fundamental features in the development of the skeleton, etc. (2) Frogs in their tadpole stage have an organization similar to that, which remains permanent in the case of certain amphibia, the Perennibranchiata (Fig. 5), which stand lower in the sys.

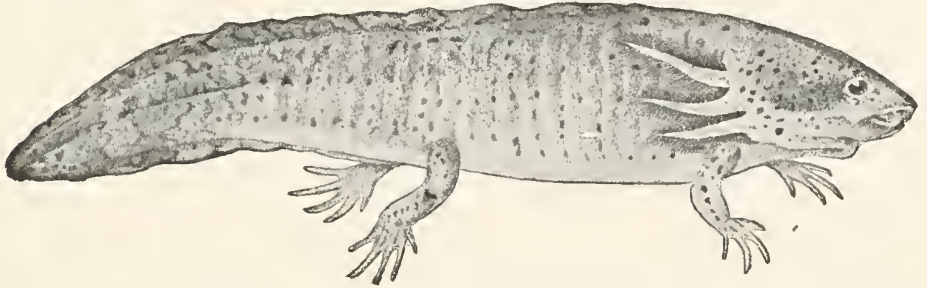

FIG. 5.-Siredon pisciformis (Axolotl). (After Duméril and Bibron.)

tem; they have a rudimentary tail and tuft-like gills, which are lacking in the adult frog. (3) There are certain parasitic crabs, which live upon the gills of fishes, and

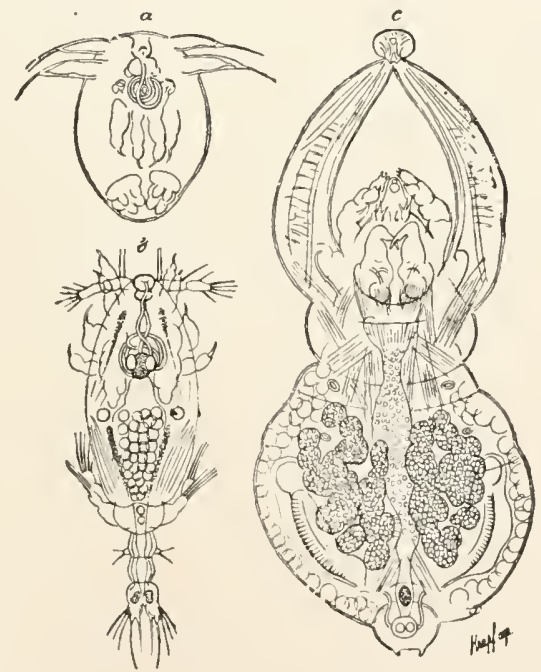

Fig. 6.-Achtheres Percarum. "n, nauplius-, b, cyclops-stage; $c$, female. (After Claus.) seem not at all like the other crabs. They are shapeless masses which were formerly regarded as parasitic worms. Their systematic position can only be determined through 
their embryology (Fig. 6). Here it is shown that they pass through a nauplius-stage (Fig. 6, $a$ ) characteristic of most crustacea, and that they then assume the shape of completely formed small crabs (Fig. 6, b), like those under the name of Cyclops ( $\mathrm{Fig} .8, A$ ), so widely distributed in fresh waters. Very often the males make a halt in the cyclopsstage and the female develops farther and becomes the shapeless mass, so that there arises a very remarkable sexual dimorphism (Fig. 7). All these examples, which can be multiplied by hundreds, can be explained in the same way. The more developed forms pass through the stage of organization of the less developed, because they spring from ancestors which were more or less similar to the latter. Man in his embryological development passes through the fish stage, the frog the perennibranchiate stage, the parasitic crab first the nauplius- and then the cyclops-stage, because their ancestors were once fish-like, perennibranchiate-like, nauplius- and cyclops-like. Here is expressed a
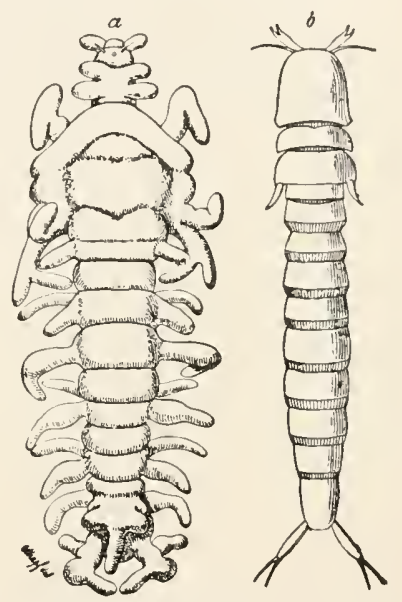

FIG. 7.-Philicthys Xiphice, a, female (after Claus), $\times_{4} ; b$, male (after Bergsoe), $X$ I3. general phenomenon which Haeckel has stated in a general proposition under the name of "the fundamental law of Biogenesis." "The developmental history (ontogeny) of an individual animal briefly recapitulates the history of the race (phylogeny); i.e., the most important stages of organization which its ancestors have passed through appear again, even if somewhat modified, in the development of incividual animals."

Examples of the Application of this Law.-The Nerzous Systcm. - The fundamental law of biogenesis applies as well to single organs as to the entire animals. The central nervous system of the lower animals (echinoderms, colenterates, many worms) forms part of the skin; in its first 


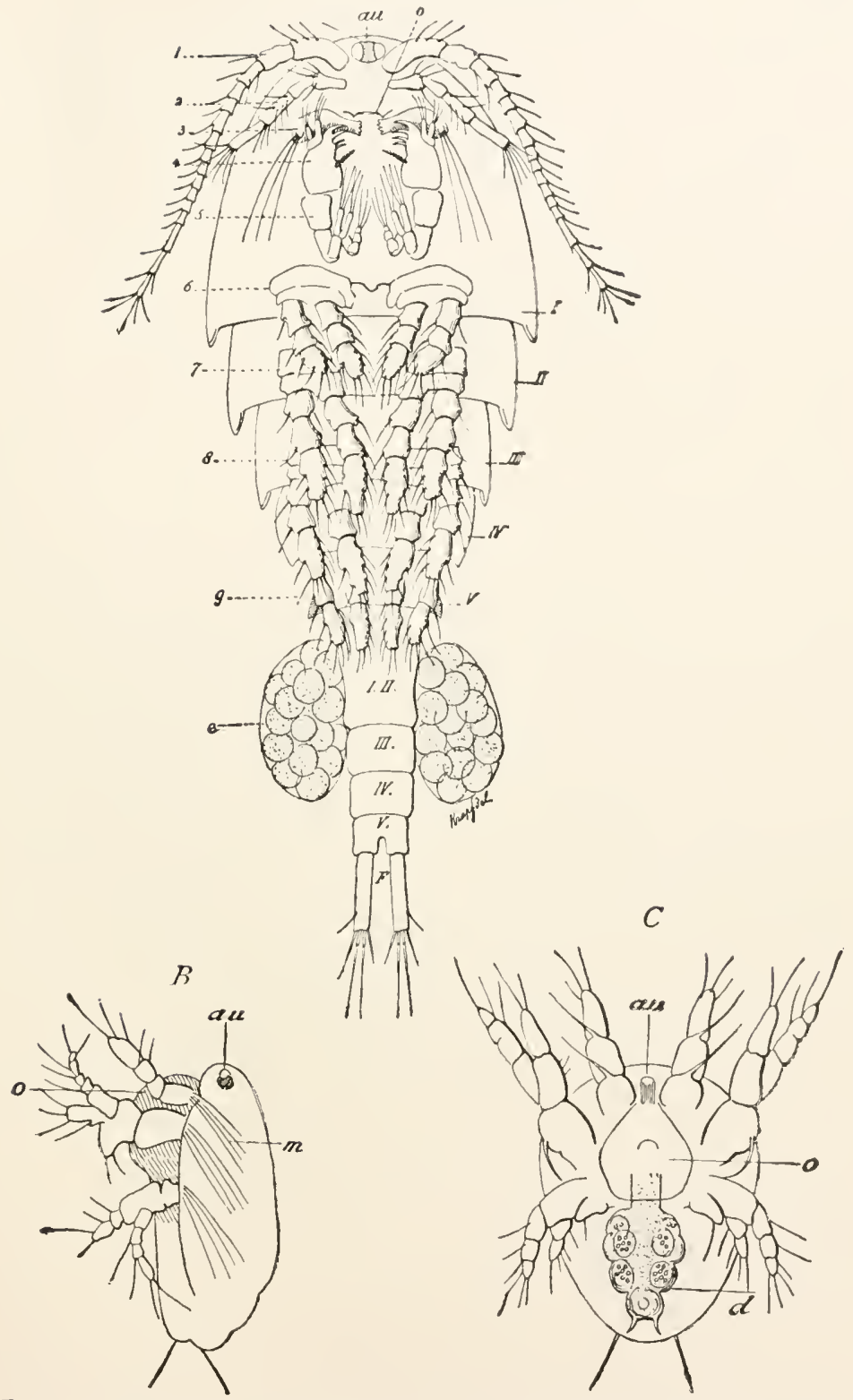

FIG. 8.-Cyclops coronutus $(A)$ and also the nauplius in lateral $(B)$ and in ventral view $(C$ ) $I-V$, the five thoracic, and behind these the five abdominal segments; $F$, furca $;$, the first, 2, the second, antennx: 3 , mandibles : 4, maxilla; 5, pedes maxillares (maxillipeds); $6-9$, the first four pairs of biramous feet. while the rudimentary fifth pair are hidden ; au, eye ; 0 , upper lip ; $e$, egg-sacs; $d$, gut ; $m$, muscle. 
appearance it belongs to the surface of the body, because this mediates the relations with the external world, the regulation of which relations is subserved by the central
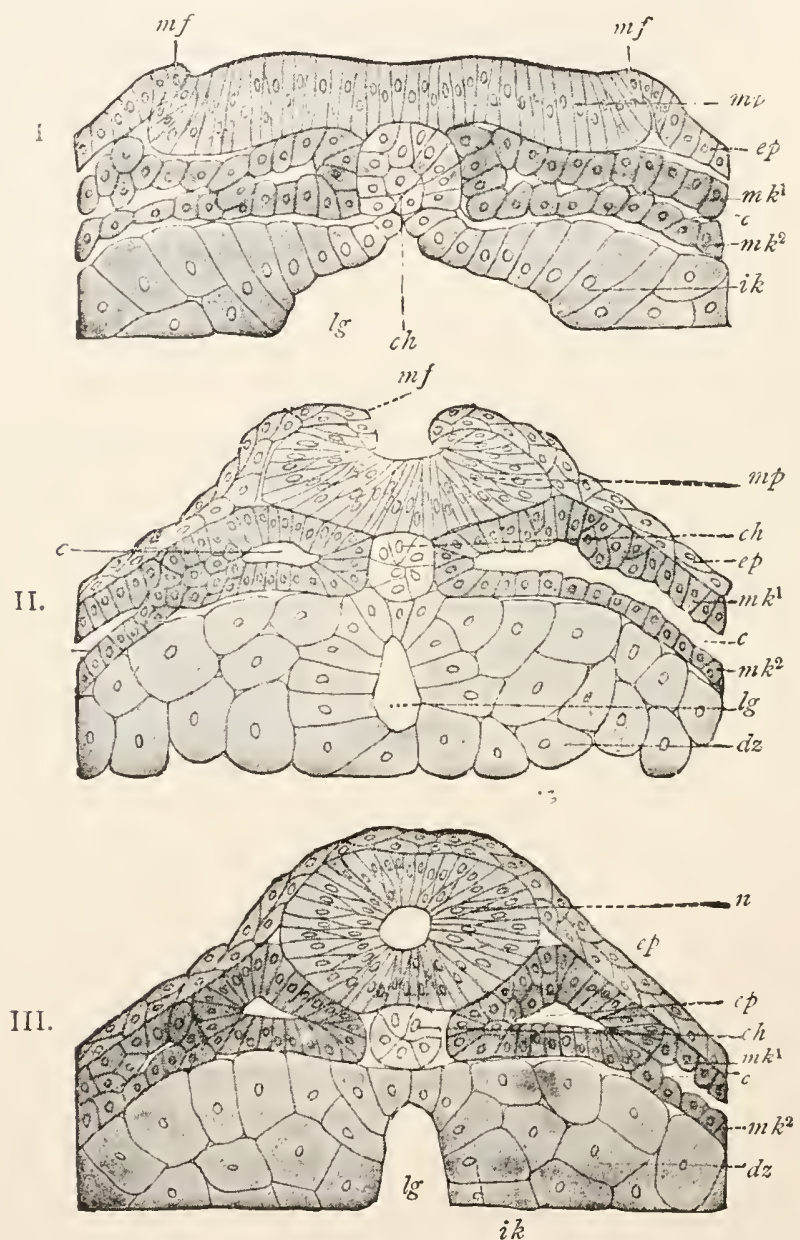

Fig. 9. - Cross-sections through the Dorsal Regions of Triton embryos at three different ages. (From O. Hertwig.) I. The Medullary Plate (rudiment of the spinal cord), $m p$, is marked off from the skin, $e p$, by the medullary folds $m f$. II. The Medullary Plate has become bent into a furrow through apposition of the medullary folds. III. The Mledullarv Plate has closed up, forming the spinal cord. $m f$, medullary folds; $m p$. medullary plate; $n$, the medullary or neural tube (spinal cord) arising from it ; eth skin (epidermis); $c h$, notochord; $m k$, middle germ-layer ; ( $m k^{1}$, its parietal, $m k^{2}$, its visceral laver); $c$, colom (body-carity); ch, cavity of a primitive segment or mesoblastic somitc; $i k$, inner germ-layer ; $d z$, its yolk-cells; $l_{s}$, lumen of the gut.

nervous system. In the case of higher organized animals, e.g. the vertebrates, the brain and spinal cord lie deeply embedded in the interior of the body; but in the embryo 
it is laid down likewise as a part of the skin, and only gradually through infolding and cutting off from this does it come to lie internally. One can demonstrate in case of each vertebrate this change of position by cross-sections through the dorsal region of embryos of different ages (Fig. 9).

The Skclctal Sy'stcm. - The skeleton of vertebrates is a further example. In the lowest vertebrates, amphioxus and the cyclostomes, the vertebre are lacking, and in theirplace we find a cylindrical cord of tissue, the chorda dorsalis (notochord). In the fishes and amphibia usually the notochord persists; but it is partially compressed and narrowed by the vertebræ, which in the lower forms consist of cartilage, and in the higher of bone or a combination of bone and cartilage. Mature birds and mammals finally have a completely ossified vertebral column; their embryos, on the other hand have in the early stages only the notochord (amphioxus stage); later this notochord becomes narrowed by the vertebre (fish-amphibia stage) and finally entirely replaced; the vertebral column is in the beginning cartilaginous, only later becoming ossified. Comparative Anatomy and Embryology thus give the same developmental stage of the axial skeleton: (I) notochord, (2) notochord and vertebral column, the latter at first formed of cartilage, then of bone.

We have here spoken of a parallelism between the facts of Comparative Anatomy and those of Embryology. But as a matter of fact we should expect a threefold parallelism; for according to the descent theory the systematic arrangement of animals is conditioned by a third factor-the historical development of the animal world, or Phylogeny. The boundary stones of phylogenesis, the fossils, must now, so we should expect, in the successive geological strata give the same progressive series as the stages of forms found by Comparative Anatomy and Embryology. In point of fact we know instances of such threefold parallelisms. Comparative Anatomy teaches that the lowest developed form of a fish's tail is the diphy- 
cercal (Fig. IO, $A$ ); that from this the heterocercal $(B)$, and from the heterocercal the homocercal form of tail-fin can
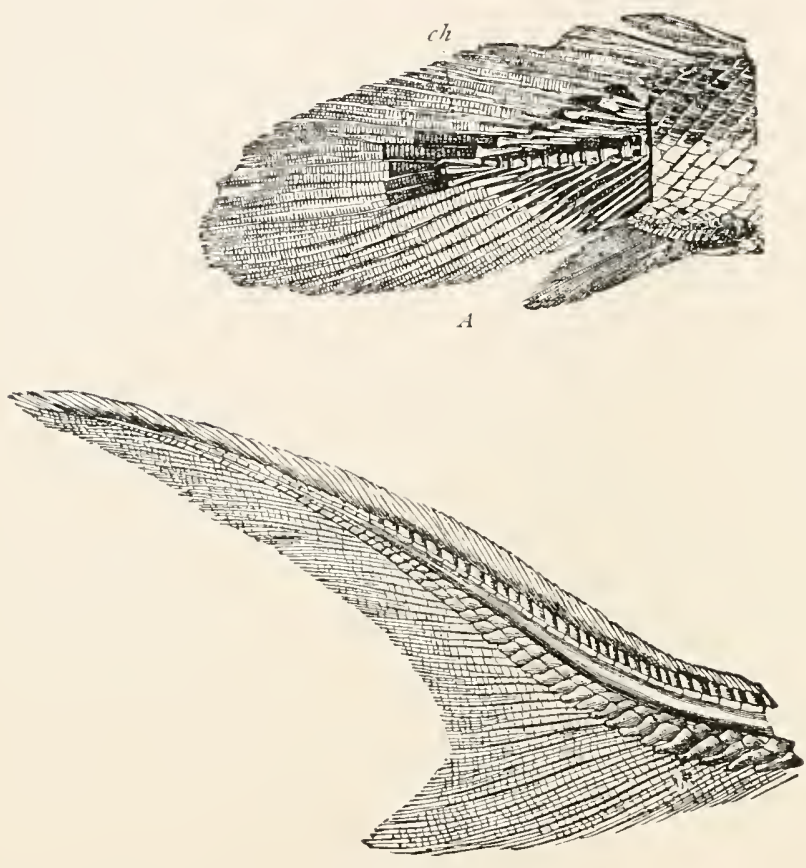

1

Fig. ro.-Tail-fins of various fishes (From Zittel.), h, chorda. $A$, Diphycercal fin of Polypterus bichir. (Vertebral column and notochord divide the tail into symmetrical dorsal and ventral portions.) $B$. Heterocercal tail of the Sturgeon. (As a result of an upward bending of the notochord and vertebral column the fin has become asymmetrical, the ventral portion much larger than the dorsal.)

be derived. Embryologically the most highly developed fishes are first diphycercal, later heterocercal, and finally become homocercal. Last of all, paleontologically the oldest fishes are diphycercal or heterocercal, and only later do homocercal forms appear.

What has here been referred to is only a small fragment of the weighty materials for proof which Morphology offers in favor of the descent theory, it can only serve to show how morphological observations can be employed. For the reflecting naturalist the facts of Morphology are a 
single great inductive proof in favor of the Theory of Descent.

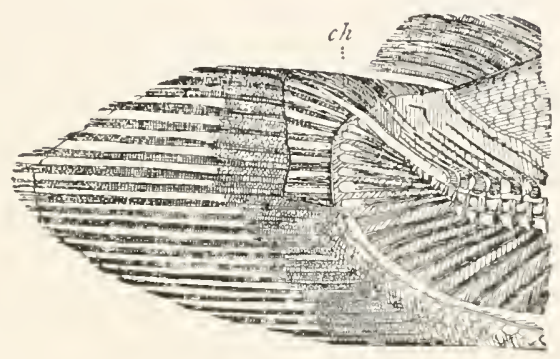

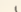

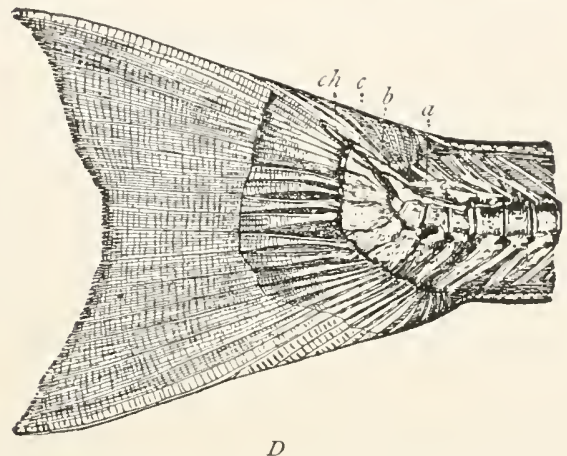

FIG. I0.-Tail-fins of various fishes. (From Zittel.) $c h$, chorda, $a, b, c$ : cover-plates. $C$, $D$. Homocercal fins, $C$, of $A$ mia calra; $D$, of Trutta salar. (By a still greater upward bending of the notochord and vertebral column the dorsal portion has almost entirely disappeared and the ventral portion almost alone forms the fin, externally apparently symmetrical, but in its internal structure very asymmetrical.)

Study of the Distribution of Animals-Finally now in regard to Animal Geography: here we learn that the present state of distribution of animals is the product of past hundreds and thousands of years. It will therefore be possible from this to figure out many of the earlier conditions of things, if one proceeds with the utmost caution and after overcoming extreme difficulties.

If we assume that from the beginning all animal species were constituted as they now are, they would then have been placed by the purposeful Creator in the territories best suited to their organization; their distribution would 
therefore have been finally determined by the favorableness or the unfavorableness of the conditions of life prevailing in the various regions, as the climate, food-supply, etc. If on the other hand, we assume that the animal species have arisen from one another through variation, then there must have been, as an influence determining the manner of distribution, besides the conditions of existence, still a second factor, which we will call the geological. We know that the configuration of the earth's surface has in many respects changed in the course of the enormous space of time of the geological periods; that land areas, which earlier were united, have become separated by the encroachments of the sea; that by the upheaval of mountains also important barriers to the distribution of animals were formed. From the circumstance that these two changes, the changes in the earth's surface and in the animal world established upon it-have gone on hand in hand there follows necessarily the consequence that so much greater differences in the faunal character of two lands must result the longer they have developed independently of one another, without interchange of their animal populations, and the longer the inhabitants have been separated by impassable barriers. For the various animal groups the character of the barriers is different; terrestrial animals which cannot fly are hindered in their distribution by arms of the sea; sea-dwellers contrariwise by land areas; for terrestrial mollusks high mountain ranges, which are dry and barren, or constantly snow-capped, are effectual.

Instances of Proofs.-Since attention has been given to these conditions, many geographical facts favorable to the descent theory have been ascertained: (I) Of the various continents Australia has faunally an independent character; when discovered it contained almost none of the higher (placental) mammals, except such as can fly (Chiroptera), or marine forms (Cetacea), or such as are easiiy transported by floating wood (small rodcnts), or such as were introduced by man (Dingo, the Australian dog); 
instead, the remarkable birdlike animals (haring a beak and a cloaca), and the Marsupials, which in the Old World, as also in America (with the exception of the Opossums), have become quite extinct. The phenomenon is explained by the geological fact that in the earth's history Australia, with its surrounding islands, was certainly the earliest to lose all its connection with the other continents. While in the other four parts of the earth the higher vertebrates, which were developed from the marsupials and their lower contemporaries, came, through the lands connecting the various continents, to have a wide or even a cosmopolitan distribution, in isolated Australia this process of evolution did not go on, and its ancient faunal character was preserved. (2) As Wallace has shown, the Malay Archipelago is divided faunally into an eastern and a western half ; within each group there are islands which, in spite of a different sort of climate, have a very similar fauna. On the other hand, the faunal boundary passes between the two islands Bali and Lombok, which have the same climate and geographically are very close together. But the depth of the strait in this region shows that here runs a boundary of extraordinarily long geological duration, and that in the earth's history Bali has developed in connection with the western, Lombok with the eastern chain of islands. (3) Even a long time before Darwin, the renowned geologist Leopold von Buch, from studying the distribution of plants on the Canary Islands, had come to a conclusion in regard to the change of species into new species; viz., on islands peculiar species develop in secluded valleys, because high mountainchains isolate plants more effectually than do wide areas of water. M. Wagner has collected many instances which prove that localities inhabited by certain species of beetles and snails have been sharply divided by wide rivers or by mountain chains, while in neighboring regions so-called "vicarious species" are found.

Causal Foundation of the Theory of Descent.-The Darwinian theory, so far as the above exposition shows, is fundamentally like the theories of descent advocated at the 
beginning of this century by Lamarck and other zoologists; it is distinguished from these only by its much more comprehensive empirical foundation, and further in that it abandoned the successional arrangement laid down by the type theory, and replaced it by the branched, treelike mode of arrangement, - the genealogical tree. But still more important are those advances of Darwinism which relate to the causal foundation of the descent theory. The doctrine of causes which has brought about the change of species forms the nucleus of the Darwinian theory, whereby it is especially distinguished from Lamarckism. In order to substantiate causally the change of species, Darwin' proposed his highly important doctrine of "Natural Sclection by means of the Struggle for Existence."

Artificial Selection.--In the development of this doctrine Darwin started from the limited and hence easily comprehended subject of Domestication, the artificial breeding of our races of domesticated animals. Many of our domesticated animals sprang undoubtedly from a single wild living species; others originated from several species, but now have the appearance of a single species. How have arisen such extraordinarily different races of pigeonsthe fan-tail, the pouter, long- and short-billed pigeons, etc., the long- and short-horned cattle, the heavy, slow Percherons and the slenderly-built, fleet-footed Arabian horses? Undoubtedly through that same more or less conscious influence of man, which is still employed by the animal-breeder who pursues a purpose. If he wishes to obtain a particular form, he chooses from his stock suitable animals, which he pairs together if they in ever so slight a manner approach nearer than the others to the sought-for ideal. By repetition of this selection according to plan, the breeder attains a slow but sure approximation to the desired goal, since from each new generation he uses for breeding only the suitable individuals. If he wishes, for example, to breed fan-tail pigeons, he selects from his stock animals. with the greatest possible number and strongest developed tail-feathers. In the course of generations, then, charac- 
teristics cumulate; the number of pigeons having an increased number of tail-feathers becomes greater, and thus material is obtained which is adapted to a further increase in the number of feathers.

Factors of Evolution in Breeding.-The remarkable results of breeding are well known to every observer of our domesticated animals. These results depend mainly upon three factors: (I) I crriability; the descendants of one pair of parents have the capability of developing new characteristics thereby differing in appearance from their parents. Hereditability of newly-acquired characters. This consists in the tendency of the daughter-generation to transmit the newly-developed characteristic to the succeeding generations. (3) Artificial sclection; man selects for breeding purposes suitable individuals, but is hindered by the fact that a new character which has arisen through variation disappears through crossing again with animals of the opposite variational tendencies.

Factors of Evolution in Nature.-If we compare with the facts of domestication the conditions of animals living in the state of nature, we find again as efficient forces, inherent in all organisms, variability and heredity, though the former is not everywhere of the same intensity. There are many species which vary not at all or only slightly, and therefore have remained unchanged for thousands of years. But over against these conservative species stand in every group progressive species, active species, which are in the process of rapid change, and therefore are the only ones of importance in causing the appearance of new species. Since. the power of heredity is present in all organisms, there is. only lacking a factor corresponding to artificial selection, and this Darwin discovered in the so-called "natural selection."

Natural Selection: Struggle for Existence-Watural sclection finds its basis in the enormous number of descendants which every animal produces. There are animals, e.g. most fishes, which produce many thousands of young in the course of their lives; not to mention parasites, whose eggs are numbered by millions. For the de- 
velopment of this animal throng there is no room on the earth; for even if we compute upon the basis of a slowlymultiplying animal, as, for example, the elephans, and assume that all the progeny live and reproduce normally, it would only be a few centuries before the entire earth would be occupied by herds of elephants. In order to preserve the equilibrium in the household of nature there must perish great numbers of unfertilized and fertilized eggs, as well as young animals and many that are mature but have not yet attained their physiological destiny. Many exist. ences will undoubtedly be blotted out by purely accidental causes; yet on the whole those individuals which are best protected will best withstand pressing danger. Slight superiorities in structure will be of importance in this struggle for existence, and the possessors of these will gain an advantage over their companions of the same species, just as in domestication each character which happened to be or is fancied to be useful to man insures advantage to the possessor. Among the numerous varietics that appear the fittest will survive, and in the course of many generations the fortunate variations increase by summation, while destruction overtakes the unsuitable varieties. Thus will arise new forms, which owe their existence to "natural selection in the struggle for existence."

The "Struggle for Existence."-The expression "struggle for existence" is a figurative one, for only in rare cases does an active conscious struggle take place in regard to the prospects of an animal's existence; as for example in the case of the beasts of prey, that one which by means of his bodily strength is best able to struggle with his competitors for his booty is best provided in times of limited food-supply. Much more common is the unconscious struggle: each man who attains a more favorable position by special intelligence and energy, limits to an equal degree the conditions of life for many of his fellow men, however much he may interest himself in humanity. The prey which by special craft or swiftness escapes the pursuer causes the voracity of the enemy 
to satisfy itself upon the least favored of its companions. It is noticeable that in a severe epidemic certain men do not fall vic ${ }^{2}$ ms to the disease, because their organization better withstands infection. Here applies much better the term "survival of the fittest" which Spencer has adopted in preference to the term "struggle for existence."

Instances of the Struggle for Existence.-Although the foregoing general considerations suffice, to show that the Struggle for Existence plays a very prominent rôle in the organic world, yet on account of the importance of this feature it will be illustrated by a few concrete examples. The migratory rat (Mus decumanus), which, at the beginning of the last century, swarmed out from Asia, has since then almost completely exterminated the house-rat (Mus rattus) indigenous to Europe, and is pushing on to make existence impossible for it in other parts of the world. Several European species of thistle have in the La Plata states increased so enormously that they have in localities completely crowded out the native plants. Another European plant (Hypocharis radicata) has become in New Zealand a weed overrunning everything. Certain races of men, like the Dravidian and Indian, die off to the same degree that other races of men, like the Caucassian, Mongolian, and Vegro, spread. The more one attempts to seek explanations of that endlessly complicated web of the relations of animals to one another, the relations of animals to plants and to climatic conditions, as Darwin has done, so much the more does he learn to appreciate the method and results of the Struggle for Existence. Then will he become conversant with many extremely interesting phenomena, which immediately find an explanation through the doctrine of the Struggle for Existence, which formerly were not intelligible. Islands lying in the midst of the ocean have a disproportionately large number of species of wingless insects, because the flying forms are easily carried out to sea. For example, on the Kerguelen Islands, remarkably exposed to storms, all the insects are wingless; among them 
are one species of butterfly, several flies, and numerous bcctles. But most interesting are the cases of sympathetic coloration and of mimicry, and finally, the appearance of sexual characters as the result of sexual selection.

Sympathetic Coloration.-Very often, in regions which have an entirely or preponderatingly uniform coloring, the coat of the animals is distinguished by the same or at least by a very similar coloring; this phenomenon is called sympathetic coloration. Inhabitants of regions of snow are colored white, desert animals have the pale yellow color of the desert, animals which live at the surface of clear water are transparent like crystal; representatives of the most diverse animal branches show the same phenomenon. The advantage connected therewith scarcely needs an explanation. Every animal may have occasion to conceal himself from his pursuers; or it may be his lot to approach his prey by stealth: he is much better adapted for this the closer he resembles his surroundings. Natural selection fixes every advantage which makes in either of these directions, and in the course of many generations these advantages increase.

Mimicry is referable to the same principle, except that the imitation is not here limited to the color, but also influences form and marking. Exceedingly often parts of plants are imitated, sometimes leaves, sometimes stems. Certain diurnal butterflies with beautifully colored upper surfaces of the wings escape their pursuers by the rapidity of their flight; if they alight to rest they are protected by their great similarity to the leaves of the plants, around which they chiefly fly. When the wings are folded over the back, the dark coloring of their under sides comes into play and conceals the array of color on the upper side. The parts are so laid over one another that the whole takes on a leaflike form, and certain markings heighten the imitation of the nervation of the leaf. Among the numerous species of leaf-butterflies there are different grades of completeness of mimicry; in many even the damage done by insects is imitated; in others the form and marking are still incompletely leaflike, the marking being the first to come 
into existence. Among the grasshoppers also there are imitations of leaves, like the "walking-leaf," Phyllium siccifolium, $P$. Scythe, while other very nearly related forms again more or less completely approach the appearance of dried, sometimes of thorny twigs ( $\mathrm{Fig}$. I2, $a$ and $b$ ).

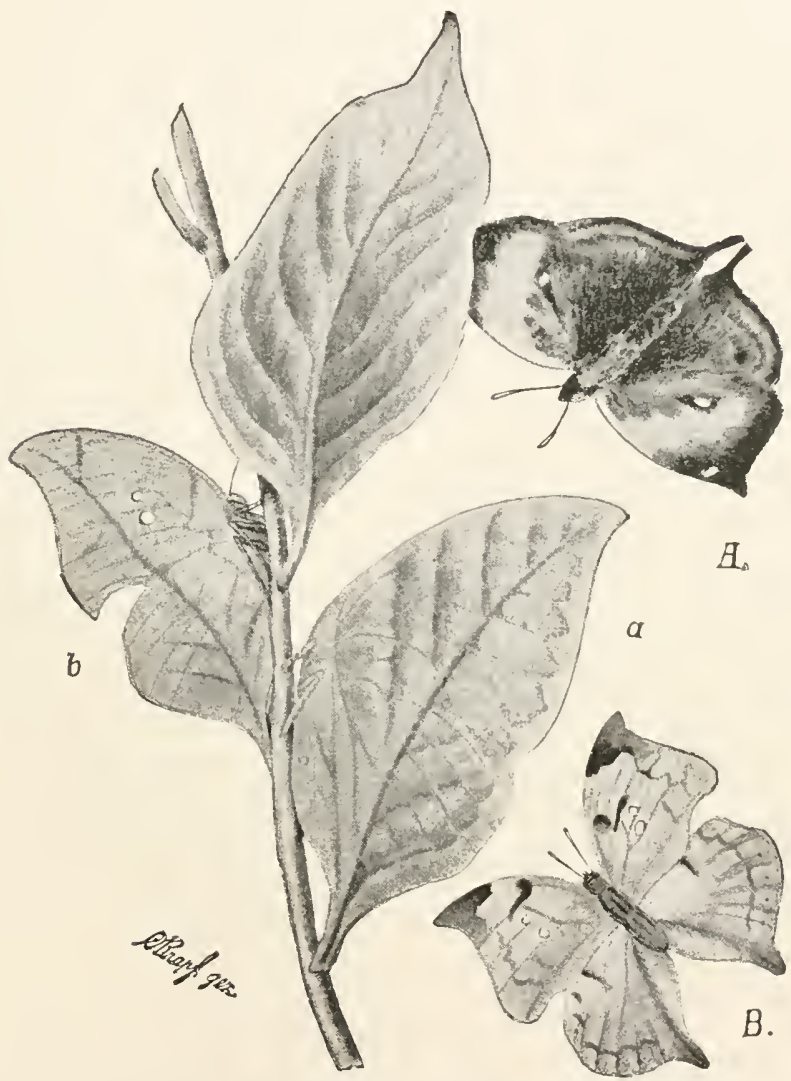

Fir. I1.-Leaf-butterfly. A, Kallima paralecta, flying; $a$, at rest. (After Wallace.) $B$, Siderone strigosus, flying; $b$, at rest. (After C. Sterne.)

Examples of Mimicry.-Very often insects are copied by other animals. Certain butterflies, Heliconia, fly in large swarms, clumsy and yet unmolested by birds, because they contain a bad-tasting mass of fat. Another species of butterfly accompanies them, Picriek, which do not 

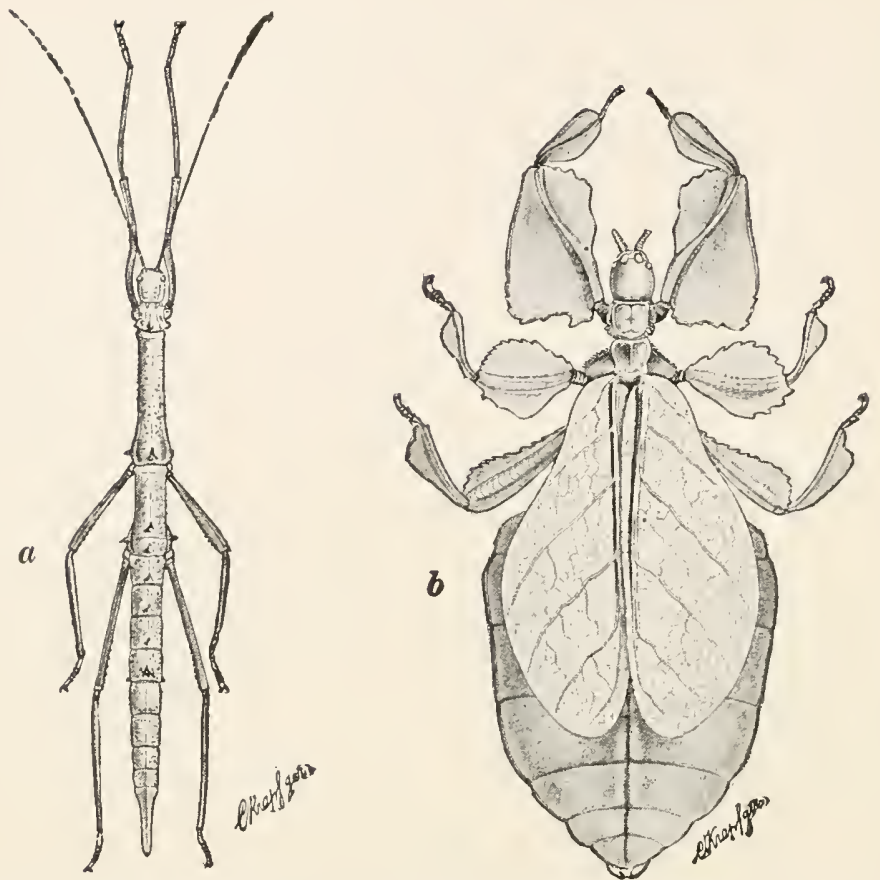

FIG. 12.-Grasshopper mimicry, a, Acanthoderus Wallacei + . b, Phyllium Scythe $q$.
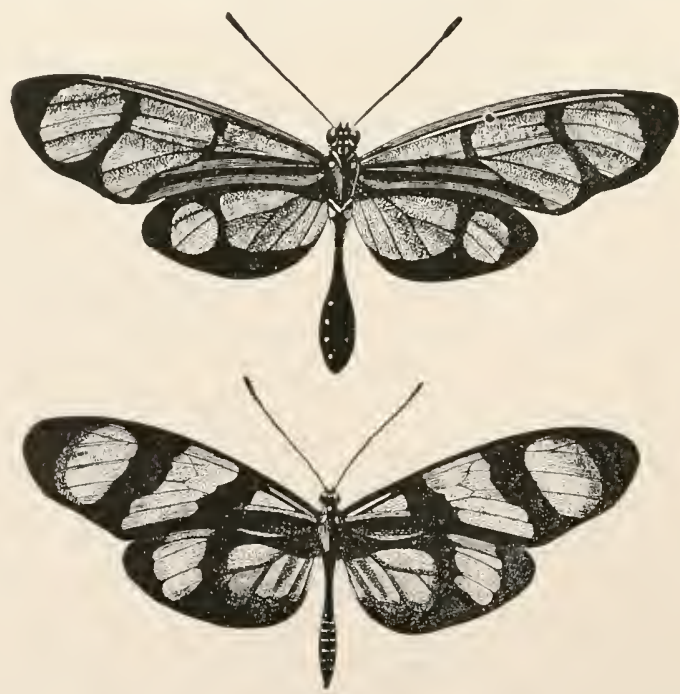

Fig. 13.- Wethone psidii, a bad-tasting Heliconid, copied by the Pierid, Leptalis orise. (After Wallace) 
taste bad, and yet are not eaten, because in flight, in outline, and in marking of the wings they imitate the Heliconia so closely that even a systematist might be easily deceived as to the systematic position (Fig. I3). In a similar way bees and wasps, feared on account of their sting, are imitated by other insects. In Borneo there lives a large black wasp, whose wings have a broad white

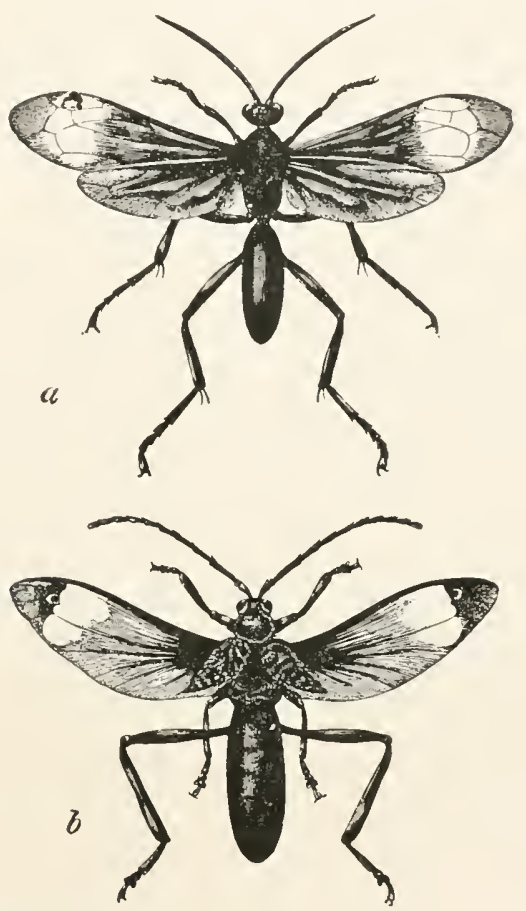

FIG. 14.- $a$, Mygnimia aviculus, a wasp imitated by a beetle ; $b$, Coloborhombus fascinti. pennis. (After Wallace.) $\frac{3}{4}$ nat. size.

spot near the tip (Mygnimia aviculus). Its imitator is a heteromerous beetle (Coloborhombus fasciatipennis), which, quite contrary to the habit of beetles, keeps its hinder wings extended, showing the white spot at their tips, while the wing-covers have become small oval scales (Fig. 14).

Sexual Selection is understood to mean a special 
phase of natural selection, which has chiefly been observed in the case of birds and hoofed animals. For the fulfilment of his sexual instincts the male seeks to drive his competitors from the field, either in battle or by impress-

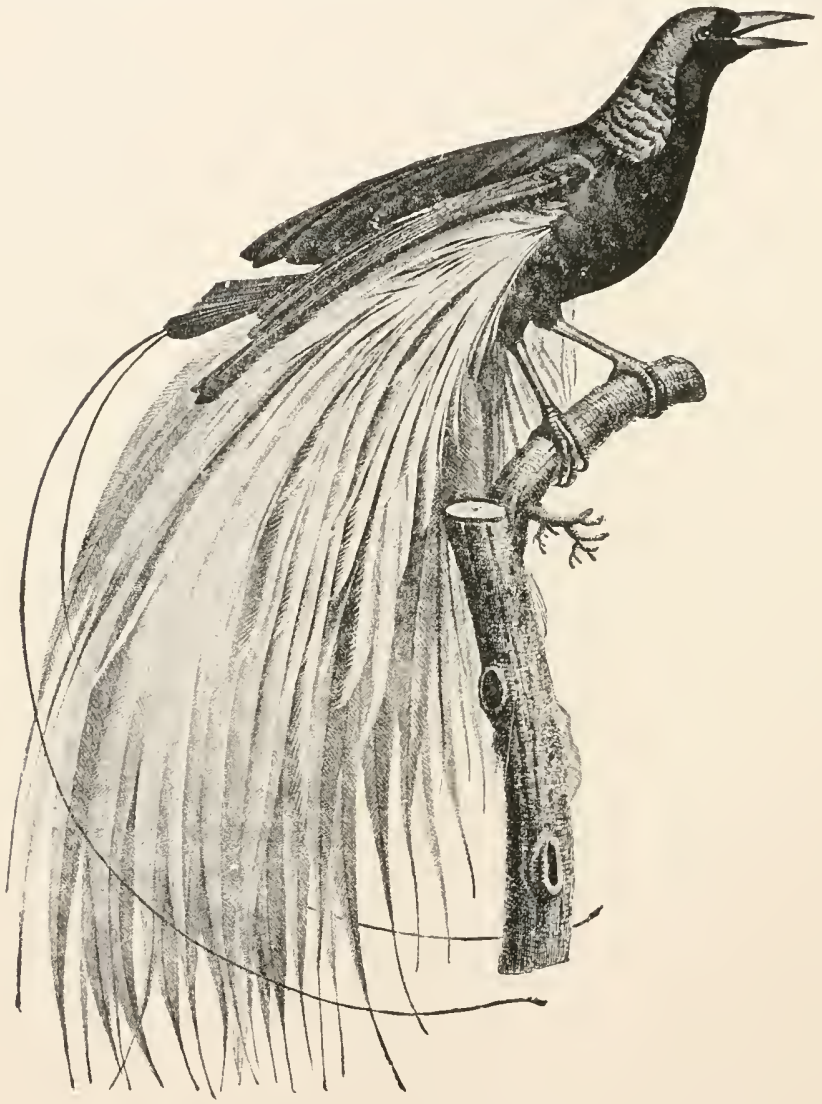

Fig. 15A.-Paradisea apoda, male. (After Levaillant.)

ing the female by his special excellences. With strong wings and with spurs the cock maintains possession of his flock, the stag by means of his antlers, the bull with his horns; the birds of paradise by means of beautiful coloring win the favor of the females, most singing birds by means of their song, many species of the fowl tribe by 
peculiar love-dances. Since all these characters belong chiefly to the male, and since it is only exceptionally that they are inherited by the female (and even then less distinctly stamped), it is almost certain that in a great measure they have been acquired by the males through the struggle for the female. In the case of birds undoubtedly a second factor has co-operated to impress distinctly the often enormous difference between the feathers of the male and of the female-as is shown, for example, in the case of the birds-of-paradise; for the nesting female inconspicuous

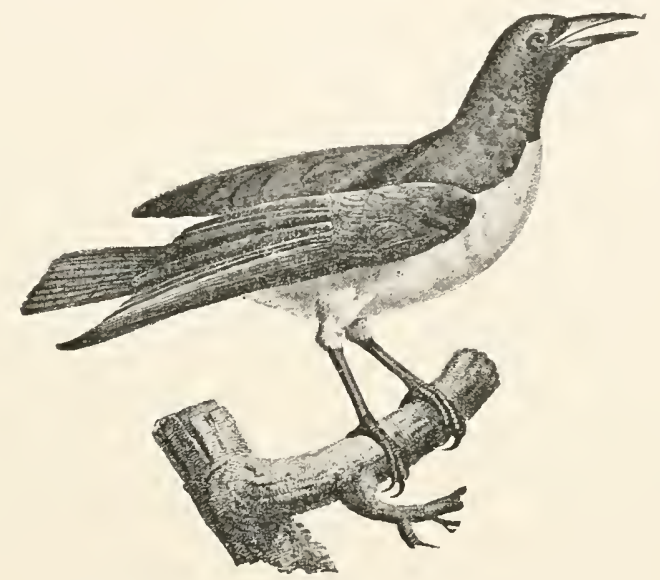

FIG. 15B. - Paradisea afoda, female. (After Levaillant.)

colors and a close-lying coat of feathers will be necessary in order that, undisturbed by enemies, she may devote herself to the brooding process.

On the Efficiency of Natural Selection.-In the course of the last decade there has been much controversy as to how far natural selection by itself alone is a speciesbuilding factor. From many sides the objection has been raised that the variations occurring in nature are at their first appearance generally much too small to be of value to the organism, and thus to become subject to natural selection. Thus, for example, the wing of a bird in order to be used for flight must have already reached a size far beyond 
the ordinary; the muscles for moving it, the supporting skeletal parts, the nerves running to it must have a definite formation and arrangement; in short, there must exist a harmonious co-operation of parts, which presupposes a progressive and well-regulated development extending through a long space of time during which the struggle for existence could have exerted no directing influence. A further objection is that the action of natural selection would under ordinary conditions be compensated by the swamping effect of unhindered crossing of the varying forms. If, for example, we do not isolate fantails from other pigeons, they will cross with these, and their descendants will soon take on the character of common pigeons. Finally, it has been claimed that for the formation of new species a simple variation of forms is not sufficient; it must reach still farther: (I) a variation in different directions, a divergent development of the individual constitution of a species; (2) the disappearance of the transitional forms, which unite the divergent species.

The objection that the struggle for existence cannot bring about the divergent development of individuals necessary for improvement is of least importance. It need only be added that of the many variations appearing at the same time in a species two or more may be equally useful; that then one set of individuals will seize upon one, another set upon the other advantage, and that in consequence of this both sets will develop in different directions. Consequently the intermediate forms which are not especially stamped in the one or the other direction will be in an unfavorable position, and must carry on the struggle for existence with both groups of partially differentiated companions of their species, and being less completely adapted, must yield to them.

More important are the two first-named objections; they have led to theories which originally seemed destined to complete the Darwinian theory, but in the course of discussion they have more and more raised the claim of entirely supplanting it. In the following paragraphs will be found 
an exposition of these theories, but it is to be taken into consideration that, at the present time, we are still in the midst of the reform movement, and it cannot yet be said whether the theories will be able to stand beside the theory of the struggle for existence or will supplant it.

Migration Theory.-To explain how it comes about that characters newly formed by variation become fixed, and do not disappear again through crossing with differently modified individuals, M. Wagner has proposed the theory of geographical isolation, or the Higration Theory. New species may arise if a part of the stock of individuals of one species should take to wandering, or should be passively transplanted, and thus should come to a new place of residence, in which crossing with the companions of their species who were left behind is not possible. The same might occur, if the region inhabited by a species should be by geological occurrences divided into two parts, between which interchange of forms would be no longer possible. The animals remaining under the old conditions would retain the original characteristics of the species; the wanderers, on the other hand, would change into a new species. Direct observations speak for the justification of this theory. A litter of rabbits placed at the beginning of the fifteenth century on the island of Porto Santo has in the meantime increased enormously and the descendants have taken on the characteristics of a new species. The animals have become smaller and fiercer, have acquired a uniformly reddish color, and no longer admit of pairing with our native rabbit. A further proof in favor of the theory of geographical isolation is the peculiar faunal character of territories which are separated from adjacent lands by impassable barriers, broad rivers or straits, or high mountains (comp. p. 5); especially instructive in this regard is the peculiar faunal character of almost every island. The fauna of an island resembles in general the fauna of the mainland from which the island has become separated by geological occurrences; it usually has not only these but also socalled "vicarious species," i.e., species which in certain 
characteristics closely resemble the mainland species. Such vicarious species have plainly arisen from the fact that isolated groups of individuals, scattered over the islands, have taken on a development divergent from the form from which they started. With all due recognition of the migration theory, it will never be possible by it alone to explain the multiformity of the organic world. In addition, it must be assumed that formerly the earth's surface possessed an inconceivable capacity for changes; and yet the more recent investigations make it probable that the distribution of land and water has not varied to the degree that was formerly believed. The experience of botanists, too, teaches that several varieties can arise in the same locality and become constant.

Lamarckism.- While the migration theory agrees with Darwinism in this, that the new characters appearing through variation are to be regarded as the products of chance, yet it is just this part of the theory which has been subjected to searching criticism. Many zoologists have again adopted the causal foundation of the descent theory proposed by Lamarck and believe that the cause of species formation is to be found, in part, in the immediate infucnee of changing conditions of cxistence, in part in the varying use and disuse of organs, brought about by alterations in the conditions of life. Both principles ought to be sufficient, even without the help of the struggle for existence, to explain the phylogenesis of organisms.

Influence of Environment.-To what extent can the conditions of existence bring about a permanent change in the structure of plants and animals? To decide this is no simple problem, on account of the complexity of the influences entering into the question.

In cases where the food-supply is altered, organisms change in a very remarkable manner, and within a short time; but yet these changes (Nägeli's "Modifications through Nutrition") seem to have no permanence. Plants which, found in nature in poor soil, are transplanted into rich soil, or aice iersa, soon acquire quite a different ap- 
pearance, and preserve this also through the following generations, so long as they remain in the rich soil; but the plant quickly returns to its former appearance when replaced in its previous conditions of existence.

In general, a change seems to be the more permanent the more slowly it has developed. In researches upon the influence of the conditions of existence, we can, therefore, rely soonest upon results, if we experiment with slowlyworking factors, such as light and heat, dry or moist air, different intensities of gravitation, of stimuli, etc., which can be excluded from the environment of the organism.

Use and Disuse.-Now, in regard to the efficiency of use and disusc, there is no doubt that the shape of an animal is influenced in a high degree by the manner in which the organs are used. The organs which are much used will become especially strong in him, anc a'ice a'erse those which are debarred from use will become weak. It is only questionable whether these, in the strongest sense of the word newly-acquired characteristics thus arising, are transmitted to the offspring, or whether the descendants, in order to attain to the same degree, must not begin anew in the same way use and disuse. In the latter case the cumulation of characteristics, and therefore the possibility that these may become permanent, is excluded. It is to be regretted that accurate results are still lacking on a point so well adapted for experimental treatment. At this time vestigeal organs speak most strongly in favor of the Lamarckian principle; for we see that cave animals, which for many generations have lived in darkness, are blind, either having no longer any eyes at all, or only vestiges of such, quite incapable of function. This seems to justify the view that this condition is attributable to lack of use, since it has brought about a functional and anatomical incapacity, which has increased from generation to generation. Now we must believe that what is true for disuse must express itself in the reverse sense in the case of use.

Nägeli's Principle of Progression.-In conclusion, there is still to be considered the change of species from sub- 
jective causes, to which C. E. von Baer gave the poorly adapted because easily misleading term "Zielstrebigkeit" (the striving toward an ideal), and which Nägeli has termed the "perfecting principle," or the "principle of progression." It cannot, indeed, be denied that each species is compelled, by some peculiar internal cause, to develop into new forms, independently of the external conditions of existence, and up to a certain degree, independently of the struggle for existence. In all animal branches we see the progress from lower to higher going on, very often in a quite similar way, in spite of the fact that the animals live under very different conditions of development. WV see how the nervous system lying near the surface in the lower animals becomes in the higher animals concealed in the depths of the body; how the eye, at first a simple pigment-spot, becomes in worms, Arthropods, mollusks, and vertebrates, provided with accessory apparatus, as lens, vitreous body, iris, choroid, etc. Herein we see an energy for perfection which, since it occurs everywhere, must be independent of the individual conditions of life, and must have its special explanation in the character of the living substance.

It is by no means justifiable to call an assumption, as here expressed, teleological, and to reject it as unscientific; rather the organism seems to be just as mechanically conditioned as a billiard-ball, whose course is determined not only by friction with the banks of the billiard-table, but also in a large measure by its indwelling force, imparted to it by the stroke of the cue. An organism, too, is a reservoir of force which must necessarily from itself develop more, only that it is of more extraordinary complexity, and in an equal degree also is independent of the external world. A complete independence is naturally never present, and Nägeli has not so maintained. Along with it rather goes always an "action" of the external world, a modifying influence which is carried on by the external conditions of existence, either directly or by the mediation of use and disuse. 
The exposition of the descent theory has been elaboorated here in a rather detailed way, because in the history of Zoology it is undoubtedly the most important feature. No other theory has gained such a hold in the course of the development of zoological investigation, none has propounded so many new problems and opened so many new fields for research. There is no zoological theory which compares with it in value as a working hypothesis. To the many objections which have been made that the theory is insufficiently grounded, it can only be replied that in the present state of our knowledge it is the only theory which agrees with our experiences and explains these in a simple way and on a scientific basis. In this sentence is given the merit of the descent theory, but at the same time also a limitation of its applicability. For on the one side the statement attributes the merit in the applicability of the system to the necessity of the human mind for simple explanations of the facts of natural science, and on the other hand it makes the degree of correctness dependent upon the state, whatever it may be, of our knowledge. On both sides no constant quantities are involved. Many investigators see no necessity of reconciling paleontology and our knowledge of plants and animals. To such, therefore, the Darwinian theory proves just as little as any opposing theory. Meanwhile reflecting naturalists will be obliged ever to keep in mind that our knowledge of nature is making considerable advances, and is visibly undergoing a widening and deepening. It is possible, nay, indeed probable, that these advances will lead to many modifications of the theory. For instance, the theory of the causes which condition the formation of new species will undergo numerous changes. On the other hand, we can affirm with great certainty that the principle of descent, which through Darwinism for the first time obtained credence, will be a permanent landmark of zoological investigation. 


\section{GENERAL MORPHOLOGY AND PHYSI- OLOGY.}

General Zoology: Animal Morphology.-In the vital phenomena of animals a certain degree of similarity can be followed through the entire animal kingdom; the way in which animals are nourished and reproduce their kind, how they move, and how they gain experience, is in great groups essentially the same, and even in case of widely separated forms shows many agreements. Corresponding to this, the apparatus which is concerned with the above-mentioned functions, the organs of nutrition and reproduction, of motion and sensation in their grosser and finer structure, and in their ontogeny, must be similar to one another and show evidence of some fundamental characters which always or frequently recur. All this needs a general explanation before we can go into a description of the separate branches of animals. This explanation is the subject of General Zoology, specially of General Anatomy and Embryology, or Animal Morphology.

Ecology or Biology.-If by means of anatomy and embryology we have learned the general character of the animal organism, we must yet farther study their relations to their environment. For this study of the conditions of animal life, Ecology or Biology, we have to consider the geographical range of animals, their distribution over the surface of the earth and in the different depths of the sea; further, the reciprocal relations of animals and plants, and of beast to beast, as these find special expression in colony-building, symbiosis, parasitism, etc.

General Anatomy.-In the case of Gencral Anatomy, with which we shall begin, the fundamental proposition will be, How does an organism build itself up from its constituent parts. We shall thereby in spirit follow the 
opposite course from that which anatomy actually takes, for this resolves the animal body into its elementary parts, its organs, tissues, and cells.

Instead of analytical we will pursue synthetic anatomy.

The synthesis of an organism, of which in General Anatomy we can only gain an idea, actually takes place in nature during the development of every animal. Embryologically every organism is at some time a simple element, a cell; this cell divides and gives rise to tissues; from the tissues are formed organs, and from the organs the regularly membered whole of the animal body is combined. If the general ontogeny proceeds synthetically, it then agrees in its manifestations with the processes which go on in nature and which are accessible to direct observation.

\section{GENERAL ANATOMY.}

The Morphological Units.-The expression "constituent parts of the animal body" can be used in a double sense. We can speak of the chemical units, the chemical combinations, which form the tissues; these are the subject of animal chemistry, and may therefore be passed over here. But we may also speak of the constituent units (morphological units) of the animal body; these are the cclls.* These and their transformation into tissues, organs, and entire animals are for us of vastly greater importance.

\section{The Morphological Units of tile Animal Body.}

The Cell.-The study of the morphological units of the organic body first found a firm foundation in the cell theory. Every scientific animal and plant Anatomy must therefore take as its starting-point the study of the cell.

* The cell is not the ultimate unit of structure. All organisms digest, assimilate, excrete, and reproduce. In the higher organisms each of these functions is carried on by groups of cells, but in the unicellular forms all the functions are performed by the single cell; hence there must be in the latter certain units of a lower grade, i.e., molecules set apart for special functions. The cell, then, is to be regarded as equal to a complex molecule or group of molecules.-ED. 
History of the Cell Theory.-The conception of the cell, as adopted in the morphology of animals and plants, has in the course of time undergone many changes, which must be known to some extent in order to understand completely the name and the conception. When Hooker, Marcello Malpighi, and Nehemia Grew, in the seventeenth century, introduced the term into vegetable anatomy, they understood thereby small chambers surrounded by firm walls and filled with air or fluid contents. When, also, at the beginning of the present century, it was correctly recognized that the cell is the anatomical and physiological vegetable unit by changes of which all the other parts of the plant are formed, and when the English botanist Brown discovered in the interior of the cell that small body previously overlooked, the kernel of the cell, or mucleus, the old conception remained, and as such was accepted by Schleiden in his cell theory. Schleiden added as new a completely erroneous view of the origin of cells; that in a sort of matrix, the "cytoblast," first a granule, the nuclear body, was formed, then around this granule a membrane, the nuclear membrane, arose by precipitation, and around the thus completed nucleus a larger membrane (the cell membrane) was precipitated. Thus for the formation of the cell the nucleus would be of most importance.

The Schleiden-Schwann Cell Theory.-Since it is the nuclei of cells which are most easily demonstrated in the animal body, and even now are particularly useful for deciding questions concerning the presence of cells, it is readily understood how the Schleiden theory, which placed the nucleus so much in the foreground, should have led Schwann to apply the cell theory to the animal kingdom, and thereby raise it to a principle of general application. We usually therefore, speak of the Schleiden-Schwann cell theory.

As a result of this theory the walls, the cell membrane, were regarded as most important for the function of the cell; through the cell membrane diffusion currents must 
pass between the surrounding medium and the contents of the cell; the character of the membrane and of the cellsap must determine the condition of the diffusion-currents, and thereby also the functional character of the cell; the different appearance of tissues is chiefly conditioned by the fact that the cells, spherical in the beginning, change their form; in the case of fibrillar connective tissue, for example, they increase enormously in length and become fine fibrilla. Since the life of an organism is nothing else than the cooperation of all its cells, they flattered themselves that through the cell theory and the discovery, brought about by it, of the physical unity of the animal and vegetable body they had made an important advance in the great problem of the physical explanation of the phenomena of life. Cell genesis also seemed, according to the theory, to be just as satisfactorily explained on a mechanical basis as the formation of a crystal. In the "cytoblast" the nuclear bodies, nuclear membrane, and cell membrane must be formed by precipitation just as in the process of crystallization.

Reform Movements.-Since that time our conception of the character of cells has completely changed. The cell does not, after the manner of a crystal, arise as a new formation in a matrix, but it presupposes the existence of a living mother-cell, from which it arose by division or budding. Just so also the cell is not a physical unit, but is itself an organism which shows to us all the enigmas of life, the physical basis of which our investigations must ever keep in view as a goal, though it be still indiscernibly distant. The membrane and cell-sap are of quite subordinate importance for the character of the cell; rather the most important thing in it is the previously disregarded substance, for which $H$. von Mohl introduced the name protoplasm. According to the newer conception the cell is practically a small lump of protoplasm, usually, perliaps always, provided with one or more nuclei. This newer conception of the character of a cell has developed so gradually, and has so slowly supplanted the Schleiden- 
Schwanin view, that the old name has been retained, although it no longer at all fits the new conception. We have indeed become so thoroughly accustomed to the name that we no longer notice the contradiction of terms when we call a solid lump without a membrane a "cell."

Discovery of Protoplasm.-The reformation of the cell theory was begun by discoveries which were made in very different regions and only lately have been brought to a focus.

I. Already, at about the beginning of the nineteenth century, Bonaventura Corti and Treviranus had seen that the chlorophyl bodies, which cause the green color of plants, in many species stream around in a lively manner in the interior of the cell, but Mohl was the first to find out that this motion is not active, but rather that they are moved by a homogeneous substance in which they are embedded. This substance, which Mohl, in order to bring it into prominence, named protoplasma, obtained by a second observation still greater importanee. In the case of reproduction of the simplest algx, it was found that the protoplasm, together with the chlorophyl bodies, balled itself into an oval mass, and that this body left the cell membrane and swam freely in the water. Since the cell-wall no longer showed signs of life, while on the other hand the protoplasmic body came to rest and formed a new plant, it was shown beyond doubt that this was the most important constituent part of the cell (comp. Fig. I IO).

2. In the study of animal tissues the importance of the peculiar cell-substance, the protoplasm, was still more plainly brought out. Here, in spite of the long-prevailing preconceived idea, unbiassed observation led to the discovery that animal cells, in general, had no cell-membrane.

3. Very important finally was the study of the lowest organisms, the protozoa. Dujardin sought by extremely careful observations to adduce the proof that these animals had no organs, but consisted of a uniform granular substance, the sarcode. The sarcode alone could condition 
all the vital phenomena, such as movement, sensation, assimilation, previously ascribed to many organs. Dujardin's theory was stoutly contested by Ehrenberg and his school, but finally attained general acceptance through the pioneer work of Max Schultze and Haeckel.

Schultze's Protoplasm Theory.-On the basis of the three above-mentioned series of observations, Max Schultze finally established the above briefly sketched reformation of the cell theory, when through an exact study of the appearance and the vital phenomena, and by means of numerous experiments, he proved that the cell-substance of animals, the sarcode of protozoa, and the protoplasm of plants are identical, and that to this substance, for which he retained the name protoplasm, all the vital phenomena of animals and plants are referable in the ultimate analysis. The second important reform concerns the changes of cells into tissues. These follow not so much through changes of form and modification of the cells into the tissue elements, as Schwann thought, but rather by means of chemical changes. By means of its formative potentiality the protoplasm gives rise to non-protoplasmic structural parts, as, for example, connective-tissue fibrils, muscle fibrils, nerve fibres, etc., but which nevertheless make up the specific character of the various tissues, and perform the functions of these, and also in addition retain as the source of life and formation the unemployed remnants of cells, the connective-tissue corpuscles, muscle corpuscles, etc. We will now trace out farther these two fundamental ideas in Max Schultze's "protoplasm theory," and thereby briefly sketch the foundation of the modern theory of tissues.

Nature of the Cell.-The size of the animal cell varies to a considerable degree; the smallest elements are the male sexual cells, the spermatozoa, whose bodies, particularly in case of the mammals, are even less than $0.005 \mathrm{~mm}$.; the largest, on the other hand, with the exception of the giant plasmodia of some mycetozoa, are the egg cells. The yellow portion of the bird's egg, which 
alone forms the egg in the narrower sense, apart from its coverings, has for a time the morphological value of a cell, and in the case of the ostrich egg may reach a diameter of several inches. The form of the cell is likewise variable. Free living cells, whose form is not determined by the environment, in the resting condition are usually spherical or oval, as the egg cell shows; united into tissues, the cells, on the contrary, may be pressed together into polygonal or prismatic bodies, or may run out spindle- or star-shaped projections.

Protoplasm.-So there is left to characterize the cell only its constituent substance, the protoplasm. Here, also, is a distinction of a chemical character. It is not known whether protoplasm is a definite chemical body, which from its constitution is capable of infinite variation, or whether it is a varying mixture of different chemical substances. So, also, we are by no means certain whether or not these substances (as one is inclined to believe) belong to those, in themselves, enigmatical substances the proteids. IVe can only say that the constitution of protoplasm must, with a certain degree of homogeneity, have a very extraordinary diversity. For if we see that from the egg of a dog there comes always and only a dog, and indeed an animal with all his individual peculiarities, that a sea-urchin's egg, placed under the most diverse conditions, produces always a sea-urchin, that a species of amœba always performs only the movements characteristic of that species, we must assume that the functioning constituent part of this cell, the protoplasm, has in each case its peculiarities. We are driven to the assumption of an almost unlimited diversity of protoplasm, even if we concede an important share in the prominent differences to the nucleus, of which we shall speak later.

General Properties of Protoplasm.-The similarity of protoplasm, still recognizable through all its variations, expresses itself in its appearance and in its rital phonomena. Under slight magnification, protoplasm appears as a faintlygray substance, sometimes colored yellowish, reddish, etc., 
by pigments taken up by imbibition, in which numerous strongly-refracting granules are embedded. The vital characteristics of this substance are moscment, irritability, power of assimilation and of reproduction.

\section{Movement of Proto-} plasm.-Mor'cment expresses itself firstly in clianges of form of the whole body-amoboid morement-and secondly in the change of position of the small granules in the interior of the protoplasm-straming of gramules. Examples of amaboid moacment (Fig. 16) are chicfly the movements of

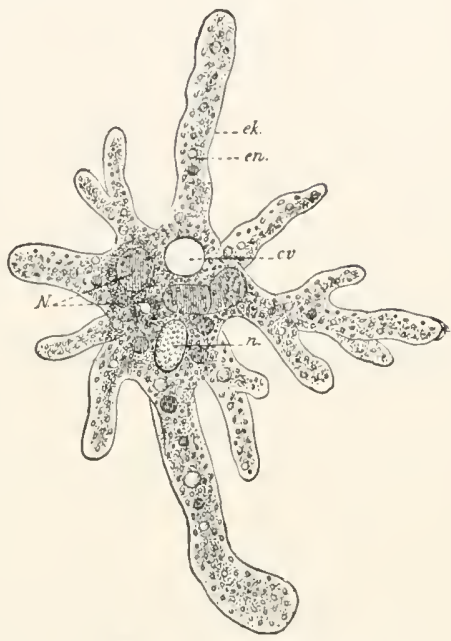
many frotosod, and of the colorless blood-cells (white blood-corpuscles) of multiceliular animals; here the protoplasmic body sends out coarser and finer projections, which may be again withdrawn, serving for locomotion and hence calied pseudopodia or false feet. The strcaming of gramules can be observed in the interior of the cell-body, as well as in the pseudopodia extending from this. The pseudopodia may even be so fine as to be at the limits of visibility with our strongest magnifications (Fig. I 7 ), yet in them it can still be observed that the granules wander hither and thither like walkers on a promenade, simultaneously centripetally and centrifugally, some with greater, others with less speed. And yet the granules are only passively moved by the protoplasm which is at the basis. For if we feed the creature with some arbitrarilychosen pigment granules, e.g., finely-pulverized carmine, these pigment granules show the same remarkable streaming. Indeed nothing is better suited for illustrating the great complexity in the structure of protoplasm than these 


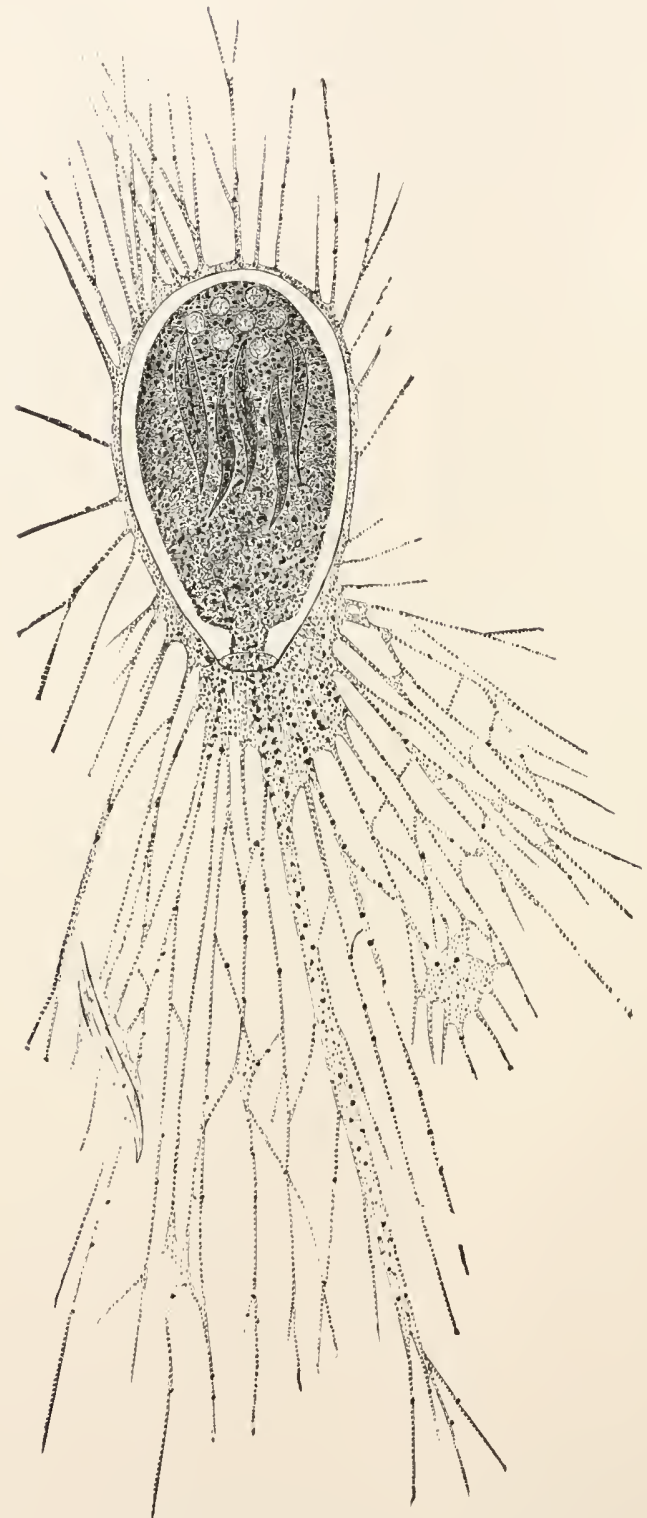

FIG. 37.-Gromia oziformis. (From Lang, after M. Schultze.) 
extremely complicated phenomena of motion in such narrow limits as pseudopodia in general.

Irritability of Protoplasm.-That amoboid movements and streaming of granules can be induced, brought to a standstill, and modified by mechanical, chemical, and thermal stimuli, is a sure proof of the irritability of protoplasm. Most important are the thermal stimuli; if the surrounding medium rises above the ordinary temperature, the movements at first become more rapid up to a maximum: from that point begins a slowing, finally coming to a standstill.

Heat-rigor. - If the high temperature continues much longer, or if it rises still higher, death results. The fatal temperature is found for most animals between $40^{\circ}$ and $50^{\circ}$ Celsius $\left(104^{\circ}-122^{\circ} \mathrm{F}\right.$.) ; its influence explains the injurious effects which high-fever temperatures have upon the human organism.

Cold-rigor. - Like the heat-rigor, so there is also a cold-rigor, induced by a sharp sinking of the temperature below the normal. This is accompanied by a gradual diminution of mobility; it results in death by freezing, which is, however, not so easily induced as death by heating. It is a remarkable fact that many animals, consequently their cells, may be frozen; and in this condition can endure still severer cold without dying. (For example: goldfish, a temperature of $-8^{\circ}$ to $-15^{\circ}$ Cent.; frogs, to $-28^{\circ}$; newts, to $-25^{\circ}$.)

Nutrition and Reproduction.-Irritability and power of motion are the prerequisites of assimilation, the change of food-substances into protoplasm. Most animal cells, as, for example, almost all tissue cells, are not suitable for studying assimilation, because they live upon liquid nourishment. But certain cells of higher animals, the colorless blood-cells, and most unicellular animals can be fed also with solid substances; they take the food-particles into the midst of the protoplasm by flowing around them with the pseudopodia. They withdraw all the assimilable and reject the indigestible portions (Fig. I6).

In the case of assimilation it is to be noted not only 
that the cells use for their own growth and for replacing worn-out parts the food which they have taken up, but also that most of them have the power of producing substances other than protoplasm, as, for example, many protozoa form organic aggregates which are hardened with silica or chalk. This formative power, the building of "protoplasmic products," is, as we shall shortly see, the starting-point for tissue-formation.
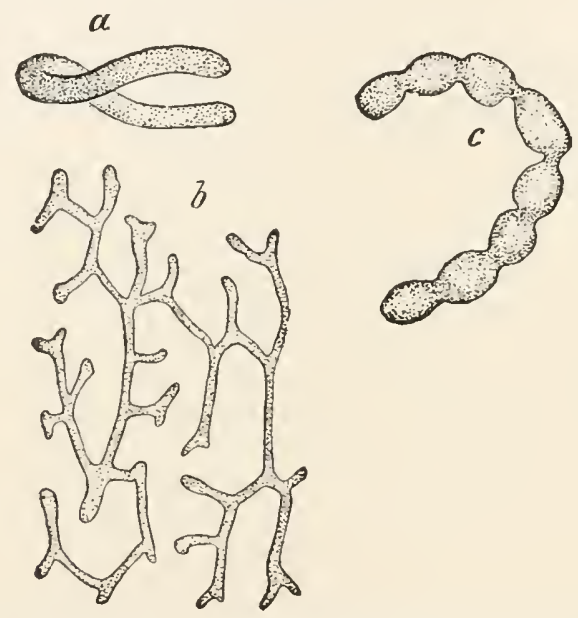

FIG. 18.-Various forms of nuclei, $a$, horseshoe-shaped nucleus of an Acinete; $b$, branching nucleus from the Malpighian vessel of a Sphingidze larva; $c$, rosary-shaped nucleus of Stentor caruleus.

Cell Nucleus. - The reproduction of protoplasmic bodies is synonymous with the division of the cell; but to understand this we must first consider the second important constituent, the muclcus.

The coll mucleus is a body enclosed in the protoplasm, whose form, though definite for each kind of cell, shows in other respects wide variations. Usually it is a spherical or oval vesicle; but it may be elongated or club-shaped, bent into a horseshoe, with constrictions like a rosary, or even be branched, treelike (Fig. I 8 ); in many cells it is disproportionally large, so that the protoplasm surrounds it only with a thin layer, in others again it is so small that it can scarcely be found in the protoplasm and surrounding 
substances. Formerly, on this account, it was in very many cases overlooked, and, even yet, it can often be demonstrated only by the exercise of great care, and by employment of a special technique based upon the peculiar reaction of the nuclear substance.

The Nuclear Substance.-The nuclear substance is distinguished from protoplasm among other ways by its greater coagulability in certain acids, e.g., acetic and chromic acids, which therefore are often used for demon-
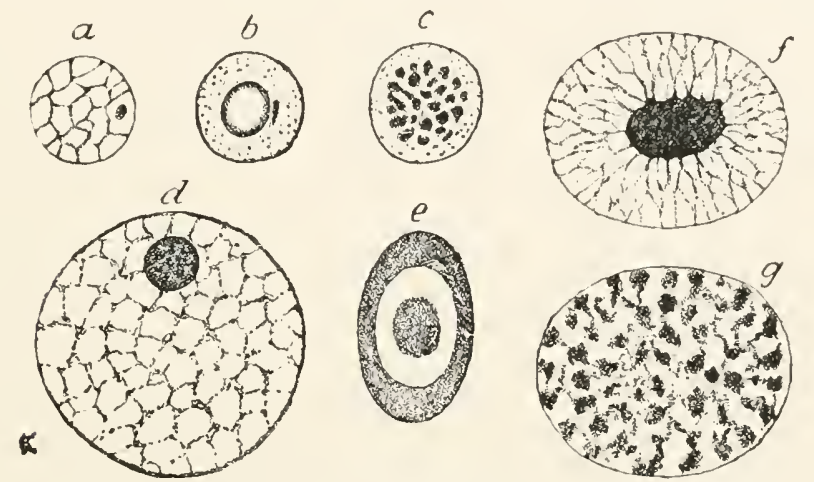

FrG. Iq-Vesicular nuclei with different arrangements of the nuclear substance, $a$, Egg nucleus of Toxppneustes lizidus; $d$, germinal vesicle of the same animal ; $b, c$, nuclei of Actinospharium Eichhorni; e, nucleus of an Acanthometra; $f, g$, nuclei of the salivary glands of Culex pipiens (larva).

strating the nucleus. If in a living cell the nucleus is invisible on account of the similarity of its refraction to that of the protoplasm, the addition of $2 \%$ acetic acid will often bring it into sharp contour.

Structure of the Nucleus.- The distribution of the nuclear substance in the nucleus is very varied (Fig. I9); often it forms a spongy network of larger or smaller meshes running throughout the whole cell $(a, g)$, or it is collected into a single large or several small bodies, the nucleoli (mono- and pluri-nucleolated nuclei) $(b, c)$, or the formation of nucleoli is combined with a nuclear network $(d, f)$; a part of the nuclear substance lying in the periphery may even produce a continuous superficial crust (c). By this arrangement there is left a more or less considerable space between the meshes of the nuclear network or between the 
nucleoli, which is filled by a white-of-egg-like fluid, the nuclear sap.

Nuclein and Paranuclein.-Here now we encounter a mooted question: is there one or are there several kinds of nuclear substance? We shall here distinguish two kinds, the maclcin or the chromatin, and the paranuclein or the achromatin. The difference becomes apparent by the parts which they take in the process of cell division (described later) and by the following reaction to dyestuffs (carmine, hematoxylin, aniline solutions). By correct use of the latter only the nuclein is stained (hence called chromatin), while the paranuclein remains entirely unstained. Each of these two substances may appear in the form of a network as well as of nucleoli, so that we must distinguish chromatic and achromatic networks and nucleoli. Most frequent is an achromatic network with chromatic granules scattered in it (Fig. I9, $g$ ).

Significance of the Cell Nucleus.-For a long time the functional significance of the nucleus in the cell was shrouded in complete darkness, so that it began to be regarded in comparison with the protoplasm as a thing of little importance. The evidence that the nucleus plays the most prominent rôle in all fertilization processes, and the numerous researches on this point, have more and more confirmed the view that the nucleus determines the character of the cell; that the potentiality of the protoplasm is influenced by the nucleus. If from the egg a definite kind of animal develops, if a cell in the animal's body assumes a definite histological character, we are, at the present time, inclined to ascribe this to the nucleus. From this, then, it follows farther that the nucleus is also the bourer of heredity; for the transmission of the parental characteristics to the children (a fact shown to us by our daily experience) can only be accomplished through the sexual cells of the parents, the egg and sperm cells. Again, since the character of the sexual cells is determined by the nucleus, the transmission in its ultimate analysis is carried on by the nucleus. Within the nucleus the chromatin is probably 
the peculiar hereditary substance (as observations upon furtilization seem to show), while the achromatin plays a rôle in cell multiplication.
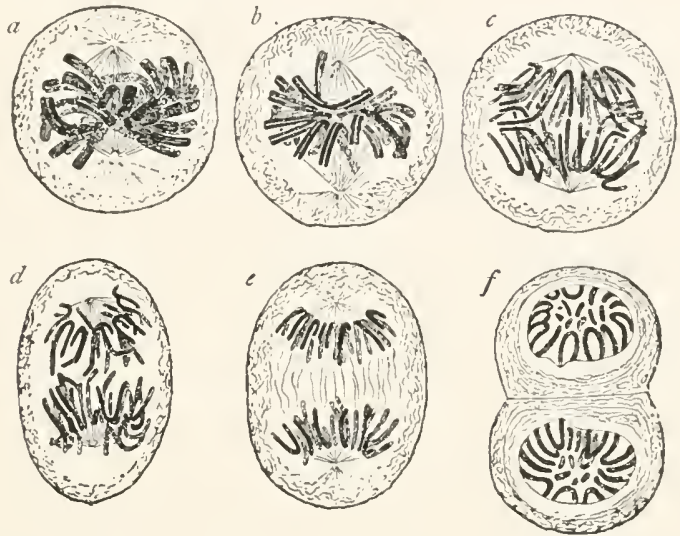

FIG. 2o.-Cell division according to Rabl. (Skin of Salamandra maculosa.)

Cell Budding. - Cell multiplication is undoubtedly brought about chiefly by division, and usually indeed by binary division. On the surface of the cell there appears a circular furrow which, deepening, cuts the cell into two equal parts (Fig. 20). (Division in the narrower sense.) Less frequently cell budding (gemmation) takes place, in the course of which a large mother-cell cuts off from itself one or more daughter-cells (Fig. 2I). For a long time there was a controversy concerning

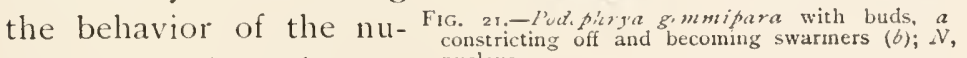
cleus; some investigators

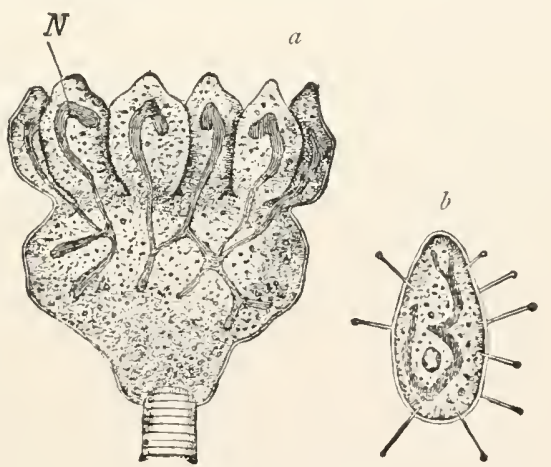
affirmed that the nucleus disappeared previous to the division, and that in each daughter-cell a nucleus was formed anew; other investigators believed that the nucleus was cut in two analogously to the cell. Although the first- 
named authors made the best observations, the second party was correct in principle. This is explained by the fact that the nucleus in process of division passes into a stage in which it absolutely cannot be recognized without the use of suitable and only recently discovered reagents, because in its pface is to be seen only an indistinct lighter spot in the protoplasm. This almost complete disappearance of the nucleus was entirely overlooked by the zoologists of one party, but on the other hand it was correctly observed by the other, though falsely interpreted. For the nucleus, as treatment with acetic or chromic acid shows, is still present in the light spot, and has only undergone a transformation into the "nuclear spindle" (Fig. 20).

Indirect Nuclear Division, Karyokinesis.-As the name indicates, the nucleus at the critical stage has assumed the form of a spindle (or often a barrel shape) and the two opposite ends, either pointed or flatly rounded, are the poles of the nucleus $(a)$. The greatest circumference is about midway between the poles, in the equator of the spindle. Here all the chromatin is collected into an "cquatorial plate," not, however, forming a continuous mass; on the contrary, the chromatic nuclear substance acquires the form of small granules, or of straight or V-shaped rods, which are called chromosomes. Their number, which may be either small or very considerable, is pretty definite for each form of cell. Diverging from the poles of the nucleus and meeting the chromosomes are delicate achromatic threads, the spindle-fibres, which condition the form of the spindle and play an active rôle in the nuclear division. That is, each chromosome of the equatorial plate splits into two parts (Fig. 20, b), and under the directing influence of the spindle-fibres the products of the splitting separate and move, one half toward one, the other half toward the opposite pole of the nucleus $(c, d, c)$.

The collections of chromatin thus arising from the splitting of the entire equatorial plate are called the daughterloops. The elements of the daughter-loops again unite with one another and form the two daughter-nuclei. 
Nuclear Spindle and Centrosomes.-In spite of numerous recent researches some features of cell division remain still undecided; e.g., the spindle-fibres are by many investigators explained as formed from the protoplasm of the egg (cytoplasm), by others as derived from the achromatic nuclear substance. But the following questions especially demand more thorough study. At the poles of the spindle there have been often found colorless small rounded corpuscles or plates, the centrosomes. They are especially conspicuous during the cleavage of the egg of the round-worm (Ascaris) (Fig. 92, B), and continue to be visible after the completion of the daughter-nuclei; by a new division they form for each daughter-nucleus two centrosomes, which pass to opposite ends of the nucleus and thereby introduce again the process of division. Since, also, centrosomes have been found in resting vegetable and animal nuclei, the theory has been proposed that, in addition to the nucleus, there is present permamently a special cell-organ (the centrosome) for the inception of division.

Multinuclearity, Multicellularity.-Nuclear division and cell division commonly constitute a well-arranged mechanical process, the separate phases of which are joined to one another according to a definite law. The plane of division stands perpendicular to the long axis uniting the two poles of the spindle. The poles of the spindle exert a determining influence not only upon the chromosomes, but also on the protoplasm of the cell; the latter arranges itself around the pole in radiating lines, and generally leads to that arrangement of the granules known as the protoplasmic rays. Thus it comes that for Fig. 22.-Giant-cell each phase of nuclear division there is a cor-

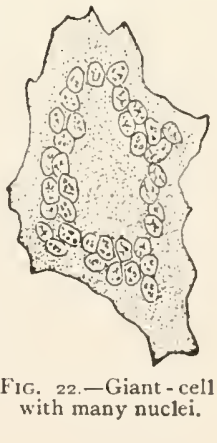
responding definite phase of division of the cytoplasm. But this interrelation of cytoplasm and nucleus is by no means an unchangeable and indissoluble one, for very often nuclear division takes place without participation of the cytoplasm. If this process is repeated several times, there 
is found a mass of protoplasm with many nuclei (Fig. 22), which now again on its part may become many cells, if subsequently the protoplasm divides according to the number of nuclei. Multinucleated protoplasmic masses are consequently transitional stages between the simple mononucleated cell and a collection of several mononucleated cells, and in consequence of this are sometimes regarded as the equivalent of onc cell, sometimes as equivalent to many cells, and are called sometimes multinucleated giant-cells, sometimes cell-complexes, Syncytia. In the following pages a multinucleated mass of protoplasm will be considered as a single coll, for therein is given the essential feature of the character of the cell, that it constitutes a vital unit, it has a physiological individuality. But in this respect a multinucleated mass of protoplasm behaves almost like a mononucleated; as the tissue cells and the protozoa show, the plane of organization is not raised in the least by the multinuclearity. A change only begins at the moment when many small lumps of protoplasm are marked off from one another, and thereby are formed many vital units; i.e., when in place of multinuclearity a true multicellularity comes about.

Direct Nuclear Division.-Before closing the consideration of nuclear division we must briefly recognize the simplification which obtains in the above-mentioned processes. There are instances where the nucleus, without essential changes of structure, stretches out in case of cell division, and separates into two parts by an equatorial constriction (Figs. 2I, I4O, I45). We then speak of a dircct nuclar division, in distinction from the previously-considered process, the indirct nuclcar division, or karyokincsis. Between these there are many intermediate forms, thus precluding the idea that these processes may differ in principle.

Probable Significance of Direct and of Indirect Nuclear Division.-For correctly estimating the differences which occur, a valuable hint is given us by the fact that the direct nuclear division obtains chiefly in the nuclei of the 
protozoa which are rich in chromatin. Accordingly the chromatin contents and the degree of organization of the cell must condition the different character of the processes of nuclear division. As mentioned above, there is reason to regard chromatin as the bearer of heredity. Now the more highly an animal is organized, so much the more are peculiarities transferred from cell to cell, so much the more complicated must be the structure of the hereditary substance, the chromatin, so much the more delicately elaborated, therefore, must be those processes which condition the definite distribution of the hereditary substance to the daughter-cells. The significance of indirect division can only be sought in this, that the hereditary substance present in small amount must be handed over to the daughter-cells in equal quantities and of the same constitution. This object is simplified in the case of the lower animals, in which much chromatin is present, and this, too, of a simple composition.

\section{The Tissues of the Animal Bodr.}

Definition of Tissue.- In the formation of tissues two processes are operative: (I) the multiplication of cells by means of division into cell-complexes, and (2) the histological differentiation of cells. A tissuc, therefore, can be defined as a complcx of differcntiated cells histologically similar.

Nature of Histological Differentiation.-The histological differentiation is chiefly expressed in this, that the cells have definite form and definite position relative to the neighboring cells; in addition, there almost always comes: in, as a second and more important feature, the histological alteration of the cell. The fact has already been men tioned that the cell uses its food-material, not only for its own growth, for increase of its protoplasm, but also, in another manner, for forming substances, protoplasmic products, either in its interior (internal plasmic products), or more often on its surface (external plasmic products). Now 
the histological change is the formation of spccifically functioning plasnic products. If we take as an exam-

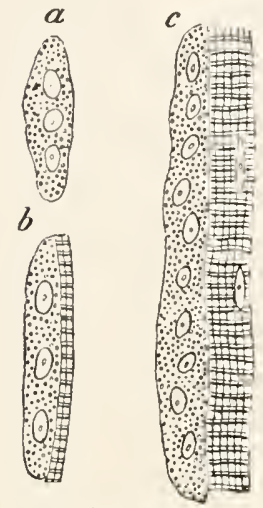

FIG. 23.-Formation of muscle fibrils in the frog. (Diagram.) $a$, formative cell: $b$, formative cell with two transversely striated muscle fibrils: $c$, formative cell with numerous muscle fibrils. ple the manner in which a cell becomes a muscle fibre (Fig. 23), we see that it continually secretes upon its surface new fibres of specific muscle substance, in the case of the vertebrates, new cross-striated muscle fibrils, until finally the remnant of the formative cell, the muscle corpuscle, is contained in a mantle of muscle fibrils. In an analogous way, each tissue shows itself upon histological examination to be composed of cells and plasmic products. The former care for the formation, the renewal, and the sustenance of the tissue; the latter are the agents of its physiological function. The advantages of tissue formation are far-reaching, since in general they are connected with division of labor (frequently referred to later). So long as the cells unite in themselves all the vital functions, they are incomplete because they mutually hinder each other in their free development; the plasmic product, on the other hand, serves only the single function peculiar to it and can therefore discharge its duties with greater completeness. The muscle fibrils, the characteristic elements of the muscles formed by the cells, have of the various peculiarities of protoplasm preserved only the capability of contraction; but this power of contraction is much more energetic and stronger than the mere movement of protoplasm. The nerve fibrils serve only for the transmission of stimuli, but in an extraordinarily more rapid and orderly manner than does simple protoplasm.

The case is the same as in human life: a man who wishes to be his own tailor, shoemaker, etc., at the same time to study science and art, will with the same talent accomplish less in each branch than another who concentrates his whole energy in a definite direction. 
Classification of Tissues. - Since in every tissue its function interests us most, it would be natural to base the classification of tissues upon the function and the intimate structure connected therewith.

For a long time the tissues have been arranged in four groups: I. Epithelial tissue; 2. Supporting tissue; 3. Muscle tissue; 4. Nervous tissue. Within these, however, certain constituent parts of the animal body find no shelter, constituent parts to which indeed the term "tissue" is scarcely applicable: these are the sexual cells, the blood, and the lymph. The former may be spoken of in connection with the epithelium, the latter in connection with the supporting substances.

\section{EPITHELIAL TISSUES.}

Morphology of Epithelial Tissues. - On several grounds the epithelia must be first considered. They are the oldest tissues; they are the first to appear in the animal kingdom, there being animals which consist only of epithelia. Further, each separate organism during the first stages of embryonic life consists only of epithelial Iayers, the germ-layers. With this is also connected the fact that in epithelial tissues the cells have undergone the least degree of histological change, and that the formation of plasmic products is subordinated.

Function of Epithelium.-The most important purpose of the epithelium is to form over surfaces a protecting and excluding covering, equally valuable whether the surfaces are external (surface of the body) or caused by cavities in the interior of the body (the body cavity, lumen of the gut, of the blood-vessels). The importance of the epithelia in this respect is shown by the fact that if the protecting layers are removed, inflammation arises and continues until the epithelium is regenerated. Only exceptionally do areas occur which are free from epithelium; the teeth of vertebrates, the antlers of stags, are parts of the body which, on 
account of their hardness, can exist, at least for a more or less considerable time, without epithelial covering.

Glandular Sensory Epithelia.-By their superficial position the epithelia are suited for presiding over two other functions: all substances which ought to be removed from
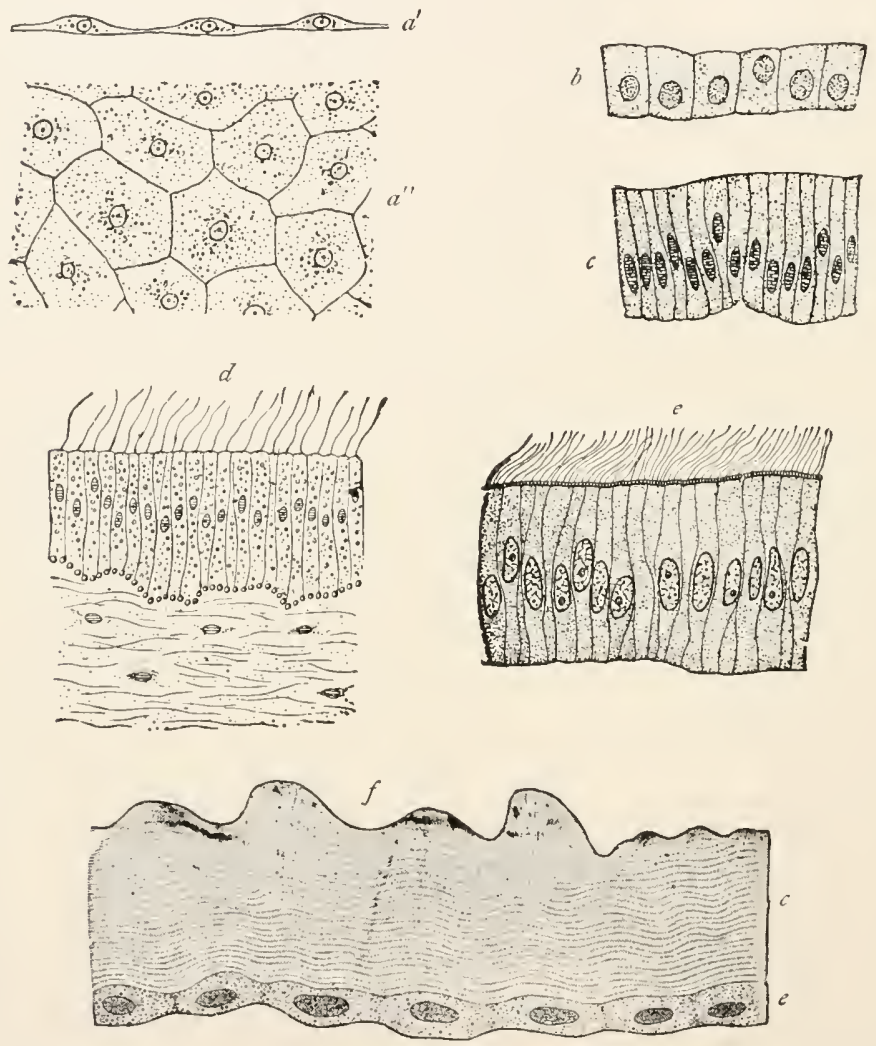

FIG. 24.-Various forms of the different epithelia. a, flattened epithelium of Sycandra raphanus, $a^{\prime}$ in cross-section, $a^{\prime \prime}$ in surface view ; $b$ and $c$, cuboidal and columnar epithelium of a snail (Haliosis tutierculuta); $d$, flagellated epithelium of an Actinian ( $C$ alliactis parasitica): $e$, ciliated epithelium from the intestine of the fresh water mussel: $f$, epithelium with cuticle of Cimber coronatus (a wasp).

the body - some because they have become useless, and consequently injurious (excreta), and others, as, for example, the digestive fluids, because they have to perform still further important functions (secreta)_-must pass the surface, 
and are therefore separated by the epithelia; these are the slandular cpithclia. Further, all influences of the external world chiefly impress the surface of the body, causing sensations; hence also certain epithelia are of the greatest importance for the reception of sensory perceptions, and serve for hearing, seeing, smelling, tasting, and touching. Such areas of epithelium are called sensory epithclia.

Our attention will be directed chiefly to the ordinary covering epithelium, so far as this serves exclusively for protection, or only incidentally has excretory and sensory functions.

Covering Epithelium.-The covering cpithelium consists of cells which, in order to serve the function of the tissue, are united by a small quantity of cementing substance. We speak of one-layered or of many-layered epithelia, according as we find in sections running perpendicularly to the surface one or several superimposed layers (Figs. 24, 25).

One-layered Epithelium. - Exclusively one-layered epithelia are found in all invertebrated animals and in Amphioxus; in the vertebrates, on the other hand, they are limited to the internal cavities of the body, and even here are occasionally, as always in the skin, replaced by a many layered epithelium. According to the shape of the cells we distinguish cuboidal or pavement, flat, and columnar epithelium. In the case of pavement epithelium (Fig. $24, b$ ) the cells are all developed about equally in all directions of space, and because they have become compressed by lateral pressure have the appearance of cubical blocks or paving-stones. In columnar epithelium the long axis, the distance from the central to the peripheral end of the cell, is especially great (Fig. 24, c); finally, in flat or squamous epithelium the longitudinal axis is greatly shortened (Fig. 24, a) and the separate cells have become changed into thin scales.

Flagellated and Ciliated Epithelia.-Further differences which obtain in the three above-mentioned kinds of epithelium are conditioned by the presence or absence of 
projections (cilia, or flagella) on the peripheral end of the cells. Both are fine threads which arise from the body of the cell, extend above the surface and here maintain an extremely lively motion. In case of flagellated epithelium (Fig. 24, d) each cell has only one vibratile projection, but this is especially strongly developed; in the case of ciliated epithelium (Fig. 24, c), on the other hand, the surface of the cell is covered with a thick forest of minute threads moving in unison.

Cuticle.-The majority of the one-layered epithelia are covered by a cuticlc, a membrane which is secreted by the epithelium cells in general, and hence very frequently show's as polygonal markings the impression of the cells. In many cases thin and inconspicuous, it may in other instances become thickened into a very considerable layer, much thicker than the matrix layer of epithelium which secretes this cuticle. The cuticle then is evidently composed of layers parallel with the surface, and forms a more effective protection for the surface of the body than does the epithelium; it becomes a protective armor, as shown, among other examples, by the calcareous shells of mollusks and the chitinous integument of insects (Fig. 24, $f$ ).

Many-layered Epithelia.-The protection furnished by the cuticle in the case of the one-layered epithelium, may in the many-layered be obtained immediately through a chemical change of a part of the cells themselves.

In the case of the many-layered epithelia the cells of the various layers always can be distinguished by their form: the deepest layer of cells consists of cylindrical cells; the superficial, on the other hand, of more or less flattened elements; between lie several layers of transitional forms, so that starting from the cylindrical cells we gradualiy pass through the cubical cells to the flat cells of the surface. As this arrangement shows, there exists a genetic connection between the cell-layers: the lower cylindrical cells are in a state of active multiplication; their descendants with gradual changes of form push into the superficial layers, 
here to replace an equal quantity of worn-out cells (Fig. $25 \mathrm{~A})$.

In the course of this change of position, the protoplasmic bodies may undergo an alteration; in the reptiles, birds, and mammais (Fig. 25li) they became cornified, i.e., first the borders, then the inner part of the cell,

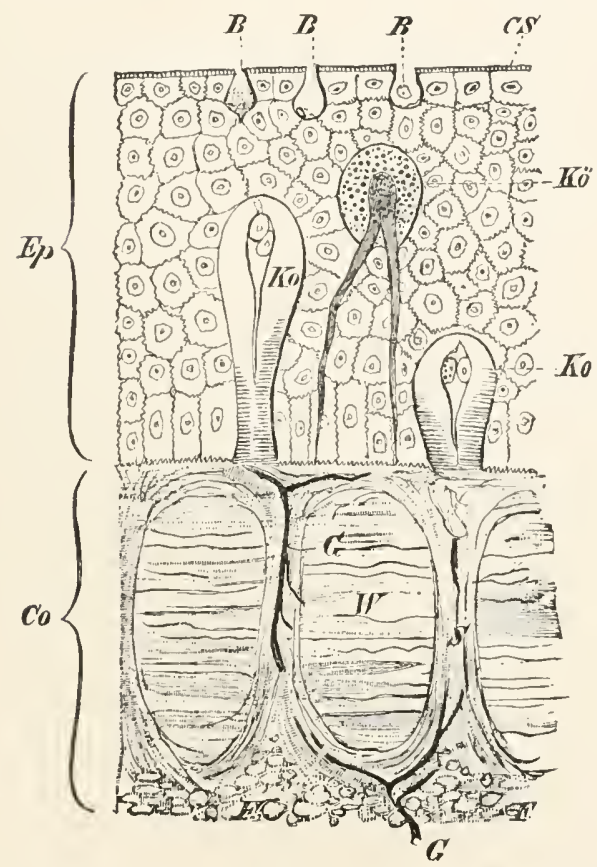

FIG. 25A.-Section through the skin of Ptromyzon Planeri. ep, the many-layered epithelium of the epidermis, including $b$, goblet cells; $K o$, granular cells : $K o$. Co, dermis (with blood-vessels $G$ ), consisting of bundles of fibrils running horizontally $(W)$ and vertically $(S$. (From Wiedersheim.)

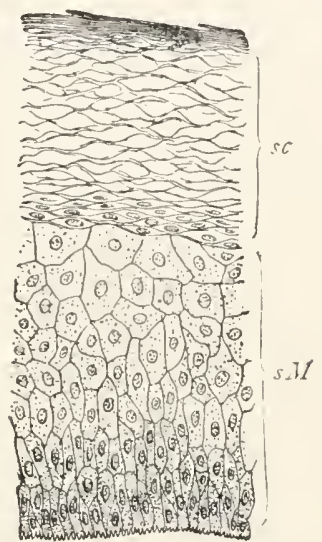

FIG. 25B.-Many-layered epithelium of man. s.11, stratum Malpighi ; sc, stratum corneum.

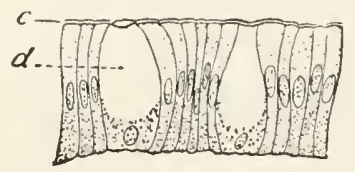

Fig. 26.-Single-layered epithelium of a snail. $c$, cuticle; $d$, goblet cells.

change into horn. Of the living cell there remains for some time still the nucleus, until at length this vanishes, and then the cell becomes completely changed into a dead, horny scale. In the skin of the higher vertebrates the zones of the living protoplasmic, and the cornified cells no longer capable of life. are sharply marked off from one 
another. In cross-section they are readily distinguished as the stratum corneum (sc) and the stratum Malpighi ( $s . I I)$ of the skin (Fig. 25B). In the many-layered epithelia the cuticle has lost its importance, and it is either an inconspicuous bounding line or is entirely absent.

Glandular Epithelium.-Glandular epithelium is distinguished physiologically from ordinary pavement epithelium by the fact that it at the same time also produces secretions or excretions; anatomically it is recognizable by the presence of "gland cells," cells which carry on the secretion and, to a greater or less extent, reveal their character by their structure. Characteristic glandular cells are, for example, the goblet cells; here the secretion, usually slime, is collected as a vitreous mass in the interior of the cell, the cytoplasm, thereby compressed into a thin external wall, reminding one of that of a goblet containing the nucleus at its base (Fig. 25A, $26 d$ ). Other gland cells are the granular cells, swollen bodies completely filled with secretory granules (Fig. 25A, Kö). Naturally between pavement and glandular epithelium all grades of transition are found. Commonly the latter name is only employed when the gland cells are especially numerous, thereby giving to the epithelial area the first stage of secretory importance. This is especially the case with the apparatus which go by the special name of " glands," among which we distinguish unicellular and multicellular glands.

Unicellular Glands. - Uniccllular and multicellular glands lead to an increase of the secretory surface by invagination. Invagination of a single cell produces the unicellular glands which are chiefly found among the invertebrated animals (Fig. 27); a gland cell here grows so enormously that there is no room for it in the epithelium, but it is pushed into the deeper, the subepithelial layers. Here swollen up with secretion lies the cell body with its nucleus; a delicate necklike projection, furnishing a passage for discharging, extends to the epithelial surface.

Multicellular Glands. - In the formation of multicellular glands, an extensive area of the glandular epithelium 
grows as a cylindrical cord or tube from the surface down into the deeper layers of tissue; this cord of cells seldom remains simple; it usually branches and forms the compound glands, which may consist of hundreds or thousands of glandular pouches, all emptying into a common duct. Among the multicellular glands are to be distinguished tubular and acinous forms. In the case of the tubular slands (Fig. 2S) the simple or branched glandular pouches preserve the same tubular calibre from beginning to end; in the acinous glands (Fig.

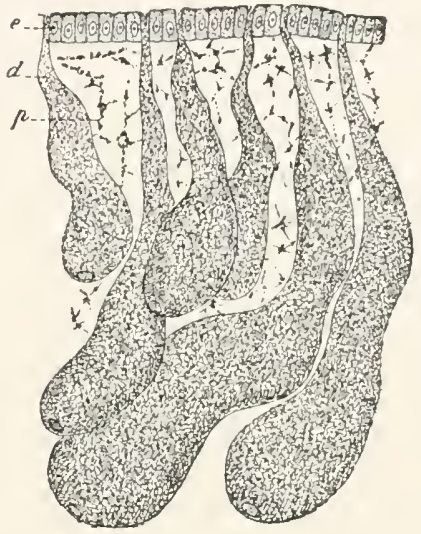

FIG. 27-Unicellular glands from edge of the mantle of Helix pomatia. e, epithelium; $d$, unicellular glands ; $\not p$, pigment cells.

29), on the contrary, the blind end of the glandular pouch widens into a swelling, which chicfly comprises the secre-

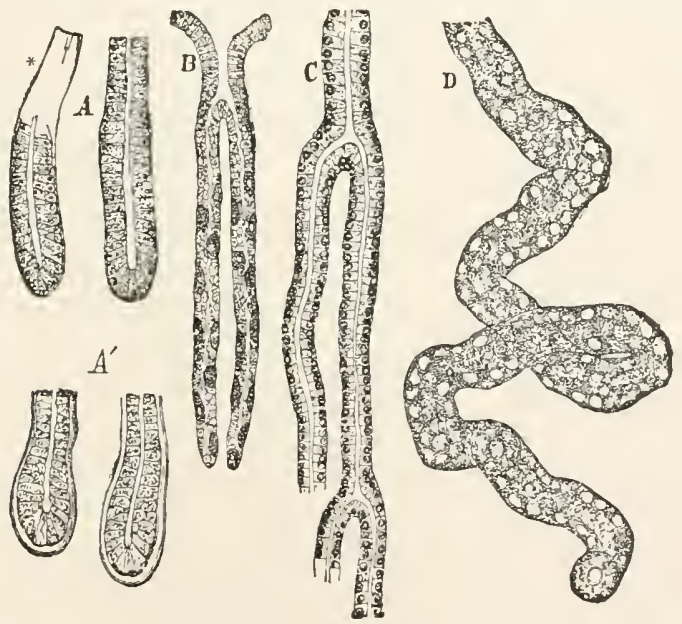

Fig. 28.-Tubular glands. (After Toldt.) $A$, glands of Lieberkijhn from the human intestine ; $A^{\prime}$, of the conjunctiva of the eye; $B$, of the cat's stomach; $C$, from the pyramids of the dog's kidney; $D$, from the cortex of the rabbit's kidney.

tory cells, and is related to the anterior part of the glandular pouch, the duct, as grapes are to their stem. To the 
tubular glands belong the liver, kidney and sweat glands of man; to the acinous belong the salivary glands, not only of the vertebrates, but also of the arthropods and mollusks.

Sexual Epithelium.-In connection with the glandular epithelium we consider appropriately the sexual cells. As

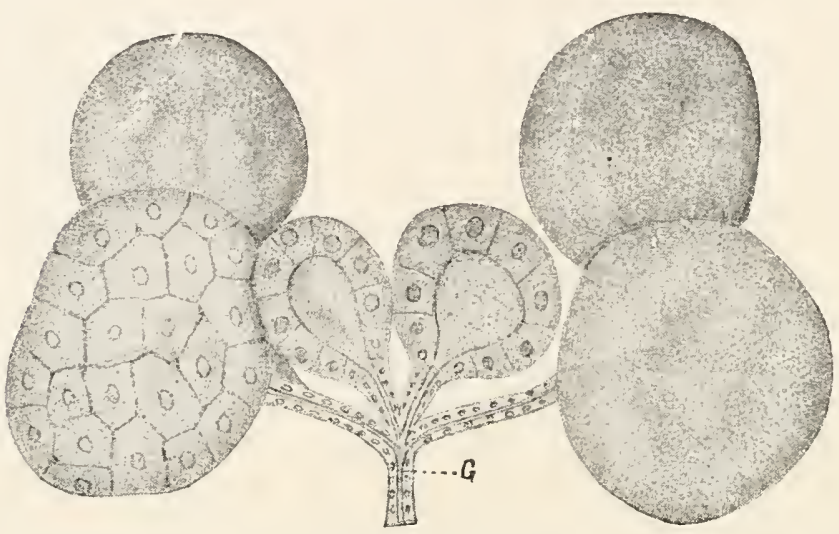

Frg. 29.-Acinous salivary gland of Orthezia cataphratu (after List); in some acini the nuclei and boundaries of the cells are shown.

the secretion of the former must be expelled from the body, so also the sexual cells form elements which are no longer

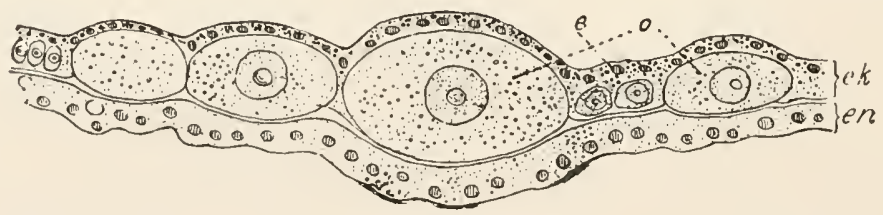

Fig. 30.-Germinal epithelium of a medus a. $e k$, ectoderm ; en, entoderm; $o$, egg ; $e$, epithelium.

a part of the organism, and must reach the exterior in order to perform their function. Just as the gland-cells are usually scattered among ordinary epithelial cells, so the sexual cells, almost without exception, lie embedded in epithelium; it may be in the epithelium of the skin (Fig. 30) of the gut, of the body-cavity, or of parts separated from this (Fig. 3I). This connection of the sexual cells with 
the epithelium has a still wider basis in the fact that many organisms, and particularly organisms of low structure, consist exclusively of epithelia and therefore must necessarily develop their sexual products in epithelium. In other words, sexual and epithelial cells are the oldest elements of

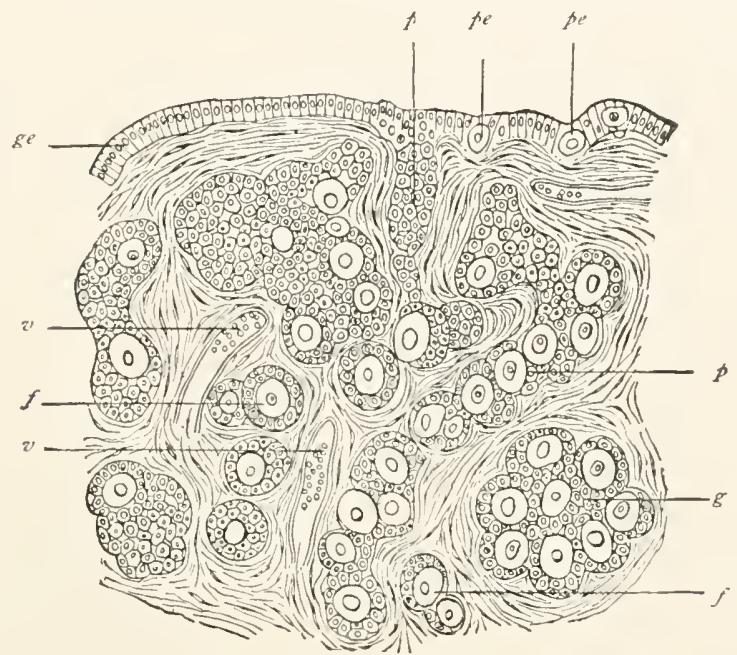

FIg. 31.-Section through the ovary of a new-born child. (After Waldeyer) ge, germinal epithelium; $p e$, primitive egg in the germinal epithelium; $f$, egg-pouch; $g$, group of eggs constricted off from the pouchlike growth $(p) ; f$, single egg with follicle; $z$, bloodvessel.

the animal body, and hence very early came into relation with one another.

Sexual epithelium, or, as it is often also called, germinal epithelium, like the glandular epithelium has the tendency to grow down into the subepithelial tissues in the form of isolated or branching pouches (Figs. 3I,, , 32), and thus in many groups of animals the sexual organs bear the character of branched glands; for this reason therefore one may speak as often of sexual glands as of sexual organs (Fig. 32). The male and female cells, the specific elements of the germinal epithelia and of the sexual glands, differ, as has already been mentioned, in the fact that the egors are generally the largest, the spermatozoa the smallest, cells of the animal body. 
Egg cell.-The egg-coll (Fig. 33) as it is formed in the ovary has various sizes according to the animal

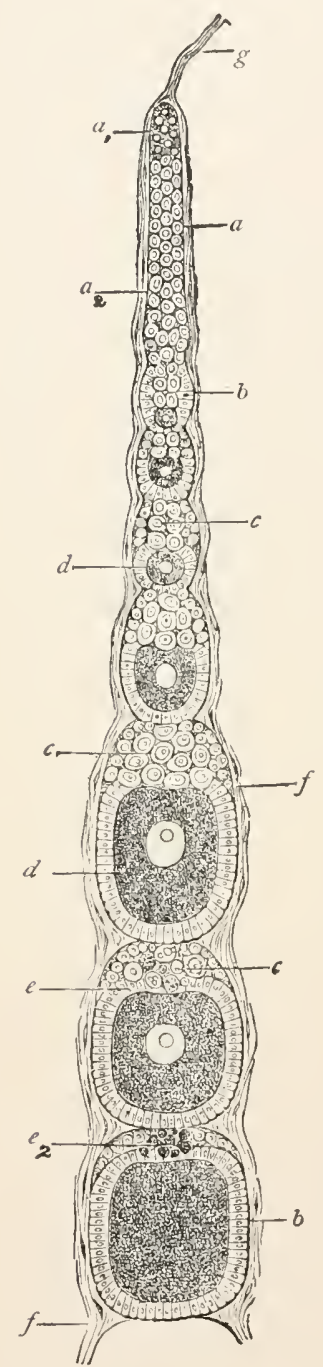

FiG. 32 . group: in case of the microscopically small Gastrotricha, it is less than 0.04 mm., in man about $0.2 \mathrm{~mm}$., in the frog several millimetres, and in the large birds often several inches; however, only the so-called "yellow" of the egg is to be regarded as the egg-cell, while the white of the egg and the shell are structures which are formed outside of the ovary in the oviduct. These remarkable differences in size are conditioned less by the quantity of the peculiar cell-substance, protoplasm (formative or primary yolk), than by the accumulation of deutoplasm (food or accessory yolk, also briefly called yolk). The function of the accessory yolk is to nourish the embryo during development, and hence consists of substances rich in fat and proteid, arranged in spherical oildrops, or in fine granules or polyg-

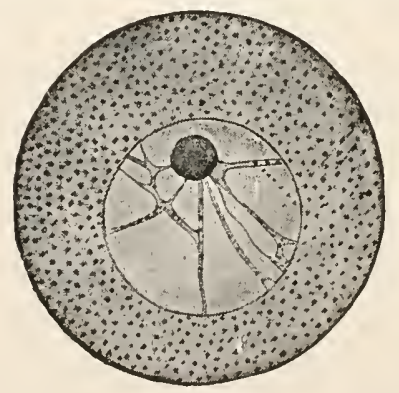

FI $i$; 33 .

FIG. 32. - Oviduct of an insect, Vanessa urtica. $a$, formative cell ; $b$, follicular epithelium; $c$, nutritive cells; $d$, egg-cells ; $f$, fibrous covering extending out into the ter minal fibres $(g)$ (After Waldeyer.)

FIG. 33.-Egg-cell of Strongylocentrotus iividus.

onal bodies, the yolk-particles. It is present in so much 
greater quantity, and therefore causes the greater dimensions of the egg, according to the length of time during, which the egg is cut off from any other supply of nourish. ment. We find the largest eggs in general in the case of the highly organized oviparous animals, where a longcontinued course of development is necessary to lay the foundation of the manifold organs. Besides the formative

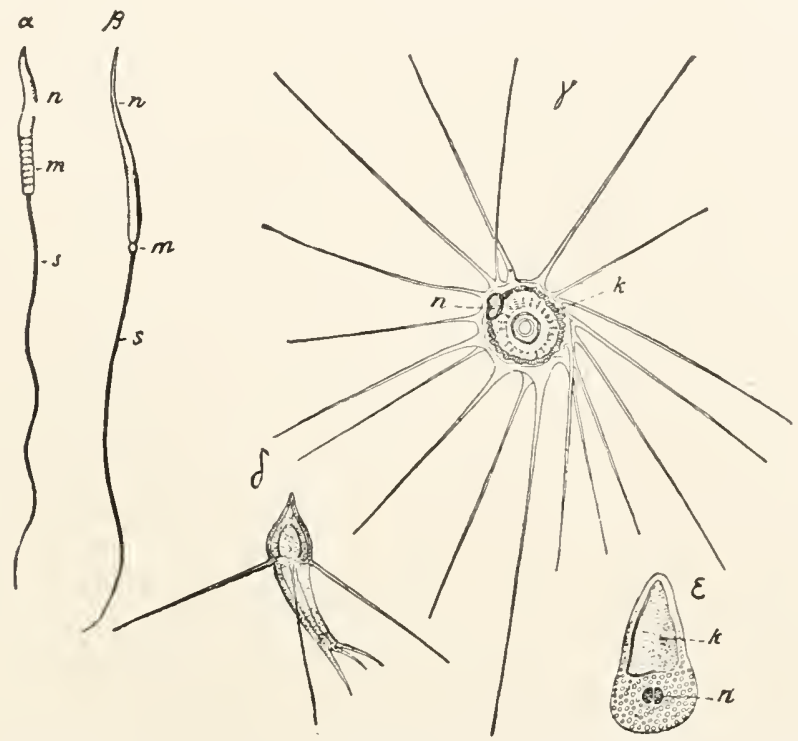

FIG. 34.-Various sperm tozoa. $\alpha$, of the night-hawk; $\beta$, of the green trog; $\gamma$, of the crayfish; $\delta$, of a crab: $\epsilon$, of the round worm (Ascaris); $n$, nucleus; $m$, middle piece; $s$, fagellum; $k$, homogeneous body.

yolk (protoplasm) and food-yolk (deutoplasm), there is always found in the egg the coll-nucleus or the germinal vesicle-sometimes to be seen in large eggs even by the unaided eye-surrounded by a firm membrane. Its contents are mainly the nuclear sap, through which is distributed an achromatic network, and in addition the nuclear corpuscle, or nucleolus, called also after the discoverer the Wagnerian spot, or the germinal spot. Often there are multinucleolated germinal vesicles, especially in eggs which contain very much yolk. 
The Spermatozoa, the morphological elements of the male sperm, are so small that their finer structure can be studied only with the strongest powers of the microscope (Fig. 34, $\alpha$ and $\beta$ ). Easiest to recognize in them is the head, which from its variety of form, spherical, oval, sickleshaped, etc., often renders possible the specific determination of the spermatozoa. The head is the closely compacted chromatic part of the nucleus, and hence colors very deeply in staining fluids. On it rests an unstaining second part, the middle piece, probably the achromatic part of the nucleus, and on the latter again the tail, a long flagellum, which makes possible the active motility of the ripe spermatozoon. Cytoplasm is usually present only in extremely slight traces, as a thin layer surrounding the nucleus.

The spermatozoa of nearly all animals, except the ncmatodes and crustaceans, are constructed according to the above-described plan. In these two groups it is worthy of notice that the spermatozoa are remarkably large and incapable of motion, and that they enclose a homogeneous strongly refractive body (Fig. $34, k$ ), previously not found, the significance of which is not clear. The spermatozoon of Ascaris (Fig. 34, c) has the form of a sugar-loaf with a broad rounded end, containing the nucleus; the spermatozoon of the crayfish (Fig. 34, $\gamma$ ), on the other hand, has the shape of a cake-pan, from whose periphery springs a circle of fine, stiff, and pointed fibres.

Sensory Epithelium.-The modification of the epithelium remaining to be spoken of is the scnsory cpithelium. This obtains its special character through the connection which some of its cells, the sensory cells, enter into with the most delicate branches of the ramifying nerves coming from the central nervous system. The sensory cells concerned are commonly to be recognized by their form; they are long, fine threads in which a varicosity is caused by the inclusion of the nucleus ( $\mathrm{Fig}$. 35). Thus the cell-body consists of a peripheral end which has to do with the reception of the sensation, and a proximal 
end which establishes the connection with the nerve. The proximal end branches into two or more finer continuations which take on the character of nerve-fibrilla, or stand at least in contact with the ends of nerve-fibrilla; the former usually bear special accessories relative to sensation, such as, for example, auditory and tactile hairs, pencil-like projections in the case of organs of smell and taste, very considerable rods in the cells of vision. Also in sense-organs in which the nerve-endings do

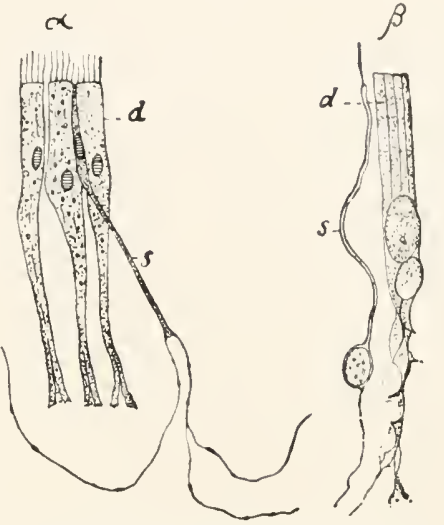

Fig, 35.-Sensory epithelium. $\boldsymbol{a}$, of an Actinian; $\beta$, from the olfactory epithelium of man; $d$, supporting cells; $s$, sensory cells.

not lie at the surface of the body, as in the ear and eye of man, areas of sensory epithelium are functionally the most important parts. Here almost always it can be shown by embryology that the sensory epithelia are parts which have become separated from the skin of the surface of the body.

Supporting Cells.-In the region of the sensory epithelium and between the sensory cells are found still other epithelial cells, which do not stand in connection with nerves, but have to do with the manifold accessory functions: they serve for supporting the sensory cells; in the eyes they contain pigment; in the auditory organs they support the otoliths, etc. They have the general name of "supporting cells."

\section{Connective Substances.}

Contrast of Epithelium with Connective Tissue.From a histological point of view there can be found no greater difference than exists between epithelium and connective tissue; the former belongs to the surface, the latter to the interior of the body; in the former, the cells play 
the chief rôle, in the latter, on the contrary, their importance is subordinate to the plasmic products, the "intercellular substances" which chiefly determine the character of the various kinds of connective tissue.

Function of Connective Tissue.-The primary function of connective tissue is to fill up the spaces in the interior of the body between the various organs, thereby uniting together not only the single parts of the organs, but also the various organs themselves. In consequence of this, the connective substances contribute to the firmness of the joints, and are correspondingly employed in the building up of the skeleton. To accomplish this, substances which usually have a greater firmness than protoplasm are formed on the surfaces of the cells, and, since they are included between the cells, these are called intercellular substances. In proportion as the intercellular substance increases in volume the cells themselves diminish and become inconspicuous corpuscles, the connective-tissue corpuscles, or, as seldom happens, entirely disappear. Since in the connective tissues the intercellular substances are most important, it is readily understood that the distinctions between the various kinds of connective tissue rest chiefly upon the differing constitution of this intercellular substance. The following forms are to be distinguished: (I) cellular connective tissue; (2) homogeneous connective tissue; (3) fibrous connective tissue; (4) cartilage; (5) bone.

Cellular Connective Tissue is least distinctly stamped with the characteristics of the group. It derives its name from the fact that the cells in it make up the chief mass, while the cell-products are present only in their incipiency. The cells are large vesicular bodies which have secreted a firm though thin covering representing the intercellular substance. Many such cells surrounded by a membrane are closely pressed together after the manner of vegetable cells and become flattened polygonally (Fig. 36).

Homogeneous Connective Tissue.-In the case of homogencous connective substance the intercellular substance is usually present in considerable quantity as a glassy, 
transparent mass, well-nigh indiscernible under the microscope, sometimes soft like jelly, often firmer ( F ig. 37). The cells lying in it are either spherical or send branching processes into the fundamental substance. Such processes may unite to form meshes which, like a pseudopodial network, unite cell to cell. Frequently the homogeneous connective substance contains, in addition, isolated firm fibres or threads, which, on account of their physical characteristics, are called elastic fibres, and consist of a substance

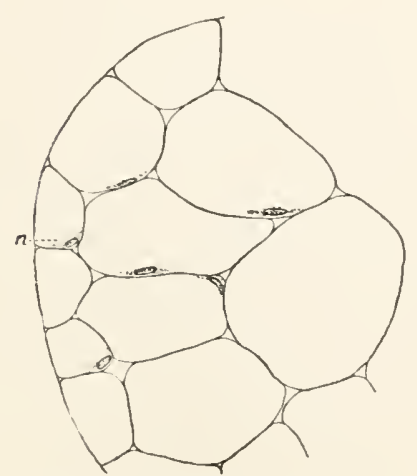

Fig. 36.-Cellular connective sulstan e. Cross-section through the notochur $\lrcorner$ of a newly hatched Trout.

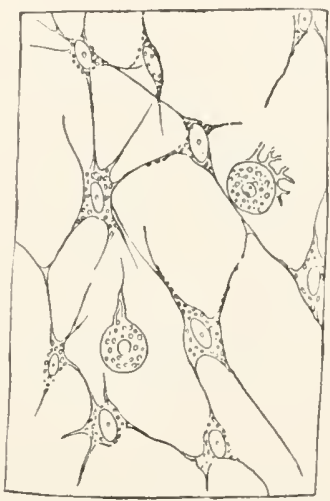

FIG. 37.- Honogeneous connective sut5itance of Sycandra raphanus. (After F. E. Schulze.)

(elastin) exceedingly resistant to all reagents. Finally, in the fundamental substance there may develop the finer connective-tissue fibrils, the characteristic element of the next group; they may become so prominent by increase in number as to determine the character of the tissue.

Fibrous Connective Tissue.-Fibrous connective tissuc is characterized by the rich supply of connectice-tissue fibril$l a$; these are fibres of extraordinary fineness, lying in a homogeneous basal substance, which is the more concealed the richer it is in fibres. In their course they may be either confusedly arranged, crossing in all directions, or may run essentially parallel and in a definite direction.

Between them are found the rounded, spindle-shaped or 
branched connective-tissue corpuscles (Fig. 38 ). In the vertebrates, numerous fibres unite into a bundle; each bundle is generally surrounded by connective-tissue corpuscles, metamorphosed into flat cells. The bundles, irregu-

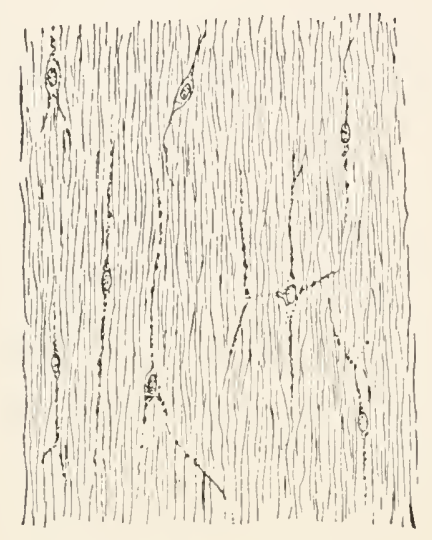

FIG. $38-$ Fibrous connective tissue of an Actinian.

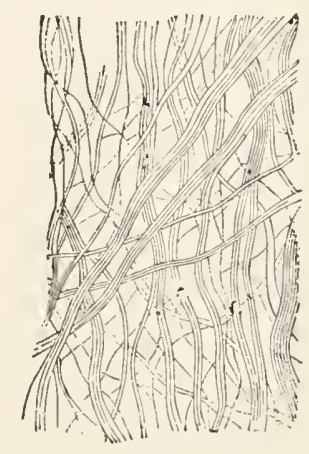

Fig. 39.-Areolar fibrous connective tissue. (After Gegenbaur.)

larly interwoven, run in all directions (areolar connective tissue, "cellular tissue" of the earlier authors) (Fig. 39), or, again, they may be arranged almost parallelly and form a compact mass of fibres (tendinous tissue) (Fig. 40). Since the fibrils of the fibrous connective tissue of the vertebrates have another peculiarity not elsewhere met with, in that they are composed of albuminoids (elastin and collagen), and upon boiling become glutin (gelatine, glue, etc.), it is proper to reserve for these forms of tissue the special name "connective tissuc."

Elastic Tissue.-In all fibrous connective tissue there may appear, as a further constituent element, clastic fibres; they may indeed supplant the ordinary connective-tissue fibrils and become the predominant element of the connective tissue, which is then spoken of as clastic tissue.

Cartilage.-Cartilage and bone are likewise tissues which find their characteristic development only in the ver- 
tebrates. In its appearance, cartilage is similar to the homogeneous connective substance of many invertebrated animals; the matrix is homogeneous and, at first glance, appears quite structureless ( $\mathrm{Fig}$. 4I), but, under the action of certain reagents, assumes a fibrous condition. This conduct, as well as the fact that the cartilage grows through changes of the perichondrium, a thin, fibrillar skin covering its surface, makes it more certainly evident that it is homogeneously fibrillar; and it is thereby distin-

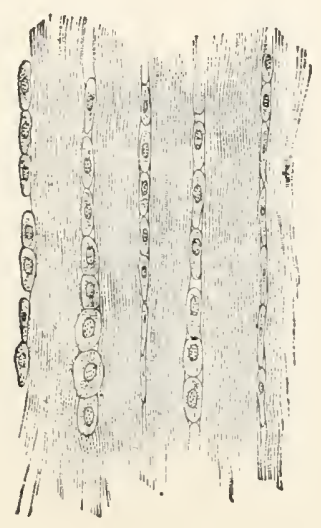

FIG. 4 .

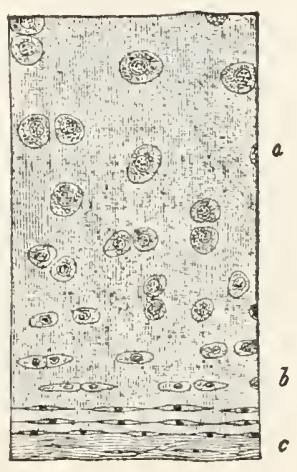

FIG. 4I.

FIG. 40.-Tenrinous tissue. (After Gegenbaur,

FIG. 4\%,-Cartilage (after Gegenbaur); $c$, perichondrium; $b$, transition into ty pical cartilage $(a)$.

guished from homogeneous connective substance since it does not, like the latter, designate a lower but a higher stage of tissue formation. In the matrix lie the cartilage cells united in groups and nests, a mode of grouping pointing to their origin, since each group of cells has arisen from a single mother-cell by successive divisions. In cartilage also, elastic fibres are found; if present in great number, these change the bluish shiny, hyaline cartilage into the yellow-colored clestic cartilage.

Bone is the most complicated structure in the series of connective tissues. It consists of a matrix (ossein), closely allied to glutin, so intimately combined with inorganic con- 
stituents that we see under the microscope only a homo-

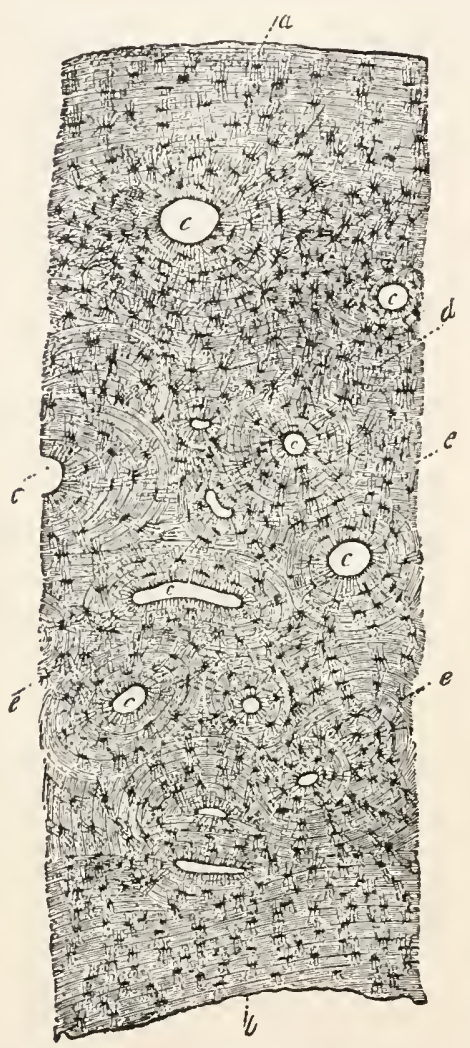

FIG. 42.-Cross-section through the human metacarpus $a$, surface of the periosteum : b, surface of the marrow-cavity : $c$, cross-sections of the Haversian canals and their system of lamella; $d$, fundamental lamella; $e$, bone-corpuscles. (After Frey.)

geneous mass. The proportion of organic and inorganic substances varies according to the age and species of animal: in man, for example, there is $65 \%$ inorganic to $35 \%$ organic substance; in the turtle, $63 \%$ to $37 \%$. Of the inorganic constituents, the most important is calcic phosphate, $84 \%$; in smaller quantities, combinations of fluoric, chloric, carbonic acids and magnesia. Morphologically the matrix is composed of the bone lamella (Fig. $42)$, whose arrangement is determined by the surfaces present in and against the bone. In a hollow bone (like that of the upper arm or of the hand) there is one surface giren by the external border to which a fibrous skin, the bone-skin or periostcum, is closely applied; the presence of the marrowcavity necessitates a sccond surface. Finally, the solid mass of the bone is permeated by the Haversian canals, which run chiefly in a longitudinal direction, united into a network by cross or oblique canals, and serve for the course of blood-vessels. Since now the bone lamella arrange themselves parallel to the surfaces mentioned, two systems may be distinguished in cross-section, the fundamental lamellx and the Haicrsian lamella. The former are arranged parallel to the surface of the periosteum 
and of the marrow-cavity and form a mantle of concentric layers around the marrow-cavity. Into this groundwork enter the Haversian canals with their lamella, destroying and superseding the fundamental lamella coming in their way. The Haversian lamelle are concentrically arranged around the lumen of the Haversian canals just as are the fundamental lamellix around the marrowcavity.

Formation of Bone.-The stratification of bone is caused by its mode of origin. Where the bone borders upon the Haversian canals, the marrow-cavity, and the periosteum, there is transiently or permanently an epithelial-like layer of cells, " ostcoblasts," which secrete on their surface the bone-substance. Certain cells in the fundamental substance participate in this secretion, and here give rise to the bone-corpuscles, which are distinguished from the cartilage-cells by their numerous processes ramifying through the fundamental substance. The processes of a bone-corpuscle branch, and unite with the neighboring cells through fusion of the processes; their arrangement is most beautifully seen in dried bone, because here the cavities and the canals of the fundamental substance are filled with air. A special modification of bony tissue the substance of fish-scales, and of the teeth, called also ivory or substantia cburnca, should be mentioned.

Blood and Lymph, here treated in connection with the connective substances, are, in reality, not tissues at all, but nutritive fluids. Two kinds of nutritive fluids occur in the vertebrates, red blood and the colorless, weakly opalescent, or cloudy white lymph. In the blood of man and the vertebrates, we should distinguish particularly the fluid and the organized constituents. The blood-fluid or blood-plasma is, apart from inorganic constituents, specially rich in proteids; after the removal of the blood from the blood-vessels a part of these separate by coagulation and form the blood-clot, made up of fibrin, leaving a fluid poor in proteids, the blood-serum. The organized constituents, 
the blood-cells, are distinguished as red and white blood-

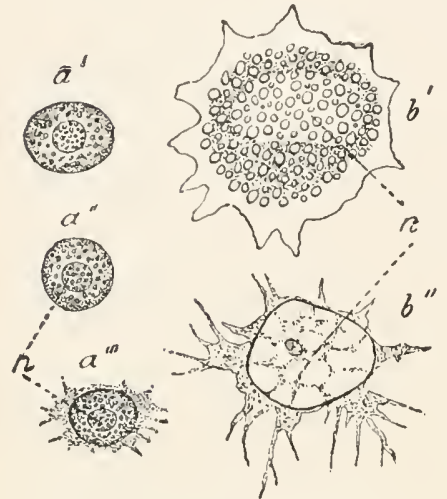

FIG. 43-White blood-corpuscles, $a$, of man; $b$, of the crab ( $n$, the nucleus).

corpuscles. The latter, the lcucocytcs, are present in smaller numbers and have great similarity to the amœbæ found in water; they are lumps of protoplasm, contain a nucleus, devour foreign bodies, as, for example, carmine granules injected into the blood, and move in the "amceboid" manner, i.e., by putting out pseuopodia (Fig. 43).

Red Blood-corpuscles.The red blood-corpuscles of vertebrates (Fig. 44), in the mature condition, are circular or oval disks, which by objective influences, e.g., by pressure, may momentarily be bent, incised, or otherwise

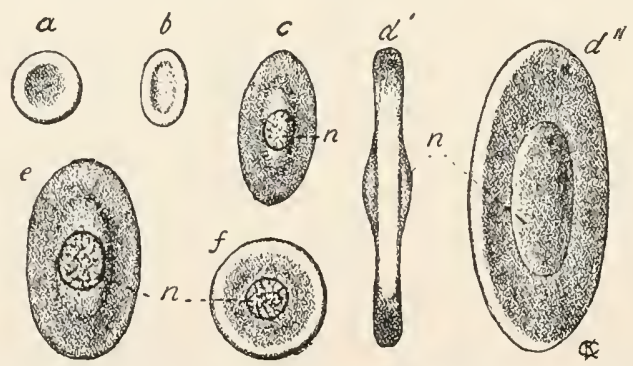

Fig. 44,-Red blood-corpuscles, $a$, of man: $b$, of the camel; $c$, of the adder; $d^{\prime}$, of Proteus (seen from the edge); $d^{\prime \prime}$. surface view; $e$, of a ray; $f$, of Petromyzon; $n$, nucleus (all the blood-corpuscles are magnified 700 times, except $l$, which is magnified 350 times).

modified in form, but cannot actively change their shape, because they no longer consist of protoplasm. Embryologically they arise from true, nucleated, protoplasmic cells; whether these cells are identical with the leucocytes is still undetermined; but later the protoplasmic cellbody changes completely into a plasmic product, the stroma of the blood-corpuscle. If in this metamorphosis the nucleus is retained, there is formed in the centre of 
the disk a slight swelling; if, however, the nucleus degenerates, the bilateral convexity is replaced by a shallow concavity. In the latter case, one has, in reality, no right longer to speak of blood-cells, since all the characteristic constituents of the cell, nucleus and protoplasm, have disappeared. Systematically the red blood-corpuscles are of interest, inasmuch as unnucleated forms are found only in the mammals (Fig. 44, $a, b$ ), nucleated ones in all the other vertebrates $(c, d)$. The mammals also have circular, the other vertebrates oval, disks. In this latter respect, however, exceptions occur, since among the mammals the Typloda (Camel, Llama) have oval, among the fishes the Cyclostomes have circular, blood-corpuscles.

Hæmoglobin.-The red blood-corpuscles are the cause of the color of the blood, as well as the supporters of one of its most important functions, the performance of the interchange of gases; both are connected with the fact that the stroma contains the coloring matter of the blood or hamoglobin. Hamoglobin belongs to the less crystallizable proteids and is remarkable for the presence of the extremely important, though small, quantity of iron, and also for its affinity for oxygen. Hxmoglobin containing oxygen, oxy-hamoglobin, causes the carmine-like color of the so-called arterial blood; oxygen-free, "reduced" hamoglobin causes the dark red, faintly bluish color of the renous blood.

Lymph is distinguished from blood by the entire lack of red blood-corpuscles and the slight coagulability of its plasma. Lymph is accordingly a proteid-containing fluid with white blood-cells, which on that account are called lymph-corpuscles.

In the majority of invertebrated animals there is present only one kind of nutritive fluid, and not even this in every class; the fluid is called blood, although it is usually colorless. Where color is present, it is generally, if not always, a yellowish red or an intense red; this may, even as in the vertebrates, be caused by hamoglobin (among the mollusks in Planorbis, Ara tetragona, A. Noa, 
Solen legumen, Tcllina planata, Pectunculus glycimeris, and others; among the annclids in the Capitcllide, Glycera, Polycirrus, Leprea, leches, and earthworms; among insects in Chironomus). Often other coloring matter occurs instead of hæmoglobin: in the cuttlefish, many snails, and in the lobster, the oxygen is taken up by the bluish hæmocyanin, which contains a trace of copper; in the Sipunculids by hæmoerythrin, etc. The blood-plasma as a rule is the seat of the color (Chironomus, Hirudinea, carthworms, and most of the other annclids); only exceptionally do colored bloodcorpuscles occur, as in the case of Area, Solcn, and the other mussels mentioned above, and also in the genus Phoronis. Colored elements containing hæmoglobin, identical with blood-corpuscles, are found besides in the colomic fluid of many annclids (Capitcllide, Glycora, Lcprea, Polycirrus), and in the ambulacral vessels of cchinoderms (Ophiactis vircns, certain holothurians). Most widely distributed in the invertebrated animals are the leucocytes, which are distinguished by their active amcboid movements; still even these may be absent, and then the blood is a fluid without any organized corpuscles.

Relations of Plasma to Corpuscies.-The blood has often been called a connective tissue having a fluid intercellular matrix. This conception is neither physiologically nor morphologically justifiable. For, if we leave out of consideration the utterly different function of the blood, it still cannot be shown that the blood-plasma is a product of the blood-cells, as the intercellular substance is a product of the cells of the connective tissue. The occurrence of blood without cells is rather a proof that the formation of blood-plasma takes place independently of the bloodcorpuscles.

\section{Muscular Tissue.}

Marked Characteristics of Muscular Tissue.-Most sharply characterized functionally is the muscle-tissue, inasmuch as it is the agent of active movements in the animal body. Since active mobility occurs in protoplasm, 
it is important to notice the differences between the two kinds of movement. The distinctions lie in the direction and in the intensity of the movement. A mass of protoplasm has the capacity to move hither and thither in all directions, because internally the most complete change of position of the smallest molecules with reference to each other is possible. All muscles and correspondingly also their separate clements, the muscle-fibres and muscle-fibrils, possess, on the contrary, the capacity of shortening only by a corresponding simultaneous increase in diameter (Fig.

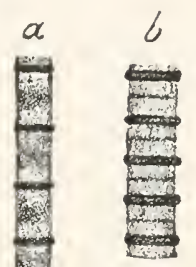
45); they can therefore accomplish motion only in a definite direction, viz., in the direction of the axis of the muscle. The muscle-substance consequently is more limited in its movement than is protoplasm, but on the other hand it has the advantages of greater energy and greater rapidity. An observer conversant with the nature of the different kinds of motion is able to decide with considerable accuracy, from the intensity and rapidity, whether in a given case a movement has been brought about by the agency of protoplasm, or by the contractile substance in the narrower sense (muscle-substance).

The Formation of Muscle-substance.-These physiological considerations demonstrate that protoplasm and the contractile substance are morphologically different things, and that therefore one must distinguish sharply between formative cells, or muscle-corpuscles, and the product of these cells, or contractile substance, just as in the case of connective tissue, between the connective-tissue corpuscles and the connective-tissue fibrils. This distinction actually occurs, but optically it is not equally demonstrable, for the reason that in histology it is not brought into prominence in the mass, as it should be. In animal histology there are recognized two kinds, it might even be said, two stages, in the formation of muscle-substance, the homogencous, or smooth, and the cross-striated. Since the former 
looks very similar to protoplasm without granules, the boundary-line between it and the muscle-corpuscle is more difficult to recognize than in the case of the cross-striated muscie-substance, which by its finer structure gives a quite different appearance from the protoplasm. In crossstriated muscles the contractile portion consists of two substances regularly alternating with one another in the direction of the contraction of the muscle, of which the one is doubly, the other singly, refractive (Figs. 23, 45, 48).

Smooth and Cross-striated Muscle-fibres.-The smooth muscle-substance betokens a lower stage of development than the cross-striated, since it chiefly occurs in the less highly organized and more inactive animal forms. Interesting in this respect is the fact that in the two stages of development of one and the same animal, the simply formed and inert polyp has smooth muscles, while the more highly organized and actively motile medusa has cross-striated muscles. The difference in their action has led in the vertebrates to the peculiar distribution of the muscle-substance, the smooth musculature being chiefly distributed to the internal organs, which are not under the influence of the will, while the musculature of the body, subject to the will and hence demanding more rapid action, is cross-striated. We must, however, guard against concluding that the difference between smooth and crossstriated musculature coincides with the distinction between intestinal and body musculature. To prevent at the outset this erroneous view, it should here be noticed that the body musculature of all molluscs is smooth, the intestinal musculature of many insects and crabs, as well as the body musculature, is cross-striated.

\section{Epithelial and Connective-substance Muscle-cells.} -The epithelium and the connective substance, the first and second of the divisions of tissues, are two fundamentally different forms of tissue. This distinction is of importance in speaking of the musculature; for it is shown that epithelial cells as well as connective-tissue cells have the power of forming contractile substance, and that geneti- 
cally, therefore, there are two kinds of muscle, the cpithclial musile-cell and the connectio'-substanee muscle-cell, for the latter of which we have used for a long time the term "contractile fibre-cell." Both kinds of muscle-cells can form a priori smooth as well as cross-striated muscle-substance; but, generally speaking, the (smooth) musculature of the internal organs arises from the connective tissue-cells, while the epithelial ceils form the (striated) body musculature.

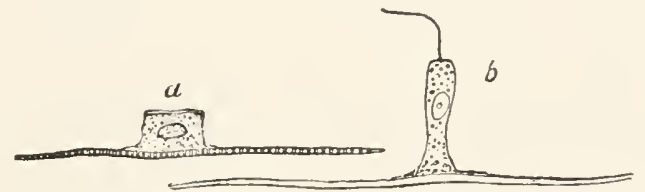

Fı. 46.-Epithelial muscle-cells. $a$, of a medusa ; $b$, of an Actinian.

Epithclial muscle-cclls are cells of which one end cxtends to the surface of the body or the surface of an internal cavity (body-cavity, lumen of the gut, etc.), and may here have a cuticle, cilia, and flagella, while at the opposite end it has secreted contractile substance in the form of muscle-fibrils (Fig. 46). They combine the double function of epithelial and muscle cells.

Contractile fibre-cells, on the other hand, are connectivetissue cells, which usually have surrounded themselves on all sides with a mantle of contractile substance; corresponding to their origin, they have the form of connective-tissue cells, and are spindle-formed or branched; in the latter case the branches are functional to the very ends (Fig. 47). The similarity of form renders difficult the distinction between ordinary connective-tissue cells and fibre-cells; if the contractile layer on the surface is slightly developed, the distinction is impossible. To recognize the character of the elements, therefore, we must choose well-defined examples, in which the uninucleated or the multinucleated mass, the "axial substance," is sharply marked off from the muscle-mass, the "enveloping layer" (Fig. 47, $c, d, c$ ).

In vertebrates and arthropods the contractile fibre-cells 
occur in the vegetal organs as elements of the "organic musculature" ; on the other hand we find here the epithelial musculature in the cross-striated primitive bundles, separated from the epithelium, and only developmentally

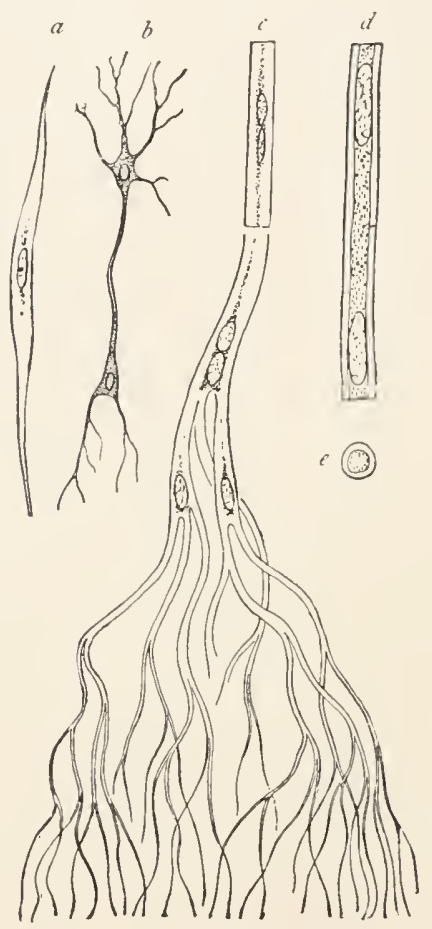

FIG. 47.

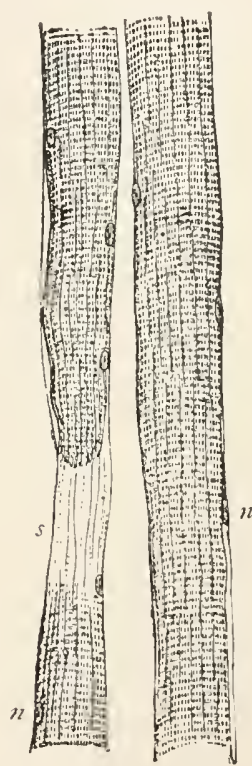

FIG. 48 .

FIG. 47.-Contractile fibre-cells. $a$, of man; $b$-e, of Beroë (a Ctınophore); $b$, young fibres ; $c$, branched ends; $d$, middle portion of a fibre; $e$, cross-section.

FIG. 48.-Cross-striated primary bundle. $n$, nuclei; $s$, a point where the sarcolemma is plainly shown on account of the tearing of the fibres. (After Gegenbaur.)

still referable to the epithelium of the body-cavity (Fig. 48). A primary bundle is a cylindrical mass, bounded externally by a structureless skin, the sarcolemma. Its contents consist of fine fibrils, which, closely parallel to one another and strongly compressed, run from one end of the mass to the other. Each fibrii is formed of singly and cioubly refractive parts, which alternate with one another in more or less complicated arrangement. Since now the doubly-refracting parts of the fibrils within a bundle lie at 
about the same height, there is caused a cross-striation extending through the whole bundle. Finally, sprinkled here and there between the muscle-fibrils are the muscle-corpuscles, spindle-shaped protoplasmic bodies with a nucleus, the remnants of the cells, which have formed the musculature.

\section{Nervous Tissue.}

Function of Nervous Tissue.-As the muscular tissue brings about motion, so the nervous tissue serves for the transmission of stimuli. It communicates the stimulations of the sense-organs at the periphery to the central nervous system, the seat of consciousness, and here brings about perception; further, it transmits the voluntary impulses to the periphery, particularly to the musculature. By the nervous system, finally, the stimuli arising in various places are coordinated, thus furnishing the elements for that which we call independent psychic activity.

Elements of the Nervous Substance.-Here also the recipient of the stimulus must be a specific substance, the nervous substance, different from protoplasm, a nervefibril analogous to the muscle-fibril. But the difference between substance and protoplasm is in practice difficult to determine, so that we will start from the scientifically justifiable distinction of nerve-substance and nerve-corpuscles. The elements of nervous tissue are ganglion-cells and neriefibres.

The ganglion-calls range from very small corpuscles up to very considerable spheres, which in animals are surpassed in size only by the eggs, and correspondingly also they have a large nucleus reminding one of the germinal vesicle. Multipolar and bipolar ganglion-cells are chiefly distinguished in the acrtcbrates (Fig. 49). The bipolar cells are so called from the two projections which become nerve-fibres, and consequently are cell-bodies interpolated in the course of a nerve-fibre. In the case of the multipolar ganglion-cells two kinds of processes are found: the dendritic or protoplasmic processes, 
and the nerve or axis-cylinder processes. The dendritic are

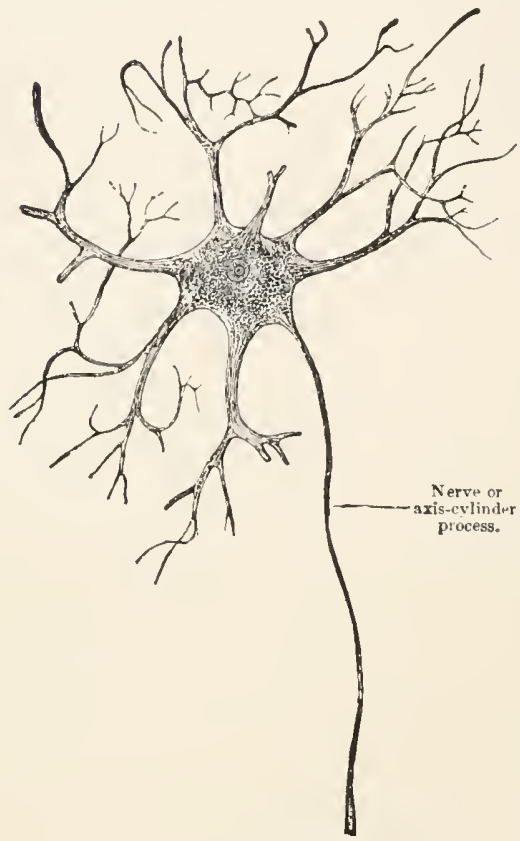

much branched, forming thereby very fine fibres, whose nervous nature was earlier generally assumed, but of late has been doubted from many sides. The nerve-processes, of which usually only one occurs in a ganglion-cell (Fig. 49), remain for a long time unbranched; they pass then either unbranched into peripheral nerve-fibres, or finally branch into fine nervefibrils.

For a long time apolar and unipolar ganglioncells, with no or only one process. were described Fic. 49.-Human multipolar ganglion-cell. solely in the invertebrated

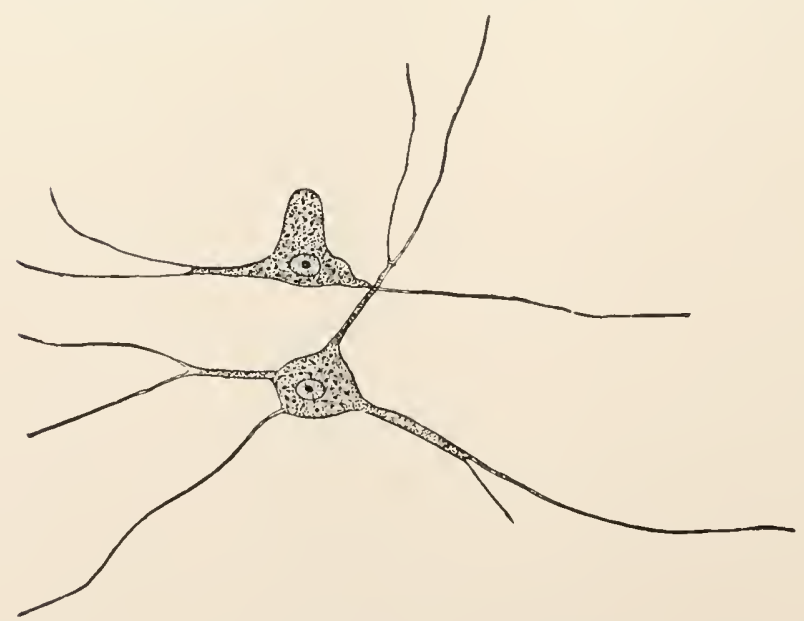

Fig. 50.-Ganglion-cells of an Actinian.

animals; both sorts are physiologically unintelligible. For 
the mode of action of a ganglion-cell is inderstood only when, on the one hand, one or numerous paths of stimulation converge to it, while, on the other, a process serves for further transmission of the stimuli onward. Probably in the case of the "apolar ganglion-cells" all, in case of the unipolar most, of the processes were destroyed by unsuitable methods of preparation. Recent investigations have justified this suspicion, since multipolar and bipolar ganglion-cells have been demonstrated by isolation in case of the exlenterates (Fig. 50) and by methods of staining in crustaceans and acorms.

The Neriefibres likewise are best known in the vertebrates (Figs. 5 I-53). The fundamental elements of these are very fine fibres, the nerve-fibrils, distinguished from muscle-fibrils by an absence of cross-striations, from connective-tissue fibrils by their great liability to injury. Even in good preparations they show a tendency to form minute swellings, the varicosities. Many parallel-running nerve-fibrils constitute a nerve-fibre, which are called gray nerve-fibres, in distinction from a second sort, the white or medullated. In the medullated nerve-fibre, the fibre itself, the axis-cylinder, is surrounded by a layer of nerve-marrow or myelin, a fatlike substance which blackens strongly in osmic acid, is very refractive, and easily decomposed into variously shaped drops, the myelin drops. The medullary sheath seems to act like an insulator.

Finally, unmedullated and medullated nerve-fibres may be surrounded by Schwann's sheath. This is found in all the nerve-fibres which run outside of the brain and spinal cord, and is just as constantly absent in the nerve-fibres within the central organs. Schwann's sheath is a delicate, structureless covering in which here and there nuclei are embedded. At greater intervals are found indentations, which extend through the medulla, quite to the axial fibres (the nodes of Ranvier).

In the invertebrates we meet simpler conditions. Here are commonly seen only nerve-fibrils, which in greater or less number combine directly for the formation of nerves. 
Here also occur more rarely bundles of fibrils or nerve-

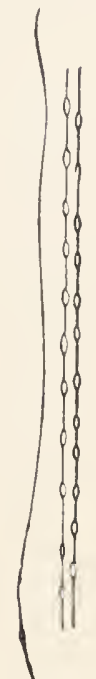

FIG. I,

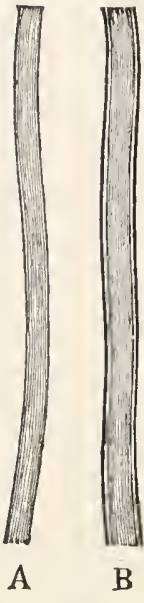

FIG. 52.

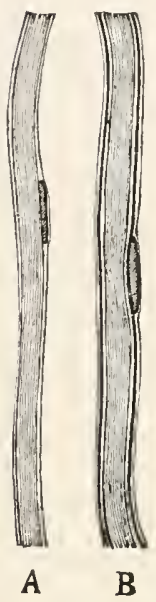

FiG. 53 .

FIG. 5I.- Nerve-fibrils. (From Hatschek.)

Frgs. 52 and 53.- Single-contoured $(A)$ and doubled-contoured $(B)$ nerve-fibres; left without, and the right with, nuclei and Schwann's sheath. (From Hatschek.)

fibres; nerve-fibres surrounded by a thin medullary layer have been demonstrated in the annelids and arthropods.

\section{SUMMARY.}

Cells.-I. The most important morphological element of all tissues is the cell.

2. The cell is a lump of protoplasm which is either nonnucleated (Cytode) or contains one or several nuclei (uninucleated, multinucleated cells).

3. The nucleus probably determines the specific character of the cell, since it influences its functions; accordingly it is also the bearer of heredity.

4. Cells and nuclei increase exclusively by division or budding.

Tissues. - 5. Tissues are complexes of numerous histologically similarly differentiated cells.

6. Histological differentiation rests in part upon the 
fact that the cells take on a definite form and arrangement, in part upon the formation of plasmic products, which determine the character of the tissue (muscle-fibres, connective-tissue fibrils).

7. According to function and structure are distinguished (I) epithelia, (2) connective tissue, (3) muscular-tissuc, (4) nervous-tissue.

Classification of Tissues. - $\$$. The physiological character of cpithclia is given in the fact that they cover the surfaces of the body, their morphological character in that they consist of closely compressed cells united only by a cementing substance.

9. According to their further functional character epithelia are divided into glandular epithelia (unicellular and multicellular glands), sensory, germinal, and pavement epithelia.

IO. According to the structure are distinguished onelayered (cubical, cylindrical, pavement epithelia) and many-layered epithelia, ciliated and flagellated epithelia, epithelia with or without cuticle.

I I. The physiological character of the conncctict tissues rests upon the fact that they fill up spaces between other tissues in the interior of the body.

12. The morphological character depends upon the presence of the intercellular substance.

I3. According to the quantity and the structure of the intercellular substance the connective substances are divided into (1) cellular (with little intercellular substance); (2) homogeneous; (3) fibrillar connective tissue; (4) cartilage; (5) bone.

I4. The physiological character of muscular tissue is contained in the increased capacity for contraction.

I5. The morphological character is found in the fact that the cells have secreted muscle-substance.

I6. According to the nature of the muscle-substance are distinguished smooth and cross-striated muscle-fibres.

I7. According to the character and derivation of the cells (muscle-corpuscles) the musculature is divided into 
epithelial (epithelial muscle-cells, primary bundles) and connective-tissue muscle-cells (contractile fibre-cells).

is. The physiological character of nervous tissue rests upon the transmission of sensory stimuli and voluntary impulses, and upon the co-ordination of these into unified psychic activity.

19. The conduction takes place by means of nervefibres (nonmedullated and medullated fibrils and bundles of fibrils); the co-ordination of stimuli by means of ganglioncells (bipolar, multipolar ganglion-cells).

20. Blood and lymph are proteid-containing fluids: rarely without cells, they may contain only colorless amceboid cells (white blood-corpuscles, leucocytes), or in addition to these also red blood-corpuscles.

21. Red blood-corpuscles occur, in the main, only in vertebrates and cause the redness of the blood; they are absent in most invertebrated animals.

22. If invertebrated animals have colored blood (red, yellow), the cause for this is usually to be found in the blood-plasma.

23. The red blood-corpuscles are nonnucleated in mammals, nucleated in all the other vertebrates.

\section{IiI. The Combination of Tissues into Organs.}

An Organ Defined.-From the tissues organs are built up. An organ may be callad a complix of tissues which is marked off from the other tissucs and has taken on a definite form for carrying on a special function. Thus a single muscle is an organ which consists of a certain amount of muscular tissue; with scalpel and scissors it can be removed from its environment and still accomplish a definite movement.

Principal and Accessory Tissues.-In each organ there is a tissue which renders possible the function of the organ, and therefore chiefly determines its physiological character. This may be called the principal tissue, for there may be other tissues present, the accessory tissues, 
which have the purpose merely of supporting or rendering possible the function of the principal tissue. In the muscle of the vertebrates we find, besides the muscle-fibres, connective substance which, like a kind of cement, unites the bundles of muscle; also blood-vessels which serve for nourishment; finally, nerves by which the muscles are aroused to action. In the human liver also, besides the functionally most important part, the livercells, there are present blood-vessels, nervous and connective tissues. These kinds of accessory tissues are usually found only in the highly developed organs; in the case of the lower animals they may be absent; thus the digestive tract of Coelenterates has only an epithelial lining; their nervous system consists merely of a cord of nerve-fibres and ganglion-cells.

Effect of Use and Disuse.-It is of the greatest importance for the permanency of an organ that it be constantly in function. Living substance is distinguished from the non-living by the fact that, if it is destroyed by use, it is immediately replaced by a quantity more than sufficient to make good the loss. Functioning tissues and organs increase in volume; on the other hand, parts becoming functionless undergo a gradual decrease, which finally leads to their disappearance.

Change of Function of Organs.-The two factors mentioned, that the permanence of the tissues depends upon continued use, and that usually several tissues enter into the structure of an organ, are important for the understanding of the principle of change of function which plays a prominent rôle in the metamorphosis of animal form. It may happen that an organ is brought under changed conditions, and no longer has an opportunity to function as before. In that case, the functioning tissue from lack of use gradually degenerates, but yet it may exist longer by means of its accessory tissues; if the new conditions make it possible for one of the accessory tissues to attain to functional activity, the organ may assume a new physiological character. 
Examples of Change of Function.-A muscle, for example, may become functionless from many different causes. Should the muscle-tissue disappear there is still left the sum of the accessory tissues, particularly, connective tissue permeated by blood-vessels; this may remain intact and form a protecting band, a tendon, or fascia. WVe have then, morphologically, the same organ, only that its physiological character has changed; the muscle has undergone a change of function, and has become a ligamentous cord. The visceral arches of fishes are another example; these in their primary significance are supports for the gills; if now by the acquirement of terrestrial habits the gills are lost, the visceral arches become functionless and correspondingly undergo a partial degeneration; but a portion maintains itself by assuming a new function, and forms the jaws, the hyoid bone, and the small bones of the ear, which in spite of their quite different functions are morphologically the same structures as the gill-arches.

Homology and Analogy.-In the History of Zoology (page 16) it was shown that Comparative Anatomy has caused a discrimination between homology or morphological equivalence, and analogy or physiological equivalence, i.e., between organs which appear in the same relative positions and the same mode of connection, and organs which have the same function. What we have here learned to recognize in the structure of organs makes it evident that morphological and physiological characters do not necessarily coincide, that morphologically similar organs may have different functions, morphologically different organs the same functions.

Systems of Organs.-Organs wholly identical, or, at least, functioning in an equivalent manner, may occur in considerable numbers in the same body. A man has many muscles, and many organs which carry on digestion. Hence we may group all organs which in the body have equivalent or similar functions into an ideal higher unit, and speak of systems of organs. In all we recognize nine such systems: (1) skeletal, (2) digestive, (3) respiratory, 
(4) circulatory, (5) excretory, (6) genital, (7) muscular, (8) nervous, and $(9)$ the system of sense-organs. The skeleton may be absent in many animals, and the other systems specialized in man may be simplified, so that, according to the fundamental vital functions, the following groups of organs can be arranged: I. Organs of assimilation (2-5); II. Organs of reproduction (6); III. Organs of motion ( 7$)$; IV. Organs of perception (8 and 9).

Vegetal and Animal Organs.-The organs of assimilation and of reproduction ( $I$ and II) are grouped together as iegctal, the others (III and IV) as animal organs. The older zoologists used to say that assimilation and reproduction are functions which are common to animals and plants; that, on the contrary, sensation and motion are lacking in plants, and are exclusively characteristic of animals. The atom of truth in the fundamental idea needs reconsideration in the light of our present knowledge. We have seen that the protoplasm found in plants and animals has not only the power of assimilation and reproduction, but also power of motion and of irritability. The latter characteristics consequently cannot be entirely lacking in all the plants, for they are found in the most important. In fact many plants, as the mimosas, the compassplants, show great irritability; many low plants, the reproductive states of algæ, move quite as actively as, or even more actively than, many of the lower animals. On the other hand, there are many animals which in the mature condition are fixed in position like plants. Many protosoa and worms, most of the soophytes, some chinoderms like the sea-lilics, even many crabs, the cirripcdes (barnacles), can change their location only during the earlier stages of development. in later life being limited to movements of single parts of the body, the arms, tentacles, etc. In the sponges even these single motions are so insignificant that they cannot be seen at all by the naked eye, and scarcely even with the aid of the microscope.

Nevertheless the two terms, animal and iegctal, must be retained. For although motion and sensation 
occur in the vegetable kingdom, still they reach no high development; indeed we may say they become more and more inconspicuous the higher the plants develop; in the animal kingdom, on the contrary, they are unfolded in extraordinary completeness, and lie at the basis of its most characteristic features.

\section{Vegetal Organs.}

\section{A. Organs of Assimilation.}

Assimilation Defined.-If the term assimilation is used in its widest sense, one must speak in this connection of all the contrivances which are found in the animal body for rendering growth possible during the period of progressive development, and also during mature life for compensating for the loss of energy connected with each period of functional activity, in order to preserve to the body its functional capability. In each period of functional activity organic compounds are oxidized, or, to speak figuratively, burnt. Compounds which are especially rich in carbon and relatively poor in oxygen, containing especially hydrogen (usually also nitrogen and sulphur), in the presence of oxygen are changed by oxidation into carbonic acid, water, and various nitrogenous products, like urea, uric acid, etc. A compensation takes place, for not only is the useless substance removed, but also compounds of oxygen and materials rich in carbon are furnished to the tissues to replace the material oxidized.

Assimilation in Animals.-In lowly-organized animals all the processes connected with compensative assimilative changes take place through the agency of one and the same organ, the digestive tract; but in the higher animals, through specialization, normal assimilation has come to exhibit a definite series of separate phenomena. Between the lower and the higher animals there are easily comprehended, intermediate conditions where specialization has halted at an earlier or a later stage.

Different Organs of Assimilation.--Every assimila- 
tion begins with the presence of suitable food; the solid and liquid constituent parts of the body must digest and incorporate this, i.e., it must be altered into a condition in which it can be absorbed and distributed to the tissues. All this takes place through the agency of the digestive tract, which is provided with accessory organs, the digestive glands; the digestive tract likewise removes all the mass remaining undigested (the faces). Oxygen, gaseous fook, so to speak, is taken up, however, by particular parts of the body, the respiratory organs, gills or lungs. The oxygen and the digested (consequently liquefied) organic and inorganic compounds must now be further distributed in the body and be apportioned to the functioning organs and tissues according to their needs. Therefore there are, in addition, blood-vessels, or circulatory organs, which permeate the body in all directions. But the tissues need not only a means of obtaining but also of getting rid of certain compounds. The accumulation of the oxidation products arising from functional activity is injurious, even to some extent poisonous, to the organism; consequently they must be removed, and in a dissolved state they are taken up by the blood-vascular apparatus, and are brought to definite places for expulsion or excretion. Fluid wastes are expelled by the kidneys of artebrates, the Malpighian ressels of insccts, the water-vascular system of worms; these, together with their accessory apparatus, are embraced under the name " excretory organs." Excreta are to be carefully distinguished from faces; excreta are substances which have been a part of the tissues of the body itself, and, through oxidation, have become useless; while those substances which constitute the fxces were useless from the beginning, and have absolutely never belonged to the body, but have remained separated from the tissues by the boundary of tine epithelium of the digestive tract. The gaseous oxidation product of the animal body, carbonic acid, is removed by the blood-vascular apparatus through the agency of the respiratory organs. Since in the respiratory organs there takes place an exchange of the 
useless carbonic acid for the oxygen necessary to life, these organs have a double function, being, at the same time, excretory organs and organs for taking up food.

After this general survey, we must enter somewhat more minutely into a discussion of the various systems of organs

\section{The Digestive Tract.*}

Archenteron or Primitive Digestive Tract.-Since the taking in of food and its assimilation are functions most

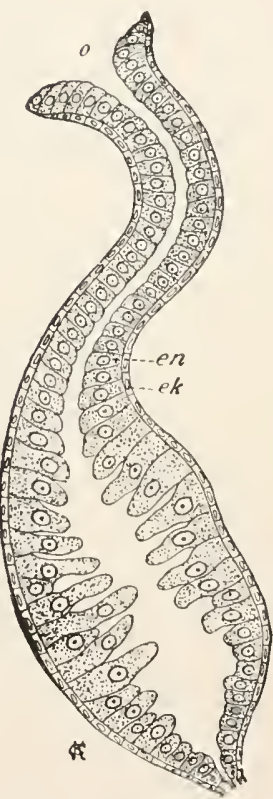

FiG. 54.

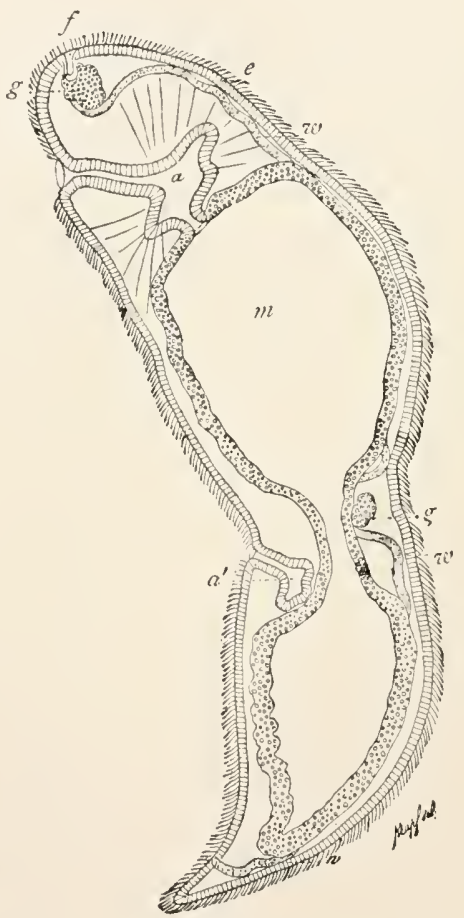

FIG. 55 .

FIG. 54,-Longitudinal section through the nutritive polyp of a S:phonophore. (After Haeckel.) $O$, mouth-opening; en, entoderm; $e k$, ectoderm.

FIG. 55.-Stenostoma leucops, in division. $a$, ectodermal fore-gut, at $\boldsymbol{a}^{\prime}$ forming anew for the hinder animal; $m$, the blindly ending entodermal mid-gut ; $e$, ectodermal coliated epithelium; $g$, ganglion with ciliated pit; $w$, water-vascular canal; $g^{\prime}$, gauglion of the hinder animal.

* As a substitute for the somewhat cumbrous terms "digestive tract," "alimentary canal," etc., the term gut is coming into use among biologists to designate the canal as a whole. 
important for the well-being of the animal, it is to be expected that of all the organs in the animal series the digestive tract should be formed first, and also in almost every case should be earliest established in the embryo. The fact that many worms (Cestodes) and crabs (Rhizoccphala) have no digestive tract does not alter this statement; for with respect to these it can be definitely affirmed that, in conformity to special conditions of life, particularly as a result of parasitism (compare page 203), the digestive tract has degenerated. Very commonly the lowest-organized, multicellular, free-living animals are merely simple or branched digestive pouches which have only a single opening, functioning both as mouth and anus (Fig. 54). Such an animal has necessarily two epithelial layers, one of which lines the digestive tract, the other covers the surface of the body. These two fundamental cell-layers, which are found in all cases except in degenerated animals, are called entoderm and ectoderm. The primitive digestive cavity lined by entoderm is called the archenteron. In the case of meduse and polyps it forms the entire digestive tract.

Stomodœum and Proctodœum.-In case of most animals the digestive tract undergoes an enlargement, arcas of the surface of the body, the ectoderm, becoming invaginated. Even in many colcnterates and lower worms there arises an invagination at the anterior end of the cylindrical digestive tract, forming the ectodermal foregut or stomodaum (Fig. 55). From the higher worms onwards, it is accompanied by a second invagination at the hinder end, the ectodermal end-gut, or proctodoum (Fig. 56): embryologically, this is formed as a blind sac whose, closed end is bounded by the likewise closed posterior part of the archenteron, now called also mesenteron or mid-gut, until the separating wall disappears, whereupon mid-and end-gut communicate with each other, and the digestive tract becomes a canal extenaing through the entire body. 


\section{Various Divisions and Appendages of the Digestive} Tract.-The part which the archenteron takes in comparison with the ectodermal proctodœum and stomodœum in making up the completed digestive tract is very differ-

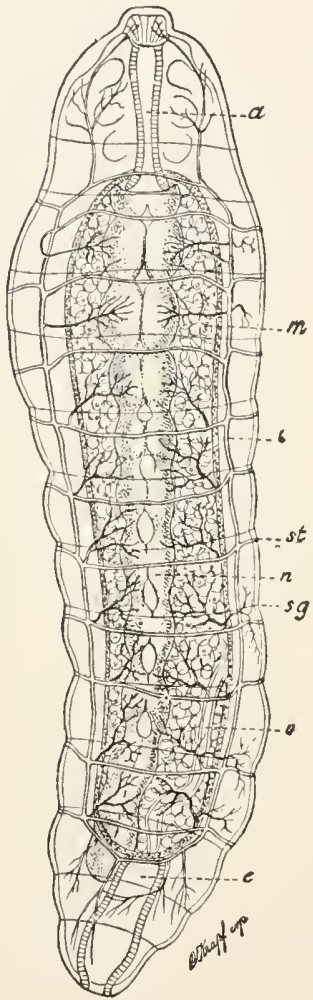

FIG. 56.

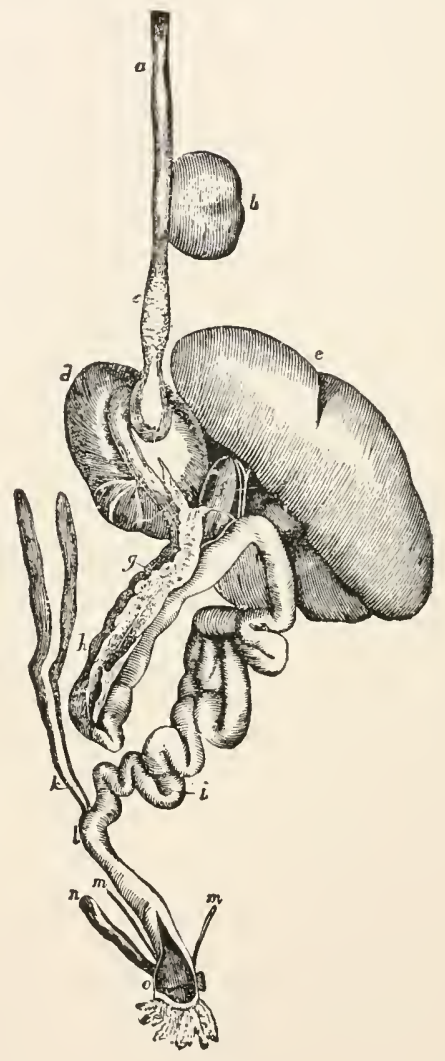

F1G. 57.

FIG, 56 - Dee-larva just after hatching: seen from the ventral surface. The digestive tract consists of three portions: $a$, fore-gut ; $m$, mid-gut $; e$. hind-gut (not yet connected with the mid-gut); sg, limits of segments; $s t$, stigma; $t$, trachea; $n$, ventral nerve-cord. (After Bütschli).

FiG. 57.-Digestive tract of the domestic fowl. $a$, osophagus; $b$, crop; $c$, glandular stomach ; $d$, gizzard; $e$, liver ; $f$, gall-bladder ; $g$, pancreas; $h$, $i$, small intestine; $k$, coeca ; $l$, large intestine; $m$, ureters ; $n$, oviduct ; 0 , cloaca.

ent in the various animal groups. On one side the inscts, on the other side the acrtebratcs, offer the strongest contrast; the insccts have a very short mid-gut and consequently a long extent of fore- and hind-gut formed from 
the ectoderm; in a'crtcbates, on the contrary, the ectodermal gut areas are extremely short.

The width of the lumen varies in the course of the alimentary canal and renders possible the distinction of different divisions, which in the animal series have been provided, so far as possible, with uniform names. Fig. 57, drawn from a domestic fowl, may serve for explanation of the usual terms. The mouth-opening leads into a wider cavity, which is usually divided into an anterior division, the buccal carity', and a posterior one, the phary'n. The narrow tube leading from this is the asophagus $(a)$; here and there it may widen, or bear a pouchlike evagination, the crop or ingluaics (b), for the temporary reception of food. From the cesophagus, the food passes into a considerable enlargement, the stomach. Birds, like many other animals, have a double stomach, a thin-walled portion rich in glands, and a second part, the walls of which are remarkable for the thick masses of muscle; the former is the glandular. stomach (c), the latter is the grinding stomach or gizward (d), serving for comminution of the food. Behind the stomach the digestive tube narrows into the small intestinc $(h)$, the hinder widened part of which is the large intestine (l), terminating in the anus. The limit of the small and large intestine is usually marked by blind pouches, the caca $(k)$. Connected with the anal gut also, are the outlets of the kidneys $(m)$ and of the sexual apparatus $(n)$; hence the terminal portion, serving as the outlet for the urine and faces, and also for the sexual products, is called the cloaca (o).

In animals which require a more abundant food, the area of the alimentary tract is not sufficient to furnish the digestive fluids, so that evaginations of the gnt-wall (glands) must serve to increase this. Into the mouth empty the salivary glands; into the first part of the small intestine, close behind the stomach, the liarer (c) and the pancras $(g)$ (or a simpler glandular apparatus, whose secretion combines the characters of gall and of pancreatic juice, the hepato-pancreas). Finally, in the end-gut there 
sometimes occur glands which form a fetid secretion-the and glands. The length of the digestive tract is chiefly influenced by the kind of food. In many groups of animals there is found a difference between herbivores and carnivores, the former having a very long and consequently tortuous digestive tract. That of a carnivore is somewhat less than four or five times the length of the body, while in an herbivorous ungulate, on the other hand, it is twenty to twenty-eight times. Similar, though not so great, are the differences between carnivorous and plant-eating beetles.

\section{Respiratory Organs.}

Sources of the Oxygen used in Breathing. - The oxygen which each animal must obtain in exchange for the carbonic acid formed in the tissues is derived either from the air or from the water, according as the animal is a landor a water-dweller. Less frequently it is the case that water-dwellers breathe air, and hence are compelled, from time to time, to rise to the surface of the water for a supply of air; this is true for the great marine mammals, and for many insects, spiders, and snails which are found in fresh water. Air- and water-breathing takes place exclusively through the skin, so long as this is soft and readily permeable, and so long as no higher development of organization necessitates a more active interchange of material. If, on the other hand, the demand for oxygen is greater, other more special breathing-organs are found-gills for water-breathing, lungs and trachea for air-breathing, in addition to which the skin functions as an accessory organ of more or less importance.

Gills. - The gills are usually thin-walled areas of the skin which are particularly well supplied with blood-vessels, and where richly branched tuftlike projections or broad leaves have grown out, thus furnishing the largest possible surface for the interchange of gases; these lie in such a position as to be most exposed to fresh water; in the 
crab, for example, they are on the legs, where the motion drives fresh water constantly through them (Fig. 58); in the swimming worms, on the back; in the tube-dwelling worms, at the anterior end, projecting out of the tube; in most amphibians, on each side of the head. More rarely the digestive tract functions for water-breathing; in the fishes, Entcropncusta, and tunicatcs gills have been formed in con-

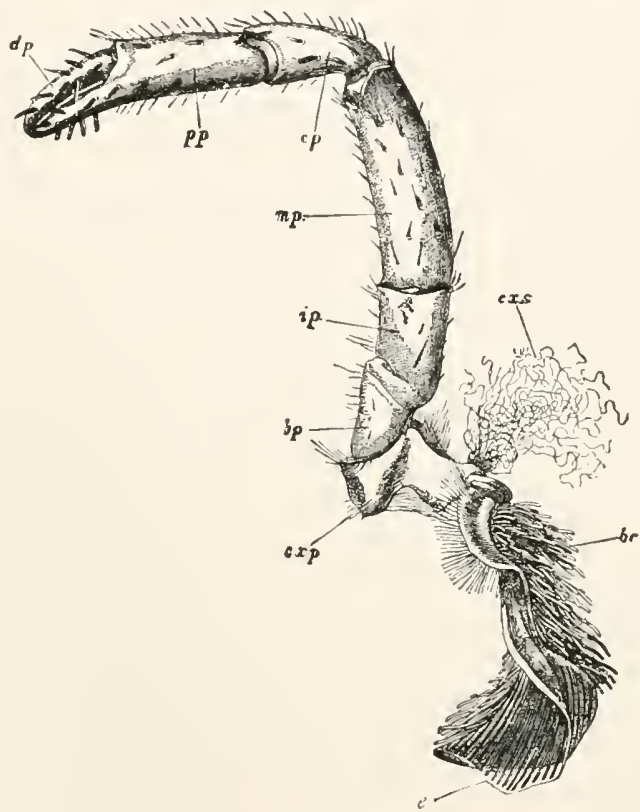

Fig. 58 - Left second foot of a crayfish with attached gill (br). (After Huxley.) crm, coxopodite; $b p$, basipodite : $i p$, ischiopodite: $m p$, meropodite; $c p$, carpopodite ; $p p$, propodite; $d p$, dactylopodite; $c x s$, bristles of the coxopodite; $e$, lamina of the gill.

nection with the fore gut, its lateral walls being pierced by the gill-slits, which open to the exterior on the surface of the body. Through the gill-slits, the water containing oxygen in suspension passes out and bathes the gill-filaments, here richly provided with blood-vessels. The hindgut also in many fishes, insccts, and worms may become an accessory organ connected with breathing, from time to time being filled with fresh water. 
Development of the Respiratory Apparatus.--In the air-breathing animals the breathing apparatus must be derived either from the digestive canal, or from the skin. With the vertebrates the former is the case, since the lungs containing air here stand, directly or by the mediation of the trachea and bronchi, in connection with the lumen of

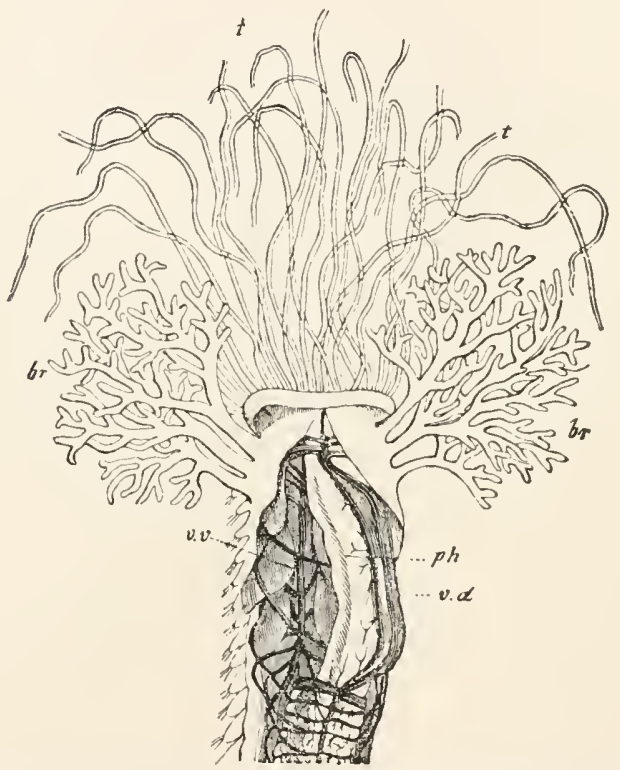

FIG. 59--Anterior end of Terebella nebulosa. (After Milne Edwards.) ph, pharynx; $v d$, dorsal, $v v$, ventral, blood-vessel ; $b r$, gills; $t$, tentacles.

the digestive tract. On the contrary, in the case of invertebrated animals (snails and spiders) when the term "lung", is used, it refers always to an invagination or sac of the skin; of such a nature are the trachere of insects, tubes containing air, beginning at the surface of the body with a hole or stigma, and branching internally (Fig. 56, st).

Distinctions between the Respiratory Systems of the Vertebrates and Invertebrates.-In general, then, a distinction can be drawn between the respiratory systems of ertebrated and invertebrated animals: in the former, the digestive tract, or derivatives from it, function for air- and 
for water-breathing; in the latter, on the contrary, it is the skin. On the side of the vertebrates the only exceptions are most amplibians and a few fishes (Protopterus), in which the gills are tuftlike projections of the skin (Figs. 4 and 5, p. 42-43); while among the invertebrates, the tunicatcs and Entcropncusta, where the digestive tract forms the gills, take a special position.

\section{Circulatory Apparatus.}

In order that the oxygen, taken up by the respiratory organs, and the constituents of the food digested in the alimentary canal may reach their goal, the tissues, there is need of no special organs, so long as the body consists of only two thin epithelial layers, the ectoderm and entoderm. When, however, a third, a mesodermal, layer is interpo-

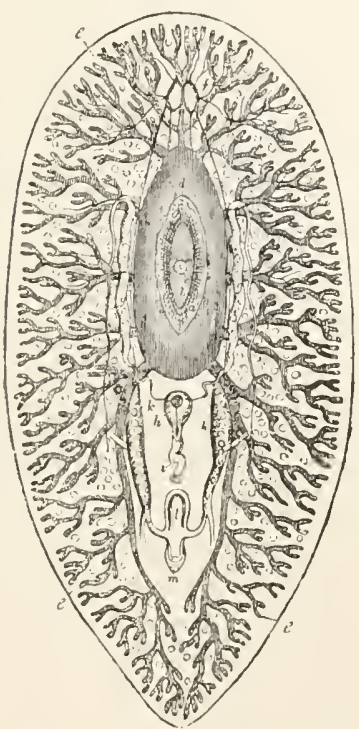

FıG. 60 . lated between these, and the body consequently becomes more bulky, there is found usually some apparatus for distributing the food.

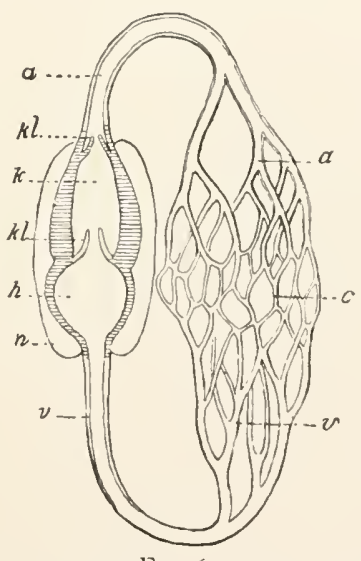

Fig. 6 t.

Fig. 6o.-Leptoplana tremellaris. $a$, mouth : $b$, buccal cavity; $c$, opening of the head of the pharynx into the buccal cavity; $d$, central stomach; $e$, branched entodermal gut ; $f$. ganglion; $g$, testicle; $h$, seminal vesicle ; $k$, uterus ; $l$, receptaculum seminis $; m$, female sexual opening

FIG. 6 I. - Schema of circulation of the blood. $a$, arteries ; $c$, capillaries ; $h$, auricle ; $k$, ventricle; $k l$, valves; $p$, pericardium ; ${ }^{\prime \prime}$, veins.

The simplest way is when the digestive tract departs from the character of a straight tube by branching, and by 
means of these branches extends into the various parts of the body. We speak then of a gastro-s'ascular sy'stcm, because the alimentary canal itself takes on the function and the branching arrangement generally characteristic of the vessels or "vascula" (Fig. 60).

Cœlom. - The distribution of food may also be effected by the body-cazity or colom, an extensive cavity which, enclosing within itself most of the vegetal organs, is lined by a special membrane, the peritoncum, or at least by a true epithelium, and is bounded by the wall of the digestive tract and of the body. The body-cavity is probably only an extension of the gastro-vascular system, for numerous embryological researches upon many cœelomatous animals have shown that the colom arises by evagination frcm the digestive tract, and hence is only a part cut off from this, an alimentary diverticulum, which has become independent.

Heart, Arteries, Veins, Capillaries. - Finally, the most complete method of food distribution is accomplished by the blood-iesscls, which, therefore, belong generally to the groups of higher animals, and function in addition, whether a body-cavity is present or not. Blood-vessels are tubes with fluid contents, for transporting the oxygen assimilated by the respiratory organs, as well as the food absorbed from the digestive tract, and later giving these up again to the tissues. Since such an interchange of substances presupposes that the blood circulates in the vessels, definite parts in the course of the blood-vessels are contractile; they are covered by muscles which by their contraction narrow the tube and push the fluid forwards. In the lower forms wide areas in the course of the bloodvessels are contractile; in higher animals a greater regularity of circulation is reached; a definite specialized muscular part of the course, the heart, alone moves the mass of the blood.

The Higher Development of the Heart.-A free motion of the heart is only possible when it is separated from the contiguous tissues and enclosed in a special 
cavity (Fig. 6I). Hence we see that the heart always lies, either free in the body-cavity, or enclosed in a special pouch $(p)$, the pricardium (in all cases a portion of the general body-cavity which has become independent). The division of the heart, into a part which receives the blood, the auricle $(h)$, and a part which drives the blood onward, the acntriclc $(k)$, is of less functional importance; hence this division is not carried out in all cases. There are also special mechanisms within the heart, the valves $(\mathrm{kl})$, which, by closing, prevent the blood from flowing back into any other chamber of the heart when the walls relax at the end of the contraction.

Blood-vessels. - In order that the blood system may properly perform its function, in addition to circulation, it is necessary that the nutritive substances be readily taken up and given over again to the tissues. The part of the course of circulation concerned in this must be general, i.e., widely distributed in the body, and having a lumen of large superficial area. These demands are met by the hairlike acsscls or capillarics (c), extremely fine and thinwalled tubes, which surround and permeate all organs. Through their walls, usually formed by a thin epithelial layer, the proteid substances for nourishing the tissues can pass, and the oxygen can be exchanged for carbonic acid. Between the heart and the capillaries there exists, corresponding to their different functions, the greatest conceivable difference in structure; they must therefore be united by special transitional vessels-vessels which begin large and thick-walled at the heart, and by branching, and thinning of their walls pass gradualiy into the capil-. laries; of such vessels there are two kinds, the firmer. artcrics $(\alpha)$ leading to the capillary region, and the thinwalled wins $\left(z^{\prime}\right)$ leading back to the heart.

\section{Correlation of Respiratory Organs and Blood Sys-} tem.-It has been determined, as a law, that in all animals the blood-vascular system has been influenced in its arrangement and structure more by respiration than by the taking up of food in the narrower sense; there exists a corrclation 
between the organs of respiration and of circulation. The correlation finds expression in the fact that a double capil-

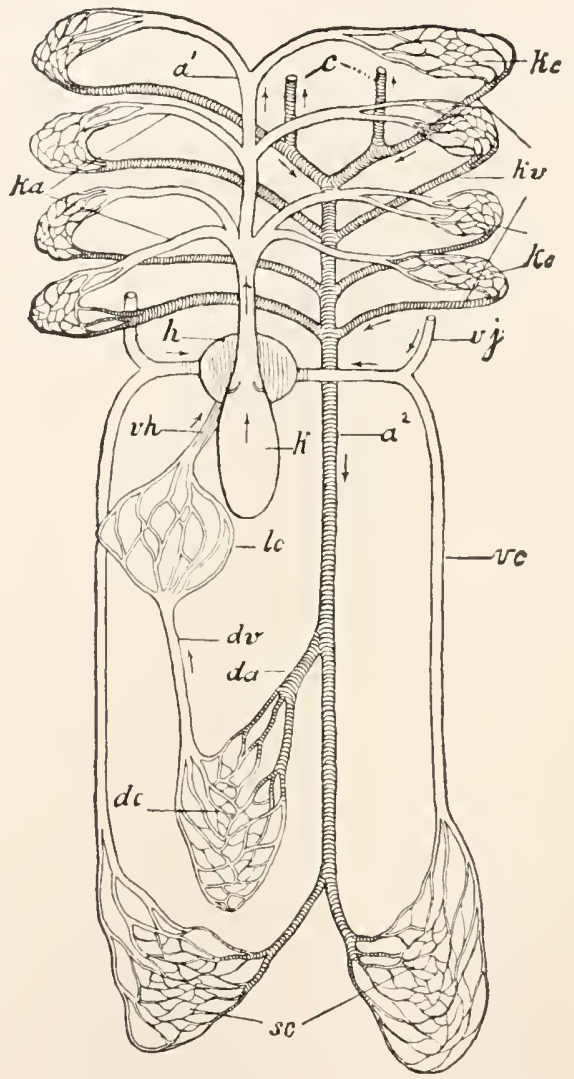

Fig. 62,- Schema of the course of circulation in a fish. $a^{1}$, ascending aorta with the gillarteries $(k a) ; a^{2}$, the descending aorta formed by the union of the gill-veins $\left(k z^{\prime}\right) ; k c$, gillcapillaries; $h$, auricle of the heart ; $k$, ventricle ; $z j$, rena jugularis; $v c$, vena cardinalis; vh, vena hepatica (inferior cava); $d a$, intestinal arteries; $d v$, intestinal veins ; $s c$, capillaries of the body ; $l c$, liver-capillaries.

lary region must be distinguished; besides the body capillary system already mentioned there is the respiratory capillary region, whose exclusive office is to remove the carbonic acid from the blood and to furnish oxygen to it (gill and lung capillaries). A twofold capillary region 
makes necessary also a twofold system of arteries and veins (systemic arteries and systemic veins, respiratory arteries and respiratory veins). The accompanying diagram (Fig. 62) of the course of the blood-circulation of the fish explains this. From the capillary region of the functional tissues of the body, veins lead to the auricle of the heart; from the auricle, the blood flows into the ventricle and through the gill-arteries on into the gill-capillaries. Thence it is conducted through the gill-veins, which unite into a single large trunk; this again gives off lateral branches passing into the capillary region of the body. Since the branches of the main trunk formed by the gill veins lead again into a capillary region, they must, like the main stem, be called arteries.

Arterial and Venous Blood.-During the course of the blood through the body, it twice changes its chemical character and correspondingly its color. The blood which flows out from the body capillary region has given up its oxygen to the tissues, receiving in exchange carbonic acid, and has taken on a dark red color. This character is maintained until, in the gill-capillaries, it again becomes oxygenated, giving up the carbonic acid and becoming bright red in color. The different character of the blood can be recognized in the arteries and veins of the systemic circulatory system: the dark blood containing carbonic acid is called ienous, and the bright red, containing oxygen, artirial blood, since the former flows in the veins, the latter in the arteries. These terms are cntirely unsuitable, as can readily be seen from the above diagram (Fig. 62), because they easily lead to the false assumption that veins must always conduct blood containing carbonic acid and arteries always oxygenated blood. In opposition to this, the diagram shows that, in the respiratory circulation (the shorter course), the conditions must be the reverse of those in the systemic circulation, since here the arteries contain "venous," while the veins contain " arterial," blood.

Closed and Lacunar Blood-vascular Systems.-Such 
a blood-vascular system as has here been described is called

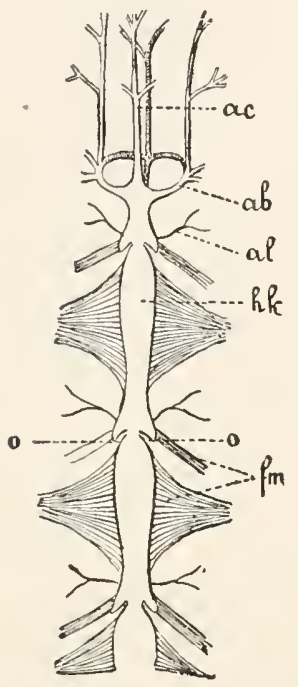

Fig. 63.-Anterior end of the heart of Scolopendra. (From Lang, after New port.) $h k$, ventricles with the muscle of flight ( $f \mathrm{~m})$ and lateral slitlike openings (o); $a b, a c, a l$, arteries going from the heart, emptying the blood into the body-cavity.

a closed one, because the blood ahways flows in special tubes provided with their own walls. Opposed to the closed stands the lacunar blood-z'ascular system ; here the blood-vessels lose, after a time, the character of tubes and become wide cavities, which, without special walls, are enclosed between the intestines and other organs. The cœlom serves as such a cavity with especial frequency.

\section{Example of Lacunar Blood-vascu-} lar System.- The best example of a lacunar blood-vascular system is furnished by the insects and "thousand-legs," which have only the heart and short arterial trunks; from the ends of the stumps of the arteries the blood enters the body-cavity, and from the bodycavity through lateral slits again enters the heart (Fig. 63). Within the groups of arthropods and molluses are found all grades betwcen so extreme a case of a lacunar blood-vascular system and the almost completely closed one. Here appears anew the closest corrclation of thi circulatory and respiratory organs, and indeed there exists a determining influence for this. If the respiration is diffusely distributed over or through the body, and the distribution of the oxygen goes on without special vessels, the circulatory apparatus is very simple; on the other hand, if the respiration is connected with definitely restricted areas, and a regular distribution of oxygen is necessary, it is differentiated into heart, arteries, veins, and capillaries. Upon this point we may compare the conditions found in crustaccans, spiders, and insects.

Lymph-vessels.-Finally, a more special part of the blood-vascular system is the lymph-iascular systcm, which 
occurs only in vertebrates. In the capillary region of the body, it is true, proteids may pass over into the tissues, but it is self-evident that a possible overflow cannot reenter the blood-vessels in the same way, on account of the higher pressure prevailing in the capillaries. This overflow is conducted back to the veins through the lymphvessels. The lymph-vessels begin with the lacunx of the tissues, and gradually pass into vessels with definite walls. The lymph-vessels of the digestive tract are particularly important since, during digestion, they become filled with the proteid and fatty constituents of the digested food; they are called the chyle-i'essels, because their contents, the chyle, is distinguished from ordinary lymph by its milky color.

Cold- and Warm-blooded Animals.-In connection with the blood-vascular system, two expressions which are much used but not generally correctly understood by the general public, viz., cold-blooded and warm-blooded-or, more correctly, animals with arriable and animals with definite temperatures--should be explained. Under the head of $\because$ aimals with varying temperature (poikilothermous) or cold blood are placed forms whose temperature is entirely dependent upon the temperature of the environment, rising and falling with it, but usually a few degrees above it. In our climate, where the atmosperic temperature is considerably lower than the temperature of the human body, such animals, for example the frog, would feel cold to our touch, since they, particularly in the cool season, have a much lower temperature than we.

Such creatures as, living under any thermal condition, maintain about the same temperature, are termed warmblooded or definite-temperatured (idiothermous, homoiothermous) animals. Man in summer and winter, under the equator and at the north pole, has approximately a temperature of $36^{\circ} \mathrm{C}$, showing higher temperatures only in fever. In order to maintain a constant temperature during the varying external thermal conditions, the animal must have a heat-regulator; it must have the power to 
regulate the warmth of its body, on the one hand by limiting the production of heat, on the other by controlling the loss of heat. If the environment is warmer than is suitable for the body temperature, then the production of heat must be limited to the smallest quantity compatible with the vital processes; but, if this does not suffice, the loss of heat must be increased by evaporation from the surface, usually accomplished by lively perspiration. If, on the contrary, the environment is cold, then, conversely,

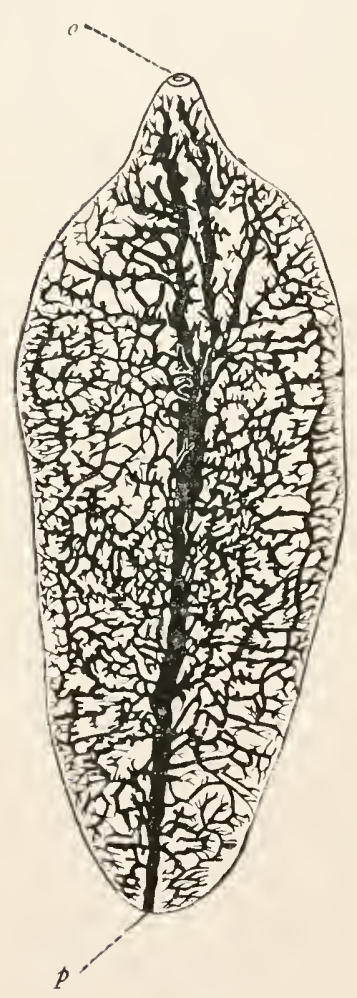

Ftg. 64 . every unnecessary loss of heat must be avoided, while the production of heat must be increased. It is clear that idiothermy, since it necessitates complicated apparatus, can occur only in the highly organized animals.

\section{Excretory Organs.}

Nature of the Organs of Excretion.-The excretory organs are tubes or glandular canals which open upon the surface of the body, either directly or by the mediation of

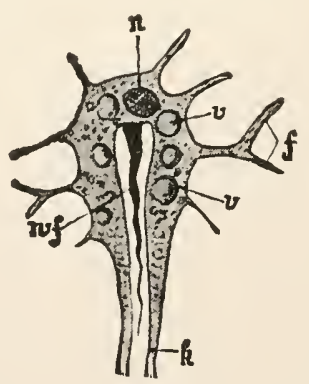

FIG. 65.

Fic. 64.-Distoma hepaticum with water-vascular systen. $p$, porus excretorius; 0 , mouthopening. (From Hatschek)

Fig $65-$ Plind end of one of the finest water-vascular canals $(k)$ of a Turlicllarian. (From: Lany.) $n$, nucleus; $f$, projection of the terminal cell; $w f$, "flame" of the terminal cell; $v$, vacuole.

an end-gut (cloaca), and conduct to the exterior substances which have become useless to the body. The presence 
of a body-cavity is of importance for their structure, as is most beautifully shown in the group of worms. Here two kinds of excretory organs occur, the wateriascular or protonophidia, and the segmontal organs or ncphritia; the former is found in the parenchymatous worms, the latter in the worms which have a body-cavity. The water-vessels begin with a closed network of small

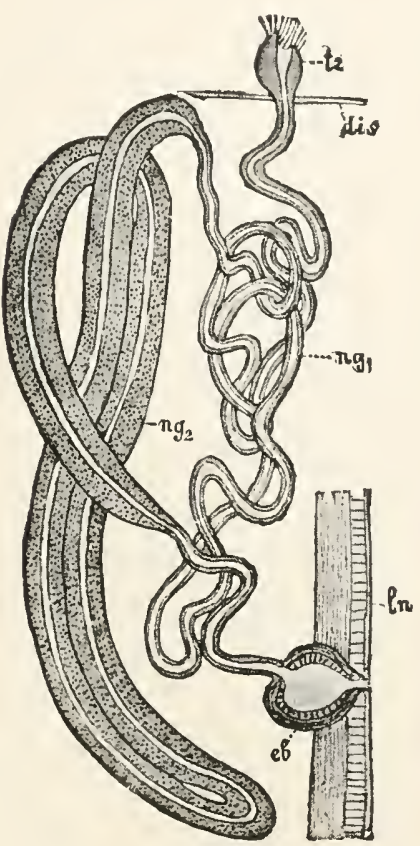

FIG. 66.

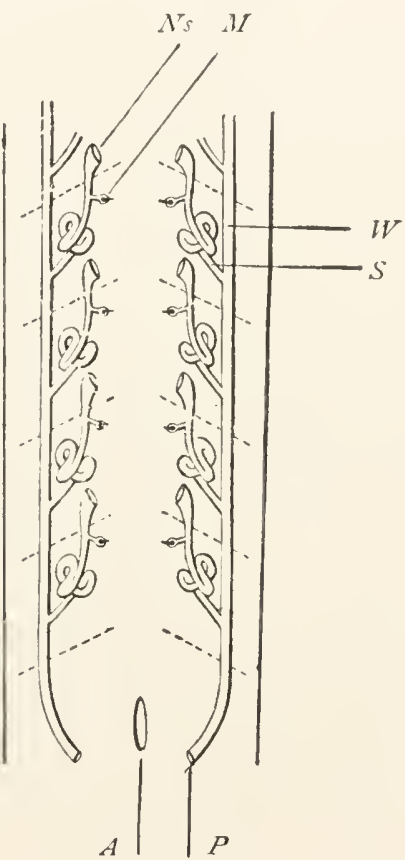

FIG. 67 .

FıG. 66-Segmental organ of an Oligochate. (From Lang.) $t z$, ciliated funnel; dis, dissepiment; $n g^{1}$, non-glandular, $\| g^{2}$, glandular, part of the canal; $e h$, terminal vesicle ; $l n$, body-wall.

FIG. 67.- I iagram of the primitive kidney of a vertebrate. (From Hatschek.) Dotted lines mark the limits of the segments. $A$, anal opening : $P$, mouth of the duct of the primitive kidney $\left(H^{5}\right) ; N s$, cillated funnel (nephrostome); $M$, Malpighian bodies of the segmental tubules $(S)$.

canals, reminding one of capillaries, uniting into one or more main stems, which usually open in common to the exterior. Just inside the orifice (porus excretorius) there is usually a dilatation forming a sort of urinary bladder, whose violent contraction expels the excretion (Fig. 64). In addition, 
the fine network of vessels is provided with blind sacs, the ends of which bear an actively-moving bunch of cilia, the Flimmerläppchen, for driving onwards the contents (Fig. 65).

Nephridia.-The segmental organs (nephridia), on the other hand, are simple tubes open at both ends; one opening leads to the exterior, the other communicates with the body-cavity; between the two openings runs a glandular tortuous canal. The opening into the body-cavity is made through a trumpetlike ciliated widening of the canal, called the ciliated funnel or nephrostome. The excretory organs of the crustacea and more certainly the kidneys of the iertebrates, are to be traced back apparently to such segmental organs (Fig. 67). The kidneys are formed as a series of canals opening by the proximal ends into the body-cavity, but with the distal ends emptying into a single canal, the ureter. Only later does the primitive kidney change into a compact glandular body, usually with the disappearance of the peritoneal funnels.

\section{B. Sexual Organs.}

Sexual Glands and Outlets.-In the sexual apparatus of animals, there must be distinguished the areas where the germinal cells are produced, the sexual glands, and the outlets for these. The former are, temporarily or permanently, present in all multicellular animals; the latter, on the contrary, may be completely absent. If the sexual products arise in the skin or in the walls of the digestive tract, as is usually the case in the colenterates, then special cutlets are superfluous, since the ripe elements can reach the exterior directly by rupture of their covering or by means of the digestive tract.

Germinal Epithelium and Germinal Glands.-Male and female sexual cells, as we have seen, originate from an undifferentiated incipient organ which is called the germinal epithelium. Its predilection is to form a part of 
the epithelial covering of the body cavity, in many animals permanently, in others only temporarily; in the latter case, it separates, usually by constriction, and forms glandlike bodies, the sexual glands.

Gonochorism and Hermaphroditism.-In most animals, the germinal epithelium produces either only female or only male sexual cells; such animals are called scparate-

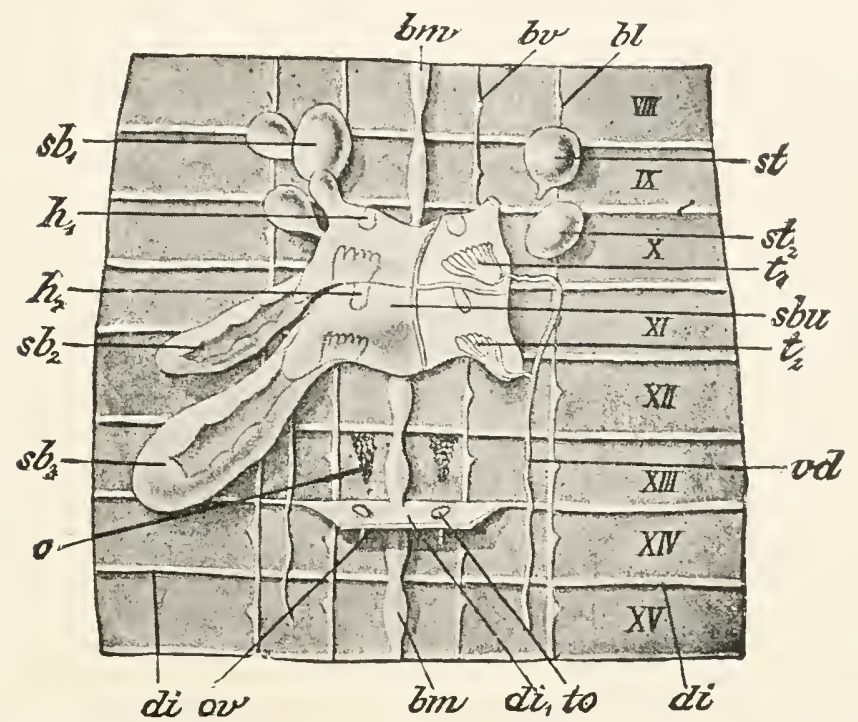

FIG. 68.-Sexual organs of Lumbricxs agricola. (From Lang, after Vogt and Yung.) The seminal vesicles of the right side are removed. $b m$, ventral nerve-cord; $b v$ and $b l$, ventral and lateral rows of setae; $s t^{1}, s t^{2}$, receptacula seminis; $s b^{1}, s b^{2}, s b^{3}$, the three seminal vesicles of the left side, which are connected with a median unpaired seminal capsule (sbu). Enclosed in the latter are the anterior and posterior testicles $\left(h^{1}, h^{2}\right)$, and the anterior and posterior seminal funnels $\left(t^{1}, t^{2}\right)$, which lead into the vas deferens ( $\left.v d^{2}\right) o$, ovaries; to ciliated funnels leading into the oviducts $(o v)$; $d i$, remnants of the dissepiments; VIII-XV, eighth to fifteenth segments.

sexcd or gonochoristic, in opposition to the hermaphroditic forms, in which both kinds of sexual glands are contained in one and the same individual. Different degrees of hermaphroditism can be distinguished; commonly testes and ovary are contained in the same animal, yet separated by a space within the body, as, for example, in our angleworm, in which only a couple of segments are male, while a third segment is female (Fig. 68). More rarely, there is 
a union of testes and ovary into a single glandular body or hermaphroditic gland; our land-snails have an hermaphroditic gland, which in the same follicle produces spermatozoa and eggs.

Occurrence of Hermaphroditism.-Hermaphroditism is, in general, of more frequent occurrence in the lowly- than in the highly-organized animals. The insects and the groups of vertebrates, the most developed classes of animals, are, almost without exception, of separate sexes; only two cases of normal hermaphroditism are known among

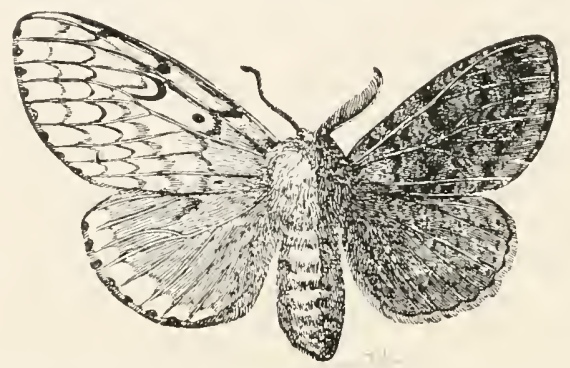

FIG. 69.-Lateral hermaphroditism of a butterfly (Ocneria dispar). Left female, right male. (After Taschenberg.)

them, the sea-perch, Serranus scriba, a bony fish, and $M y \cdot x$ ine glutinosa, the Hag-fish. More commonly, hermaphroditism is observed as an abnormality, usually in the form of lateral hermaphroditism, in which one half of the animal produces only male, the other half only female, sexual glands. If the males and females of a species are distinguishable by their appearance, then lateral hermaphroditism is expressed in their external form, since one half of the animal has the characteristic marks of the male, the other half those of the female. Hermaphroditic butterflies and bees are known in which the male half bears the special form of the male feelers, eyes, and wings, and thus is essentially different from the female half (Fig. 69). Still it must be noted here that, in many instances where the external appearance pointed towards hermaphroditism, anatomical investigation has disclosed either only male or only female sexual glands. 
True Hermaphroditism.-With extreme rarity true hermaphroditism (the presence of both kinds of sexual glands in the same animal) has been observed in mammals and in man. What is described as hermaphroditism does not, in the majority of cases, deserve the name.

Outlets.-Very frequently in the animal kingdom the excretory apparatus furnishes ontlits for the sexual products. In the annclids some segmental organs, in the iertebrates portions of the kidney system, either exclusively or in addition to their excretory function, become accessory sexual organs. Hence we speak of a "urino-genital system." This remarkable connection of genital and excretory organs has a double cause, a physiological and an anatomical. Physiologically important is the fact that eggs and spermatozoa behave like excreta; being substances which are no longer destined for the use of the individual, but must reach the exterior in order to become efficient. The anatomical cause is the relation to the body-cavity; i.e., it is always the case that a urino-genital system is formed only in animals in which the germinal epithelium arises from the epithelium of the body-cavity, and in which the kidneys, or their rudiments, stand permanently, in connection with the body-cavity and

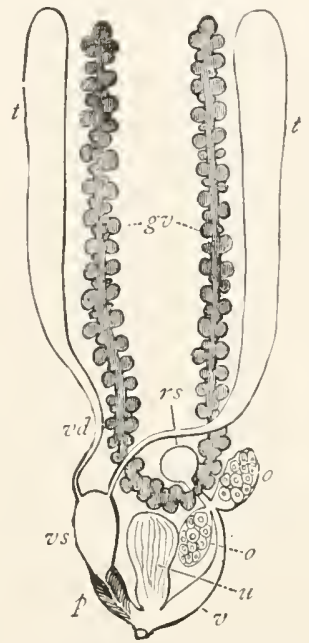

FIG.70.-Sexual apparatus of Vortex viridis (From Gegenbaur, after $\mathbf{1 1}$. Schultze.) $t$, testicle; $v d$, vasa defer. entia: $v s$, vesicula semina. lis : $p$, penis ; $o$, ovary with oviduct; $u$, uterus ; $z^{\prime}$, vagina; $r s$, receptaculum seminis; $g^{2}$, yolk-glands. thus form the natural outlet for its products. Whether the accessory sexual parts are portions of the excretory organs or are independent structures, they have in the animal series a definite arrangement conditioned by their function (Fig. 7o). Canals lead from the sexual glands to the exterior, the oviducts in the female, the arasa dcferentia in the male (and the hermaphroditic duct from the hermaphroditic gland). Oviduct and vas deferens may be 
provided with sac-like evaginations which serve for the reception of the semen. In the oviduct, these are called reccptacula scminis, in the vas deferens iesicule scminales; the former give lodgment to semen which has entered the female sexual passages during coition, the latter to semen which has been formed in the true testes.

Accessory Sexual Apparatus.--The terminal portion of the vas deferens is often very muscular and is called the ductus cjaculatorius; it may be evaginated as a ponis or cirrus, and then projects beyond the surface of the body. The terminal portion of the oviduct is usually widened so that two portions may be distinguished, the utcrus, which harbors the eggs during their development, and the a'agina, which serves for copulation. In addition there may occur in both sexes other accessory glands of the most diverse character.

\section{Animal Organs.}

\section{Organs of Locomotion.}

Voluntary Locomotion.--The power to change their location voluntarily is a peculiarity so prominent in animals that to the "laity" it is sufficient for determining whether an organism belongs to the vegetable or to the animal kingdom. On this account it is necessary to call attention to the fact that numerous animals lose the power of free locomotion, becoming fixed to the ground, to plants, or to other animals. All sponges and corals, most hydroid polyps, and the crinoids among the cchinoderms, are fixed, and have thereby obtained such a conspicuous similarity to plants that, although they are true animals, they were long regarded as plants. Further, many musscls and worms are firmly fixed within their cases; indeed, many crustacean forms, the cirrineds, have completely lost their free motility. But a more careful investigation in all these cases will show that the power of moving the separate parts exists, for the corals can draw in their crown of tentacles, the 
cirripeds their featherlike feet, and the mussel can actively close its shell.

Locomotion among the Lower Animals. - In the lower forms, the protozod, progression is accomplished almost exclusively by projections of the cell; these may be psentopodia, cilia, or flagclla. In the multicellular animals, this is only very rarely the case. Amoboid movements of the epithelial cells, indeed, occur in the ealenterates and also in many worms, but does not suffice for change of position. More effective is the ciliated or flagellated epithelium, which in etenophores, turbcllarians, and rotifers renders swimming movements possible; this occurs, besides, in many larvæ of animals which, in the mature state, are unable to change their location or do so only by the aid of muscles. In the form of the planula, i.e., as a larva swimming by means of cilia, nearly all colenterates, efhinodcrms, mollusks, and the majority of the worms leave the egg-membranes.

Locomotion among the Higher Animals. - The musculature is alone adapted for energetic activity. The arrangement of this varies with and depends upon the constitution of the skeleton. Forms without a skeleton have commonly the "dermo-muscular tunic," a cylinder of circular and longitudinal muscle fibres which is firmly united with the skin. If a skeleton is formed by the skin, as in the arthropods, then the cylinder resolves itself into groups of muscles, which find points of attachment upon the dermal skeleton; if, on the other hand, as in the artebrated animals, an axial skeleton is formed, a fixed point is furnished for muscular action, so that the musculature obtains a quite new character, in particular coming to lie deeper. A locomotory apparatus quite unique is the ambulacral system of the echinoderms, a system of delicate little tubes with protrusible portions which function as feet.

\section{Nervous System.}

Its Regular Development.-Scarcely an organic system in the animal series shows such a regular development as the nervous system. The different stages which can be 
grouped may be termed the diffuse, the linear, the ganglionic, and the tubular types.

Diffuse Nervous System.-The diffuse typc of nervous system is certainly the most ancestral; it shows the two elements, nerve fibres and ganglion cells, regularly distributed through the whole body, or, at least, through certain layers of the body. The skin of the body, the ectoderm, is to be looked upon as one of the fundamental elements in the nervous system, since it mediates contact with the external world, and hence receives the sensory impressions, so important for the development of nervous tissue. The corals and hydroid polyts serve as examples, since in them the ectoderm is permeated in all directions by a delicate, spider-weblike network of nerve fibres and ganglion cells, which encroach even upon the entoderm.

Linear Nervous System.-From the diffuse type the other chief types can be derived through localization, which indeed is chiefly conditioned by the fact that there are a few points which are most advantageously located for the reception of sensory impressions, and hence for the development of nervous elements. In the madusa such a place is the rim of the bell; consequently a stronger noriccord remarkably rich in ganglion cells is found here. This, as well as the nerve-ring and the five ambulacral nerves of cchinodcrms, may be called a central organ, thereby distinguishing the rest of the nervous network as the peripheral nervous systcm.

Ganglionic Central Nervous System.-Manifold transitional forms lead us to the ganglionic central nervous system of the worms, molluscs, and arthropods (Fig. 7I). The central nervous system here consists of two or more ganglia: each ganglion being a rounded bunch of regularly arranged nerve-fibres and ganglion-cells. The former constitute the nucleus of the mass, and, since they cross in all directions, give the appearance of fine granulation; this fact has led to the unsuitable, because misleading, name of "Leydig"s granular substance." The ganglion-cells, on the other hand, collect in a thick layer surrounding the "Leydig's 
granular substance." From the central nervous mass run out the peripheral nerves, and also the commissures, the cords connecting similar ganglionic masses.

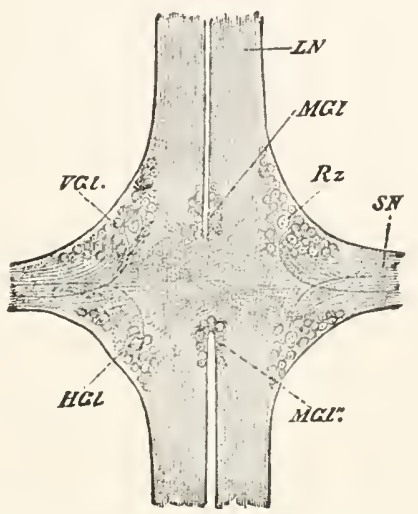

FIG. 7r.-A pair of ganglia from the ventral nerve cord of Phronima sedentaria. In the centre is Leydig's granular substance with a superficial layer of ganglion-cells $(\lambda / G L$ $l G l, H G l, K z) ; L N$, longitudinal commissure; $S \mathcal{V}$, efferent nerve-fibres. (After Claus.

Supraœsophageal (or Brain) Ganglia.-Since now most animals are symmetrically built, the ganglia are found grouped in pairs: a left and a right ganglion correspond to one another and are connected simply by a cord of nervefibres, the transverse commissure. Of most constant occurrence are two ganglia, which lie dorsally over the pharynx, and hence are called the supra-asophageal ganglia or brain ganglia. If still other ganglia occur, they lie ventrally and below the digestive tract (ventral nerve-cord).

Ladder Nervous System.-A widely-recurring arrangement is that termed the ladder norious systom (of annclids and arthropods) (Fig. 72). Numerous pairs of ganglia (in the example before us, nine) lie in serial arrangement on the ventral side of the animal, and are connected by longitudinal commissures, and also by left and right commissures connecting the left and right ganglia. The first pair of the series is formed by the subesophageal ganglion, which sends out commissures right and left, surrounding the pharynx, to the supra-cesophageal ganglion. The supra- and subœsophageal ganglia together with the 
cesophageal commissure form the asophageal ring, a nervering surrounding the oesophagus.

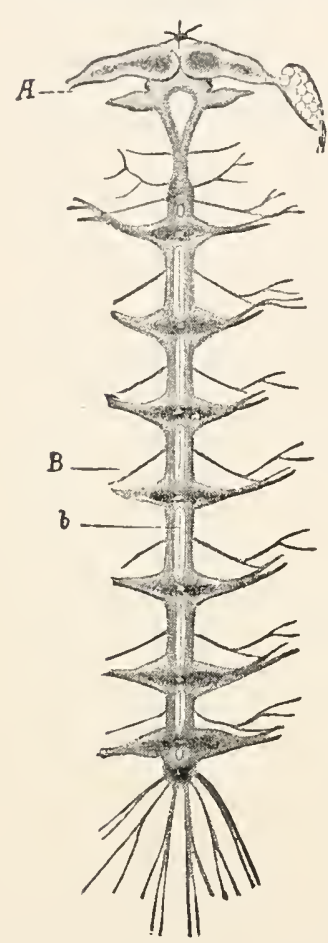

FIG. 72,- Ladder nervous system of Porcellio scaber (Assel). $A$, brain ; $B$, ventral cord, connected with the brain by the cesophageal commissures: $b$, a cord formerly regarded as sympathicus. (After Leydig.)

Tubular System.-The tubular type of nervous system is found only in the vertebrates (Fig. 73), and in the larva of tunicates, which are closely related to the vertebrates. The vertebrate brain and spinal cord may be regarded as parts of a tube with greatly thickened walls, developed in different ways. In the centre lies the extremely narrow spinal canal, which anteriorly widens into the several ventricles of the brain. In a transverse section the nervous elements are seen grouped around the spinal canal in a manner almost opposite to that described above for the ganglionic type. On the periphery lies a layer of nerve-fibres (the " white matter" of human anatomy); next is a central portion formed of ganglioncells and nerve-fibres (the gray matter), which is marked off from the central canal by a special epithelium.

\section{Relations between the Nervous} System and the Skin.-_For almost all animals, it has been ascertained that the ncrous system arises from the ectoderm. Therefore, in many animals, the nerve-cords and the ganglionic masses lie permanently in the skin; in others, only during the development, later becoming separated by splitting off or by infolding, and thus coming to lie in the deeper layers of the body (Fig. 9, p. 46).

\section{Sensory Organs.}

Sensations of the Lower Animals. - What we know of the character of the external world is founded upon ex- 
periences gained through our sensory organs. We thus know the external world only in so far as it is accessible to the senses, directed and carefully controlled by the power of judgment. If things exist outside of ourselves which have no influence upon our senses, we can form no conception of them. It follows from this proposition that we can gain knowledge of the natural capacity of the sensory organs of animals only by analogy with our own experiences. We must extend to the whole animal kingdom

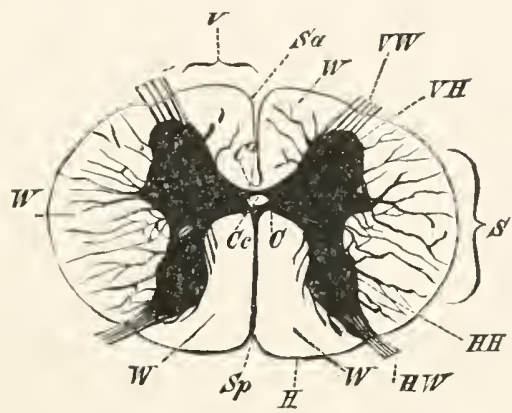

FIG. 73.-Cross-section of the human spinal cord. "(From Wiedersheim.) Black represents the gray, white the white substance of the cord; $C c$, central canal, surrounded by the anterior and posterior commissures $\left(C\right.$ and $\left.C^{\prime}\right) ; S a, S p$, anterior and posterior sulcus; $I W, H W$, anterior and posterior nerve-roots; $V H, H H$, anterior and pusterior horn of gray matter; $I, S, H$, anterior, lateral, and posterior columns of white matter.

the distinction of five senses, viz., touch (including the sense of pressure, and of temperature), smell, taste, hearing, and sight, which has become intrenched in human physiology. A priori, however, it cannot be denied that sensations occur in animals which we do not experience; in following out this course of thought, we are led to the establishment of a. sixth sense. A conception of this kind, however, must remain to us a meaningless abstraction, since it is impossible: for us to conceive of the character of a sense which we lack.

Anatomy gives Insufficient Knowledge of Sensory Organs.-A further, and still more important, reason for our very fragmentary knowledge of animal sensory life is the fact, that, in regard to the physiological meaning of the sensory apparatus, it is only selciom that we can depend upon experiments, and consequently we must base our 
conclusions upon anatomy. But the anatomy of many sensory organs, like those of smell and taste, is by no means so characteristic that it alone is sufficient to determine the physiological significance.

Tactile Organs.- The skin of animals functions as a tactile organ, usually over the whole area, although not everywhere with equal intensity. Prominent parts, like the crown of tentacles of polyps and of many i'orms, the feelers of arthropods and snails, should be taken up as a

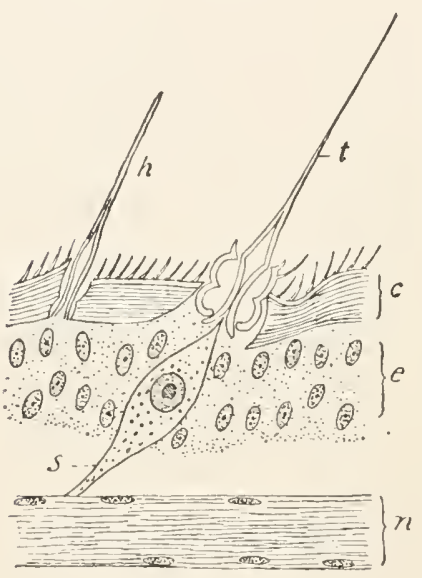

FIG. 74

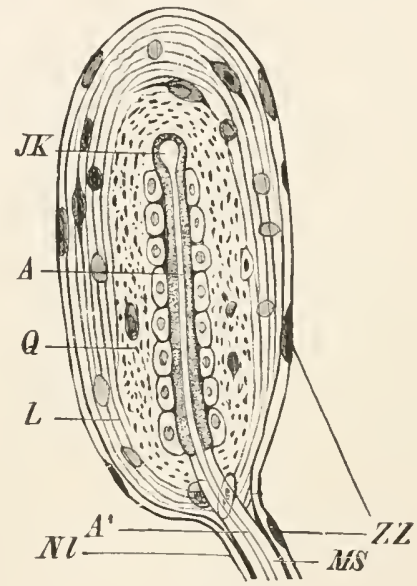

FIG. 75 .

FIG. 74. - Skin of an insect with an ordinary hair $(k)$ and a tactile hair $(t) ; n$, nerve; s, sensory cell : $e$, epithelium; $c$, cuticle. (After $v$. Rath.)

FIG. 75.-Tactile corpuscles from the bill of a duck. (From Wiedersheim). $A$, nerve-fibre with terminal bulb $\left(J K^{\prime}\right): \ell$, inner, $L$, covering lamellæ; $Z Z$, nucleus of the latter; $A^{\prime}$, axis cylinder; $M S$, medullary sheath ; $N l$, nerve-sheath.

special subject. Special epithelial cells serve for touch; these are provided with stiff hairs projecting above the surface, the tactile bristles or tactile hairs (Fig. 74). Only in the acrtcbrates do the nerves of touch terminate in specially modified end organs (Pacinian corpuscles, corpuscles of Meissner, etc.) (Fig. 75); these usually lie under the epithelium.

Organs of Smell and of Taste are known with certainty to exist only in acrtcbrates. The olfactory organ of fishes consists of two small pits in the skin, above and in front of the mouth-opening; here the epithelium is rich in sensory 
cells, the olfactory cells. In the air-breathing vertebrates the cavity becomes part of the canal which serves for respiration, leading from the surface of the skin into the pharynx. Consequently we shall be inclined to regard as organs of smell sensory organs of invertebrates, (e.g., maduse, ccphalopods), which have the form of ciliated pits and lie near the respiratory apparatus (e.g. the osphradeum of mollnses). Yet there are exceptions. Experiments seem to show that in the arthropods the antenna probably serve for smelling. Here the sensory perception can be connected only with certain modified hairs, the olfactory tubules of the crustacia and the olfactory cones of insects. In an analogous way we shall term as organs of taste certain nerve-endings directly within or in the neighborhood of the pharynx, since the taste-organs of acrtcbratcs, the so-called tastc-buds, have been observed in the mouth-cavity, especially on the tongue.

Organs of Hearing and of Sight are called the higher sense-organs, because they are of much greater importance in the totality of our knowledge than the other organs, since they furnish sensations which are quantitatively and qualitatively much more definite. Ears and eyes have therefore a complicated and characteristic structure, which renders possible a ready recognition, through the a'most invariable presence of an easily recognizable apparatus accessory to the sensory cells themselves, which are essential for sensation.

History of the Auditory Organs. - The auditory organs of aertebrates and of most of the other animal groups can be traced back to a simple fundamental form, the anditory iesicle (Fig. 76). This has an epithelial wall, a fluid contents, the cudolymph, and an auditory ossicle or otolith, formed from a single or from several fused auditory concretions. In a definite region of the epithelial wall the cells are developed into the crista acustica, the auditory ridge; they are in connection with the auditory nerve (ncrins acusticus) and bear the auditory hairs projecting into the endolymph. The otoliths themselves are concre- 
tions of carbonate or of phosphate of lime, whose function is not yet explained. They usually float free in the centre

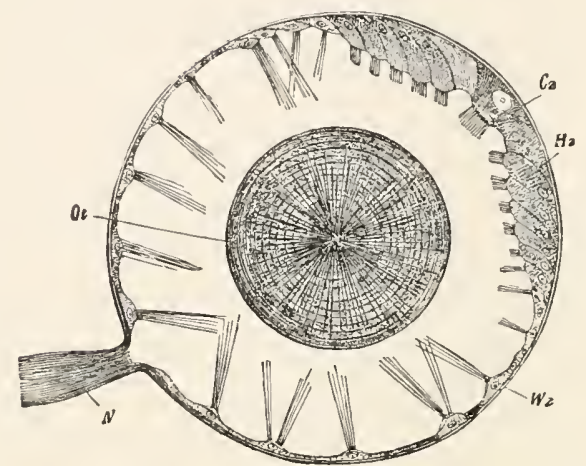

FIG. 76.-Auditory vesicle of a Mollusk (Pterotrachea). $N$, auditory nerve ; $H z$, auditory cells with the central cell; $C z$, ciliated cells; $W z$, ciliated cells; $O t$, otolith. (After Claus.)

of the vesicle, and are often held in place by bunches of cilia which project from the non-sensitive epithelial cells.

Auditory Pit.--Every auditory vesicle develops from a pitlike invagination of the skin, and consequently is for a time an auditory pit. Therefore it is not surprising that in many animals the organ has stopped at the lower stage of development; for example, the crayfish has an open auditory organ or auditory pit. On the other hand, the auditory vesicle may assume a great variety of forms. In the z'cricbrates. for example (Fig. 77 ), it is divided by a con-

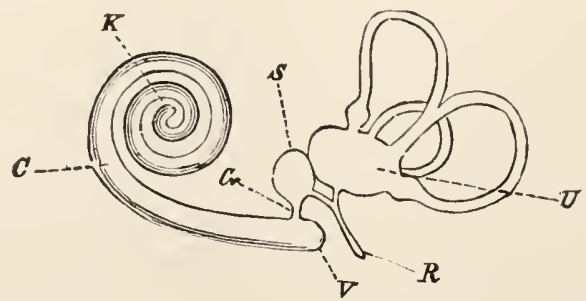

FIG. 77.- Diagram of the human labyrinth. $U$, utriculus with the semicircular canals; $S$, sacculus connected with the cochlea $(C)$ by the canalis reuniens ; $R$, recessus labyrinthi ; $I^{F}$, blind sac of the cochlea; $K$, apex of the cochlea.

striction into the sacculus and the utriculus; the sacculus is provided with a spirally-wound blind sac, the cochlea, 
the utriculus with the three semicircular canals. In addition there is formed in the mammals, as also in most i'crtebrates, a sound-conducting apparatus, so that the auditory organ acquires an extremely complicated structure.

Other Forms of Auditory Organs.-Since there are animals without auditory vesicles which hear well, like the spiders and insects, we must assume that there are auditory organs which are not formed after the type of auditory vesicles. Still we have no certain knowledge of this except in the case of the tympanal auditory organs of the grasshoppers (which compare).

Function of the Semicircular Canals. - Experiments upon representatives of the most diverse classes of acrtibrates have led to the conclusion that the three semicircular canals, standing at right angles to each other, condition the sensation of equilibrium of the body. For, after these canals are destroyed, the animals begin to stagger and lose their balance. It is possible that in fishes this is the sole function of the labyrinth; for it has not yet been definitely determined that fishes hear. Starting from this assumption, recent investigators have attempted to prove that the auditory vesicles of invertebrated animals are exclusively, or at least preponderatingly, organs of equilibration.

The Eye is in all animals recognized by the characteristics of the sensory epithelium, the retina. The latter is always marked by strong deposition of pigment which lies either in the sensory cells or in special cells arranged between or behind the sensory cells. The simplest-formed eye, therefore, appears as a pigment-spot in the epithelium of the skin sharply circumscribed, provided with nerves, commonly also with a lens (Fig. $7 S$ ).

The Rods and Cones. - The sensory cell itself bears usually at its peripheral end a projection, called the rhabdom. The rhabdom is a sort of cuticular structure, probably serving also to collect the rays of light and to transform them into stimuli, and has, particularly in the vertebrates, a complicated structure, inasmuch as each rhabdom consists of an inner and an outer portion. Here 
also can be distinguished two kinds of rhabdoms, rods and cones (Fig. 79).

\section{The Optic Ganglion.-}

Before the optic nerve divides into the separate optic cells, it forms a swelling, the optic ganglion, which either lies as a detached body outside of the eye, or fuses with the retina into a connected whole. The parts designated as reticular, the internal granular

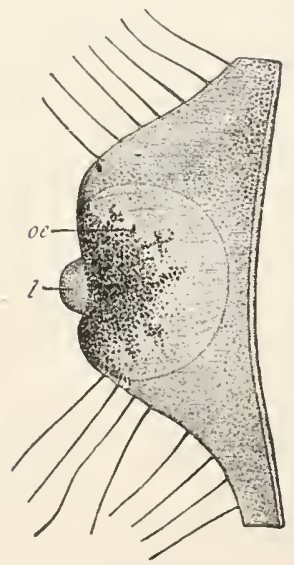

FIG. 78 .

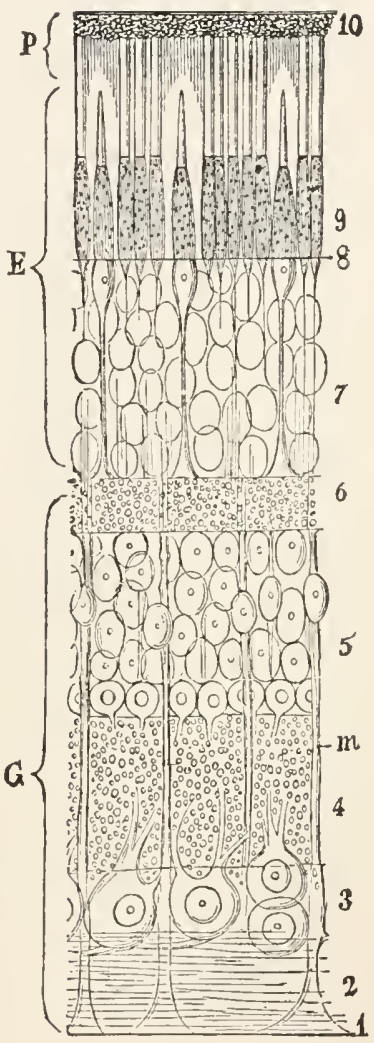

FIG. 79 .

FiG. 78.-Ocellus (oc) of a medusa (Lizzia Koellikeri) with lens (l).

Fig. 79.-Huinan retina. (After Gegenbaur.) P, pigment-layer; E, layer of sensory ce.ls ; $\mathrm{G}$, optic ganglion; $\mathrm{x}$, limitans interna ; 2 , nerve-fibre layers; 3 , ganglion-cells ; 4 , inner reticular layer ; 5 , inner granular layer ; 6 , outer reticular layer ; 7 , outer granular layer ; 8 , limitans externa; , rods and cones; ro, tapetum nigrum; $M$, Mïller's fibres.

layer and the ganglion-cells (nerve-fibre layer) (Fig. $79 G$ ), belong to the optic ganglion; the layer of the optic cells consists only of the external granular layer and the rods and cones resting upon it (Fig $79 \mathrm{E}$.)

Refractive Bodies in the Eye.-The complicated structure of the eye is further influenced by the facts that special refractive bodies (cornea, lens, vitreous body) concentrate the light in order to cast an image upon the retina; 
that the incidence of light must be regulated: that means for nutrition (the choroid coat) and for protection (sclerotic coat) must be provided. If all these parts are present a structure results such as is found in the squid and in the z'crtcbrates (Fig. So).

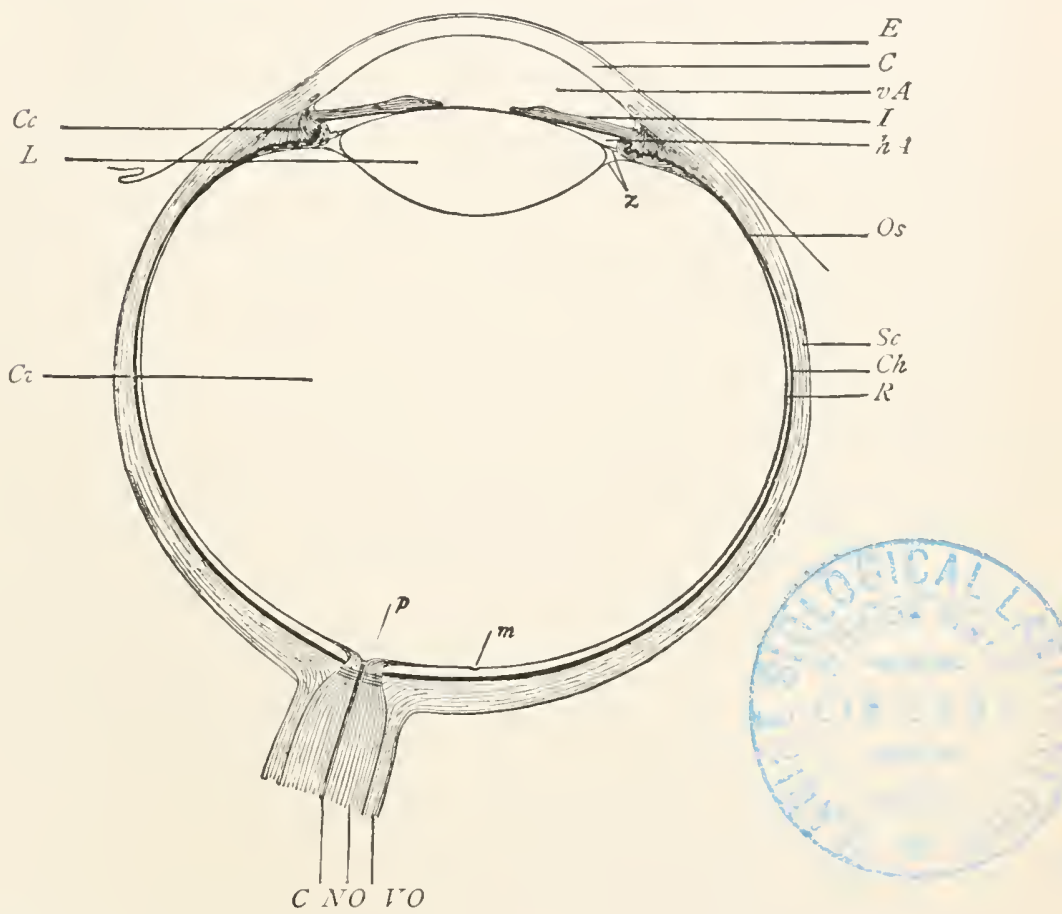

Fig. 80,-Horizontal section through the human eye. (After Arlt, from Hatschek.) E, epithelium of the cornea (conjunctiva); $C$, cornea ; $v A$, anterior chamber of the eye ; $/$, iris ; $h A$, posterior chamber of the eye: $Z$, zonula zinnii : $U_{s}$, ora serrata : $S c$, sclerotic coat; $C /$, choroidea: $R$, retina : papilla of optic nerve: $m$, macula lutea, area of most distinct vision; $V O$, sheath of the optic nerve ; $V O$, optic nerve ; $C$, arteria centralis ; $C c$, corpus ciliare ; $L$, lens: $C v$, vitreous body.

The Eye of the Vertebrates.-The eye of the s'crtebrates is a body, in general, approximately spherical, whose surface is formed by a firm membrane. Over the greater part of the circumference is an opaque fibrous or cartilaginous covering, called the sclerotic coat, or sclerotica; it is transparent only in the most anterior part, and here it forms by its greater convexity a projecting portion like the crystal of 
a watch, the cornca. Internally to the sclerotica lies the choroidca, an envelope of connective tissue, rich in pigment and blood vessels, which, at the borders of the sclerotica and cornea, is changed into the iris. The iris, the seat of the color of the eye, is pierced in the centre by the pupil. an opening whose varying size regulates the incidence of light. Next internally to the choroid follows a layer of black cells, the tapctum nigrum, and finally the rotina itself, the extension of the optic nerve which enters the eye at the hinder part. The tapetum nigrum and the retina are developed together, and hence both end at the edge of the pupil, although the retina loses its nervous character in the ora serrata at some distance from the outer edge of the iris.

In the interior of the eye is left a cavity, which is completely filled by the aitrcous body, aqucous humor, and the lens. For the act of vision the lens is the most important part, since, next to the cornea, it influences most the course of the rays of light. It lies behind the iris, fixed in the anterior wall of the choroidea, which here is changed into the corpus ciliarc. In front of it is a serous liquid, the aqueous humor, partly in the so-called posterior chamber of the eye, between the lens and iris, partly in the anterior chamber, between the iris and cornea. The single, larger cavity behind the lens is filled up by a jelly-like mass of tissue, the vitreous body.

The Various Types of Eyes.-Between the simple pigment spot and the highly organized vertebrate eye there are many transitional stages of development: pigment-spots with lens and vitreous body, with enveloping and nourishing coverings, etc. The faceted eye of insccts and crabs shows a special type of development.

\section{SUMMARY OF THE MOST IMPORTAN'T POINTS OF ORGANOLOGY.}

I. Organs are composed of tissues, and by their environment are led to the formation of a body of definite 
shape and to the performance of a single function; consequently every organ is characterized morphologically (according to its structure and its relations and physiologically (according to its function).

2. Organs of different animals may be pliysiologically equizalcnt, analogous organs (i.e., with similar functions).

3. Organs of different animals may be morphologically equiralent, homologous (developing in similar relations).

4. In the comparison of the organs of two animals three possibilities become evident.

$a$. They may be at the same time homologous and analogous.

b. They may be homologous, but not analogous (swimbladder of fishes, lungs of mammals).

$\epsilon$. They may be analogous, but not homologous (gills of fishes, lungs of mammals).

5. Organs are divided into animal and segctal.

6. Animal functions are those which are not completely foreign to plants, but in them are only slightly developed; in the animal kingdom, on the contrary, they undergo an increase and become characteristic.

7. I Egetal functions are developed with equal completeness, though in a different manner, in plants and animals.

8. To the animal organs belong the organs of mozement and scnsation, such as the muscles, the sense-organs, the nervous system.

9. To the vegetal organs belong the organs of mutrition and reproduction.

IO. Under mutrition, in the widest sense, are included not only the taking in and digestion of food and drink, but also the taking in of oxygen (respiration), the distribution of food to the parts of the body, and the removal of matter which has become useless.

II. With nutrition, therefore, are concerned not only the digestive tract and its accessory glands, but also the organs of respiration, the blood-vascular system, and the excretory organs (kidneys). 
I2. The male and female sexual organs serve for reproduction.

13. Either of the two kinds of sexual organs may be present in an animal (gonochorism), or both may be found in one and the same animal (hcrmaphroditism).

14. The highest degree of hermaphroditism is attained when one and the same gland (the hermaphroditic gland) gives rise to both eggs and spermatozoa.

I5. Very often the sexual organs and the ducts from the kidneys are closely united; we then speak of a urinogenital system.

IV. Promorphology, or Study of the FundaMENTAL FORMS OF ANIMALS.

Organic and Inorganic Bodies.--The structure of the individual animal rests upon the regular combination of differently-functioning organs. The organs thereby assume a relation to one another which is definite for each animal group, or varies only in subordinate ways. If the various animal groups are compared with reference to the principle of the arrangement of parts, there appear some few fundamental forms which play in morphology a rôle similar to that of the fundamental forms of crystals in mineralogy. But we must not, by pushing this comparison too far, attempt to compare the study of the fundamental forms, the promorphology, of animals with crystallography as of equal value. A crystal is a mass made up of similar parts; its form is the necessary and immediate result of the chemicophysical constitution of its molecules. A direct connection of this kind between molecular structure and fundamental form does not, and cannot, exist in the organism, since each organ is composed of manifold chemical combinations. Consequently there is lacking also the mathematical regularity which occurs in crystals. Even in the case of animals which have the greatest regularity in the arrangement of their parts, there is not an entire conformity to the demands of the fundamental form, so that we are compelled 
to ignore certain greater or less variations. If, for example, we call man bilaterally symmetrical, we must ignore not only the slight asymmetry of a nose awry, etc., but also what is more important-that the liver has becn pushed to the right, the heart to the left, side; and that the digestive tract throughout its entire course runs asymmetrically.

Symmetry.-Now, according to the three dimensions of space, we can pass three axes, perpendicular to each other, through the body of an animal, and up to a certain degree may characterize it according to the nature of these axes; further, we may characterize it according to the planes by which it can be symmetrically halved, the plane of symmetry. Thus we find the following fundamental forms:

I. Anaxial, asymmetrical, irregular, or amorphous fundamental form (Fig. SI).

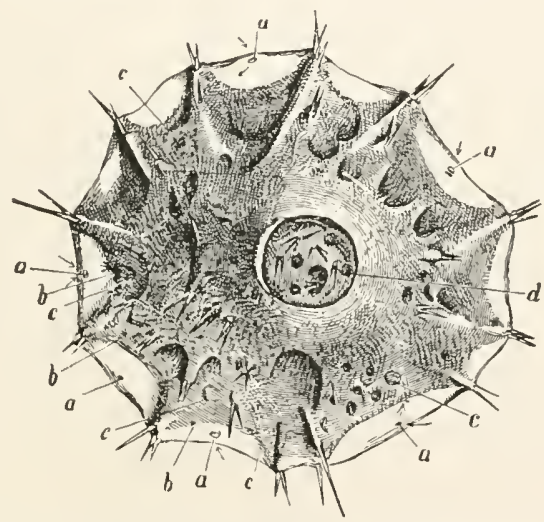

FIG. 81.-Spongilla furiatilis (After Huxley.) $a$. superficial layer with dermal pores; $b c$ region of the ciliated chambers; $d$, osculum.

2. Homaxial, symmetrical in all directions, spherical fundamental form (Fig. 82).

3. Monaxial, radially symmetrical (Fig. $\$_{3}$ ).

4. Simple heteraxial, biradially symmetrical (Figs. $\$_{4}$, S5).

5. Double heteraxial, bilaterally symmetrical (Fig. 86).

I. Anaxial or asymmetrical animals, so called, are those 


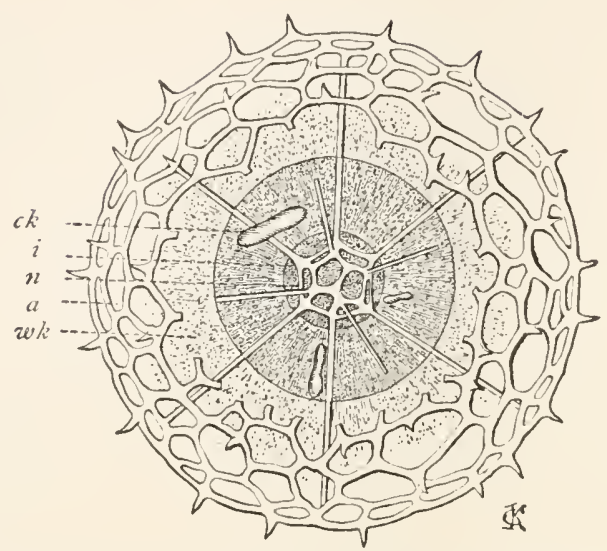

FIG. 82.-Haliomma erinuceus. a, external, $i$, internal, latticed spherical skeleton; $c k$, central capsule; $w k$, extra capsular soft parts; $n$, nucleus.

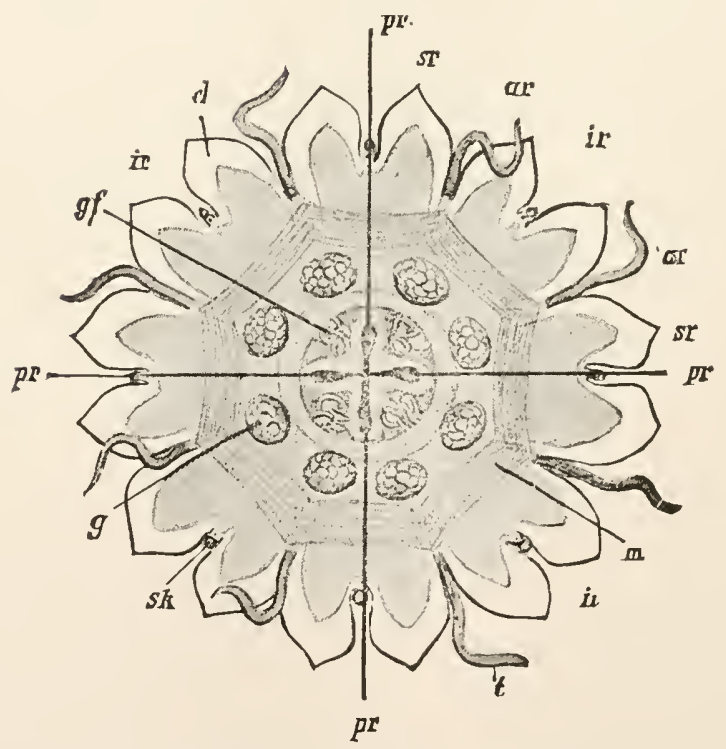

FIG. 83.-Nausithoë, an acrasped medusa (after Lang), seen from the end of the greatlyshortened main axis. pr, perradii ; ir, interradii ; $a r$, adradii (perradii and interradii mark the four planes of symmetry of the animal); sr, subradii; $r l$, mantle-lobes : $t$, tentacles : $s k$, sensory organs $: \ell$, sexual organs; $g f$, gastric filaments; $m$, subumbrellar circular muscle; in the centre the cross-shaped mouth-opening. 
in which the arrangement of parts is not regularly defined in any direction of space, and they therefore may grow irregularly in any direction. In it no fixed central point is given, and there is no possibility of running definite axes through the body or of dividing the body into symmetrical parts. (Many sponges and many protosocr.)

- 2. Homariat or spherical animals have the sphere as their fundamental form; the parts of the body are arranged concentrically around a fixed central point, so that any number of

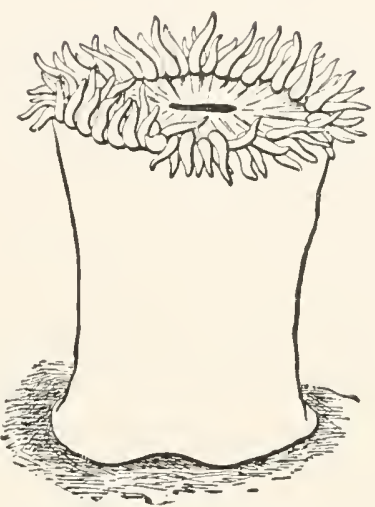

Fig.84.-Diagramof an actinian. (After Angelo Andres, from Hatschek.) Side view, perpendicular to the nuch. lengthened main axis.

axes and planes of symmetry can be passed through it; that is to say, all lines and planes which run through the central point of the sphere. (A few spherical protosoa, chiefly radiolarians.)

3. Monaxial or radial symmetry is brought about, if growth goes on in a definite direction, and correspondingly also, if the formation of organs takes place in directions other than perpendicular to this. IV e call the line which marks this direction of growth the main axis, in distinction from the accessory axes or radii, which are all similar to each other. The main axis can be determined, because it is longer or shorter than the accessory axes; but it may also be of the same length and still be entirely distinct, since it contains certain organs (e.g., the mouth-opening) which are lacking in the other planes. In radially symmetrical animals the same organs are always present in greater number and are distributed regularly around the main axis in the direction of the radii. Through such an animal a great number of sections can be made, which pass through the long axis and halve the body symmetrically. If we cut the animal in the direction of all the possible planes of symmetry, we obtain pieces which, in essential points, are similarly constructed. 
Great groups of animals, as most echinoderms and colcnterates, are radially symmetrical.

4 and 5. The next two fundamental forms have in common the fact that three unequal axes perpendicular to each other are distinguishable; these may be designated as the main axis, the cross or transverse axis, and the sagittal axis: this is the case if, leaving the main axis out of consideration, there obtains in the sagittal direction an arrangement of organs different from that in the transverse direction-if organs lie in the former, which in the latter are lacking

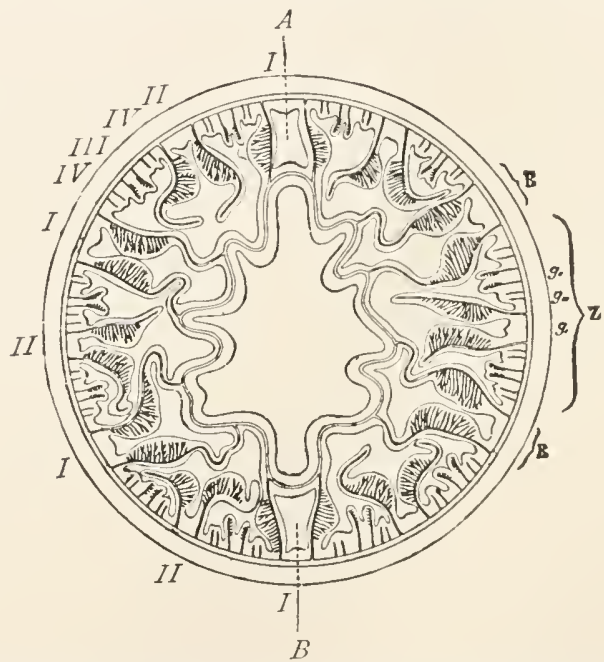

Fig. 85-Cross-section of an actinian (Adamsia dituplut na). $A B$, directive partitions, which are at the same time ends of the sagittal axis, which marks one plane of symmetry of the body, while the second stands perpendicular to it; $I-I \%$, circles of paired septa of first to fourth order.

or reversed. There are then, so long as we take into consideration the dissimilarity of the axes, two possible planes of symmetry: the animal can be symmetrically divided, (I) if the division passes through the main and transverse axes, (2) if it passes through the main and the sagittal axes. Such biradially sy'mmetrical animals are the ctenophores, actinians (Figs. 84, 85), and corals.

Bilateral Symmetry.-If now we further suppose that the ends of the sagittal axes become unlike, that at one end lie organs quite different from those at the other, we 
then reach the most usual form, bilatcral symmetry. The dissimilar ends of the sagittal axes are called "dorsal" and "ventral," and further the terms "right" and "left" are given to the ends of the transverse axis; a bilaterally symmetrical animal can be divided symmetrically into a right and a left half by one plane, the median, passing in the direction of the longitudinal sagittal axis; a frontal section (a section through the longitudinal and transverse axes) always gives dissimilar parts, dorsal and ventral sides.

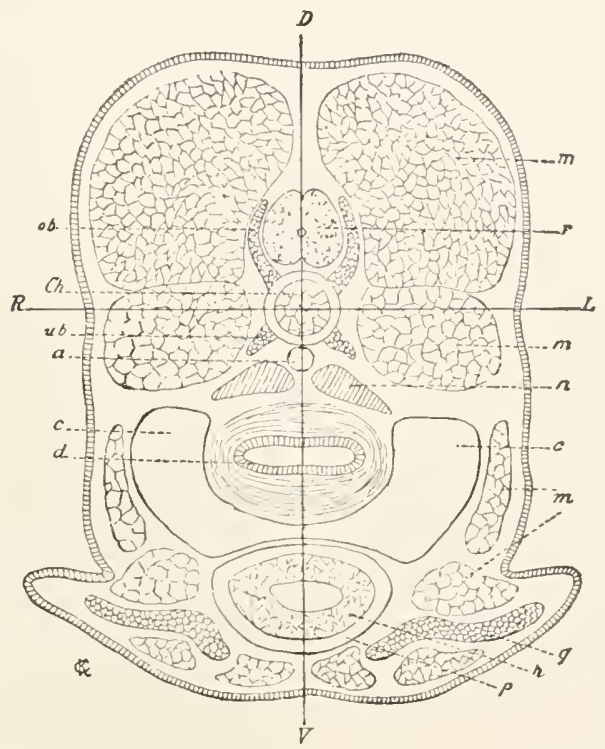

FIG. 86.-Cross-section through a fish passing through the fore limbs. $D V$, sagittal axis : $R L$, transverse axis ; $a$, aorta descendens: $c$, body-cavity ; $a$, gut ; ch, chorda : $g$, shoulder-gırdle; $h$, heart; $m$, muscles: $n$ anterior end of the kidneys; $p$, pericardium ; $o b$, neural arch ; $n b$, hamal arch ; $r$, spinal cord.

Antimeres and Metameres. - The symmetrical parts of an animal are called antimeres; each antimere has organs which occur likewise in its adjacent antimere. The right arm of man corresponds to the left, the right eye to the left, etc. The same organs are repeated in the direction of the transverse axis. Frequently however the repetition of organs occurs not only in the direction of the transverse axis, but also in the direction of the long axis. Thus the 
body is made up, not only of symmetrical parts, the antimeres, but also of similar parts placed one behind the other, the motamcrs. This leads us to the consideration of metamerism or segmentation.

\section{Internal and External Metamerism.-Mctamerism} or scgmcutation is spoken of when the body of an animal consists of numerous segments or metameres (consult Fig. 56). Very often it is recognizable externally-when, for instance, the limits of the segments are marked on the surface by constrictions (arthropods and annclids). But this "crtcrual motamerism" may be entirely lacking, and the metamerism find expression only intcmally in the serial succession of organs, in metamoric or segmental arrangcmont. Man, for example, is segmented only internally; in his skeleton there are numerous similar pieces, the vertebræ, which follow one another in the long axis. In fish the musculature also is made up of numerous muscle segments, as any one can readily see by examining a cooked fish. In the case of the externally segmented cartha'orm also, the ganglia of the nervous system, the vascular pulsating "hearts," the kidney tubules or segmental organs, the seta, and the dissepiments of the body-cavity are repeated in each segment.

Homonomous and Heteronomous Metamerism.The examples mentioned are well adapted for elucidating the character of the different forms of metamerism, the homonomous and the hatcronomous metamerism. The earthworm is homonomously metameric, because the simple segments are much alike in structure, and only slight differences exist between the anterior, the posterior, and the genital segments. Man and all vertebrates, on the contrary, are heteronomously metameric, because the successive segments, in spite of many points of agreement with one another, have become very unlike. The segments of the head have an importance, for the organism as a whole, quite different from those of the neck, the thorax, or the tail. A division of labor has taken place among the segments of an heteronomous animal. 
Heteronomy and Homonomy.-The distinction between heteronomy and homonomy is of extreme physiological interest. The more different the segments of an animal become the more dependent they are upon one another in order to be able to function normally; so much has the whole become unified that the single parts can live only while the continuity is maintained. On the contrary, if the connection between the parts is less intimate, they are more similar, and the more able to exist after separation from one another. This is most beautifully shown in instances of mutilation. It has been observed that when many species of Lumbricide are cut in two each part not only lives on by itself, but it even regenerates the part which is lacling; if, on the other hand, the same thing is done to a heteronomously-segmented animal, either death immediately ensues, as in the case of the higher wertcbrates, or the parts live for a short time a hopeless existence, as can be seen in the case of frogs, snakes, insccts, ctc. In metamerism a phenomenon is repeated which obtains widely in the animal kingdom, and contributes towards its higher development; first, there is a reduplication of parts, then, a division of labor, so that the final result is a whole composed of many parts, yet uniformly organized.

\section{GENERAL EMBRYOLOGY.}

Origin of Organisms.- Since every development begins with an act of generation, the ways by which new organisms. may arise should be mentioned first in this chapter. If we: wish to limit ourselves to that which has been actually observed, we must still cling to the old saying of the renowned Englishman Harvey, "Omne vivum ex ovo," and modifying it somewhat say, Omne vivum e vivo: that every living organism is derived from another living organism. We must limit ourselves to the mode of origin which has been termed tocogony, or generation by parents. The great importance which the question of generation without parents, or spontaneous generation, has obtained through 
the evolution theory renders a consideration of this question necessary at this point.

\section{Generatio Spontanea, Archegony.}

Theory of Spontaneous Generation.--The old zoologists, even Aristotle himself, believed that many animals, including even highly-organized forms, like frogs and most insects, arose by spontaneous generation from the mud. Not until the seventeenth and eighteenth centuries did this doctrine find energetic opponents, in Spallanzani, Francesco Redi, Rösel v. Rosenhof, Swammerdam, and others, who sought to adduce the experimental proof that all animals lay eggs which must be fertilized by the spermatozoon of the male in order to develop further. By their conclusive investigations the doctrine of spontaneous generation was driven into the realm of the natural history of the lower animals. Here it found a new foundation in the occurrence of parasites inside of animals which, at the beginning of their life without doubt, must have been free from these internal inhabitants. Parasitologists maintained that the parasites arose quite anew from the superfluous plastic material of their host; finally, by a series of epoch-making researches, the way was discovered by which the young forms of the parasite, developing from eggs, find their way into the body of their host. It was until recently considered a proof of the doctrine of spontaneous generation that, after a time, animal and plant life, (unicellular organisms, infusorian animalcules, etc.), became evident in water supposed to contain no living thing whatever: further, that organic fluids became foul by the development of the lowest of the plants, the bacteria. At the present time, we know that in all these cases germs of organisms, which have been carried about by the air, are the causes of the new development of life. If the germs are killed by heating the glass and boiling the fluid, and if by suitable means the entrance of new germs is prevented, then such a "sterilized fluid" remains permanently un- 
changed. It has been found, indeed, that spores, particularly of bacteria, develop an extreme power of resistance, and in many cases must be boiled more than ten minutes before they are destroyed. As the final result of all the recent experiments and observations it can only be said that the present cxistence of spontancous gencration is not proacd. Now the question is, With what right can it be claimed that spontaneous generation is now going on or has ever taken place?

First Origin of Life.-Whoever, in agreement with the teachings of astronomy, adopts the view that our earth was at one time in a fluid condition and has gradually cooled, must assume that life on the earth has not existed from eternity, but at some time has had its beginning. If he wishes to base his explanation, not upon a supernatural act of creation, nor upon arbitrary hypotheses, like that of the transferrence of living germs from other worlds through the agency of meteors, there is left to him only the hypothesis that, according to the generally prevailing and still to be observed laws of affinity, or chemical relationship, compounds of carbon, oxygen, hydrogen, nitrogen, and sulphur have been brought together to produce living substance. This process is called spontancous generation. If the carbon, oxygen, nitrogen, etc., which are now combined in a stable manner in organisms were formerly unstable, the conditions for the origin of organic compounds, through whose wider combination life would be possible, may have been more favorable. Thus the hypothesis of the first origin of life through spontancous gencration is carricd to a logical postulate.

But the theory cannot be extended to mean that spontaneous generation must even now exist. For that there can be no basis; indeed, many facts point in the contrary direction. As Darwin, in his doctrine of the struggle for existence, has shown in a masterly way, the potentialities of existence upon the surface of our earth are exhausted. New living creatures are only possible when others perish. Why, then, should spontaneous generation engage further 
in the increase of individuals and species, where the space is not sufficient for the already more favorably situated organisms?

\section{Generation by Parents, or Tocogony.}

Two Principal Methods.-As mentioned above, we shall deal here only with those methods of reproduction which have actually been observed, i.e., generation by parents. These methods fall mainly into two great groups, asexual and sexual generation, monogony and cmphigory, to which may be added a third group, a combination of these two methods of reproduction.

\section{a. Ascxual Reproduction. Monogony.}

Monogony Defined.-The chief characteristic of asexual reproduction is the fact that for it only a single organism is necessary. But since, in certain modes of sexual reproduction, this same fact also holds true, still further explanation is necessary. Asexual reproduction is prepared for by a rapid growth of the organism; it is, as it has been described, an overgrowth, a growth beyond the indizidual limits. So soon as an organism grows beyond the definite size suited to it, the material of its body divides into two or more animals. The growth of the organism may be either a general one and lead to a regular increase of the animal in all its parts, or it may be localized and cause a partial increase, and consequently the formation of an outgrowth at the point of greatest increase; in the first case, division takes place, in the latter, budding.

Division.-In the case of division, an animal falls into two or more parts equivalent to one another, so that it is not possible to distinguish the mother and the daughter animal; for the original animal has completely disappeared in the young generation. The division is commonly a transverse one, in which the plane of division stands perpendicular to the long axis of the animal; less common is longitudinal division, rarest is oblique division (the planes 
of division passing in the direction of the long axis, or forming an acute angle with it).

Budding.-In the case of budding, the products arising from it are unequal. One animal maintains the identity of the mother animal; the outgrowth, on the contrary, the bud, caused by local growth, appears as a new formation, as the daughter individual. Yet the difference between division and budding is bridged by intermediate conditions; for, if we start with binary division, this is found to approach budding in the same degree as the division products become unlike, so that the one takes on more and more the character of a bud, the other retaining continuously the character of the mother organism. Such transitions are chiefly possible in the case of terminal budding, where the buds appear elongating the maternal organism at one end of the main axis. The character of budding is, on the contrary, unmistakable, if the buds, by a new formation of their axis of budding, arise as lateral outgrowths of the mother (Fig. S7), or, if from the same mother

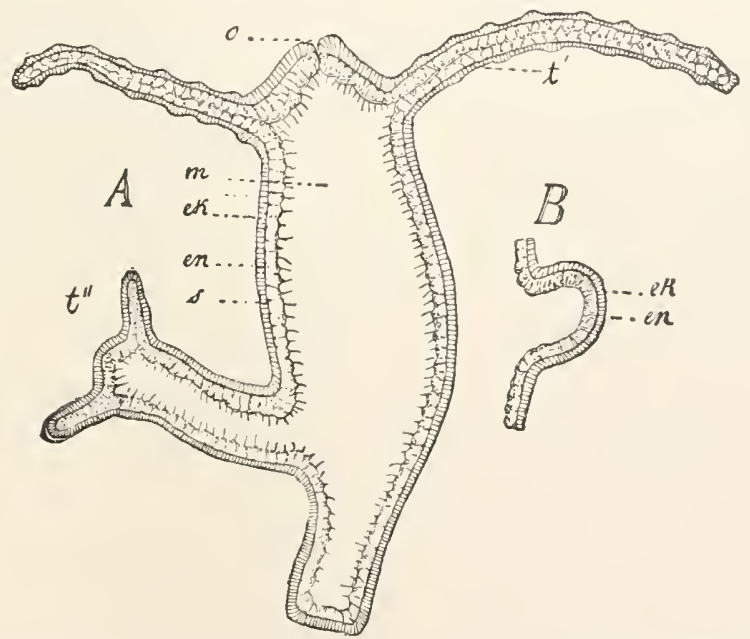

FIG. 87.-A, Hydra grisea in optical section, with a bud in the long ax's; also $B$, first rudiment of a bud. $e n$, entoderm; $e k$, ectoderm; supporting lamelia; $t^{\prime}$, tentacle of the mother animal ; $t^{\prime \prime}$, tentacle of the bud; $m$, stomach; 0 , mouth-opening.

numerous buds are simuitaneously cut off (lateral and multiple budding) (compare Fig. 2 I). 


\section{b. Scxual Reproduction: Amphigony.}

Amphigony Defined.-For sexual reproduction two animals are commonly necessary, a female and a male; the reproductive cells, the eggs, of one must be fertilized by the reproductive cells, the spermatozoa, of the other, and thereby acquire the capacity of giving rise to a new organism. Now, since there are hermaphroditic animals which produce simultaneously eggs and spermatozoa, and since many of them at least lack the power of self-fertilization, it becomes clear that the emphasis in the definition of sexual reproduction must be laid, not upon the individual, but upon their sexual products. Conscqucntly the csscntial point of scxual reproduction is to be sought in the union of male and fomale sexual cells.

Parthenogenesis and Pædogenesis.-This explanation is applicable to by far the greater majority of cases, namely, to all cases where the term "sexual reproduction" can be applied. Still, in the course of the last twenty years it has been demonstrated in many instances that two modes of reproduction, formerly considered as monogony, parthcnogencsis and padogcnesis, must be regarded as special modifications of sexual reproduction, although the abovementioned conditions are not strictly fulfilled. In both cases the eggs develop on account of some peculiar internal stimulus, without the occurrence of fortilization by spormatowod. In case of padogencsis there is the additional circumstance that reproduction is accomplished by animals which have not completed their normal development; for example, the larvæ of certain flies reproduce before they have passed through the pupa stage and become flies. Padogencsis consequently is the parthenogcnesis of an immature organism.

\section{Parthenogenesis and Typical Amphigony.-.-Some} investigators have attempted to exclude parthenogenesis from sexual reproduction, by claiming that those eggs which deveiop parthenogenetically are pseud-ova, structures 
which are not actual eggs. This view is absolutely untenable in view of the proof that the "pseud-ova" arise just like ordinary eggs and develop like them, since they cleave and form germ-layers. The equivalence of parthenogenetic eggs to those which are fertilized is best shown in the case of the bee, where similar cells give rise to a female or a male insect according as they are or are not furnished by the queen during oviposition with a spermatozoon. Parthenogrenesis is, therefore, not an asexual reproduction which precedes sexual reproduction, but rather a reproduction which must have been derived from the sexual; it is a scuual reproduction in which a degencration of fertilization has taken place. In consideration of this condition, we must accustom ourselves to the conception that, for the essential point of sexual reproduction, fertilization (the entrance of the spermatozoon) forms indeed an extremely important, but a by no means indispensable, characteristic. To all cases comprised under amphigony this definition alone applies: "scxual reproduction is a reproduction by means of scxual colls."

Sexual and Somatic Cells.-The distinction of sexual cells from the asexual reproductive bodies, the parts arising by division and budding, is shown by their relations to the vital processes of animals before the beginning of reproduction. The cells of a bud have had a share in the vital processes of the animal; they were functional or "somatic" cells. In a fresh-water polyp, when a bud arises, the cellular material employed is that which was used previously by the mother animal exactly in the same manner as the other parts of the body-wall. The sexual cells of an animal, on the contrary, are permanently, or at least for a long time, excluded from the vital processes, remaining in a resting condition, and conserving their vital energies. Therefore, there are lacking also in sexual reproduction the relations to growth which are so remarkable in asexual reproduction. For, although very often sexual reproduction does not begin until the bodily growth is completed, yet it is found repeatedly that animals, as for 
example all fishes, continue to grow after the beginning of sexual maturity, until they are double or many times their size at that time. Sexual reproduction is not even a special form of growth, but a complete renewal of the organism, a rejuvenescence of it. By this is explained the important phenomenon that asexual reproduction is suppressed more and more by sexual reproduction; the higher the organization of the animal the more the vital energies of its cells must be employed to meet the increasing demands upon their functional capacity.

\section{c. Combined Modes of Reproduction.}

Occurrence in the Same Species.-Very often there occur in one and the same species of animal two modes of reproduction side by side. Many corals and worms have the power of increasing by division or budding, and also of forming eggs and spermatozoa; again others have no asexual reproduction, but their eggs develop according to circumstances, either parthenogenetically or after fertilization. The appearance of two kinds of reproduction is very often governed by the fact that individuals with different modes of reproduction alternate in a quite definite rhythm with each another. Such a development is called altcrnation sf gencrations in the wider sense; and of this, two special forms are distinguished: metagcncsis, or alternation of generations in the narrower sense (progressive alternation of generations), and heterogony (regressive alternation of generations).

\section{Progressive Alternation of Generations. Meta-} genesis.-Altcrnation of gencrations in the narrower sense, or metagenesis, is the alternation of at least two generations, of which one increases only asexually, by division or budding, the other sexually-either exclusively, or at least preponderatingly. The first generation is called the nurse, the second the sexual animal. The reproduction of hydromoduse furnishes the best example (Fig. 88). The nurses here are the polyps, which, usually in numbers, united with 
one another into a colony, never produce sexual organs, but sexual animals, the maluse. The maduse are altogether unlike the polyps, being much more highly organ. ized, and freely motile; only very rarely have they preserved the asexual mode of reproduction; on the other hand, they develop eggs and spermatozoa, from which the non-motile nurses, the polyps, develop. This example shows that, in alternation of generations, there is present

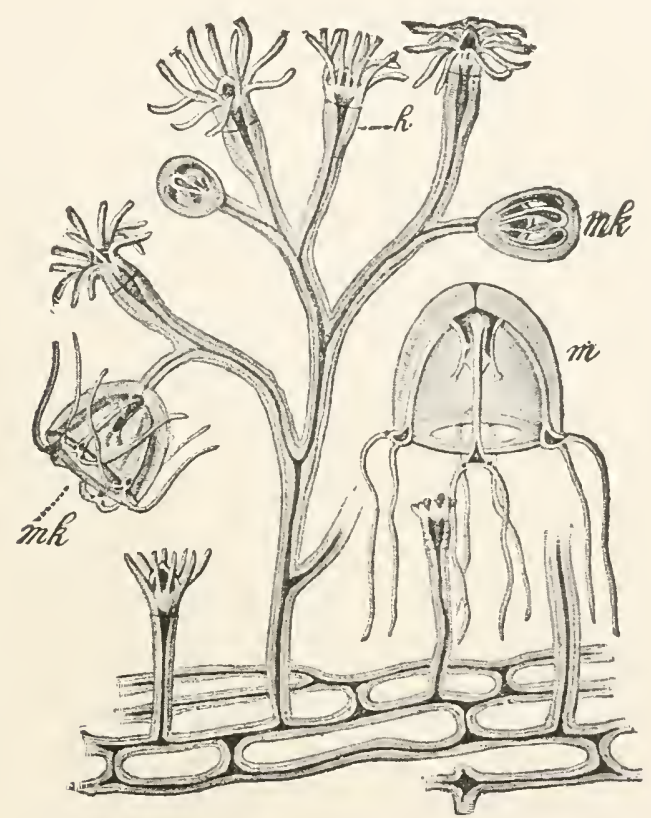

FIG. 88.-Bowgainzillea ramosa. (From Lang.) h, hydranths which have given rise to medusa-buds ( $m h$ ) (nurse.); $m$, separated medusa, Margelis ramosa (sexual animal).

not only a difference in the mode of reproduction, but that, usually, there obtains, in addition, a difference in form and organization. Between polyp and medusa the difference is so great that for a long time these two, though representatives of the same species, were referred to quite different classes of the animal kingdom. In many cases the alternation of generations may be still further complicated by two asexual generations following each other, 
before the return to the sexual generation takes place; one speaks then of grand-nurse, nurse, and sexual animal.

Heterogony is distinguished from the ordinary alternation of generations, or metagenesis, by the fact that the asexual generation is replaced by parthenogenesis. Consequently there alternate animals of sometimes quite different structure, of which the one arises from fertilized, the other from unfertilized, eggs. Certain crabs, the Daphnide, show heterogony in a typical manner. During a long period of the year, only females are found; these increase parthenogenetically by "summer eggs"; then males appear for a short time; they fertilize the "winter eggs," which are meantime produced, from which again parthenogenetic generations arise. Very often heterogony has been insufficiently discriminated from metagenesis, chiefly for the reason that parthenogenetic reproduction was regarded as an asexual mode, as was the case in the Tromatodes. The sexually ripe Distoma produces the very abnormally formed sporocysts; these again give rise parthenogenetically to the larve of the Distoma, the Ccrearia. For a long time the erroneous view was held that the cells from which the Cercarix arose were not eggs, but " internal buds," " germinal granules." On the other hand there have been included under heterogony modes of reproduction in which no parthenogenesis whatever occurs. Cases have been called heterogony, when two generations which have only different forms and organization alternate. In the frog's lungs, lives Ascaris nigroienosa, an hermaphroditic worm; it produces the separate-sexed Rhabdonema nigrowenosum living in mud, from whose eggs the ascarid of the frog is again produced.

Asexual and Sexual Reproduction.-The distribution of the modes of reproduction in the animal kingdom shows, in an almost convincing manner, that asexual is the lowly, sexual the highly, developed type of reproduction. Asexual reproduction predominates among the Protozoa; among the crlentcrates, it is found together with the sexual method; it disappears in case of the worms, and, 
among the clinoderms and the higher animals, it does not occur at all. On the contrary, sexual reproduction appcars among the Protozoa only in its first beginnings; it gradually supplants the asexual mode among the colcuterates and worms, and predominates among the cchinoderms and higher animals. Parthencgenesis occurs, we may say, interpolated into the region of sexual reproduction chiefly among the arthropods, more rarely among the worms. The manner in which this takes place, the parthenogenetic mode of reproduction in addition to the strongly sexual mode, is a more certain proof that here originally in all cases a normal fertilization prevailed, and only special conditions of life have brought it about that the eggs have acquired the capacity to develop without spermatozoa. For many species it has been conclusively shown that the purpose of parthenogenesis is to render possible a rapid increase of the species because of the scarcity of males. So long as parthenogenesis prevails, bark-lice and water-ficas distribute themselves with quite extraordinary rapidity over the area accessible to them, while the appearance of males occasions a slower increase.

GENERAL PIIENOMENA OF SEXUAL REPRODUCTION.

In sexual reproduction, a series of developmental processes is observed which is repeated in an essentially similar manner in all multicellular animals, and hence these should be spoken of here together. They are: (I) the maturation of the egg; (2) the process of fertilization; (3) the process of cleavage; (4) the formation of the three germ-layers.

\section{Maturation.}

The egg with the large vesicular nucleus, the germinal vesicle, as we have learned to call it in histology, cannot yet be fertilized; to render it capable of fertilization it must undergo a series of changes-the process of maturation (ripening), which consists in the replacement of the germinal vesicle by a very much smaller egg-nucleus, and simulta- 
neously the constriction at one pole of the egg of the "directive corpuscles " or " polar bodies.'

Formation of the Polar Bodies. - The germinal vesicle initiates the changes, its walls disappearing, its contents, in part, minging with the cytoplasm of the egg, in part, probably being employed for the formation of a nuclear spindle. The latter, called also the directive spindle, places itself with its axis in a radius of the egg so that one pole is turned towards the centre and the other fixed in the superficial layer of the egg (Fig. $89, a$ ). Now begins a regular cell-division process, but the products of the division are
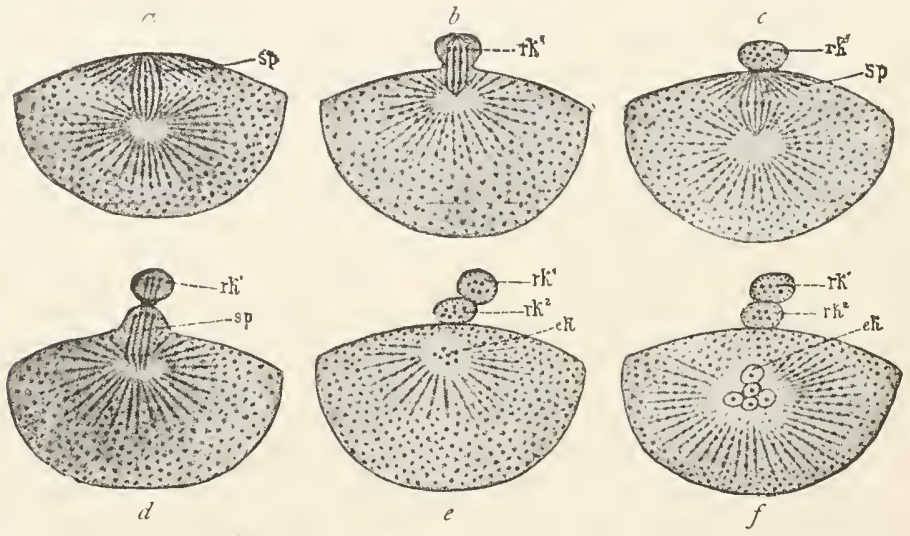

FIG. 39.- Successive stages in the formation of the polar bodies of Asterias glacialis. sp, directive spindle $; k^{1}$, first polar body ; $r k^{2}$, second polar body; $e k$, egg-nucleus in process of formation.

of very unequal size; the larger part is the egg, the smaller quite insignificant part is the polar body (Fig. 89 , $b, c)$. The latter raises itself as a projection above the surface; into this the directive spindle pushes one half of itself; in the cutting off this half of the spindle is included in the polar body.

The Sccond Polar Body.-The part of the directive spindle remaining in the egg is immediately perfected as a new spindle; the cell-budding is repeated and leads to the formation of the second polar body. As a result, two small cells lie at one pole of the egg, in many cases even three, since, during the formation of the second polar body, 
the first may have again divided ( Fig. $89, d-f$ ). The part of the directive spindle still remaining after the second division becomes a resting vesicle-shaped nucleus, which is called the $\operatorname{sgg}$-nucleus, the characteristic feature of the ripe egg capable of fertilization. In other words, by a double division there have been formed from the unripe egg four (sometimes three) cells, of which one has received by far the greatest part of the original mass of the cell and constitutes the ripe egg, while the others are small bodies like rudimentary eggs. The name "directive corpuscles" was given to them from the fact that in very many cases their position renders possible a definite orientation of the egg: i.e., a diameter, the long axis, can be passed through the egg, one end of which is marked by the directive corpuscles. With reference to later processes of development, this end is called the animal pole of the egg, the opposite end the regetal polc.

Relation between Maturation and Fertilization.--In most cases the maturation takes place either in the ovary or at the beginning of the oviduct, previously to the entrance of the spermatozoon into the egg; in many animals, on the contrary, there ensues a pause after the first polar body has been formed; the egg then requires the penetration of a spermatozoon in order to complete the further changes, i.e., the cutting off of the polar bodies and reconstruction of the egg-nucleus. This dependence of the last phenomena of maturation upon the beginning of fertilization led for a long time to the error that the formation of the polar bodies formed a part of the fertilization process itself.

\section{Fertilisation.}

Copulation and Artificial Fecundation.- If one wishes to use the term "fertilization" in the scientific sense, he must limit himself to the intimate occurrences which, after the meeting of the egg and spermatozoon, go on in the interior of the former and result in a complete fusion of the two sexual cells; on the other hand, he must 
choose special expressions for those progressive occurrences whose purpose is to render fertilization possible. Very often, but not in all cases, there is necessary an active transmission of the sperm from the male to the female, a copulation. In case of many marine animals, particularly most fishes, chinodcrms, calcntcrates, the eggs and the spermatozoa are discharged into the water, and the union of these (impregnation or fecundation) depends upon chance. One can bring about then artificially what is accomplished by nature, by obtaining from the sexual organs the ripe products and bringing them together. For example, from the uterus of a female frog one may take the eggs and impregnate them with sperm from the testes of the male; or by suitable pressure upon the body of sexually ripe fishes, the eggs may be collected in one dish, the sperm in another, and the contents of the latter poured over the former, and thus in many cases an entirely normal development may be obtained. Such a proceeding is called artificial fertilization; it would be more correct to call it artificial fecundation.

Fertilization.-Let us now pass to the process of fertilization in the narrower sense; this begins with the entrance of the spermatozoon into the egg. Usually the egg is surrounded by a gelatinous envelope, the chorion, to the surface of which the spermatozoa remain attached, and through which they bore until they reach the surface of the egg (Fig. 90). But since the chorion, particularly in eggs which are laid in the open air, must be hard and resisting, there exists in it very often a special arrangement, the micropyle, rendering possible the entrance of the spermatozoon; this is a single canal extending through the entire thickness of the chorion, as in the egoss of fishes, or a group of such canals, as in those of almost all insects.

Monospermy and Polyspermy.--Through the gelatinous envelope, or through the micropyle canal, many spermatozoa may pass, but under normal conditions never more than one serves for fertilization. To meet that spermatozoon which is in ever so slight a degree in advance of the others, 
the egg sends up a projection by which it can enter into the interior of the yolk; thereupon the egg becomes inaccessible to all the other spermatozoa, and the unsuccessful ones perish. Only in case of pathological changes, or where eggs are injured by long waiting, can it happen that two or more spermatozoa enter. Over against the normal simple fertilization or monospermy, we must place, as a pathological phenomenon, multiple fertilization, dispermy and polyspermy. There are means of protection against this abnormal fertilization. One of these, though by no
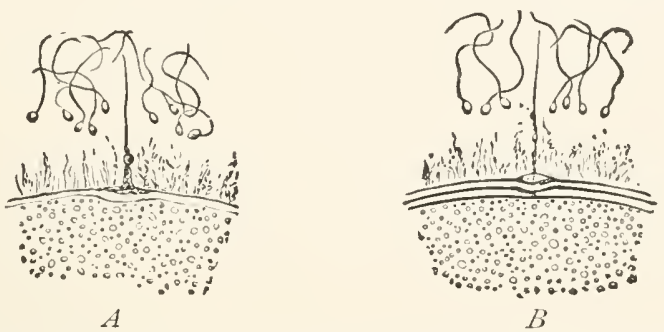

Fig. go.-Egg of Asterias glacialis during fecundation. A, entrance of the spermatozoon, $B$, the spermatozoon has entered : the yolk-membrane has formed. (After Fol.)

means the only one, is the formation of the yolk-membrane, an impermeable envelope which is suddenly secreted from the surface of the egg, as soon as the spermatozoon has accomplished the impregnation. Within the yolkmembrane the body of the egg contracts into a smaller volume by discharging some of the more fluid constituents, so that, between the yolk-membrane and the surface of the egg, a cavity is formed by which one can easily recognize the smaller fertilized egg (Fig. 90, $b$ ).

Essential Feature of Fertilization.-After the spermatozoon has penctrated into the egg, the head and the centrosome can still be recognized, but the tail becomes fused with the yolk of the egg. In the cytoplasm of the egg the achromatic end of the sperm-nucleus gives rise to conspicuous rays, like those observed during division. Preceded by these rays the sperm-nucleus travels towards the egg-nucleus until it reaches it (Fig. 9l); the sperm and egg-nuclei unite and form a single nucleus, the clearage 
nucleus, which rapidly forms a nuclear spindle (cleavage spindle), thereby giving the impulse to the beginning of embryonic development, the cleavage of the egg (segmentation of the egg). Since, not until this point is fertiliza-
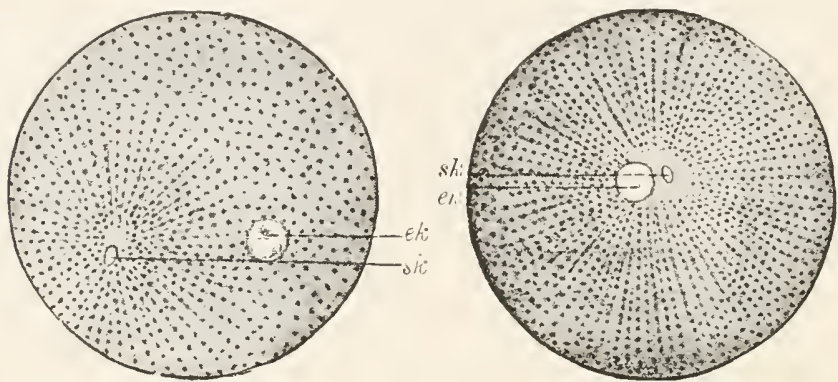

F1G. 9r.-Stages in the fertilization of the egg of the sea-urchin. (After O. Hertwig.) The sperm-nucleus $(s k)$ with its rays in one egg is near the surface, in the other near the eggnucleus $(e k)$.

tion completed, we here find the impoitant fundamental proposition that the esscntial foature of fertilization consists in the union of cgo and sperm nuclci.

\section{Part Played by the Two Nuclei in Fertilization.-} In many cases an abbreviation of development may take place, the stage of the cleavage nucleus being omitted, and the egg and sperm nuclei, without previously uniting, pass directly into the cleavage spindle. This fact in no wise
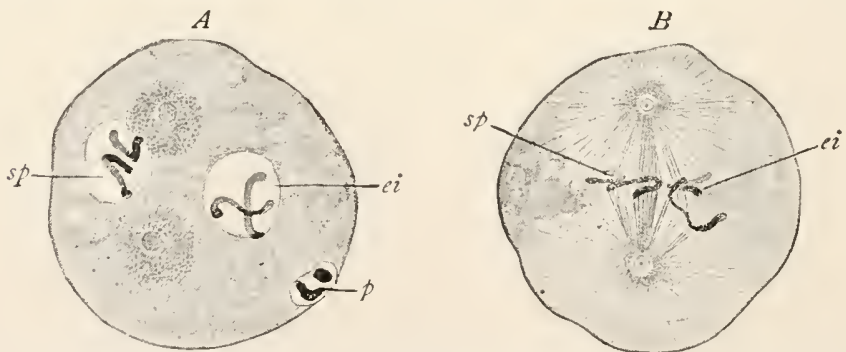

Fig. 92.-Fertilization of Ascaris megalocephala. (After Boveri.) $A$, the ends (centrosomes) of the spindle formed ; $B$, the spindle completed; $s p$, sperm-nucleus with its chromosomes; $e i$, egg-nucleus; $p$, polar bodies.

alters the above-mentioned proposition, but yet it is important, because it shows more plainly in what way the two nuclei participate in the formation of the cleavage spindle. It shows that of the chromosomes, i.e., the chromatic ele- 
ments, which form the equatorial plate of the nucleus, exactly one half are furnished by the egg-nucleus, the other by the sperm-nucleus. For, even before the spindle has been formed and the contour of the two nuclei has disappeared, the chromosomes destined for the spindle are completely developed in each of these (Fig. 92).

Heredity.-Recent observations have furnished a definite basis for the study of heredity. By heredity we understand the transmission of parental characteristics to the offspring. This transmission, on the whole, takes place with equal energy from the father's and from the mother's side; if we take the average of numerous cases, the result is that the child's peculiarities hold the mean between the peculiarities of father and mother; or, in other words, male and female individuals in the average have an equal power of transmitting characteristics.

The Material Basis of Heredity.-Since in case of all animals with external fertilization a material connection between parents and offspring can exist only through the sexual cells, consequently these latter must contain the substances which render heredity possible; further, the two hereditary substances, in cases of equal capacity for transmission, must be present in the egg and in the spermatozoon in equal quantity. By this course of reasoning, the chromatic nuclear substance which forms the chromosomes has come to be regarded as the bearer of heredity; for we know that the egg contains a great quantity of cytoplasm, but the spermatozoon only the slightest trace of it; that, on the other hand, egg-nucleus and spermnucleus furnish equivalent substances, and particularly the. same quantity of chromosomes, to the cleavage spindles; hence only the chromatin can be regarded as the hereditary substance. From this an earlier expressed view, that the nucleus is the bearer of hereditary qualities and determines the specific character of the cell, gains further support (con. sult p. So). 


\section{Cleavage Process.}

Arrangement of the Cleavage Planes.-The fertilized egg-cell divides in rapid succession into $2,4,8$, 16 , etc., cells, which become continually smaller, since the mass of the egg undergoes no increase. The cells are called cleavage spheres, the whole process the cleavage process, because, at each division, furrows arise on the surface which continue to penetrate more deeply (Fig. 93). In general the rule holds that each new plane of

I

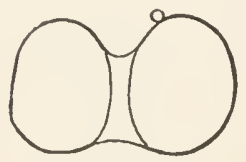

II

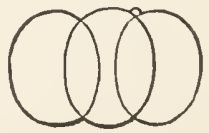

III

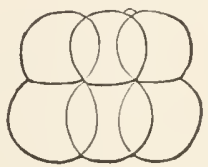

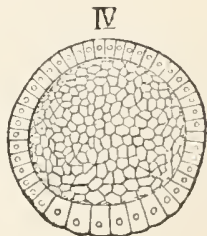

FIG. 03. - The equal cleavage of Amphioxus lanceolatus. (After Hatschek.) I, division into two (formation of the first meridional furrow) : I1, division into four (second meridional furrow) forming four cleavage spheres (third is hidden); 11I, division into eight (equatorial furrow ; the eighth cleavage sphere is hidden); $1 \mathrm{~V}$, blastula in optical section. A single layer of cells surrounds the cleavage cavity. In I, 11, 111, a little body (the polar body) is shown.

cleavage is as nearly as possible perpendicular to the preceding. Hence the first three cleavage planes, which cause the division into 2,4 , and 8 parts, are similarly arranged in almost all animals. Using the globe as a basis for comparison, one speaks of a first and a second meridional furrow (I, II), and calls the third the equatorial furrow (III). The intersections of the two meridional furrows form the poles of the egg, the animal and the vegctal, so called because the material of the one is used chiefly for animal organs (nervous system), the material for the other for vegetative organs (digestive tract).

Influence of the Yolk upon the Cieavage Process. - In embryology there are distinguished different kinds of cleavage processes, whose differences depend upon two factors: (I) upon the quantity of material, food-yolk, serving for nourishment of the egg; (2) upon the arrangement of this. The food-yolk hinders the division, since it is a material which is not capable of active movement, and is 
only passively divided through the activity of the protoplasm in the cleavage cells. The more the mass of this ballast increases in relation to the protoplasm, so much the more slowly does the cleavage process proceed. Finally there comes a point where the resistance of the yolk becomes so great that the protoplasm is no longer able to completely carry out the work; then only the protoplasmic part of the egg is divided, that which is rich in yolk remaining an undivided mass. In this case, one speaks of a partial cleavage in comparison with the ordinary and more primitive mode, the total cleavage; further, the eggs which show a partial cleavage are called meroblastic, because only the segmented part of the egg is directly employed in the formation of the embryo or bud $(\beta \lambda \alpha \sigma \tau$ rs s), while the undivided main mass serves merely as food-material in the course of growth. Eggs with total cleavage, on the contrary, are called holoblastic.

Distribution of the Yolk.-As to the second point, the arrangement of the yolk: this is connected with the position of the nucleus; either the egg-nucleus maintains

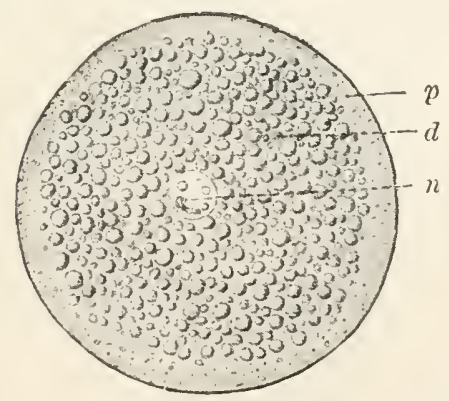

FIG. 94.

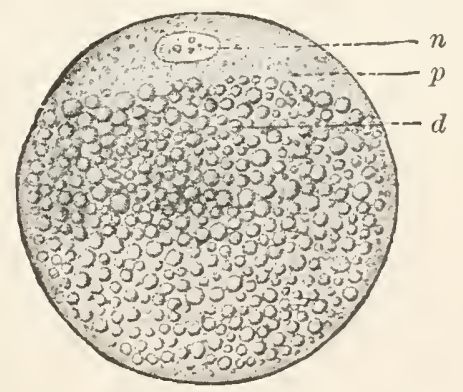

Fis. 95.

FıG. 94.--Centrolecithal egg. (After 0. Hertwig.) $n$, nucleus; $\not \phi$, portion of the egg rich in protoplasm ; $d$. portion rich in yolk

Fig 95.-1elolecithal egg. (After O. Hertwig.) $n$, nucleus; $f$, portion of the egg rich in protoplasm; $d$, portion rich in yolk.

a central position and collects the yolk around itself in concentric arrangement (centrolecithal cggs) (Fig. 94), or it is pushed, together with the greater part of the protoplasm, to one pole of the egg, while at the other pole the yolk predominates (tclolecithal $\cos s$ ). Since the nucleus-con- 
taining pole, in the course of development, always becomes the animal pole, there can be distinguished in the egg an animal part rich in protoplasm and a vegetal part rich in yolk (Fig. 95). In many telolecithal eggs the two regions pass gradually into one another, but in others the distinction is sharply expressed, so that a distinct boundary separates an almost purely protoplasmic animal portion from a yolk-containing vegetal portion. This condition is most beautifully shown in the bird's egg (Fig. 96). Here only the yellow of the egg is to be regarded as an egg in the embryological sense, while the white portion, the

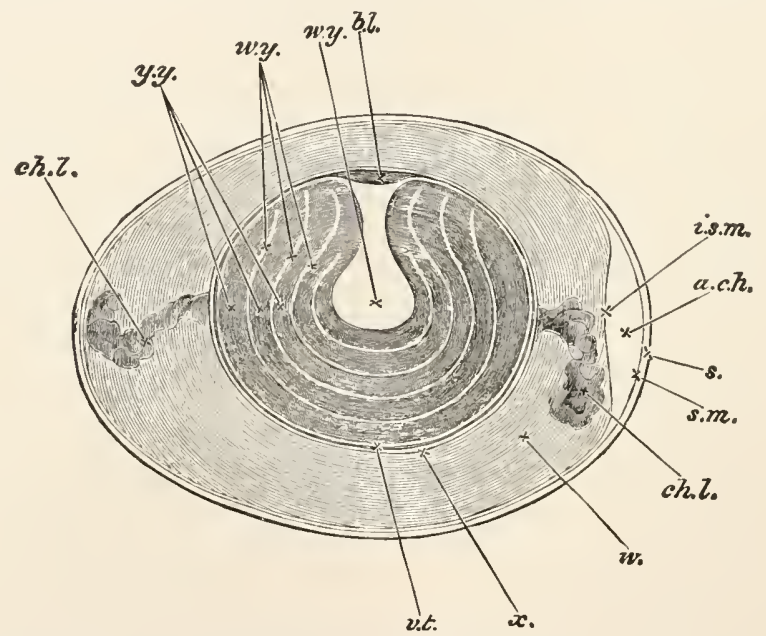

F1G. 96-Diagrammatic longitudinal section through a bird's egg. (After Billfour) (I) The egg : b.l, blastoderm; w.y., white yolk; $y$ y., yellow yolk (2) Coverings of the egg: \%.t. yolk membrane (vitelline membrane) ; $x$, and $w$., inner and outer layers of white; ch.l., chalaz: ; ..s.m. and s. m., inner and outer shell-membrane; between then at the right end is the air-chamber (a.c.h.); s, shell.

fibrillated egg-membrane, and the calcareous shell are only later depositions upon the surface of the egg. The chief mass of the yellow is food-yolk, upon which rests a thin layer of protoplasm, the blastoderm, always uppermost whatever the position of the egg. The protoplasmic layer contains the egg-nucleus, and, after fertilization, by progressive development continually separates itself more and more sharply from the underlying yolk.

Various Modes of Cleavage.-After the foregoing 
remarks a brief explanation will suffice to render intelligible the following figures of the various modes of cleavage.

\section{a. Holoblastic Eggs with Total Cleavage.}

I. Equal Claarage.-The yolk, present only in small quantity, is distributed equally through the egg; upon cleaving, the egg divides into parts of approximately the same size and equally rich in yolk (alecithal eggs) (Fig. 93).

2. Unequal Clearage.-The yolk is abundant, but not in such a quantity as to prevent complete cleavage; it lies especially at the vegetal pole of the egg, causing the cleavage in this region to progress more slowly; here larger cleavage spheres are formed, because richer in yolk; hence the embryo, at the very first, is found to be composed of smaller animal cells poor in yolk, and larger vegetal cells rich in yolk (telolecithal, holoblastic eggs, Figs. 97 and 98 ).
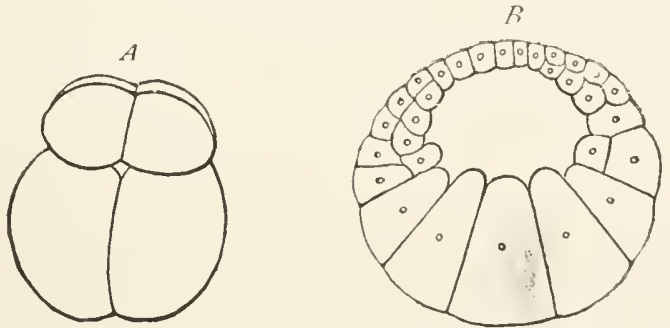

Fig. 97.-Unequal cleavage of the egg of Pitromyzon. (After Shipley, from Hatschek.) $A$, stage of eight cleavage spheres; $B$, blastula in meridional section. The dissimilarity of the cleavage spheres begins with the equatorial furrow.
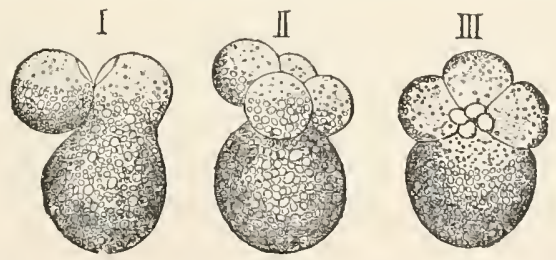

F1G. 98.-Unequal cleavage of a snail's egg, Nassa mutabilis. (After Bobretzky.) I, the first meridional furrow has divided the egg into unequal parts : 11 , the second meridional furrow has formed three smaller and one larger cleavage sphere (seen from the side); III, the equatorial furrow has formed four smaller animal and four larger but unequal vegetal cells (seen from the animal pole).

\section{b. Meroblastic Eggs with Partial Cleavage.}

3. Discoidal Clearage.-The yolk is so collected in the vegetal portion of the egg that it prevents cleavage; cleavage, therefore, is limited to the region around the 
animal pole and here forms a disk of small cells, the rudiment of the embryo, or the blastoderm (telolecithal, meroblastic eggs) (Fig. 99).
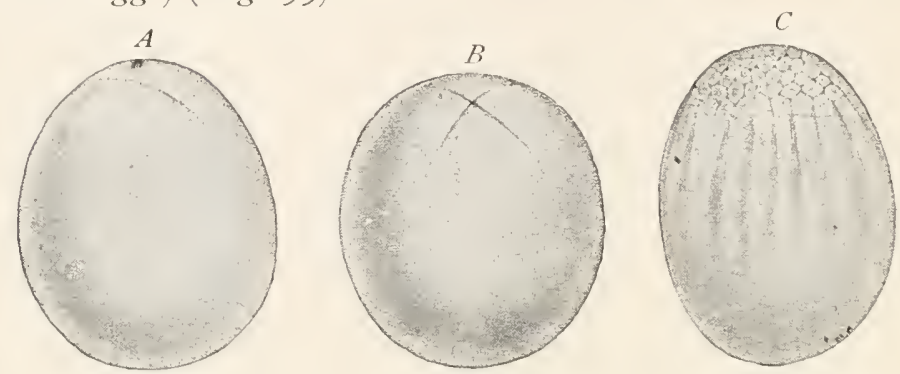

FıG, 9 j.-Discuidal cleavage of the egg of a Cephalopod (Loligo Pealii.) (After Watase.)

4. Superficial Clearage.-The yolk is collected in the centre of the egg and prevents cleavage; in consequence of this, only the outer layer of the egg divides into cleavage cells, which, in the form of a continuous superficial layer, enclose the unsegmented central mass (centrolecithal eggs) (Fig. I OO).
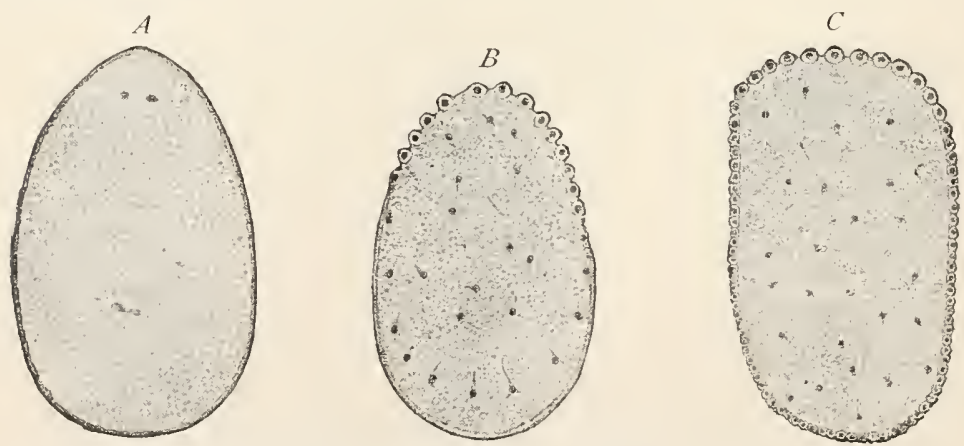

FIG. roo.-Superficial cleavage of an insect's egg (Pieris crategi). A, division of the cleav. age nucleus; $B$, movement of the nuclei to the periphery to form the blastoderm;, , formation of the blastoderm. (After Bobretzky.)

Distribution of the Modes of Cleavage - Of the four modes of cleavage mentioned the superficial one has an interest from the point of view of the systematist, since it occurs exclusively in the Arthropods. The other modes of cleavage are distributed as follows: the discoidal has been observed in the majority of the vertebrates and in the most highly organized molluses, the cuttlefishes, while 
the equal and the unequal cleavage can be found in all the groups of the metazoa.

Blastula.-Even during the first stages of segmentation there is formed a cavity, the clearage cavity, in the interior of the egg between the cells; with the progress of development this cavity becomes continually larger. Around it the cells lie in the form of a one-layered or of a manylayered epithelium and form the blastoderm. Hence the name for this stage, a'sicula blastodormica or, briefly, blastuld. The more yolk there is present, the smaller is the diameter of the cleavage cavity; in centrolecithal eggs with superficial cleavage it is entirely absent.

\section{Formation of the Germ-layers.}

Gastrula.-Besides the blastula there is still a second stage of development, the gastrula or the two-layered embryo, which is common to all the metazoa. This stage is understood easiest in the case of eggs which have an equal cleavage (Fig. IOI, $B$ ); here it has the form of a double-walled cup with a wider or narrower mouth. The cavity of the cup (the primitive digestive tract or archenteron) is the rudiment of the most important part of the digestive system; the opening is the primitive mouth or the prostome (called also the blastopore). Of the two layers of cells forming the wall of the cup and uniting at the prostoma, the external is the cotoolast or outer germ-layer, the internal the cntoblast or inner germlayer. In the gastrula stage, we meet for the first time the formation of germlayers, i.e., the formation of definite embryonic layers marked off from each other, the cells not yet differentiated,

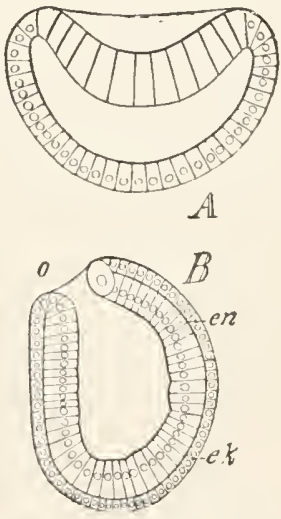

Fig. Ior. - liastrulation of Amphiorus (A f $\mathrm{ter}$ Hatschek.) The arimal pole here is above, and the vegetal pole below. in comparison with Fiy. 93. In Fig. A the cells of the vegetal pole are beginning to $\sin \mathrm{k}$ in $B$, the invagination conpleted; the clcavage cavity reduced to a slit between the entoblast $(e n)$ and the ectoblast $(e k) ; 0$, gastru'a-moutr. from which organs arise through organological and histological differentiation. 
Invagination.-The gastrula is formed from the blastula by invagination (Fig. IOI, $A$ ). The result is the same as when by pressure of the finger upon a hollow india-rubber ball one side is pressed in against the other; the layer of vegetal cells gradually sinks in and becomes surrounded by the cells of the animal pole (Fig. IOI, B). Thus there arises in the egg, in addition to the cleavage cavity, a new cavity, the rudiment of the lumen of the digestive tract; this increases and finally entirely obliterates the cleavage cavity, so that the invaginated part of the blastoderm, the entoblast, becomes pressed against the part which remains external, the ectoblast.

Modified Modes of Gastrulation.-In the case efgs with much food-yolk, the relation of the structure and of the mode of formation of the gastrula is more difficult to understand. Here, however, it is sufficient to mention the fact that the gastrula stage has fortunately been discovered for almost all eggs with a great quantity of food-yolk, and that the yolk-material finds lodgment principally in the entoblastic cells.

Epiblast and Hypoblast.-For outer and inner germlayer the terms cpiblast and hypoblerst, upper and lower germlayer, have been much used; these names actually apply best only to those eggs with discoidal cleavage. In the bird's egg, for example, the two germ-layers form over the unsegmented yolk, from which they become separated by the gastrular cavity; thus then the external germ-layer actually lies above, the internal below. Other terms for the two germ-layers are cotodcrm and cntoderm. These names were originally used for the body-layers of mature animals, the cœelenterates, and were only later transferred to embryology. In this book they will be used only in their original signification for cell-layers which have already undergone organological and histological differentiation, since for embryonic cell-layers the names entoblast and ectoblast are more suitable.

Delamination.--In regard to the mode of development of the gastrula many controversies have arisen which are 
not yet finally settled; in addition to invagination there may cxist still a second, but at all events, a very much less
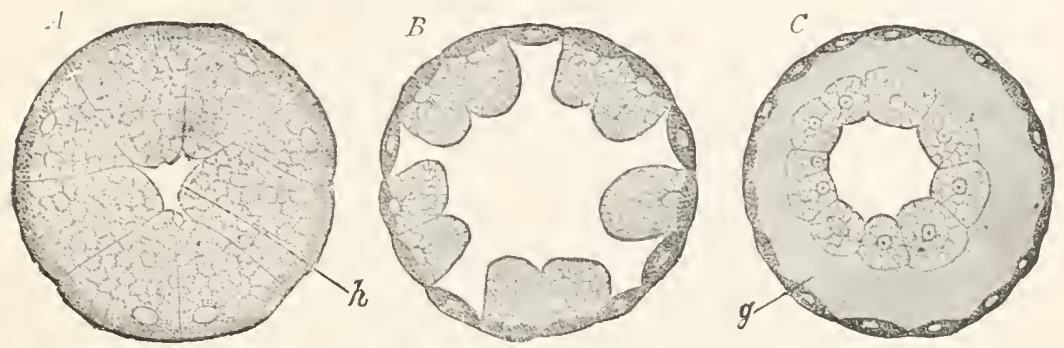

Fig. 102.-Delamination of the egs of a fieryonid. (After Fol; from Korschelt-Heider.) $h$, cleavage civity ;, jelly.

frequently occurring mode of development, dclamination. In delamination the blastula may become two-layered by tangential division of its cells (Fig. IO2); each single blastoderm-cell, or, at least, the majority of these cells, by this division falls into a peripheral ectoblastic and a central entoblastic cell. In case of delamination, the cleavage cavity becomes directly the cavity of the digestive tract, a fact which renders it difficult to regard delamination and invagination as modifications of one and the same process.

Formation of the Miesoblast. The Mesenchyme.Many lower animals, e.g. most calcuterates, have in general only two germ-laycrs. When these are laid down there begins immediately the differentiation of muscle and nerve fibres and the other processes of histological changes of the cells, as well as a series of changes of form, by which the gastrula becomes the adult animal. In higher organisms, on the other hand, before organological and histological differentiation begins, there arises still a third germ-layer, which, owing to its position between the first two, is called the mesoblerst or middle germ-layer: this naturally can come only from the cell-material of the existing germ-layers, and indeed only the entoblast seems to participate in it. Two methods can be distinguished in the formation of the middle germ-layer. In one case, the space between ectoblast and entoblast becomes widened by the secretion of jelly, and from the entoblast isolated cells 
push into this jelly; thus there arises a middle layer, the mescnchyme (Fig. IO3), somewhat similar to gelatinous con-

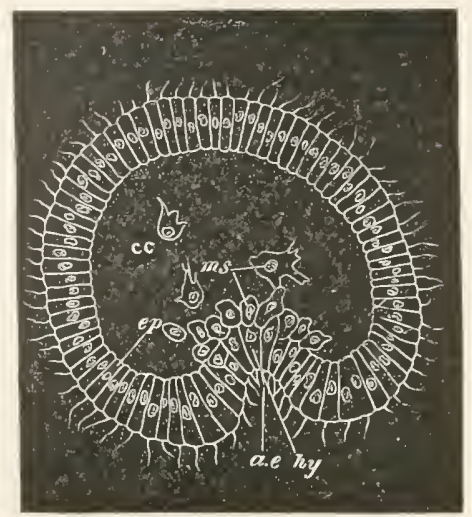

FIG. 103.-Formation of the Mesenchyme and beginning of gastrula ion in Holothuria tubulosa. (After Selenka, from Balfour.) $c$, cleavage cavity; $e f$, ectoblast; $h y$, entoblast ; $m s$, mesenchyme-cells; $a c$, archenteron.

nective tissue, from which certain organs take their origin either wholly or in part.

Mesepithelium.- In the second case, the middle germlayer may preserve the epithelial character of the two primary germ-layers, so that it is called mescpithclim.

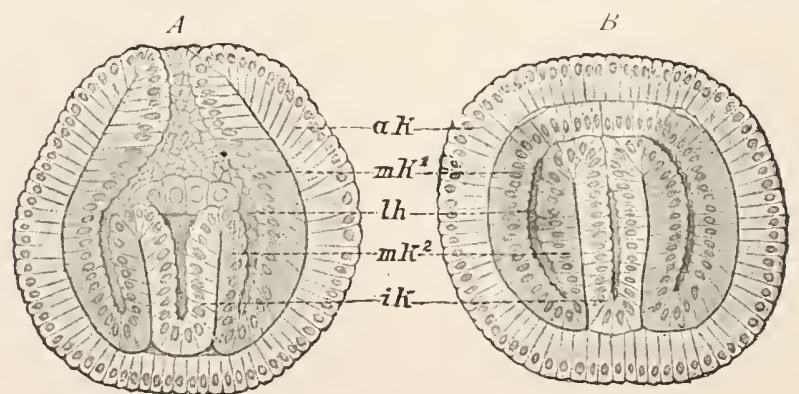

Fra. ro4.--Formation of the mesepithelium and of the coelcm of Sagitta. A. From the bottom of the gastrula arise two folds, which divide the archenteron into the permanent digestive tract and the colomic diverticula. $B$. The separation is almost completed by the pushing up of the folds. $a k$. outer, $m k$, middle, $t k$, inner germ-layer; $m k^{\mathbf{1}}$, somatopleure ; $m \AA^{2}$, splanchnopleure; $l h$, body-cavity.

The mesepithelium is a part of the entoblast constricted off, the mode of development of which is shown in the embryology of the worm Sagitta (Fig. IO4). 
Cœlomic Pouches.--When the gastrula of Sagitta has been formed. there arise on the walls of the archenteron opposite the mouth two entoblastic folds, symmetrical with the mid-line of the body, which divide the archenteron into three cavities, at first still in communication-the permanent digestive tract and the two rudiments of the body-cavity, the coelomic diverticula. Then the blastopore closes and the entoderm folds extend even into the anterior end of the gastrula, fusing here with the walls. In this way the two colomic diverticula become completely separated from the digestive tract; farther, in a corresponding manner, the hitherto continuous entoblast is divided into three epithelial pouches; the middle one is the lining of the digestive tract or the secondary entoblast (glandular lining of the intestine), the lateral ones are the lining of the coelomic sacs, or the paired rudiments of the middle germlayers. In each of these rudiments two layers are to be recognized, which become separated by the body-cavity; one layer lies against the digestive tract and is hence called the splanchnopleure, the other layer comes closely under the ectoblast, forming the external wall of the body, and is called the somatopleure. From what has been said above it is evident that the epithelial mesoblast is strictly not a single layer, but consists of two layers which pass into each other, and that its origin is closely connected with the formation of the body-cavity.

\section{Occurrence of Mesenchyme and Mesepithelium.-} Now as regards the mode of distribution of the mesenchyme and of the mesepithelium, there are three cases possible, and actually occurring. There are purely mesenchymatous animals, like the flat-zerms, and purely mesepithelial, like Sagutta, many annelids, and Amplioxus; but there are also animals in which the mesoblast consists of mesenchyme and mesepithelium: either the mesenchyme arises first and later the mesepithelium, as in the cchinoderms, or the reverse order is followed, as in most iertcbrates.

Histological and Organological Differentiation.-All the organs of an animal arise from the three germ-layers in 
this way: first, embryonic cell-material is marked off into a special aggregation, usually by infolding (organological differcutiation), and then later, this aggregation becomes changed into tissue (histological differentiation). The way in which this happens differs in the various animal groups. The following is the most general mode: from the cotoblast arise the skin with its glands and appendages, the nervous system, and the sensory epithelium; the cntoblast gives rise to the most important part of the digestive tract with its most essential glands; while muscles, blood, supporting and connective substances, excretory organs, in whole or in part, arise in the mesoblast; the sexual organs are also usually mesoblastic.

Relations of the Germ-layers in Budding.-Often of late the question has been raised as to how far the germlayer theory is applicable to the occurrences in asexual reproduction. At first, one would expect in budding, and still more in the case of division, that each organ of the daughter animal would be split off from the corresponding organ of the maternal animal, or, if that is made impossible by conditions of space, from a mass of tissue belonging to one of the same germ-layers. In many instances, this is certainly the case, as, for example, in the budding of Hydroids the entoderm and ectoderm of the bud arise from the corresponding layers of the maternal body (Fis. 87 ). But, through recent investigations, exceptions to this rule have become known. In Bryozoans and Tunieates there are undifferentiated cells which are employed in cases of budding; these are elements not yet furnished with the characteristics of a definite body-layer which, independently of the position which they assume in the maternal animal, can be employed, according to need, in the the building up of organs.

\section{The Different Forms of Serual Deaclopment.}

\section{Embryonic and Postembryonic Development. -} While the occurrences described are going on (fertilization and cleavage of the egg, formation of the germ-layers) 
the young animals are usually still enclosed within a firm protective covering, or even in the maternal sexual apparatus (uterus), and are hence called cmbryos. Later stages, even the formation of the most important organs, may fall in the time of embryonic life, as we see in case of the mammals, birds, reptiles, many fishes, worms, and crabs, which, upon arriving at the end of their embryonic existence, are completed in all their parts, and in addition need only the maturity of the sexual organs and growth of the body as a whole, in order to reach the climax of their development. On the other hand, there are animals, chiefly marine, which, after leaving their eggmembranes, still undergo important changes, like the colcnterates, chinodems, insects, amphibians, etc. The colenterates, cchinodorms, and many worms usually break through the coverings even before the formation of the ga:m-layers, and, as free-swimming ciliated "planula," form the germlayers and organs. Since there is here a more or less extensive post-embryonic development, it is a misnomer to apply the term "embryology" to both stages; it is necessary, rather, to limit the name to the developmental processes inside the egg-membrane, and, on the other hand, to speak generally of the history of the development of the individual, or ontogeny. As the undeveloped animal within its membrane is called an cmiryo, so the name lared is applicable to the free-living but not completely matured animal.

\section{Direct and Indirect Development-Metamorphosis.} - Larval development may be either a direct or an indircet one. In the direct development the larva, as the name implies, pursues the direct way towards its goal, the sexually mature animal, since the organs which are lacking to it are laid down one after another, and hence it is continually becoming more like the sexually mature animal. The indirect development, on the contrary, makes deviations; organs are formed which later are destroyed, belonging only to the larval life, and hence called larad organs. Therefore in the definition of indirect development, or as 
it is commonly called metamorphosis, special emphasis is to be laid upon the presence of "larval organs." Thus the caterpillars of butterflies are distinguished, not only by the absence of compound eyes and wings, but also by the presence of anal feet and spinning-glands, which are absent in the butterfly, and further by the different shape of the jaws, antenna, and legs, the different arrangement of the trachea and nervous system, etc. Tadpoles are distinguished from frogs, not only by the absence of lungs and extremities, but also by the presence of gills and tail. The more evident the larval organs, the plainer, therefore, will be the character of the metamorphosis.

Oviparous and Viviparous Animals.-The point of time at which the egg leaves the mother's body is independent of the time at which the embryo escapes from the egg-membranes. Two extremes are known, the oviparous or egg-laying animals, and the viviparous or those which give birth to living young. As strictly oriparous animals can be considered only those forms in which the egg, at the time of laying, has still the character of a single cell, in which case it is either not fertilized until after extrusion, as in the case of most fishes, sca-urchins, etc., or during extrusion, as in the case of batrachians and insects. In the case of riviparous animals, on the contrary, birth and the rupture of the eggmembranes occur quite, or almost, at the same time, and from the maternal vagina there emerges an animal which has completed its development or, at least, has progressed so far that it is able to live without protective coverings.

Ovo-viviparous Animals.--Varying degrees of "ovoviziparous" development mediate between these two extremes. What here appears at birth, at first impresses us on account of its covering as being an egg; but the first stages of development have already passed, so that, by artificial rupture of the egg-membranes, an embryo more or less developed, but usually not yet capable of independent life, is exposed. Birds are to be reckoned in the category of ovo-viviparous animals, for their eggs are fertilized long before they are laid, and have aiready completed the for- 
mation of the blastoderm. In the case of many worms the egg-shell may contain, even at the time of laying, an animal all ready for hatching.

\section{No Sharp Line to be Drawn between Oviparous} and Viviparous.-Transitional forms of this kind show that between "egg-laying" and "bearing living young" no sharp line can be drawn, and one must guard against attributing too much importance to the apparent distinctions. It was entirely erroneous for Linnæus, following the example of Aristotle, to regard the time of birth as of systematic importance. In many divisions of animals, oviparous as well as viviparous forms are found. The majority of sharks are viviparous, but a few species lay eggs; on the contrary, for bony fishes the rule holds that the eggs are laid before fertilization. Exceptions to this are the viviparous Zoarces riviparus and others. Most of the amfilibia, reptiles, and insects are egs-layers, but not a few forms are viviparous. Even among the mammals, for which for a long time the "bearing young alive" was regarded as diagnostic, there have been discovered lately egg-laying forms, the Eiludua and the Ornithorlunchus. Finally, exceptions to the rule occur in one and the same species. Adders commonly lay eggs, but under unfavorable conditions they retain them inside their body until ready to hatch.

\section{SUMMARY OF THE FACTS OF ONTOGENY.}

I. The development of an animal begins with an act of seneration; spontaneous generation and generation by parents are to be distinguished.

2. Spontancous gencration (Generatio aequivoca, or spontanea; Abiogenesis) is the origin of living beings from lifeless matter (without pre-existing organisms).

3. The present existence of spontaneous generation is neither shown by observation, nor is it, on the whole, probable; yet spontaneous generation is a logical postulate, in order to explain the first origin of life on our globe.

4. Generation by parents (Tocogony), derivation of an 
animal from an animal of the same or similar structure, can take place either by the sexual or the asexual mode.

5. Ascrual generation is, in the last analysis, caused by the growth of an organisin above its individual mass, since this surplus finally leads to a division into two or mo:e individuals.

6. Asexual generation may be either by division or by budding.

7. In case of division, an organism grows regularly in all its parts, and by constriction falls into two or more equivalent new pieces.

8 . According to the direction of the plane of division in reference to the long axis of the animal, we speak of longitudinal, transverse, and oblique division.

9. In case of budding, a local growth occurs; the local outgrowth, the bud, separates itself off from the mother as a smaller, usually also as an incompletely formed, animal.

IO. According to the position and number of the buds, we distinguish lateral, terminal, and multiple budding.

I1. Sexual reproduction is reproduction by means of more special cells, the sexual cells, which do not take part in the ordinary growth of the body.

12. In sexual reproduction two kinds of cells unite, the female egg and the male spermatozoon (fertilization).

I 3. In rare cases the egg develops without fertilization: parthonogenesis; this is a sexual reproduction with degenerated fertilization.

I4. Padogcnesis is parthenogenetic reproduction by a young (i.e., incompletely developed) animal.

I 5. Different modes of reproduction (asexual, sexual, parthenogenesis, pædogenesis) may occur in the same species; then these often occur in a regular order, and in such a way that individuals with different modes of reproduction alternate with one another: alternation of generations in the wider sense.

I6. Altcrnation of generations in the narrower sense (progessive generation, metagenesis) is the alternation of two generations, of which one reproduces by division or 
budding, the other sexually. The former is called the nurse, the latter the sexual animal.

I7. If more asexual generations follow one another before a sexual animal appears again, one speaks of grandnurse, nurse, sexual animal.

18. The alternation of parthenogenesis or padogenesis with pronounced sexual reproduction: is called regressive alternation of generations or heterogony.

I9. Development which is inaugurated by sexual reproduction shows in nearly all multicellular animals a general agreement in the incipient stages: iertilization, cleavage, formation of germ-layers.

20. The essential point of fertilization lies in the complete fusion of egg and spermatozoon, particularly in the fusion of the nuclei, egg and sperm nuclei, to form the cleavage nucleus.

21. The cleavage of the cgg is a cell division, a division of the fertilized egg into the cleavage spheres. The cleavage may be total (holoblastic egg) or partial (meroblastic egg); total cleavage is either cqual or unequal, the partial either discoidal or superficial.

22. By progressive division of the cleavage spheres, and by the formation of a cleavage cavity, there arises a one-layered embryo, the blastula (vesicula blastodermica).

23. By the invagination of the blastula the gastrula or two-layered embryo arises.

24. The gastrula surrounds a cavity, the primitive digestive tract or archentcron, opening to the exterior through the gastrula-mouth; it consists of two epithelial layers, the cntoblast (hypoblast) or the inner germ-layer, ining the primitive gut (archentcron), and the cetoblerst (epiblast) or outer germ-layer.

25. Between the inner and the outer germ-layer, still a third, the middle germ-layer, mesoblast, may be formed.

26. The middle germ-layer arises either by an infolding, or a cutting off of a part of the entoblastic epithelium, epithelial mesoblast, mescfithclium; or by the migration of separate cells to form a gelatinous tissue: mescnchy'me. 
27. Many animals deposit their eggs before or shortly after fertilization (oxiparous) ; others lay eggs which have already been fertilized in the maternal uterus, and at the time of laying have passed through some of the stages of development (oro-viviparous). A third series of animals give birth to living young (viriparous).

28. The development of an animal is either direct or indirect (metamorphosis).

29. Indirect development or metamorphosis is where the young animal, as it comes from the egg, differs from the sexually mature animal in two points:

(a) by the lack of certain organs which occur in the sexually mature animals;

(b) by the appearance of organs, larval organs, which are lacking in the sexually mature animals.

\section{RELATION OF ANIMALS TO ONE ANOTHER.}

General Relations.-Just as between the organs of one and the same animal there exists a regular connection which is termed correlation of parts, so also the different iindividuals of the animal population stand in manifold and intimate reciprocal relations to one another. Darwin has shown in a great number of instances how the conditions of existence of many animal species are altered, if other forms appear anew or disappear, or an extraordinary reduction or increase of the number of individuals. takes place. Such reciprocal actions are usually of a more special nature and can be understood only by individual study; a few conditions are of wide occurrence and are hence suitable for a general consideration; to such belong colony and state formation, parasitism, and symbiosis.

\section{RELATIONS BetTEEN INDividuals of THE SAME SPECIES.}

Colony Formation.-Colony and state formation are conditions which exist between individuals of the same species. By an animal colony is understood a union of 
numerous individual animals which depends upon an organic bodily connection; the latter may arise in two ways: first, by animals originally separate approaching one another and partially fusing together; secondly, by animals formed by division and budding remaining united with one another instead of separating. The first case is extremely rare, and in the animal kingdom plays no rôle whatever.

Colony Formation by Fusion.-Many protosod fuse with one another and form larger bodies in which the individual animals can still be recognized. Among the multicellular animals, that of Diplosoon paradoxum is the only case known where animals (Diporpa) normally two (Fig. I05), sprung from different eggs, unite into a double animal -which recalls certain double monsters, as for example the Siamese twins.

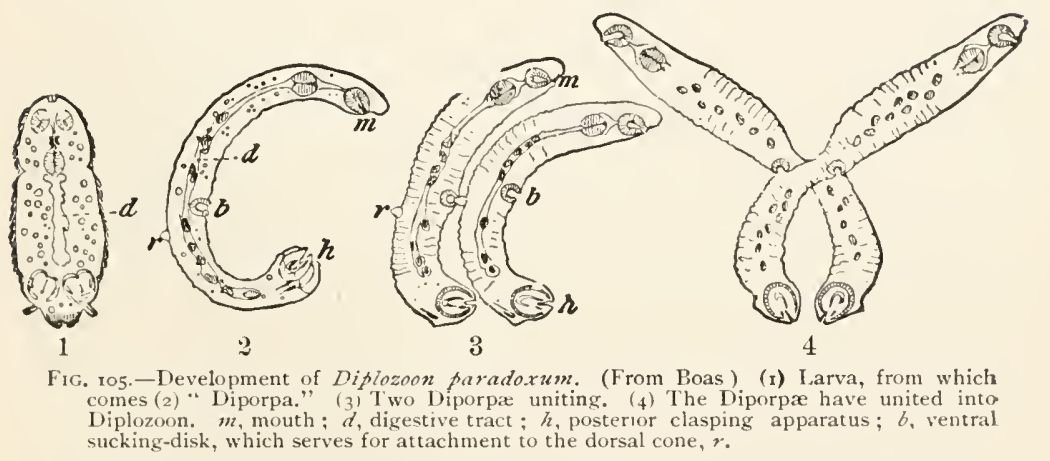

Colony Formation by Incomplete Division and Budding.- In general it can be said that the important instances of colony building occurring in nature rest upon incomplete division or budding. An animal has the power of asexual multiplication: but this does not go on to. the normal conclusion, since complete separation is not: accomplished, though indeed two or more individuals are formed. There persist more or less extensive bridges of tissue, which unite the divided parts with one another. or the buds with the mother. The marine colonies of coral; and hydroids (Fig. 88) may consist of thousands of individuals which, by repeated incomplete budding or 
division, have sprung from a single sexually-produced mother-animal.

Community of Functions.-The connection of tissue, in the majority of cases, conditions a not inconsiderable degree of community of functions. Stimuli which affect one individual are transmitted by common nerves to the other animals of the colony; thereby movements in common are rendered possible. In a similar way the food captured and digested by one animal serves for the colony in common. On account of the community of its functions, a colony appears like a unified whole, like an individual of a higher order; the same process which led to the formation of multicellular organisms is repeated. Just as there the elementary organisms, the cells, are united into a single animal, so here the single animals are united into a colony.

Polymorphism. - When a whole is made up of numerous equivalent parts, the conditions for division of labor are furnished. Instead of the functions of the entire organism being distributed equally to the individual parts, many of the latter become employed solely for this, others again solely for that function, and acquire a corresponding structure. In case of such animal colonies one speaks then of multiformity or polymorplism. Polymorphism appears oftenest in connection with the vegetal functions, leading to a distinction between sexual animals and nutritive animals, as in the case of most Hydrozod, where often nutrition is provided by animals without sexual organs, and reproduction is carried on by animals without a mouth. But other functions, movement, sensation, offence and defence, may also become specialized. Siphonophores are the classical examples of polymorphism (Fig. 106). Here united into a single body are locomotive animals, the swimmingbells, serving only for locomotion; covering parts, which serve only to protect the others; nutritive polyps, which alone take in and digest food; sexual animals and tactile polyps, which are concerned only in sexual reproduction and with sensation. In regard to the other functions each animal is referred here to its brothers and sisters; its very 
existence therefore has become dependent upon these; the single individual can continue to live only while a part of a whole. Thus also division of labor leads to greater centralization; the more polymorphic an animal colony

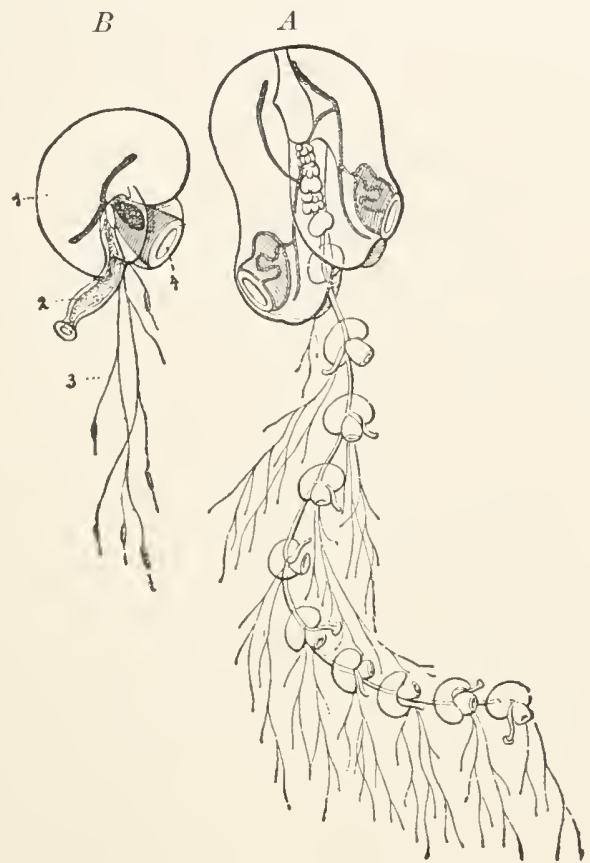

FIG. 106.-Praya diphyes. (After Gegenbaur) .4, the entire animal; $B$, a single group of individuals greatly magnified (Ludoxia). I, protective scale; 2 , nutritive polyp; 3 , nettle-threads; 4 , sexual bell.

becomes, the more unified it is, the more it gives the impression of being a single animal instead of an aggregation of single animals.

State Formation.-In case of statc formation the reciprocal dependence of the animals is much less, since here there exists no organic connection, only a voluntary communal cohabitation. As in the case of colony building asexual reproduction is of importance, so liere the sexual plays a prominent rôle. Under the influence of the sexual impulse, many animals, even some of the lowest organisms, flock together, either permanently or periodically; sca-urchins, sca-cucumbers, many fishes, collect near the coast at the time of egg-laying. The sexual impulse 
draws together herds of deer, elephants, etc. The care of the young offspring further leads to a closer organization, to a state formation in the narrower sense; all insect states are built up on this basis. Consequently, since the sexual life is the starting-point of state building, it is further conceivable that, in the different groups of individuals ranking as "states," the sexual organs are influenced in their development. Besides males and females (kings and queens) there are still other animals with degenerated sexual organs incapable of function, the workers; the latter are either only females (bees and ants) or females and males (termites). While the kings and queens give rise to posterity, the duty of the workers is to care for the young brood, to look after the hive, to provide food and protection, and also to serve for defence, if the latter is not delegated to a special class, the soldiers (termites.)

\section{Relations between Individuals of Different SPECIES.}

Causes of Close Relation.-Where individuals of different species stand in close reciprocal relations to each other, the cause is to be found in the advantages which the one species derives from the other, or which these both furnish reciprocally; the former case is called parasitism, the latter symbiosis.

Parasitism. - By parasites we understand animals which find their dwelling-place upon and obtain nourishment from another animal, the host, and which consequently have come into a dependent condition and have undergone a more or less extensive ch,unge in their organization.

True Parasitism.-The fact that an animal has settled down upon another is not sufficient to characterize it as a parasite. There are many animals which in general are sedentary, and which, when opportunity offers, attach themselves to a stone, a plant, or another animal; in such cases to speak of parasitism is a misnomer, becalise it cannot be called a dependent condition. If a hydroid polyp fastens itself upon the back of a crab instead of on a stone, 
it is the result of chance, in which the nature of the hydroid polyp is in no way concerned. The case must be considered quite otherwise, if the polyp in question were able to live only upon the crab, and perished, if in any other place. Such a dependent condition usually occurs only when the mode of nutrition is also dependent upon the place of abode; when the host not only serves for a dwelling-place, but also furnishes the dweller with food; when, consequently, the dweller lives at the expense of the host.

Degeneration Caused by Parasitism. - The degree to which a parasite has become dependent upon its host varies in the different species; it is determined by the extent to which the parasite has adapted itself to the organization of its host. Therefore it is necessary in speaking of parasitism to consider the changes of form which the parasitic mode of life has cansed in the structure of animals. These concern most immediately the organs of locomotion and mutrition. Since a parasite needs to fix itself as firmly as possible to the host, the locomotor apparatus gradually disappears, or at least becomes less highly developed. An apparatus for fixation to the host becomes necessary; parasites of the widest diversity are provided with hooks, claspers, sucking-disks, etc. The blood, or tissue-sap, or liquid food of the host furnishes nourishment to the parasite: these are substances in solution which scarcely need digrestion. Usually, therefore, the digestive canal is simplified or quite disappears; among the parasites there are gutless worms as well as gutless crustacea. The mode of life of a parasite is also simplified, since it is no longer compelled to seek for food; in all parasites the nervous system and sense-organs undergo a high degree of degeneration; the former becomes limited usually to the most indispensable portion, the latter may entirely disappear.

\section{Modification of the Sexual Apparatus by Parasitism.}

-The scrual apparatus, on the contrary, undergoes a strong development. While it becomes easier for the parasite to maintain itself, the existence of the species is more precarious. If a man dies, then most of his parasites die with 
him, namely, those which exist in the interior of his body. In order that a certain parasitic species may not become extinct in a short time, it is necessary that the eggs be introduced into a new host. Since this transmis. sion is attended with difficulties, the parasites must produce an enormous number of eggs. The eggs, too, are distinguished by great resisting power and well-developed protective organs, such as strong shells, etc.; thus it is known, for example, that the eggs of Asearids continue to develop for some time in alcohol, being protected by their impermeable. shell.

Ectoparasites and Entoparasites.-All the abovementioned phenomena are more conspicuous in the case of
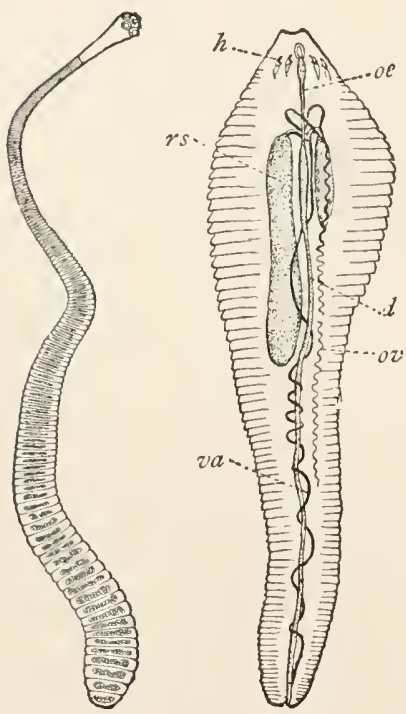

Fiv. 107.
FIG. 108.
Fig. 107.-Tania nana. (After Leuckart.)

FIG. 108. - Pentastomum tonioides. Female. (After Leuckart.) $h$, hook right and left of mouth : ov, unpaired ovary, branching into two oviducts, which unite into the unpaired vagina $\left(\tau^{\prime} a\right)$; the latter receives the outlets of two receptacula seminis $(r s)$, and winds around the digestive tract $(d) ; a$, cesophagus.

parasites which live inside of other animals, cutoparasites, than in the case of the dwellers upon the skin or other superficial organs, the ectoparasites. In case of entoparasites the transforming influence of parasitism is so considerable that representatives of the most diverse animal groups take on a remarkable similarity of appearance and structure. Pentastomum tanioides (Fig. IOS), for example, belongs in the same class with the spiders, the Arachoidea, but in external appearance it is entirely unlike them, resembling the flat worms (Fig. I07). Hence for a long time all entoparasites, on account of their similarity, were united into a single systematic group under the name of " Helminthes," comprising erustaceans, worms, and spiders, as well as animals of entirely different groups of the animal kingdom. Only 
through embryology was the unnaturalness of this grouping recognized. Entoparasitism therefore is one of the most beautiful examples for elucidating the character of contergent breding, i.e., how animals of different systematic position acquire, under similar conditions of life, a great similarity of structure and appearance.

Symbiosis.-Less frequent than parasitism is $5 y^{\prime} m-$ biosis, or the cohabitation of animals for reciprocal advantages. Among animals which form states, it is not infrequently observed that they not only hold certain animals in bondage, but even seek to protect and serve them; as, for example, in the company of ants are found certain blind beetles, like Claitiger, or some species of flantlice, or even ants of other species and genera. But such cases of cohabitation correspond rather to the domestication of animals, or to slavery, as carried on by man. The ants hold the plant-lice in order to lick the sweet juice which is secreted in their honey-tubes; they steal the pupe of other ants and rear them, to use them later as slaves. This state of things rests, consequently, not upon equal rights, since the one animal, in the present example the ant, brings about the cohabitation, while the other animal is passively led into it.

An Instance of Truc Symbiosis. - An instance of most complete equal rights and true symbiosis is furnished us, however, by a crab and an actinian, Pagurus Pridcauxi and Adamsia palliata. Like every species of Pagurus this hermit-crab also inhabits a snail's shell, from the opening of which only his legs and pincers are protruded. Upon the snail-shell a small actinian fixes itself, surrounding with its body the entrance of the snail-shell. When the crab in the course of his growth is compelled to seck a new and larger snail-shell, he invariably takes the actinian with him. The advantage which the actinian derives from this symbiosis is clear; it gains a share of the booty which the nimble-footed crab obtains. It is less clear why the crab lays so much stress upon this cohabitation; however, the actinian is perhaps a protection to him, since it covers 
with its nettle-batteries the entrance to the shell, and consequently wards off intruders which might slide into the interior of the shell and become injurious to the soft hinder part of the crab's hody.

Occurrence of Symbiosis. - That animals in general rarely live with one another in symbiosis rests mainly upon the fact that the conditions of life of all animals up to a certain degree are similar or identical. They all take in compounds rich in carbon and nitrogen, decompose them, and, in the presence of the oxygen of the air, separate them into carbonic acid, water, and oxidation products containing nitrogen. All animals consequently are competitors in the common struggle for food. For the same reason, conversely, symbiosis between plants and animals is not at all uncommon. In particular there are certain lower algx, the Zooxantholle, which often live in animals. Certain rhisopods, particularly the radiolarians, contain with such constancy in their soft bodies green-or yellow-colored cells that for a long time these were regarded as constituent parts of the rhizopod. Quite similar yellow and green cells inhabit the stomach epithelium of many actinians, corals, and even of many worms. The Zooxantholle are nourished by the carbonic acid which is formed by the animal tissues, and breathe out oxygen, which in turn serves as food for the animal; further, they form starch and other carbohydrates, and there is nothing to prevent any surplus thus formed from becoming food-material for the animal. Thus, on a small scale, that cycle of matter obtains which exists on a grand scale in Nature between the animal and vegetable kingdoms. By aid of chlorophyl and of the chemical influence of sunlight, the plants decompose water and carbonic acid and form from them oxygen, which they breathe out, and compounds rich in carbon, which they store up in their tissues: they are ralucing organisms. On the contrary, animals breathe out carbonic acid and water, but take their oxygen from the air, and carbon compounds in their food; they use oxygen to break down the chemical 
combinations, to oxidize: they are oxidizing organisms. This explains why the favorable influence of plants upon animals ceases immediately, when they change the character of their metabolism. With the disappearance of their chlorophyl moulds and bacteria lose the power of reducing carbonic acid; they derive their food from other organisms and decompose this into carbonic acid, water, etc.; like animals, they are oxidizing organisms, and consequently dangerous competitors. When they establish themselves upon the animal body, they almost always work injury to it: hence in animals they are the cause of many extremely dangerous ailments.

\section{ANIMAL AND PLANT.}

Distinction between Animal and Plant.-The consideration of symbiosis has led us up to the fact that between plants and animals a distinction exists in the mode of metabolism, which may be expressed thus: plants usually take in carbonic acid and breathe out oxygen, while animals breathe in oxygen and give out carbonic acid. Hence it may be concluded that it must be easy to discover differences which generally obtain between plants and animals, for, as a matter of fact, the laity are never in doubt in deciding to which realm of nature belong the more highly organized animals and plants, which are the only ones known to them.

Doubtful Cases. - But the more one studies this question, the more difficult becomes the solution of it. The old zoologists indeed formed the conception that there are organisms which stand on the limits between the animal kingdom and the vegetable, and the Englishman Wotton named these directly plant-animals or zoophytes. Now we know that Wotton's plant-animals are true animals with but a superficial similarity to plants; but, by means of the microscope, we have become acquainted with numerous lower organisms, and it is still doubtful in which of the two 
realms of nature these belong. As such may be mentioned the myxomycetes and many flagellata.

Distinction on a Physiological Basis.-If one wishes to discover sharp distinctions between animals and plants,

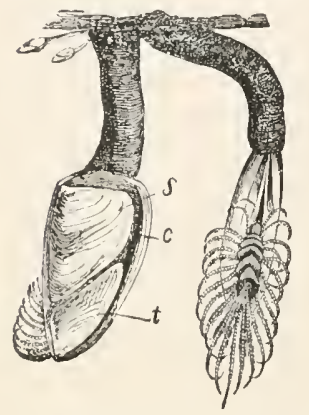

Fig. 109-Lepasanutifera. ifter Schmarda) $c$, carina ; $t$, tergum ; s, scutum. he may take into consideration on the one side physiological, on the other morphological, characters. Starting from the physiological point of view, Linnæus ascribed to plants only the capacity of reproduction and nutrition, but to animals the power of motion and sensation in addition to these. However, we know that vegetable protoplasm, just as well as animal, is irritable and is capable of movement, as is shown by the active movements of the lower alga, the great sensitiveness of the Mimosa, and other plants; but further, we know that even many of the more highly organized animals, e.g. crabs (Fig. Iog), lose the power of locomotion and become fixed, and many fixed forms, e.g. the sponges (Fig. SI), even under the closest examination appear immovable and unaffected by stimulation; thus we are led to abandon the idea that the socalled animal functions are to be regarded as accurate distinctions.

\section{Difference in Metabolism not a Safe Criterion.-} Even the difference in metabolism is by no means sufficient. Every plant has a double exchange of material. In its movements and other vital functions the vegetable protoplasm produces carbonic acid and consumes oxygen; at the same time, there goes on here, under the influence of sunlight and of chlorophyl, the reduction of carbonic acid, and the giving off of oxygen. In chlorophyl-containing plants, during the day, the reducing process preponderates so considerably that there is evident, as the final result, the giving off of a greater quantity of oxygen, and only at night, when the reducing process becomes interrupted on account of the lack of sunlight, does the production of car- 
bonic-acid compounds become perceptible. But the reducing processes become immediately preponderant, if the chlorophyl is absent; chlorophylless moulds and bacteria have, therefore, the same metabolism as animals.

Cellulose not a Sure Test.-So also it is incorrect to say that only plants have the porrer to mater collulose, for cellulose is found in many lower animals, the rhizopods, and in the highly-organized group of tunicates; according to recent investigations, it appears to be found even among the arthropods.

Distinction on a Morphological Basis.-Turning to the morphological characteristics, multicellular animals and multicellular plants are readily distinguished, sirce the former in the formation of the germ-layers have a principle of cell-arrangement which is peculiar to them. With the appearance of the gastrula stage, each organism is characterized as undoubtedly animal. But in unicellular animals the arrangement of the cells is lacking, and only the constitution of the single cell guides us. Now are there unmistakable morphological differences between the animal and the vegetable cell?

Plant-cells have a Cellulose Membrane--In the structure of plant and animal cells an important distinction is found in the fact that the former has a cellulose membrane, but the latter is usually membraneless. To this distinction must be referred in the last analysis the widelydifferent appearance of the two realms. Since the plant$c: 11$ is carly surrounded with a firm armor, it loses a large put of its power of further changing its form; hence vegetable tissues and organs are uniform in comparison with the inconceivable multiformity which animal histology and organology disclose. The numerous higher stages of organization which the animal kingdom reaches, even in its lower classes, is in great part, indeed, the result of the fact that the cells of animals do not become encapsuled, but have preserved the capacity for more varied and higher development.

Transitions.-But even here transitions are found 
between the lower plants and animals. In the lower alge the cells have power to emerge from their cellulose mem-

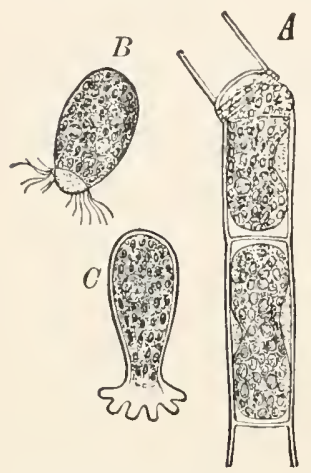

Fig. Iro.-CEdogonium in spore - formation. $A$, a piece of the filament of the alga with escaping cellcontents: $D, \quad$ zoospore formed from the contents : $C$, zoospore fixed and germinating. (After Sachs.) brane, and to swim about freely (Fig. I IO), before they encapsule themselves anew. On the other hand, most unicellular animals encyst: they pause in their ordinary functions of life, become spherical, and surround themselves with a firm membrane, in some cases even of cellulose. Since in both cases an alternation between the encapsuled and the free-living condition occurs, only the longer duration of the one or of the other can lead to a distinction. But herewith occurs the possibility that undifferentiated intermediate forms exist; their actual existence prevents, even yet, a sharp distinction between the animal and vegetable kingdoms.

\section{GEOGRAPHICAL DISTRIBUTION OF ANIMALS.}

The Different Faunal Regions.-Even a superficial knowledge of the mode of distribution of animals shows that the animal fauna in different regions of the earth has an essentially different character. In part this difference of fauna is the immediate result of climatic differences. The polar boar, arctic fox, cidcr-ducks, and many aquatic birds are restricted to the polar zones, because they cannot endure more than a certain degree of warmth; on the other hand, the larger species of cats, the apes, the humming-birds, etc., occur only in tropical or sub-tropical regions, because they are not sufficiently protected against cooler weather.

Climate not the Only Consideration.-If climate were the sole factor determining distribution, the faunal character of two lands which had similar climatic conditions would be essentially the same; conversely, the separate 
regions within a continuous territory extending through several climatic zones must have quite different fauna, according as they are nearer the equator or the poles. But such is not the fact: two tropical countries may differ more widely in the characteristics of their fauna than the hot and cold regions of one and the same country.

Factors in Distribution.-Modern zoology endeavors to explain these peculiar conditions, by regarding the present distribution of animals as the product of two factors; the gradual changes of the animal world, and further the gradual changes of the earth's surface, serving for the extension of the animal kingdom. The history of the earth as disclosed by geology shows two facts: (1) that the connections between parts of the earth have varied greatly: that, for example, at a time when the Mediterranean had not yet reached its present extent; Morocco, Algiers, Tunis, and Egypt were more closely united with the European coast of the Mediterranean than with the southern part of the African continent separated from them by the Sahara; (2) that considerable variations of climate have taken place: there prevailed in Europe in the tertiary period a subtropical climate which rendered possible the existence of animals which now occur in Algeria (lions). But later a glacial period began, which introduced over a wide area of the European continent the conditions of arctic life, and consequently a fauna of northern animals (reindeer). Hand in hand with the geological changes there took place also changes in the animal world; the then present species dying out under the change of conditions of existence, or forming new species through gradual variations. Thus animal geography constitutes an extremely complicated problem, the solution of which necessitates a comprehensive course of preliminary work. It must be known with certainty how the connections between the continents, and the distribution of climates, have changed, particularly in the later geological periods; further, we must study, not only how animals at the present time distribute themselves over the earth's surface, but also how 
they were distributed in earlier times. Finally, by means of anatomy and embryology we must have the conditions of relationship of animals laid before us in a very detailed manner.

Difficulties of the Subject. - The path to the solution of the subject, here only briefly sketched, is well-nigh endless; what has hitherto been studied can only have the importance of a preliminary proof that zoology, with its prevailing views of the changes of animals and of the earth, is on the right track. It would be a test of the correctness of this view, if it could be shown that the faunal similarity of two land areas depends, in the first place, upon how long they have been in close connection with each other, consequently allowing an interchange of the animals inhabiting them. Two land areas, separated early in the earth's history, and never again connected, must have very different faunal characters; if two areas are still in connection, or only recently separated, the faunal differences will be relatively less. In carrying out more closely the points of view mentioned, animal geographers have attempted to mark off the great faunal belts of the earth, the animal provinces or regions, and within these again less important divisions, subregions. These provinces have been based chiefly upon the manner of distribution of mammals, somewhat upon that of birds and the other animals; for the manner of distribution of mammals is chiefly determined by those changes of the earth's surface which are best known geologically and possess most interest. A rising or sinking of the earth's surface often opposes impassable barriers to most mammals: rising, because it leads to the formation of mighty-glaciered mountain-chains; sinking, because as the result arms of the sea are formed, which perhaps, even if only narrow, interpose between two hitherto connected land areas straits which are impassable for most mammals. Birds and insects which fly well are less affected by all such changes of the earth's surface; the majority of them can fly over arms of the sea and mountain-chains. for 
there are birds which can cross even great seas like the Atlantic Ocean.

The Six Primary Regions.-Of the systems of animal geography proposed up to the present time, the division advocated by Sclater and Wallace finds most favor. These English scholars distinguish the six following primary regions: (I) the palcarctic, comprising all Europe, northern Africa as far as the Sahara, and northern Asia as far as the Himalayas; (2) the Ethiopian, all of Africa south of the Sahara; (3) the oriontal, including upper and lower India, southern China, and the western Malay Islands; (4) and (5) the nearctic and the neotropical regions, which make up the American continents and are divide 1 by a line drawn at about the northern border of Mexico; (6) the Australian, in which, besides Australia itself, are included the larger and smaller islands of the Pacific Ocean and the eastern Malay Islands, together with Celebes and Lombok.

(I) The Australian region is most sharply distinguished from all the others, for undoubtedly the area of land included under this name was earliest separated from the rest of the mainland. The marsupial fauna is particularly characteristic of it. The marsupials, which during the tertiary period inhabited the whole earth's surface, have become entirely extinct in Europe, Asia, and Africa, and in America only the opossum family persists, but in Australia they have undergone a higher development. Yet until they were introduced by man Australia lacked the higher placental mammals which have supplanted the marsupial fauna of the Old World. A few aquatic forms: are found there, as well as mice and bats-animals which are easily transported by flight, or by means of floating wood. A few small carnizores, hoofed animals, and apes exist only upon the islands bordering upon the oriental region. Further peculiarities of the Australian region are the birds-of-paradise in New Guinea, the egg-laying mammals Ornithorhynchus and Echidna, the remarkable Hatteria, 
and the Kiwi of New Zealand, the cassowary, and the Dromans now' Hollandia.

(2) Next to the Australian the best circumscribed is the ncotropical region, South America, with the adjacent part of Central America. Here we find the area of ditribution of the broad-nosed apcs, while the small-nosed apes belong to the Old World; we find the armadillocs, sloths, ant-catcrs, opossums exclusively in America; of birds, the humming-birds, the remarkable Cotingida, Tandsridce, etc.

The Four Remaining Proninces. - The boundaries of the four other provinces are not so easily defined as those hitherto considered. Since North America is connected by a chain of islands with northern Asia, undoubtedly the nearctic and the palaarctic have been subject to an interchange of forms. Further, in the repeated alteration of the climate of the nearctic and palæarctic regions is furnished the possibility that their animal world has mingled on the one side with the neotropical, on the other with the Athiopian and oriental. In the same way the oriental animal province has lost its sharp demarcation from the Australian, since the continuous chain of Malay Islands renders possible a constant interchange of forms. Yet each of the four provinces named has numerous genera and families peculiar to itself, and is distinguished by the absence of certain living forms.

(3) The ncarctic region has peculiar to it three mammalian families, the prong-horncd antclope, the opossums, and the Haplodonta; of the group of Amphibia, the Sircmide and Amplinmide. The Nearctic is to be distinguished from the nearest related palaarctic region through the crowding in of neotropical forms like the raccoon, opossum, humming-birds, etc.

(4) The palaartic region covers the greatest area and consequently abuts upon many other animal provinces. Hence there exist important differences between the various local faunas, which are conditioned by climate and great distances, but these are explained by the fact that 
the palæarctic region has no families peculiar to itself alone. The families which here at least have reached their development are the decr, eattle, the shecp kind, and camcls; especially conspicuous genera are the chamois, squirrel, badger, and whistling hare.

(5) The Ethiopian region has many animals found only there; among these the hippopotamus and giraffe, the Cape pig, and, if we include Madagascar, the fingered animals (lemurs) are most characteristic. Equally noteworthy is the entire absence of extremely remarkable families and genera, such as the bears, moles, decr, goats, slace, the true cattle and swinc, provided they have not been domesticated and introduced. Within the group the island of Madagascar occupies a highly remarkable position. This island is the land of the Lcmurs and of the Inscetivora; that is to say, no land is so rich in lemurs, as the majority of the genera live exclusively in Madagascar. On the other hand, the large beasts of prey, the cats, hyenas, dogs, and the bcars (which, however, do occur in Africa), all the true apes, antelopes, clcphants, and the various species of rhinoceros are absent. Consequently, since Madagascar is distinguished quite conspicuously from Africa, many zoologists separate the island from the Ethiopian region; many even wish to give it the rank of an independent main region.

(6) The oricntal region contains, next to Madagascar, the most Lcmurs; among which the Tarside and Galcopithecide (the latter usually reckoned with the Inscctivora) are exclusively oriental. Remarkable representatives of the province are the gibbons and orang-utangs, the muskdccr, numerous families and genera of birds.

Arctic and Antarctic Provinces.-Of late the view has continually gained ground that, besides the six mentioned, two other, circumpolar, provinces must be distinguished, the arctic and the antarctic. Both have an animal world consisting of few species but numerous individuals, of which the auks, polar bear, reindecr, arctic fores are 
characteristic of the northern or arctic region, the penguins of the antarctic.

The Distribution of Aquatic Animals. - To animal geography further belongs the distribution of animals in the sea, and in fresh water. Since most seas are connected, the faunal regions cannot be distinguished so sharply as in the case of the land faunas; conspicuous differences are present only when two oceans are separated Ly continents extending far to the north and south; such, for example, exist between the Red Sea and the geographically neighboring Mediterranean, between the east and west coasts of North America, even where they are separated only by the narrow isthmus of Panama.

\section{Changes in the Fauna Conditioned by Depth.-} Much more remarkable in the marine fauna are certain difierences brought about by the changes of the conditions of life in the different depths of the sea. A dccp-sca fauna, a coast fauna, and a pclagic fauna can be distinguished. The coast fauna embraces the animals, some freely motile, some fixed, which inhabit the plant-covered rocky or sandy shore as far as a depth of IoO meters. The deep-sea fauna swims, creeps, or is fixed at the bottom of the ocean at depths of 1000 to almost 9000 meters; it is distinguished from the coast fauna by its archaic character, for here very often genera and entire groups of animals exist, like the Hcxactincllide, crinoids, certain starfishes and sea-urchins, etc., which for a long time were chiefly known through fossils from earlier geological ages.

The Plankton.- The pclagic animal world comprises all which swim freely in the water, the "plankton"; here belong many calcntcratcs, medusa, and ctcnophores, entire groups of protozoa, like the radiolarians, many crabs and crab larva; of the mollusks the Hctcropods and Ptcropods. These animals live either at the surface of the sea itself or freely suspended in greater or lesser depths, to 8000 meters or even more. Usually they are soft like jelly and of glasslike transparency; this must be regarded as sym- 
pathetic coloring and adaptation to the transparent clearness of the water.

Distribution of Fresh-water Animals.-In fresh water two groups of animals must be distinguished, of which the one comprises mainly the more highly organized forms, the mollusks, fishes, and higher crabs, the other the lower animal world. The mode of distribution of the former is mainly determined by the same factors which are at work in the separation of terrestrial forms; the mode of distribution of the latter, however, is a cosmopolitan one. The same infusorians and rhizopods, copepods, fresh-water sponges and polyps which occur in America seem to be distributed over the entire earth. This is connected with the fact that all these animals have resting conditions in which they endure desiccation. The resting stage, be it as a hard-shelled egg or as an entirely encapsuled animal, may be borne about by the wind as dust, or may be carried with the mud by aquatic birds, and upon again reaching the water the animal resumes its active state. 



\section{INDEX.}

Abiogenesis, I66, I95

Achromatin, So

Ethiopian region, the, 215

Agassiz, Louis, 25

Albertus Magnus, Io

Aldrovandus, $I 6$

Alecithal egg, I 85

Alternation of generations, 172,196

Ambulacralsystem ofechinoderms, 145

Amoba proteus, 75

Amoboid movement, 75, I45

Amphigony, I68, I 70

Amphioxus, 89

Analogous organs, 157

Analogy, I6, 120

Anal glands, 128

Anatomy, general, 68

Anatomists of classic antiquity, I 3

Angle-worm, hermaphroditism of, I II ; sexual organs of, I4I

Animal and plant, 207; distinction between, 207; on a morphological basis, 209; on a physiological basis, 208

Animal geography, 49, 2 I I ; organs, I2I

Animal pole, the, $\mathbf{I 7}$

Animals, their relation to one another, 198

Annelids, 22

Antimeres, Ió3

Aorta, I34

Aquatic animals, distribution of 216 ; change in fauna conditioned by depth, 2I6; distribution of fresh-water forms, 217

Aqueous humor, 156

Aristotle, 7 ; his knowledge of the subject, 7-8; his writings, 7 ; his systemization, 8

Archæopteryx, to

Archegony, I66

Archenteron, I24, I25, I87, I97

Arctic and Antarctic provinces, 215
Arteries, I32

Articulata, 22

Artificial selection, 52

Arthropoda, 22

Ascaris, 83,98

Asexual reproduction, I68, I7 I

Assimilation, 75, 77; defined, I22;

in animals, I22; different organs of, I 22

Auditory nerve, I5I; organs, I53; history of, I5I: ossicle, I5I; pit, I 52 ; vesicle, I5 I

Auricle, 133

Australia, fauna of, 50

Australian region, 213

Baer, C. E. von, 4 I

Beetle imitating a wasp, 59

"Bible of Nature," the, I5

Biogenesis, the law of, 4I

Biology, 68

Blastoderm, Is 7

Blastopore, 187

Blastula, I 87,197

Blood, 87, II 8 ; arterial, I35; venous, 135

"Blood" of invertebrates, Io7-Ios

Blood-cells, I05-I06; -corpuscles, I06; -fluid, I05; -plasma, I05; relations of plasma to corpuscles, I08; -serum, I05; red, I06; -vascular systems, closed and lacunar, I 35; -vessels, I 33

Bone, IO2, I03; composition of, IO4; -corpuscle, I05: cross-section of, I04; dried, I05; formation of, I05

Brachiopoda, 22

Brain, I 47

Breeding, factors of evolution in, 53

Bryozoa, 22

buccal cavity, 127

Budding. I68, I69, I96; lateral, I69; multiple, I69; terminal, I69; 
of the cell, $8 \mathbf{1}$; in Bryozoans, I92; in Hydroids, 192 ; in Tunicates, I92; relations of the germ-layers in, 192

Buffon, 26

Butterflies, leaf-, 56-57

Canary Islands, distribution of plants upon, $5 \mathrm{I}$

Cantipiatensis, Thomas, Io

Capillaries, I32, I 33

Cartilage, IO2-IO3; hyaline, I03; elastic, I03

Cataclysm theory, the, 24; objections to, 25; its downfall, 27

Cellulose, 209

Central nervous system, 146

Centrolecithal eggs, ${ }_{1} s_{3}$

Centrosomes, 83

Cell. the, theory, 20, 69; the history of, 70; a single cell defined, 84 ; -budding, $8 \mathbf{I}$; characteristics of, 73; defined, 7I: early conceptions of, 70; the egg-, 96 ; -multiplication, $8 \mathrm{I}$; nucleus of, 78,97 ; size of, 73 ; summary of, II 6

Cells, "gland," 92; sensory, 98; sexual, I7I; somatic, I7I; supporting 99

Cercaria, 174

Cestodes, I25

Change of function, examples of, I 20

Chitin, 90

Chlorophyll, 72

Chorda dorsalis, 47

Chorion, I 78

Choroid coat, 155

Christianity, its early influence on zoology, 9

Chromatin, So, 82,85

Chromosomes, 82,83

Chyle-vessels, I 37

Cilia, 90, I 45

Circulation of the blood, schema of, I3I; in the fish, 134

Circulatory organs, 123

Cleavage, I97; -cavity, I87; discoidal, I85; distribution of the various modes of, I 86 ; equal, I 85 ; holoblastic, I ${ }_{3}$; meroblastic, 183 ; partial, I83; superficial. I86; total, I33; unequal, I85; various modes of, 184

Cleavage process, the, IS2; planes, arrangement of the, IS2; of amphioxus, IS2; influence of the yolk upon, I82
Cloaca, I26, I27

Cochlea, 152

Coeca, I26, I 27

Coelentera, 22

Coelom, 132; formation of, in Sa. gitta, 190

Coelomatous a nimals, 132

Coelomic pouches, I9I

Cuiter, $\mathrm{I}_{4}$

Cold-blooded animals, I37

Cold-rigor, 77

Collagen, $\mathrm{IO}_{2}$

Coloration, sympathetic, 56

Colony formation, I 98 ; by fusion, 199: by incomplete division and budding, 199

Coordination of stimuli, II

Commissures, 147

Community of functions, 200

Comparative anatomy, $3, I_{3}$; of the Middle Ages, I3; embryology, I9, 20

Condylarthra, 40

Connective substances, 99; tissue, II 7; bone, I03; blood, I05: cartilage, IO2; cellular, IOO; corpuscle, IOO, IO2; elastic, IO2; fibrils, IOI; fibrous, IOI; function of, Ioo; homogeneous, IOO

Contractile-fibre cells, I I I

Convergent breeding, 205

Copulation, 177

Cornea, $154, \mathbf{1} 56$

Cornification, $9 \mathbf{I}$

Corpus ciliare, I56

Correlation of parts, 16 ; of respiratory organs and blood-system, I33

Crop, the, I 27

Crossing of species and varieties, 32

Crustaceans, 93

Cuticle, 90

Cuvier, I6, I7, 4I; his type theory, I 7

Cytoplasm, $8_{3}, 92,98$

Darwin, Charles, 28; biographical sketch, 28; his works, 29; "The Origin of Species," 29; theory of the origin of species, 30

Darwin, Erasmus, 26

Darwin's predecessors, 26

De Gecr, I 5

Delamination, I88; of a Geryonid egg, Is9

Descent, causal foundation of the theory of, $5 \mathrm{I}$

Deutoplasm, 97 
Development, embryonic and postembryonic. I92

Differertiation, histological, II 6 ; histological and organological, I9I; nature of histological, 85

Digestive tract, the, 12t; the divisions and appendages of, I26; relative length in herbivores and carnivores, I 28

Diphycercal tail, 48

Diplozoon paradoxum, r99

Diporpa, I99

Direct development, 193

Direct nuclear division, $S_{t}$

"Directive corpuscles," I77

Distoma, I $7+$

Distribution, 2Io; factors in, 2II; the six primary regions of, $2 I_{3}$

Distribution of animals, 49 ; proofs of phylogend from, 50

Dirision, direct nuclear, $8+$, I68

Domestication, 52

"Dorsal," I63

Ductus ejaculatorius, I +4

Dujardin, 2I

Earth-worm (angle-worm), sexual organs of, IfI; hermaphroditis $m$ of, $I+I$

Echinoderma, 22

Ectoblast, I87, I97; organs formed from, I 92

Ectoderm, I 98

Ectodermal gut-areas, I26, I27

Ectoparasites, 204

Egg, the, 95; of the bird, 73; -cell, 96; of echinoderm (S. lividus), 96 ; -nucleus, the, I77; of the cephalopod, I36: of the insect, I86; of Nassa mutabilis, IS5; of Petromyzon, I85; alecithal, I85; cent rolecithal, I83, r86: diagrammatic section of the hen's, I8+; holoblastic, I85; meroblastic, I85; telolecitha?, I 83

Eggs, "summer," I 74 ; “winter," I $7+$

Eichhorn, I5

Elastin, IO2

Embryo defined, I93

Embryology, 4, I65, I93

Embryonic development, I92

Endolymph, I 5 I

Enteropneusta, I29, I3I

Entoblast, 187, 197; organs formed from, I92

Entoderm, Is 8

Entoparasites, 204

Environment, influence of, $6+$
Eiihippos, 40

Epiblast, I 88, 197

Epigenesis, I9

Epithelia, I 77; glandular sensory E., 85; many-layered E., 90; sensory E., 89

Epithelial tissues, morphology of, 87

Epithelium, 98; ciliated E., 89; contrasted with connective tissue, 99; columnar, 89 ; covering E., 89; cuboidal or pavement E., 89; flagellated E., 89; flat E., 89; function of, 87; germinal E., Ifo; glandular E., 92; one-layered E., 89; sensory E., 98, 99; sexual or germinal. 94, 95

Equatorial plate, 82

Evolutio, I9

Evolution in breeding, factors of, 53 ; vs. creation, 27 ; state of the question in 1830,$27 ; 2^{\prime}$. e epigenesis, 19: in nature, factors of, 53 ; original meaning of, I 9

Excreta, 58, I 23

Excretion, nature of, $\mathrm{I}_{3} \mathrm{~S}$

Eye, 153; section of human, I55; of the vertebrates, 155; phylogeny of, 66 ; refractive bodies in, I 54

Eyes, various types of, I56

Fabricius ab Aquapendente, It

Factors of evolution in breeding, 53 ; in nature, 53

Frces, I23

Fecundation, artificial, 177

Fertility of hybrids and mongrels, the, 34

Fertility in sexual reproduction, conditions governing, 35

Fertilization, I77, I78, I96; artifi. cial, I78; essential feature of, I79, I97; part played by the two nuclei in, Iso

Flagella, 9o, I 45

Flimmerläppchen, I to

Food-yolk, 97

Fore-gut, I 26

Fossils, 39; old ideas regarding, 24

Functions, community of, 200

Funnel, the ciliated, Ifo

Galen, It

Galenus, Claudius (Galen), I3

Ganglion-cells, II 3 ; apolar, II ; bipolar, II3; multipolar, IIt; unipolar, IIt 
Gastrotricha, 96

Gastro-vascular system, I32

Gastrula, I87, I97; of amphioxus, I 87

Gastrulation, modified modes of, I SS

Gegenbaur, 2 I

Gelatine, IO2

Gemmation, 8I

Generatio spontanea, I66

Generations, alternations of, I72, I 96

Generation by parents, I6S, I95; asexual, 196 ; sexual, I96; spontaneous, 37

General embryology, I65

Geography, animal, 2 I I

Geographical distribution of animals, 2ı; isolation, Wagner's theory of, 63

Geology, its part in the overthrow of the cataclysm theory, 28

Germinal epithelium, Ifo; of Medusa, 94

Germinal glands, I fo

Germ-layer, theory, 2I; the middle, I 89

Germ-layers, I7I ; formation of, $\mathrm{I} 87$; inner G.-layer, 187 ; outer G.-layer, 187

Germinal spot, 97; vesicle, 97

Giant cell of the marrow, 83

Gills, I 23, I 28

Gill-slits, 129

Gizzard, I 27

"Gland-cells," 92

Glands, 92 ; acinous, 93 ; formation of, 92 ; germinal, 140 ; multicellular, 92 ; tubular, 93 ; unicellular, 92, 93

Glandular epithelia, 89,92 ; sensory epithelia, 88

Glue, ro2

Glutin, I02

Goblet-cells, 91, 92

Goethe, I6, 26

Goeze, I 5

Gonochorism, IfI, I58

Granules, the secretory, 92

Grasshopper mimicry, 58

Grew, N., 70

Gromia oviformis, 76

Gut, I 24

Haeckel, 21, 29

Hremocyanin, ros

Hrmoglobin, I07 ; oxy-, I07 ; “reduced," IO7

Harvey, I65
Haversian canals, I05; lamellæ, 104

Hearing, organs of, $I_{5} \mathbf{I}$

Heart, I32; higher development of the, I32

Heat-rigor, 77

heliconia, 57

Hiepato-pancreas, 127

Hereditary substance, the, $8 \mathbf{I}$, I 8 I

Heredity, ISI ; material basis of, I 81 ; the bearer of, So

Herma phroditism, I+I, I 58 ; occurrence of, I 42 ; true, $I+3$

Heterocercal tail, +8

Heterogony, I72, I74, 197

Heteronomy, I65

Hind-gut, I 26

Histology, 2I

Histological differentiation, II6

History of zoology, 7

Hooker, 30, 70

Homocercal tail, t $^{8}$

Homoiothermous, 137

Homologous organs, I 57

Homology, 16, I20

Homonomy, 165

Horn, 9I

Horse, phylogeny of, 40

Human embryo, third to fourth week, 42 ; compared with a tad. pole, $4^{2}$

Huxley, 2I, 30

Hybrids and mongrels, the fertility of, 34

Hydra in optical section, I69

Hy poblast, I 88,197

Idiothermous animals, I 37

Inbreeding, 35

Indirect nuclear division, $\$_{2}$; development, I93

Inflammation, 87

Ingluvies, the, I 27

Inorganic bodies, 158

Insects of Kerguelen Islands, 55

Intercellular substance, Ioo

Integument of insects, 90

Intercrossing, effects of, 62; of species, the, 33

Interrelation of cytoplasm and nucleus, 83

Intestine, large, I27 ; small, I27

Invagination, ISS; formation of gastrula by, I $\$ 8$

Iris, 156

Irritability, 75, I2I; of animals, I 2 I of plants, I 2 ; of protoplasm, I 2 I

Ivory, 105

Karyokinesis, 82,84 
Kerguelen Islands, insects of, 55

Kidneys, I 40 ; of vertebrates, I23; of invertebiates. I23

Kölliker, 2I

Kowalersky, 2I

Labyrinth, diagram of the human I 52

Lamarck, I6, 26, 32; biographical sketch, 26

Lamarckism, 64

Lamarckian factors of evolution, use and disuse, 26

Larval development, I93; organs, I 93

Leaf-outterflies, 56, 57 ;

" Left," I6 3

Lens, I $5+$

Leptoplana tremellaris, I3 I

Leucocytes, Io6, Ios

Leuckart, 22

Leeuwenhoek, I4; introduced the use of the microscope, I 5

Leydig's granular substance, I 46

Life, first origin of, 167

Linnæus, Io ; biographical sketch, Io ; nomenclature, II

Linnan system, influence of the, I2; compared with the Aristotelean, 13

Liver, I27; the human, II9

Locomotion among the higher animals, I 45 ; organs of, I +4 ; among the lower animals, I +5 ; voluntary, I 44

Lung, I 30

Lungs, I 23

Lymph, 87, I05, II8; -corpuscles, I05-I06; coloring matter, IO7; vessels, 136

Lyell, 27, 30

Lyonet, I5-I6

Malay Archipelago, the faunal division of, 5 I

Malpighi, Marcello, I 4 , 7o

Malpighian vessels, I 23

Man's relation to other animals, I

Marrow-cavity, the, I05

Maturation, I 75, I 77

Meckel, I6-20

Medusa, germinal epithelium of, $9+$

Meissner's corpuscles, I50

Mesenchyme, IS9), I97; occurrence of, I9I

Mesenteron, I25

Mesepithelum, I9I, I97; formation of, Igo
Mesoblast, I97; formation of, I 89

Metagenesis, I72, I96

Metameres, ${ }^{6} 6_{3}$

Metamerism, I64; external, I64; heteronomous, I6t; homonomous, 164 ; internal, 164

Metamorphosis, 193, I98

Micropyle, 178

Mid-gut, I 26

Migration theory, the, 63

Mimicry, 56: example of, $57-58$

Modifications through nutrition, 64

Mollusca, 22

Mohl, H. von $7 \mathrm{I}$

Mollusks, shells of, 90

Monogony, I68

Monospermy, i7s

Morphology, 2; animal, 68; contrasted with anatomy, 3; dawn of independent observation, I5; development of, I3; embryology, 4 ; its scope, 2; ontogeny, 4; paleontology, 5, 25: proufs from, 4o; scientific method, 3 ; zootomy, its beginning, It

Movement, 75; in aninals and plants, I 2 I

Müller, Fritz, 30; Johannes, 2 I; O. F., I5

Multicellularity, $s_{3}$

Multinuclearity, 83

Muscle, Io8; physiology of, Io9

Muscle-cells, epithelial, I IO-III; connective substance, IIO-I I I

Muscle-corpuscle, the, $\$ 6$

Muscle-fibres, smooth, I Io; crossstriated, IIO, II 2 ; the formation of, 86; I09

Muscle-nuclei, II 3

Muscular tissue, 87 , IOS, II 7 ; characteristics, IOS; elements, IO9; homogeneous, I09; striated, IO9

Musculature, the, I 45

Mycetozoa, 73

Myelin, I I 5

Nägeli, 30, 64, 65

Natural history contrasted with modern zoology, 2

Natural selection, 52 , 53 ; the efficiency of, $6 \mathrm{I}$; objections to the theory of, 6 I

Nearctic region, the, 2 It

Nematodes, 98

Neotropical region, the, 2 I 4

Nephridia, I39, I to

Nephrostome, I 40

Nerve-fibres, II3; gray, II5; medullated, II5; nodes of Ranvier. 
I I5; non-medullated, I I5; white, I I 5

Nerve-fibrils, the, 86 ; processes, the. I I 4

Nervous system, the, ft; development of, I 45 ; its relations to the skin, $\mathbf{1}^{\mathrm{S}}$; types of-diffuse, I 6 ; ganglionic, I46; ladder, I 47 ; linear, 146 ; tubular, 148 ; tissue, 87 , I 3 , II 7; elements of, II3; function of, II 3

Nomenclature, the binomial, I I

Notochord, 47

Nuclear division, probable significance of direct and of indirect, $5_{4}$; spindle, 82,83 ; substance, 79

Nuclei, various forms of, 73

Nuclein, 80

Nucleoli, 79-8o

Nucleolus, 97

Nucleus, 97; behavior during division, $\mathrm{SI}_{\mathrm{I}}$; physiology of, II6; significance of, So; structure of, 79; substance of, 79

Nucleus of the cell, 78, т 16

Nutrition, 77, I57

CEcology, 65

CEsophagus, I27

Oken, 26

Olfactory cells, I5I; tubules, I5I ; cones, I 5 i

Ontogeny, 4, I93; summary of the facts of, 195

Optic ganglion, I 54

Organ, an, change of function of, I I9; defined, i IS; effect of use and disuse, II9; principal and accessory tissues, II

Organology, summary of, ${ }_{5} 6$

Organisms, origin of, $\mathrm{I}_{5}$

Organs, systems of-circulatory, I 2 I; digestive, I20; excretory, I2I ; genital, I2I ; muscular, I2I : nervous, I 2 I ; respiratory, I 20 ; of sense, I2I; of smell, I 50

Oriental region, the, $2 I_{5}$

Origin of species, Darwin's theory of, 30

Ora serrata, 156

Organic bodies, I5S

Ossein, IO3

Osteoblasts, I05

Otoliths, 99, I 5 I

Outlets of sexual glands, r.jo; products, I+3

Ovary of a new-born child, section through the, 95

Oviduct of an insect, 96
Oriducts, I +3

Oviparous, I94, 193

Ovo-viviparous, I 94, I 93

Owen, 2I

Oxidation, I 23

Oxygen, sources of, used in breathing, I 28

Pacinian corpuscles, I 50

Paedogenesis, I 7o, I 96

Palxarctic region, the, $2 \mathrm{I}_{4}$

Paleontology, 5-25; proofs of phylogeny from, 39

Paleontological proof, examples of, 39

Paleozoology, 5

Pancreas, 127

Paranuclein, So

Parasitism, 202; degeneration caused by, 203; modification of sexual apparatus by, 203; true, 202

Parthenogenesis, I 7o, 196

Penis, It+

Pentastomum tænioides, 204

Perennibranchiata, +3

Pericardium 133

Periosteum, IO4

Peripheral nervous system, $x 46$

Peritoneum, I32

Pharynx, I27

"Philosophie zoologique," 26

Phylogeny, 5, 36; proofs of 33

Physiology, \&; biology, 5; explanation of the organic bodily form, 4 , 5 ; life, 4 ; aecological problems, 5; $\operatorname{aecolog} y, 5$; vital process, the, 4

Physiologus or Bestiarius, the, IO

Pieridx, 57

Pigment-spot (simplest eye), I53

Plankton, the, 2 I 6

Planula, I45, I93

Plasmodia, 73

Pliny, 9

Poikilothermous animals, I37

Polar bodies, formation of, 176

Polymorphism, 200

Polyspermy, I 73, I 79

Porto Santo, the rabbits of, 63

Post-Darwinian writers, 29

Post-embryonic development, 192

Praya diphyes, $20 I$

Proctodoeum, I 25

Progression, Nägeli's principle of, 65

Promorphology, I 58

Prostoma, I 87 
Protonephridia, I39

Protopterus, I3I

Protoplasm, 7I, 7f; discovery of, 72 ; diversity of, 74 ; general properties of, $7+$; irritability of, 77 ; streaming of granules in, 75 ; Schultze's theory of, 20,73

Protoplasmic products, 78,85

Protozoa, 22, 72, $S_{4}$

Proteids, the, $7 t$

Pseudopodia, I +5

Pseudova, I 70

Race, histcry of the, 37

Radiata, the, 21 ; divided into Cœlentera and Echinoderma by Leuckart, 22

Ranvier, nodes of, I 55

Rathke, 2 I

Ray's conception of species, 23

Réaumur, I 5

Receptacula seminis, I +4

Red bluod-corpuscles, Io6; hæmoglobin of, ro7; of camel, llama, IO7; of the Cyclostomes, IO7

Refractive bodies in the eye, I5t

Regions, the six primary of distribution, 213

Rejuvenescence, 172

Relations between individuals of different specics, 202

Relationships of anima!s, 22

Remak, 2 I

Reproduction, 75, 77; combined modes of, $172 ;$ distribution of the asexual and sexual modes 174 ; sexual, r 70

Respiratory apparatus, development of the, I3o; organs, I23

Respiratory systems of the vertebrates and invertebrates, I30

Retina, 153

Rhabdom, I 53

Rhizocephala, I 25

" Right," I 63

Rigor, heat-, 77; cold-, 77

Rods and cones, I 53

Rösel von Rosenhof, I5-I6

Sacculus, 152

St. Hilaire, Geoffroy, I6, 26

Salivary gland (acinous) of Orthezia, 94

Salivary glands, I 27

Sarcode, 72

Sarcolemma, I I 2

Savigny, I6

Scales, formation of $9 \mathrm{I}$
Schleiden, 20; -Schwann cell theory, the, 70

Schitfer, I5

Schultze, Max, 2I, 73

Schwann, 20, 70

Schwann's sheath, II 5

Sclerotic coat, I 55

Secreta, 88

Secretory granules, 92

Segmental organs, I39, I fo

Segmentation, I64

Selection, artificial, 52; natural, 52; sexual, 59

Semicircular canals, I52; function of the, 153

Sensation in the lower animals, I 48

Sense organs, 99; nerve-endings in, 99

Sensory cells, 98 ; epithelia, 89 , $9 \mathrm{~s}$

Sexual apparatus, the accessory, I $4+$; cells, 87,94, I7I; e pithelium, 94: development, the different forms of, I92; glands, I fo; outlets of, Ifo; products, outlets for, I.+3; reproduction, I 7o, 196 ; conditions governing fertility in, 35 ; general phenomena of, 175 ; selec. tion, 59

Shells of mollusks, 90

Siebold, C. Th, von, 2I

Sight, organs of, I5 I

Siphonophore, nutritive polyp of, I 24

Skeletal system, the 47

Skin of petromyzon, 9I; of man, $9 I$

Smell, organs of, I5o

Somatic cells, I I I

Somatopleure, IgI

Species, 23; the change of varieties into, 36; the intercrossing of, 33 ; Linnaus' definition of, 24 ; logical value of the term, 23; the nature of, 23: Ray's conception of, 23; related to each other in unequal degrees, 36 ; variation within the, 32 ; "vicarious species," 5 I

Species and varieties, the crossing of, 32 ; distinction between, 30

Spermatozoa, $73,95,97,98,158$

Spinal cord, section of the human, I 49 : the directive, 176

Spindle-fibres, $\$ 2$

Spontaneous generation, 37, 165

Splanchnopleure, I9I

Sporocysts, I7t

"Sports," 3I 
Stomach, the glandular, I27; the grinding, 127

“States," bees, ants, termites, 202

State formation, 20 I

Stomodœum, 125

Stratum corneum, 92; Malpighi, 92

Streaming of protoplasm, 75

Struggle for existence, 53-54

Summary, cells, I 6 ; tissues, I 6

"Summer eggs," I 74

Supporting cells, 99

Supporting tissue, $S_{7}$

Supra-cesophageal ganglion, I +7

Swammerdam, I4, "Bible of Nature," I 5; "Dissertatio de Bombyce," It; his discoveries, It

Swim-bladder, 157

Symbiosis, 205; instance of true, 205; occurrence of, $2 \mathrm{c} 6$

Symmetry, I59; anaxial, I59, I60; asymmetrical, 159, I6I; bilateral, I59, 162 ; biradial, I59, I62; heteraxial, I59; homaxial, I59; I6I, I6I; monaxial, I6I; radial, I59; I6I; spherical, I6I

Sympathetic coloration, 56

Syncytia, 84

Systema naturæ, I 2

Systematic zoology, development of, 9

Systemization, Aristot!e's, 8; difficulties in, 35 ; the present system, 22; proofs of phylogeny from, 38

Tactile organs, I 50

Tails of fishes, types of, 48,49

Tapetum nigrum, ${ }_{56}$

Taste-buds, 15 I

Taste, organs of, 150

Telolecithal eggs, I 83

Tendon, I20

Tendinous tissue, $\mathrm{IO}_{3}$

Tentacles, 150

Theory of descent, history of, 23

Thomas Cantipratensis, Io

Tissues, of the animal body, $S_{5}$; classification of, 87, I I 7 ; defined, 85: formation of, 78,85 ; physio1 gical characteristics, II 7 ; morphological characteristics, II7; principal and acessory of organs, II 8 - I I9

Tocogony, 165, I68, 195

Tunicata, 22, I 29, I3I

Type theory, Cuvier's, I 7,4 I

Units, the morphological, 69

Ureter, I 40
Urinary bladder, I 39

Urino-genital system, I 43

Uro-genital system, 158

Use and disuse, 26; 65; effect of, II 9

Uterus, I4t

Utriculus, I 52

Vagina, I44

Variability not proven to be a universal principle, $3 s$

Variation within the species, 32

Varieties into species, the change of, 36

Vasa-deferentia, $I+3$

Vas deferens, I 43

Vegetal organs, I2r

Vegetal pole, the, I77

Veins, I32

"Ventral," I63

Ventricle, I33

Vermes, 22

Vertebral column, development of, 47

Vertebrate, 22

Vesal, It

Vicentius Bellovacensis, Io

Visceral arches, Izo

Vital characteristics, 75

Vitreous body, I54, 156

Viviparous, 194, I9s

Vogt, Carl, 30

Wagner, Moritz, 30, 63

Wallace, A. R., 29

Warm blooded animals, I 37

Wasp imitated by a beetle, 59

Water-breathing, I 28

Water-vascular system, I3S

Weismann, 30

Wolff, Caspar Friedrich, I9; his "Theoria Generationis," I9; theory of epigenesis, 20

Wotton, Io

Wrisberg, 15

Yolk, 96

Yolk-membrane, 79

Zielstrebigkeit (the striving for an ideal), 66

Zoology, I; contrasted with natural history, 2 ; defined, 6 ; foundation of modern, 2I; general, 68 ; history of, 7 ; influence of early Christianity upon, 9; of the Middle Ages, 9, I4; scope of, 68 ; subdivided, 5

Zoological study, purpose of, I

Zoophytes, 22, 207 




\title{
HISTORY, POLITICAL SCIENCE,
}

\section{A ND SOCIOLOGY}

REFERENCE- AND TEXT-BOOKS.

\author{
PUBLISHED BY \\ HENRY HOLT \& COMPANY,
}

29 West 230 Street, New York.

Books marked * are chiefly for reference or suptementary use, and may be found in Henry Holt Eo Co.'s Miscellaneous list. For further. particular's about books not so marked see Henry llolt Eo Co.'s Descriptize Educational Catalogue. Either list free on application. Postage on net books no per cent additional.

Aclams The science of Finatee By Prof. H. C. ADAss of Univ of Mich.

*Champlin's Jomne Folks History of the War forthe Cnion.

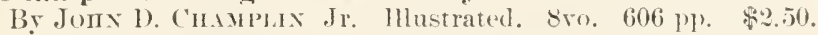

"Cory's Guide to Modern English History. By Wy. Corr.

Part 1. 1815-18:0. Sro. 2\%(6 pl). \$2.00.

Part II. 1830-1835. \$vo. 556 1\%. \$3.50.

* Cox's Introduction to the Science of Comparat ive Mythology and Folk-lore. By sir GEo. IT. Cox, M.A., Bart. 12mo. :36 pl 81.75.

* Creasy's History of the Otoman Turks. By Sir EDw. S. ('reiss. 12mo. 568 pl. \$2.50.

*Dabuegs Canses of the Fench Revolution. By Prof. R. H. DABNEY of the Eniver-ity of Virginia. $12 \mathrm{mo}$. $30 \mathrm{j}$ p. \$1.25.

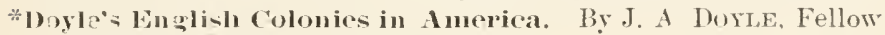
of All Souls' (ollege, Oxford. sro.

Tol I. Virginia, Matyland, and the Carolinas. $420 \mathrm{pp}$. $\$ 350$. Tols II \& III. The Puritan Colonies. $33: 3+416$ pp. \$i.00

*Durul's New Materials for the History of the Anerican Revolution. Translated from documents in the French archives and

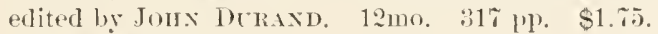

Duruy's Midale Iges. By Victor Dercy. Translated by E. H. and M. 1). WIITxEY. Edited by Prof. (iEo. B. Adass of Yale. With 1:3 wex colored maps. 12mo. 60: pl. \$1.60, net.

_- Molern Times (145:3-1789). Translated by EDwix A. Frosvexor. With 5 colored maps and full index. $12 \mathrm{mo}$. 575 pl. \$1.60. net

* Escott's England : Her People, Polity, and Pursuits, By T. 11. S. FAсотT. 850. 6:5 pp. $\$ 4.00$.

* Falke". Greece and Rome: Their Life and Art. Translated by l'rof. Wy. HAND Browx?. With 400 illustrations. 4to. 365 pj. $\$ 10.00$. 
Flenrys Ancient History, Told to Children. Translated and edited for the use of schools as an exercise for translating from English into French by Susax M. LAxE, 12mo. 118 p, 70e., $n e^{t}$.

Freeman's Historical Comse. Lnder the general editorship of Prof. EnWARD A. FEEMAN of Oxford. The editors of the various volumes have especially adapted them for America. $16 \mathrm{mo}$.

1. General sketch of History. By Prof EDWARD A. Freenan. New edition, rerised, with chronological table, maps, and index. $4: 2 \mathrm{lp}$. \$1.10, nit.

2. History of Lngland. By EdTh Thompsox. 400 pp. 88c., net.

3. History of scot land. By MARGARET MAchrtiutr. 213 pp. stec. nit.

4. History of Italy. By William IItxt, 28. pp. $80 \mathrm{c}$, net.

5. History of Gemany. By Janes Sue, $282 \mathrm{pp}$. 80e, net.

6. History of the Cnited states. By J. A. Dorte. With maps, illustrative of the acquistion of territory and the increase of population by Pres't Fr $x$ is A. WALKEn of the Mass. Institute of 'Technologry. $424 \mathrm{pp} . \$ 1.00$, net.

¿. History of France. By Chablote M. Тoxge. $267 \mathrm{pp}$. sole., mit.

Fytfe's Modern Lumope. By C. A. FrfFe, M.A., Barrister-at Law: Fellow of Eniversity College, Oxford; Viee-l'resident of the Royal Histerical society. 8 ro. $\$ 250$ per volume.

Vol. I. From the Outbreak of the Revolutionary War in 1792 to the Accession of Louis XVIll in 1814. With two maps. $549 \mathrm{pl}$.

Vol. Il. From 1814 to 1848 . Sro. 525 lly.

Vol. III From 1848 to 18.8. (With general index.) 8 ro, $580 \mathrm{pp}$.

Gallauder's International Law. A Vanual. By Pres. E. M. (i 1l.LA'DET of College for Deaf-Mutes. Washington. 12mo. 358 1). $\$ 1,30$, net.

Galdincers English History for Schools. B.C. 55-A.D. 1880. By P'rof. S. R. Girndinen of King's college, London. Edition revised for American students. 16mo. $497 \mathrm{pp}$. $80 \mathrm{c}$., net.

_ Introduction to English History. 12mo. $209 \mathrm{pp} 80 \mathrm{c}$, net.

- English History for Sudents. Being the Introduction to English History hy Prof. \&. R. (iARDINER. With a critical and biographical account of the authorities by J. BAss MuLinger, M.A., St. John's College, Cambridge. 448 pp. \$1.80, net.

Johnston's History of the United States for Schools. With an introductory history of the discovery and English colonization of North America. irith maps, plans, illustrations, and questions. By the late Prof. AlExaxdek JoHnstox of Princeton. With a bibliography. Brought up to $1894.493 \mathrm{pp} 12 \mathrm{mo}$. Half roan. $\$ 1.00$, net. 
Shorter Historyofthe Cuited states. With references to supplementary reading. 1:2mo. 350 pl. 5.5c, net.

- llistory of Imerican Polirios. Revised and enlarged hy

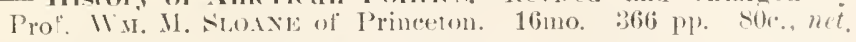
Laconbe's The Growh of a leople. A translation by LEWIs 1. Strusox of "Petite IJistoire dn Peuple Flançaise." 16 mo. 232 lp soc., net.

The same in French. 60c., wet.

* Lossing's Life and Times of Major-General I'hilip seluyler.

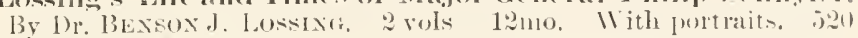
$+.561 \mathrm{pl} . \quad 83.50$

* Iaine's Ancient Law. Its connection with the Early History of

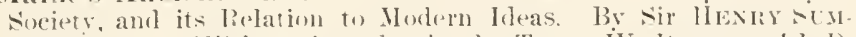
xer ViINe. With an introduction by THEO. W IWIAIT, LL D). 8 ro. 469 \%". 5830.

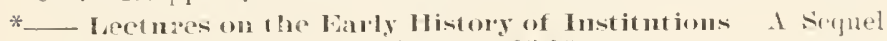

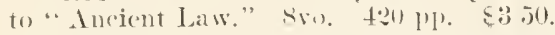

*_Village Communities in the East and Wret six Oxford lectures; 10 which ane added other lectures, addresses, and estayts.

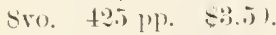

* L Larly Law and Cuntom. Taken chiefly from oxford Lectures. Sin. 40 s ple \$3.50.

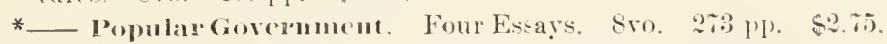

* International law. Cambridge lectures, 185\% fro 204

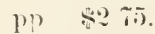

* Sir Henry Maine. A Brief Memoir of his Life iy sir M. E. limaxt DCFF, with some of his Indian spepenes and Iinutes. Selected and rited by Whitley stokes. With portait. Sro. 4.51 P. $\$ 2: 30$

* Vill's Considerations on Representative Governucut. By.

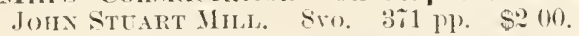

* __ On Liberty: The Subjection of Women. Svo. 394 pl. S:. (of).

* Iorgan's Aneient Society: or, liesearches on the lines of Human Progress through saragery and Barbarism to Civilization. By. LEW Is H. Morgix, I.L.I). Sro. 576 pl. $\$ 4.00$

Porter's Ontlines of the Const it utional History of the Cuitul

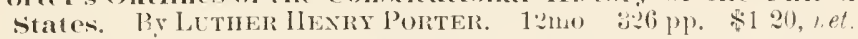

* Roscher's Principles of Political Economy. By Prof. IT.

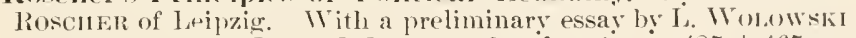
All translated by Jonx J. I.ALOR. 2 rols. Sro. $485+465 \mathrm{pl}$. 85.00 , net.

"Snmmer's History of Anerican Curpency. By Prof. W. H. (iRAIIMI SUMver With chapters on the English Bank liestriction and Austriar Paper Money. To which is appended "The Bullion Report." Large 12 mo, with diagrams. $391 \mathrm{pp}$. \$3.00.

* Collected Lisays in Political and Social science. 8ro. $176 \mathrm{pp} . \$ 150$. 
*_Lrotectionism. The "ism" which teaches that waste makes wealth. $16 \mathrm{mo} .181 \mathrm{pl}$. \$1.00.

Problems in Ecomomics. Interseaved. 16mo. $137 \mathrm{pp}$. $\$ 1.00$, net.

* Symonds' Renaissance in Itally. By Jonx ADDIxgtox Sryoxds. Cheaper edition. sro. lied clotls.

Part I. Ige of Despots. 65:3 lle. \$2.00.

Part II. The Revival of Leaming. 561 pl. \$2.00.

Part III. The Fine Arts. 548 pp. $\$ 2.00$.

Part IV. Italian Literature. With portrait of author. 2 vols. $5.6+6.531$ 1). $\$ 4.00$.

Part V. The Catholic Reaction 2 vols. $445+441$ pp. $\$ 4.00$.

* Short History of the Renaisince. 285 ple. 12mo. \$1.75.

*_L Ltalian Exways. 12mo. 318 pl. \$1.75.

*Taine's Ancient Régime. By Huppolyte Adolphe TaIxe. 'T'ranslated by JoHx DURAxD. Library edition. Large $12 \mathrm{mo}$. $43 \%$ 1. \$2. $\$ 5$ ().

* French Revolution. Translated ly Jomx DCrand. 3 rols. $36 \tau+3 z 0+52: 3$ pp. $\$ \tau .50$.

*_L The Modern Régine. 2 rols. $371+29 \tau$ pp. $\$ 2.50$ each.

*Tylor's Primitive Culture. Researches into the Development of Ilythology, Philosophy, lieligion, Art, and custom. By EDward B. TyloR, LL.D., F.R.S, 2 vols. 8vo. $514+478$ pl." \$7.00.

*-_ Researches into the Early History of Mankind and the Development of Civilization. 8 ro. 392 le 83.50.

* Walker's Wages. A Treatise on Wages and the Wages Class. By Pres't Francis A. Walker. Sro. 432 l'p. \$2.00.

* Money. Sro. $560 \mathrm{pp}$. $\$ 2.00$.

* Moncy in its Relations to Trade and Industry. 12mo. 343 p). \$1.25.

- Political Economy-Adranced Course. 8ro. 545 Pl. $\$ 2.00$, net. net Political Economy-Briefer Course. 12mo, 423 pp. \$1.20,

Political Economy-Elenuentary Course. 12mo. 332 pp. $\$ 1.00$, met.

*Wallace's Russia. By D. Mactexzie Wadtace. 8ro. 633 pp. $\$ 2.00$.

Yonge's Iandmarks of History. By Miss C. H. Yoxfe. $12 \mathrm{mo.}$

Part I. Ancient History of the Mahometan Concuest. Revised and partly rewritten by Miss EDITII M. CHASE. $231 \mathrm{pp}$. roc., net.

Part II. Mediaeval History to the Reformation. Edited by Miss Cirase. $358 \mathrm{pl}$. $80 \mathrm{c}$, net.

Part III. Modern History. Revised. $486 \mathrm{pp}$. \$1.05, net. 


\title{
REFERENCE AND TEXT-BOOKS
}

\author{
PUBLISHED BY
}

\section{HENRY HOLT \& COMPANY,}

\author{
29 West 23D Street, New York.
}

Books marked* are chiefly for reference and supplementary use, and are to be found in Henry Holt \& Co.'s List of IVorks in General Literature. For further particulars about books not so marked see Henry Holt \& Co.'s Descriptive Science Cirtalogue. Either list fiee on application. Excepting JAMES' PSYCHOLOGIHS and WALKER's POLITICAL ECONOMIES, both in the American Science Series, this list contains no works in Philosofhy or Political Economy. Postage on net books 8 per cent. additional.

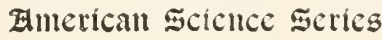

I. Astronomy. By Sim N Newcome, Professor in the Johns Hopkins University. and EDWARD S. HOLDEN, Director of the Lick Observatory, California. Adranced Course, $512 \mathrm{pp}$. 8vo. \$2.00 net.

The same. Briefer Course. $35^{2}$ pp. I2mo. \$I.12 net.

2. Zoology. By A.S. Packakd, Jr., Professor in Brown University. Advanced Course. $722 \mathrm{pp}$. 810. \$2.40 net.

The same. Briefer Course. 338 pp. r 2 mo. \$r.12 net.

The same. Elementary Course, 290 pp. 12mo. 80 cents net.

3. Botany. Fy C. E. Besser, Professor in the University of Nebraska. Adranced Course. 6ir pp. 8vo. \$2.20 net.

The same. Briefer Course. (Entirely new edition, 1896.) 356 pp. 12mo. St.12 net.

4. The Human Body. By H. Niwell Martin, sometime Professor in the Jolins Hopkins University.

Advanced Course. (Entirely nezvedition, 1896.) 685 pp. 8vo. \$2.50 net. Copies without chapter on Reproduction sent when specially ordered.

The same. Briefer Course. 377 pp. r mo. \$1.20 net.

The same. Elementary Course. $26 \mathrm{r}$ pp. $12 \mathrm{mo}$. 75 cents net.

The Human Body and the Effect of Narcotics, 261 pp. t2mo. \$r.2o net.

5. Chemistry. By IrA Remsen, Professor in Johns Hopkins University. Adranced Course (lnorganic). 850 p. 8vo. \$2.80 net.

The same. Briefer Course. (Enturely new edition, 1893.) 435 pp. \$1.12 net.

The same. Elementary Course. $272 \mathrm{pp}$. I2mo. 80 cents net.

I aboratorv Manual (to Elementary Course). $106 \mathrm{pp}$. I2mo. 40 cents, net.

Chemical Experiments. By Prof Remsen and Dr. W. W. Randal. ifor Briefer Course.) No blank pages for notes. $15^{8} \mathrm{pp} 12 \mathrm{mo} 50 \mathrm{c}$ ".t.

6. Political Economy. By Francis A. WALKer. President Massachusatts Institute of Technology. Advanced Course. 537 pp. 8\%o. \$2.00 net.

The same. Briefer Coure. 415 pp. I mo. $\$ 1.20$ net.

The same. Elementary Course. $423 \mathrm{pp}$. 12mo. \$1.0o net.

7. General Biology. By Prof. W. T. SEDGwick, of Massachusetts Institute of Techuology, and Prof. E. B. Wil son, of Columbia College. (Revised and enlarged, 1896.) 23I pp. 8vo. \$1.75 net.

8. Psychology. By William James, Professor in Harvard College. Advanced Course. $68 \mathrm{a}+704 \mathrm{pp} .8$ vo. 2 vols. $\$ 4.80$ net.

The same. Briefer Course. $478 \mathrm{pp}$. $12 \mathrm{mo}$. \$1.6o net.

9. Physics. By Grorge F. Barker, Professor in the University of Pennsylvaliia. Adrenced Course. $902 \mathrm{pp}$. 8vo. \$3.50 net.

10. Gzology. By Thomas C. Chamberlin and Rollin D. Salisbury, Professors in the University of Chicago. (In Preparation.) 
Allen's Laboratory Exercises in Elementary Fhysics. By CHARLES R. AlleN, Instructor in the New Bedford, Mass., High School. Pupils' Edition: x -f 209 pp. $12 \mathrm{mo}$. Soc. net. Teachers' Edition: \$1.00 net.

Arthur, Barnes. and Coulter's Handbcok of Flant Dissection. By J. C. Arthur. Professor in Purdue University, C. R. Barnes, Professor in University of Wisconsin, and JoHN M. Coulter, President of Lake Forest University. $x i+256 \mathrm{pp}$. $12 \mathrm{mo}$. \$1.20 net.

Barker's Fhysiss. Sce American Science Series.

Beal's Grasses of Nor'h America. For Farmers and Students. By IV. J. BEAL, Professor in the Michigan Agricultural College. 8 vo. Copiously illustrated. 2 vols. Vol. I., $457 \mathrm{pp}$. \$2.50 net. Vol. II., $707 \mathrm{pp}$. $\$ 5.00$ net.

Besscy's Eotanies. See American Science Series.

Black and Carter's Natural history Lessons. By George Asiton Black, Ph.D., and Kathleen CARTer. (For very young pupils.) $\mathrm{x}+9 \mathrm{~s}$ p. I2mo. 50c. nit.

Bumpus's Laboralory Course in Invertebrate Zoology. By Hermon C. Bumpus, Professor in Brown University, Instructor at the Marine Biological Laboratory, Wood's Holl, Mass. Revised. vi + $157 \mathrm{pp}$. $12 \mathrm{mo}$. Si.00 net.

Cairns's Quantitative Chemical Analysis. By Frfinerick A. Cairns. Revised and edited by Dr. E. WALLER. 417 pp. Svo. \$2.00 net.

Champlin's Young Folks' Astronomy. By John D. Chaxplin, Jr., Editor of Champlin's Young Folks' Cyclopadias. Illustrated, $\mathrm{vi}+236 \mathrm{pp}$. $16 \mathrm{mo}$. 48c. net.

Crozier's Dictionary of Botanical Terms. By A. A. Crozier, 202 pp. Svo. \$2.40 net.

Hackal"s The True Grasses. Translated from "Die natülichen Pflanzerfamilien" by F. LAMSON-SCRIBNER and EFFiE A. SUUTHWUR'

Hall's First Lessois in Experınental Ph, sius. For young beginners, with quantitative work for pupils and lecture table experiments for teachers. By EDWIN H. HAI.L, Assistant Professor in Har. vard College. viii + $120 \mathrm{pp}$. $12 \mathrm{mo}$. 65c. net.

Hall and Bergen's Text-book of Thysics. By EDwry H. HALl, Assistant Professor of Physics in Harrard College, and loseph Y. Bf.RGEN, Jr., Junior Master in the English High School, Boston. xviii $+3 S S$ pp. 12mo. \$1.25 net.

Postage 8 per cent additional on net books. Descriptive list free. 
Hertwig's General Principles of Zoology. From the Third Edition or Dr. Richard Ilertwig's Lehrbuch der Zoologie. Translated and edited by George WILTON Field, Professor in Brown University. $226 \mathrm{pp} .8 \mathrm{vo}$. 81.60 net.

Howell's Dissection of the Dog. As a Basis for the Study of Physiology. By W. II. HoWELL, Professor in the Johns Hopkins University. I00 pp. Svo. EI.00 net.

Jackman's Nature Study for the Common Schools. (Arranged by the Ionths.) By Wilbir JACkMAN, Teacher of NaturaI Science, Cook County Normal School, Chicago, Ill. tts pp. I2mo. $\$ 1.20$ nit.

Kerner \& 0iver's Natural history of Plants. Translated by Prof. F. IV. Oliver, of University College, London. 4 to. + parts. With over IGoo illustrations and 16 colored plates. \$i5.00 net.

Maca'ister's Zoology of the Invertebrate and Vertebrate Animals. By Alex. Macalister. Revised by A. S. Packard. 277 pp. I 6 mo. So cents net.

Mac Cougal's Experimertal Plant Physio'ocy. On the Basis of Oels' Pfanzenphysiologische I'ersuche. By D. T. MAcDougaL, University of Minnesotav vi +88 pp. Sro. EI.00 nit.

Mac'oskie's E'emcntary Botany. With Students' Guide to the Examination and Description of Plants. By GEorge MAcloskie, D.Sc., LL.D. 373 pp. I2mo. \$1.30 net.

McMurrichs Text-bock of Invertebrate Morphology. By J. PLAYFAIR MCMurricil, M.A., Ph.D., Professor in the University of Cincinnati. vii $+66 \mathrm{r}$ pp. 8 ro. New Eation. \$3.00 net.

McNab's Botany. Outlines of Morphology, Physiology, and Classification of Plants. By William RaMsay IICNaB. Revised by Prof. C. E. Bessey. $400 \mathrm{pp}$. I6mo. Soc. net.

Martin's The Human Body. See American Science Series.

*Merriam's Mammals of the Adirondack Region, Norineastern New York. With an Introductory Chapter treating of the Location and Boundaries of the Region, its Geological History, Topography, Climate, General Features, Botany, and Faunal Position. By Dr. C. HART MerRIAM. 316 pp. Svo. $\$ 3.50$ net.

Newccmb \& Hc'den's Astronomies. See American Science Series.

*Nocl's Buz; or, The Life and Adventures of a Honey Bee. By MAUrice Noel. I3t pp. I2mo. \$I.OO.

Noyes's Elements of Qualitative Anzlysis. By War. A. Noyes, Professor in the Rose Polytechnic Institute. 9I pp. Svo. 8oc. net.

Packard's Entomolocy for Beginners. For the use of Young Folks, Fruit-growers, Farmers, and Gardeners. By A. S. PACKARD. xvi +367 pp. I2mo. Third Edition, Revised. \$1.40 net.

Postage 8 per cent additional on net books. Descriptive list free. 
Packarc's Guide to the Study of Insects, and a Treatise on those Injurious and Beneficial to Crops. For Colleges, Farm-schools, and Agriculturists. By A. S. Packard. With I5 plates and 670 wood-cuts. Ninth Edition. 715 pp. 8vo. \$4.5o net.

— Out'ines of Comparative Embryology. By A. S. PACKARD. Copiously illustrated. $243 \mathrm{pp}$. 8 vo. \$2.00 net.

Zoologies. See American Science Series.

Perkins's Outlines of Electricity and Magnetism. By Chas. A. Perkins, Profesm- in the University of Tennessee. 277 pp. I2mo. $\$$ I. IO nev

Pierce's Problems in Elementary Physics. Chiefly numerical. By E. Dana Pierce, of the Hotchkiss School. I94 pp. I2mo. 6oc. net.

Price's The Fern Collector's Handbook and Herbarium. By Miss SAdiE F. Price. With 72 plates. (November, I896.)

Remsen's Chemistries. See American Science Series.

Scudder's Butterflies. By Samuel H. Scudder. $\mathrm{x}+322$ pp. I2mo. \$I. 20 net.

Brief Guide to the Commoner Butterflies. By SAmuel H. Scudder. $\mathrm{xi}+206 \mathrm{pp}$. I2mo. \$1.00 net.

The Life of a Butterfly. A Chapter in Natural History for the General Reader. By S. H. SCudDer. I 86 pp. r6mo. Soc, net.

Sedgwick and Wilson's Biology. See American Science Series.

*Step's Plant Life. By Edward Step. Popular Papers on the Phenomena of Botany. I2mo. I $4 \$$ Illustrations. \$1.00 net.

Underwood's Our Native Ferns and their Allies. By LUCIEN M. UNDERwoon, Professor in DePauw University. Revised. 156 pp. I2mo. \$1.00 net.

Williams's Elements of Crystallography. By George Huntington WiI.LIAMs, late Professor in the Johns Hopkins University. $\mathrm{x}+270 \mathrm{pp}$. I2mo. Revised and Enlarged. Si.25 net.

Williams's Geological Biology. An Introduction to the Geological History of Urganisms. By Henky S. Williams, Professor of Geology in Yale College. 8vo. $395 \mathrm{pp}$. \$2.80 net.

Woodhull's First Course in Science. By John F. Woodhull, Professor in the Teachers' College, New York City.

I. Book of Experiments. xiv +79 pp. 8vo. Paper. 5oc. net. II. Text-Book. $\mathrm{xv}+133 \mathrm{pp}$. I2mo. Cloth. 65c. net.

III. Box of Apparatus. \$2.00 net (actual cost to the publishers).

Zimmermann's Botanical Microtechnique. Translated by James Ellis Humpirey, S.C. $x i i+296$ pp. 8vo. \$2.50 net.

HENRY HOLT \& CO., 29 WeSt 23D St., NEW YORK. 



$\rightarrow$ 
